
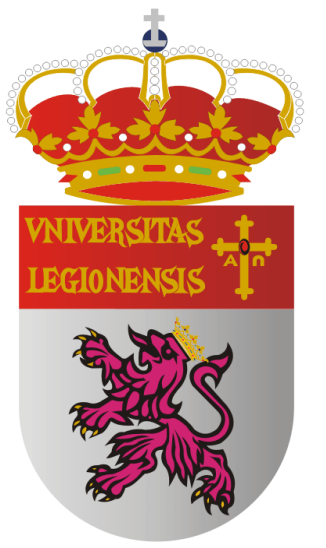

UNIVERSIDAD DE LEÓN

DEPARTAMENTO DE CIENCIAS BIOMÉDICAS

Programa de doctorado: Biomedicina

TESIS DOCTORAL

\title{
ACTIVIDAD PLAQUETARIA DURANTE LA ANGIOPLASTIA ELECTIVA TRAS INFARTO AGUDO DE MIOCARDIO FIBRINOLISADO \\ PLATELET ACTIVITY DURING ELECTIVE ANGIOPLASTY AFTER THROMBOLYSIS FOR ACUTE MYOCARDIAL INFARCTION
}

Memoria presentada por el Licenciado en Medicina D. Alejandro Diego Nieto para optar al grado de Doctor por la Universidad de León. 

La formulación de un problema es más importante que su solución.

Albert Einstein

Lo que puedas hacer o soñar, ponte a hacerlo.

La osadía está llena de genialidad, poder y magia.

Johann W. von Goethe 

A mi padre, Maxi. 



\section{Agradecimientos}

En primer lugar quisiera agradecer al Dr. Felipe Fernández Vázquez todo el tiempo y la atención que siempre me ha dedicado, durante este trabajo de Tesis Doctoral y durante todo mi periodo en León. Por abrirme las puertas de su casa y haber sido, en todos los sentidos, la guía que marcaba el camino.

Al Dr. Javier González Gallego, por la paciencia demostrada y por haber sabido orientar a quienes pasamos menos tiempo en la Universidad.

Quisiera expresar un agradecimiento muy especial a Armando Pérez de Prado, por la concepción de este y otros tantísimos estudios, por haber sido durante tantos años una fuente de inspiración y, hoy y siempre, un verdadero maestro.

A mi amigo y compañero Antonio de Miguel, por el viaje compartido, y a Carlos Cuellas por ser un rincón de paz entre toda esta locura.

A todos mis "plaquetistas" compañeros de residencia, que tuvieron la dudosa suerte de conllevar junto a mí la ardua tarea de inclusión de casos y recogida de datos: Beatriz, David, Roi, Berta, Julia, Emilio, María y Abel. Gracias por vuestro esfuerzo desinteresado.

A toda la Sección de Hemodinámica y Cardiología Intervencionista que convierten el ir al trabajo cada día en una verdadera alegría.

A Fernando Sánchez Lasheras, por su inestimable ayuda durante el proceso de análisis de resultados, por su inagotable tesón y su continua disponibilidad.

A la Fundación Uriach 1848 y a la Sociedad Española de Cardiología, por su ayuda en la financiación de este estudio.

A todos los médicos de mi familia, Tito, Mayús, Maite, Maxi, Mónica y Guillermo, porque me ayudáis cada día a reforzar mi amor por esta profesión.

Y especialmente a Amaya, ya que sin su cariño, su comprensión y su paciencia no hubiese sido capaz de terminar este trabajo. 



\title{
ACTIVIDAD PLAQUETARIA DURANTE LA ANGIOPLASTIA ELECTIVA TRAS INFARTO AGUDO DE MIOCARDIO FIBRINOLISADO
}

\author{
PLATELET ACTIVITY DURING \\ ELECTIVE ANGIOPLASTY AFTER \\ THROMBOLYSIS FOR ACUTE \\ MYOCARDIAL INFARCTION
}

Doctorando: Alejandro Diego Nieto 



\section{ÍNDICE}

RESUMEN

PLANTEAMIENTO Y JUSTIFICACIÓN DEL ESTUDIO 19

\section{ESTADO ACTUAL DEL TEMA}

1 Infarto agudo de miocardio: historia, definición y biología..........................23

2 Fibrinolisis: farmacología, indicaciones, uso actual ....................................31

3 Fisiopatología plaquetaria durante el infarto de miocardio: ......................38

3.1 Receptores plaquetarios.............................................................39

3.2 Papel de la plaqueta en la aterotrombosis coronaria y el intervencionismo coronario percutáneo...................................4

3.3 Farmacología antiplaquetaria......................................................44

3.4 Variabilidad de la respuesta a las tienopiridinas: resistencia al

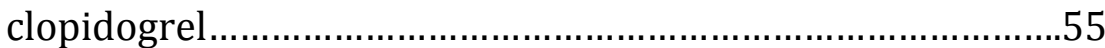

3.5 Monitorización de la actividad plaquetaria...................................63

3.6 El sistema VerifyNow ${ }^{\circledR}$...................................................................69

3.7 Hiperreactividad plaquetaria inducida por fibrinolíticos.............74

4 Estrategias de reperfusión en el infarto de miocardio................................77

4.1 Tratamiento fibrinolítico...............................................................78

4.2 Intervencionismo coronario percutáneo primario..........................79

4.3 El daño por reperfusión...............................................................80

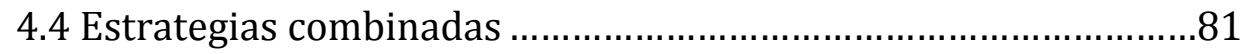

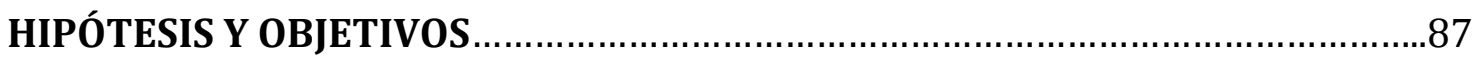

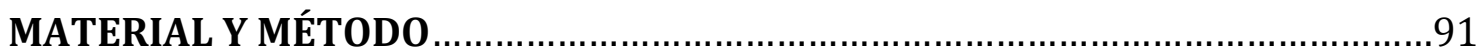

1. Diseño del estudio ......................................................................................

1.1 Selección del tipo de estudio .....................................................91

1.2 Selección de la muestra …………………………………......91

1.3 Administración de tratamiento fibrinolítico .................................93

1.4 Administración de medicación antiagregante ………………......93

1.5 Electrocardiograma y criterios de reperfusión ............................93

1.6 Otras pruebas complementarias básicas .....................................94

1.7 Determinación de la actividad plaquetaria ...................................94

1.8 Coronariografía y actitud terapéutica .........................................96

1.9 Abciximab durante el ICP y monitorización de su efectividad.....96

1.10 Seguimiento clínico ..............................................................97

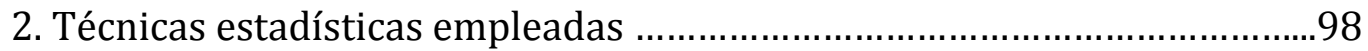

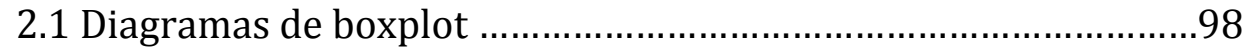

2.2 El test de Anderson-Darling …………………………..............99

2.3 Técnicas fundamentales aplicadas para la realización de la estadística inferencial ............................................................99

2.4 Técnicas asociadas a los modelos predictivos ...........................100

2.5 Ejemplo de presentación gráfica de los datos ...........................106

3. Presentación y formato de citación bibliográfica ....................................108 
RESULTADOS

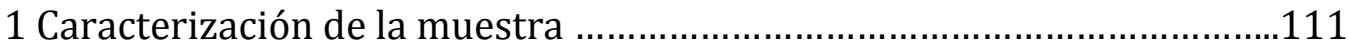

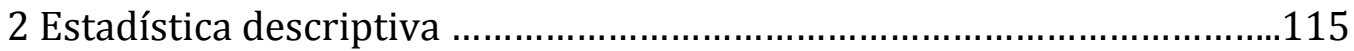

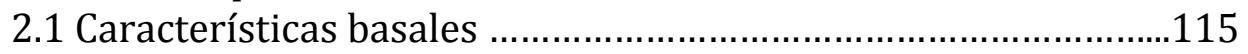

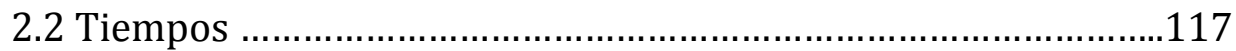

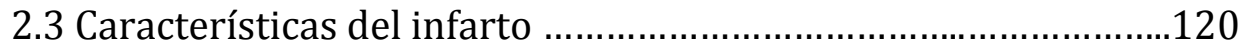

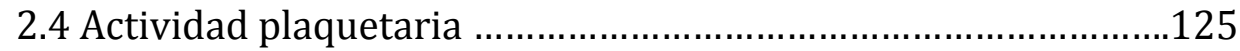

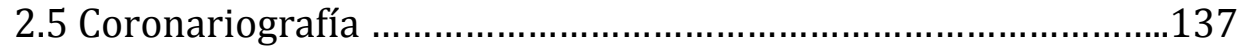

2.6 Intervencionismo coronario percutáneo .................................139

2.7 Evolución clínica intrahospitalaria ............................................142

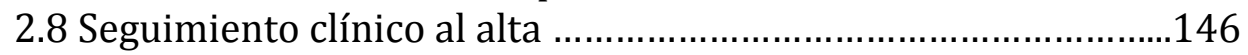

3 Estadística inferencial univariante ...................................................148

3.1 Información de los paciente previa al ingreso ..........................148

3.2 Información correspondiente al momento del ingreso ..............148

3.3 Información correspondiente a la evolución de las pruebas complementarias posfibrinolisis .......................................154

3.4 Estadística inferencial correspondiente a los datos sobre actividad plaquetaria ..........................................................156

3.5 Estadística inferencial de las variables analíticas posteriores a la coronariografía e ICP ...................................................164

4 Modelos predictivos multivariantes ….................................................168

4.1 Modelización del daño miocárdico tras ICP .............................168

4.2 Modelización de la reactividad plaquetaria postratamiento.....173

DISCUSIÓN

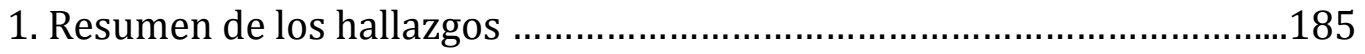

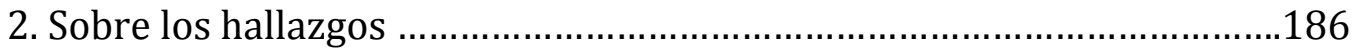

2.1 Sobre la muestra ...................................................................186

2.2 Sobre el sistema de análisis de la función plaquetaria ..............188

2.3 Sobre la actividad plaquetaria ..................................................188

2.4 Contribución del tratamiento fibrinolítico al estado de hiperagregabilidad del contexto clínico ..............................193

2.5 Sobre el seguimiento clínico .....................................................195

2.6 Sobre los modelos matemáticos de análisis multivariante .......196

3. Significado clínico de los hallazgos .....................................................197

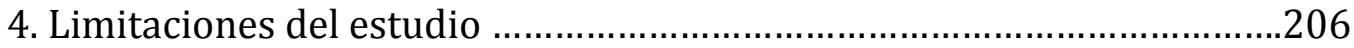

5. Implicaciones para la práctica clínica ….............................................206

6. Líneas futuras de investigación ...........................................................207

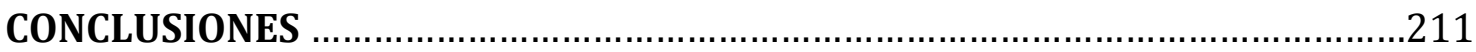

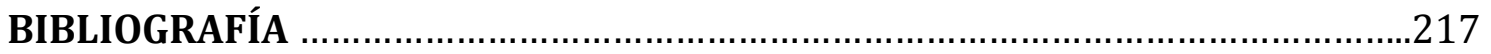

APÉNDICES

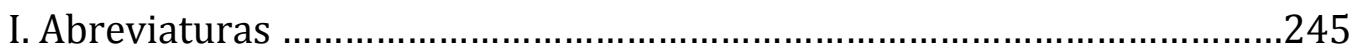

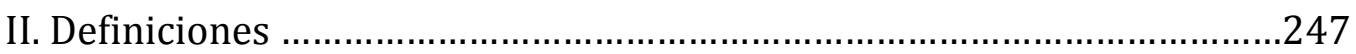

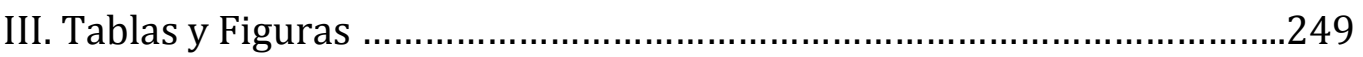


RESUMEN 



\section{ACTIVIDAD PLAQUETARIA DURANTE LA ANGIOPLASTIA ELECTIVA TRAS INFARTO AGUDO DE MIOCARDIO FIBRINOLISADO}

Introducción: el tratamiento fibrinolítico como terapia de reperfusión urgente sigue siendo un método eficaz para recuperar el flujo de una arteria coronaria obstruida. Las guías de actuación clínica recomiendan que este tratamiento sea seguido de una coronariografía para identificar la lesión responsable del infarto y eventual intervencionismo coronario percutáneo en las 24 horas siguientes. El pronóstico del ICP está íntimamente relacionado con la respuesta al tratamiento con clopidogrel y la actividad plaquetaria residual en el momento de la intervención.

Hipótesis y objetivo: teniendo en cuenta que el tratamiento fibrinolítico tiene efectos protrombóticos y proagregantes, este estudio pretende demostrar que este efecto se extiende al receptor P2Y12, produciendo una resistencia transitoria al tratamiento con clopidogrel durante el ICP electivo.

Material y método: se diseñó un estudio prospectivo observacional descriptivo con inclusión de pacientes consecutivos con infarto agudo de miocardio con elevación del segmento ST (IAMCEST) que fueran tratados con fármacos fibrinolíticos. Se administró tratamiento antiagregante con clopidogrel a dosis de carga de 300mg al ingreso seguidas de $75 \mathrm{mg}$ de forma diaria. Para determinar la evolución temporal de los parámetros de actividad plaquetaria se realizaron determinaciones con el sistema VerifyNow®-P2Y12 de forma basal, diariamente durante las primeras 48 horas e inmediatamente antes de la coronariografía electiva. Los valores se expresan en unidades de reactividad plaquetaria (URP). En caso de ICP y utilización de abciximab como terapia adyuvante, se procedió a determinación de la función plaquetaria dependiente del receptor IIb/IIIa. Se recogieron variables analíticas y electrocardiográficas y se realizó seguimiento clínico de todos los pacientes.

Resultados: un total de 41 pacientes cumplieron criterios de inclusión/exclusión durante la fase de reclutamiento. La reactividad plaquetaria estimulada con isoTRAP, independiente del receptor P2Y12, mostró un incremento significativo tras la administración del fibrinolítico $(234 \pm 67,265 \pm 60,275 \pm 60,271 \pm 56$ URP, $\mathrm{p}>0,017$ ). La reactividad plaquetaria postratamiento (RPP) mostró valores que no se modificaron de forma estadísticamente significativa entre el momento del ingreso y los primeros días tras la administración del fibrinolítico $(264 \pm 82$, $273 \pm 83,271 \pm 74,248 \pm 82$ URP, $\mathrm{p}=0,549$ ). El porcentaje de inhibición de la actividad plaquetaria en el momento de la coronariografía electiva alcanzó una mediana de 3 (0-19)\%.

El abciximab se utilizó en el 69\% de los casos de ICP. Esta molécula no presentó disminuida su capacidad para inhibir el receptor IIb/IIIa con un porcentaje de inhibición de la agregación plaquetaria del 96 (91-100)\%.

Conclusiones: la actividad plaquetaria dependiente del receptor P2Y12 se encuentra incrementada tras el tratamiento fibrinolítico por infarto agudo de miocardio con elevación del segmento ST. La respuesta al clopidogrel en este contexto se encuentra disminuida y retrasada con respecto a los valores óptimos para la realización de ICP electivo. 
PLATELET ACTIVITY DURING ELECTIVE ANGIOPLASTY AFTER THROMBOLYSIS THERAPY FOR ACUTE MYOCARDIAL INFARCTION

Introduction: thrombolytic drug administration as emergency reperfusión therapy for acute myocardial infarction is still an effective method to restore normal flow in the responsible coronary artery. Current clinical guidelines recommend elective coronary angiography to identify responsible lesion and eventually percutaneous coronary intervention (PCI) in the following 24 hours. The prognosis of PCI is strongly related to response to clopidogrel and platelet activity at the time of the procedure.

Hypothesis and objective: since thrombolytic drugs have both procoagulant and proaggregant side-effects, this study pretends to confirm that this effect is extensible to P2Y12-dependatn reactivity, conducting to a transient clopidogrel resistance during elective PCI.

Material and method: an observational prospective study was designed with inclusion of consecutive patients affected of ST-segment elevation myocardial infarction (STEMI) and thrombolytic drug administered as reperfusion therapy. Antiplatelet therapy was administered with $300 \mathrm{mg}$ loading dose of clopidogrel and $75 \mathrm{mg}$ of maintenance dose. In order to assess temporal evolution of platelet activity, determinations with the VerifyNow device were performed upon admission, daily during first 48 hours and immediately before angiography. Values are expressed in platelet reaction units (PRU). In case of elective PCI and abciximab infusion, IIb/IIIa-dependant activity was also performed. Analytical and EKG variables were recorded and clinical follow-up was completed for all patients.

Results: 41 patients fulfil inclusion/exclusion criteria during the recruitment period. Iso-TRAP reactivity, P2Y12 independent, showed a progressive increase from admission to elective angiography $(234 \pm 67,265 \pm 60,275 \pm 60,271 \pm 56$ URP, $\mathrm{p}>0,017)$. Post-treatment platelet reactivity showed no statistically significant changes in the 4 different time-points $(264 \pm 82,273 \pm 83,271 \pm 74,248 \pm 82$ URP, $\mathrm{p}=0,549$ ). Mean platelet aggregation inhibition (PAI) achieved with clopidogrel at the time of elective angiography was as poor as $3(0-19) \%$.

Abciximab was infused in the $69 \%$ of PCI cases. This drug had no impairment of its inhibition power, achieving a 96 (91-100)\% of PAI.

Conclusions: P2Y12-dependant platelet activity is enhanced after thrombolytic therapy for STEMI. In this context, clopidogrel response is delayed and poorer than considered optimal levels for PCI. 



\section{PLANTEAMIENTO Y JUSTIFICACIÓN DEL ESTUDIO}

A día de hoy, las enfermedades cardiovasculares son la primera causa de muerte en el mundo occidental, y una de las primeras también en los países en vías de desarrollo. Entre ellas, el infarto de miocardio, ocasionado por la oclusión súbita de una de las arterias coronarias, ocupa un lugar destacado sobre otros procesos como el ictus, la isquemia aguda miembros y otras entidades.

Durante las últimas décadas se han multiplicado las alternativas terapéuticas específicas para el infarto de miocardio, logrando que su mortalidad haya disminuido de forma radical, desde el catastrófico pronóstico que significaba durante las primeras tres cuartas partes del pasado siglo hasta una mortalidad inferior al $10 \%$ siempre $\mathrm{y}$ cuando el paciente alcance asistencia médica hospitalaria adecuada.

Los grandes avances que han logrado esta disminución radical de la mortalidad asociada con este proceso se centran fundamentalmente en la aplicación sistematizada de las terapias urgentes de reperfusión, la posibilidad de restaurar el flujo sanguíneo normal hacia la región del miocardio en riesgo. Entre ellas destacan fundamentalmente los fármacos fibrinolíticos, descubiertos a principios del S. XX pero no utilizados con este fin hasta su introducción por Sherry y Fletcher a finales de los años 50, y las técnicas de reperfusión mecánica transcatéter iniciadas por Dotter y Gruntzig en los años 60-70.

Durante las décadas posteriores, importantes avances se realizaron en ambos tipos de tratamiento, entre los que cabe destacar las mejora de las moléculas fibrinolíticas y la introducción del stent coronario, y, desde principios de siglo, las diferentes combinaciones de ambas terapias que pueden permitir llegar a ofrecer este tratamiento al mayor porcentaje poblacional posible, ofreciendo los mejores resultado clínicos en cada caso.

La plaqueta es uno de los tres componentes corpusculares de la sangre y es la célula del cuerpo que mayor implicación tiene tanto en la patogenia del infarto de miocardio como en la respuesta ante las distintas terapias de reperfusión y, en definitiva, mayor relación con el resultado clínico de la intervención médica durante este proceso. La fisiología de esta célula es bien conocida, pero los factores que modulan su función y su respuesta a las intervenciones médicas, tanto farmacológicas como mecánicas, son conceptos que deben ser actualizados constantemente a medida que las técnicas terapéuticas progresan.

Durante la última década se ha producido un incremento sustancial en el uso de las tienopiridinas y otros fármacos inhibidores del receptor plaquetario P2Y $\mathrm{Y}_{12}$, al comprobar su gran eficacia para disminuir la reactividad plaquetaria, especialmente en combinación con la aspirina, hasta el punto en que desde $2005 \mathrm{y}$ hasta el 2008, el clopidogrel, la más importante de las tienopiridinas, ha sido la segunda molécula más rentable a nivel global, con beneficios directos para las compañías farmacéuticas que lo sintetizaban superiores a los 5.000 millones de dólares americanos al año. 
La actividad plaquetaria es especialmente determinante de los eventos clínicos tanto durante la fase aguda de la ruptura de la palca de ateroma y la trombosis intravascular subsiguiente como durante el intervencionismo coronario percutáneo. Por este motivo es especialmente importante conocer los factores que determinan la actividad de estas células durante estos dos momentos tan delicados.

No obstante, la eficacia del clopidogrel está seriamente disminuida en determinadas circunstancias, reunidas bajo el concepto de "resistencia" al clopidogrel, un término genérico que hace referencia a la gran variabilidad interindividual e intraindividual que presenta el efecto de esta molécula. Los factores que modulan esta variabilidad no son totalmente conocidos, pero sí parece que las circunstancias protrombóticas que desencadenan los síndromes coronarios agudos pueden propiciar este estado de resistencia.

Además de los factores protrombóticos propios de todos los casos de infarto de miocardio, el tratamiento fibrinolítico, terapia de reperfusión urgente ofrecido todavía a gran parte de la población, es un factor añadido que incrementa aún más la reactividad plaquetaria, ya de por sí elevada en estos pacientes.

El mecanismo que condiciona la hiperreactividad plaquetaria secundaria a la utilización de fármacos fibrinolíticos no es del todo bien conocido. Parece que la etiopatogenia fundamental de este proceso se centra en la liberación masiva de trombina durante esta terapia y la activación de los receptores específicos plaquetarios, pero todos los autores coinciden en que la multitud de interconexiones entre las distintas rutas de la coagulación y de la agregación plaquetaria favorecen en gran medida la implicación de todas estas vías en el incremento de la actividad procoagulante.

El presente trabajo de investigación pretende desarrollar el conocimiento sobre un aspecto específico de la actividad plaquetaria: la función del receptor $\mathrm{P}_{2} \mathrm{Y}_{12}$ durante las primeras fases del infarto agudo de miocardio fibrinolisado, desde la administración del tratamiento hasta la realización de la coronariografía electiva, los momentos durante los cuales la actividad plaquetaria juega un papel más fundamental en la génesis de posibles complicaciones.

Se estudiarán a su vez la función de otros receptores plaquetarios como el IIb/IIIa y la implicación de distintas variables, tanto clínicas como analíticas, en la respuesta antiagregante a los fármacos empleados, con el fin de obtener una perspectiva mejorada de la fisiopatología plaquetaria durante las intervenciones médicas más importantes llevadas a cabo en este proceso. 
ESTADO ACTUAL DEL TEMA 



\section{ESTADO ACTUAL DEL TEMA}

Dado que el presente trabajo emplea para la modelización multitud de variables relacionadas con el infarto agudo de miocardio, las estrategias de reperfusión mecánica y la farmacología del tratamiento en la fase aguda de este síndrome, a continuación se realiza una exposición del estado actual de conocimiento sobre las distintas materias que interesan.

\section{EL INFARTO DE MICOARDIO:}

\subsection{BREVE INTRODUCCIÓN HISTÓRICA AL INFARTO DE MIOCARDIO}

Como otras tantas veces, la primera descripción conocida del cuadro clínico del infarto de miocardio se remonta al papiro de Ebers (Figura 1), de hace más de 3500 años, que data del año octavo del reinado del faraón Amenhotep I. En él se puede leer:

“...Si examinas a un hombre enfermo del cardias, con dolor en brazos, pecho y costados del corazón... amenaza la muerte”.

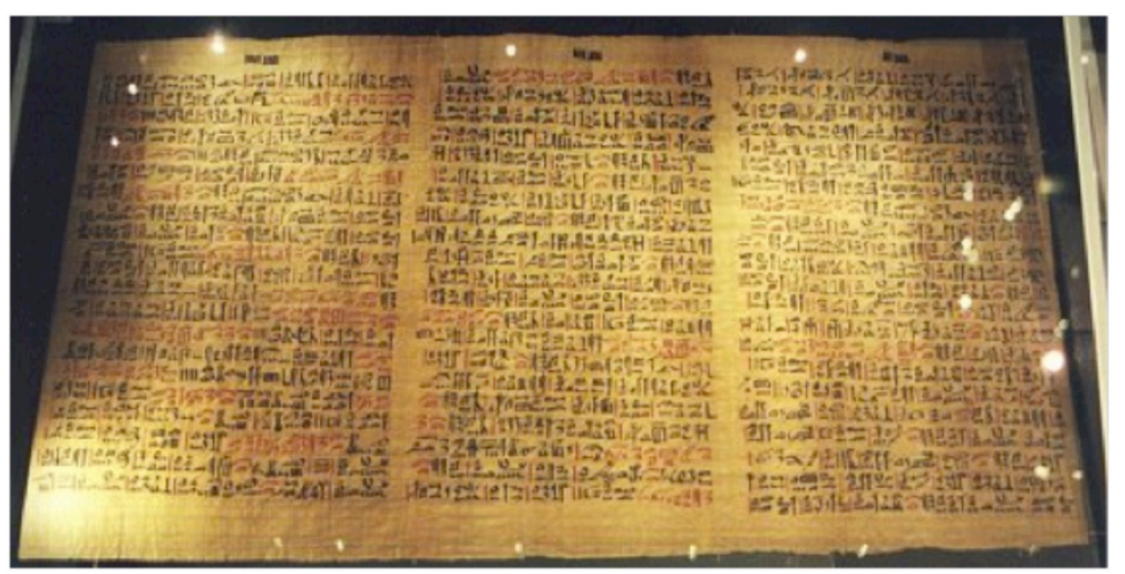

Figura 1: Fotografía del Papiro de Ebers, en el la Biblioteca Universitaria de Leipzig.

Posteriormente, en la descripción de Hipócrates de Cos (Figura 2) hiciera de esta entidad en su Corpus, se puede leer una frase similar:

“... dolores agudos, que se irradian rápidamente hacia la clavícula y la espalda, son fatales." 


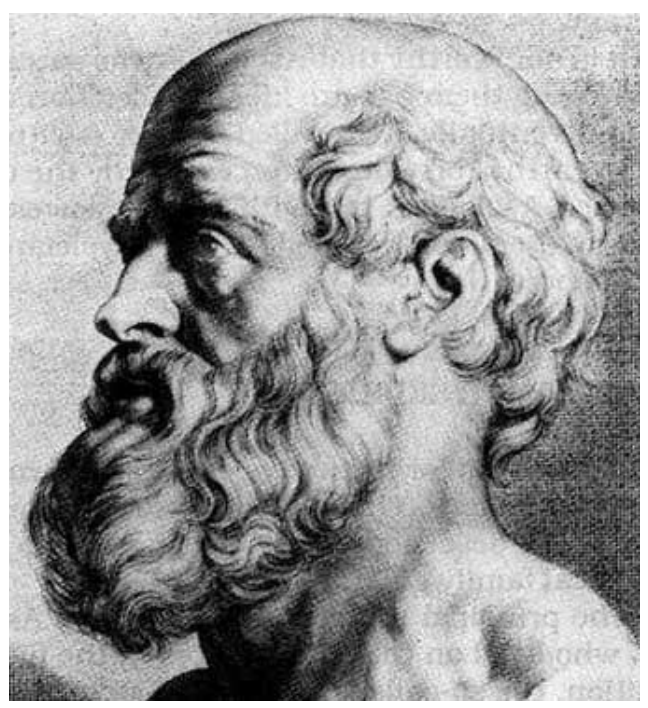

Figura 2: Hipócrates de Cos (grabado).

No hay duda de que ambas son descripciones acertadas de la muerte súbita que puede acontecer durante los primeros minutos de un infarto de miocardio, de manera que podremos afirmar que esta patología no es un mal adquirido en tiempo modernos y que ha estado presente durante toda la historia del hombre.

La suposición de que la enfermedad arterial ateromatosa y el infarto de miocardio como su consecuencia más grave ya estaba presente en tiempos de los antiguos egipcios fue confirmada en los años 60 mediante los estudios realizados sobre momias por el paleopatólogo británico A.T. Sandison(Sandison, 1962).

En un principio, este proceso debió ser una causa excepcional de muerte, siendo las causas principales las enfermedades infeccionas y las guerras durante la mayor parte de la antigüedad. No fue hasta finales del S.XX, tras la segunda guerra mundial, que las enfermedades cardiovasculares comienzan a crecer en importancia hasta convertirse en la primera causa de mortalidad en los países industrializados.

En 1804, Antonio Scarpa, discípulo del anatomista Morgagni, describió por primera vez la relación entre los aneurismas vasculares y las placas ateromatosas ulceradas en la pared vascular; subrayó que aneurisma no es simplemente una porción dilatada de una arteria normal sino el resultado de una enfermedad localizada en la pared arterial.

La primera descripción moderna del cuadro clínico fue realizada por James B. Herrick (Figura 3) en 1912(Herrick, 1983), en un artículo en el que describió la relación entre el mismo y la oclusión trombótica de las arterias coronarias. 


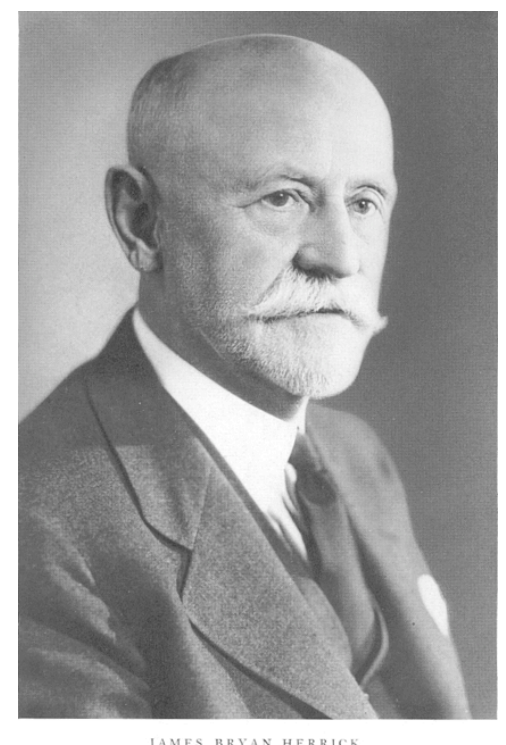

Figura 3: James B. Herrick.

Desde entonces, a pesar de la correcta descripción fisiopatológica, el tratamiento del mismo fue, en el mejor de los casos, inexistente. Los médicos que tenían que atender a los pacientes que sufrían este proceso podían hacer por ellos poco más que mitigar su dolor.

No fue hasta el descubrimiento de la sustancia secretada por los estreptococos betahemolíticos por William Tillet en 1933(Tillett, Edwards, \& Garner, 1934), que se abrió un hueco para las posibilidades terapéuticas de estos pacientes. Su introducción tuvo que esperar hasta 1958, cuando Sol Sherry y Antohony Fletcher, ya con el nombre de estreptoquinasa, inyectaron la sustancia a 24 pacientes aquejados de síntomas de infarto de miocardio. En este estudio(Fletcher, Alkjaersig, Smyrniotis, \& Sherry, 1958), el primero dedicado a la terapia trombolítica, se podía leer:

“... la rápida disolución de un trombo coronario por medios enzimáticos podría tener como resultado una reducción del área final del infarto muscular, una reducción del grado de inestabilidad eléctrica presenta en la primera y decisiva fase del infarto, y la prevención de la aparición de trombos murales o su lisis."

Coincidiendo con estos avances en farmacología, el otro gran avance médico sobre el infarto de miocardio sucede con la aparición de la cateterización cardiaca.

Tras los primeros experimentos animales en el S.XVIII, no es hasta 1929 cuando Wermer Forssmann realiza la primera cateterización documentada de un corazón humano, el suyo propio, utilizando una sonda vesical que introdujo a través de la vena basílica y posteriormente radiografió demostrando su localización en la aurícula derecha. A pesar del enorme potencial que aquella operación aportaba, en aquel entonces fue considerado un procedimiento demasiado peligroso y la técnica fue prácticamente abandonada hasta los años cuarenta, cuando André F. Cournand y Dickinson W. Richards, en el Hospital Bellevue de Nueva York, desarrollaron lo que hoy podríamos considerar como las técnicas modernas de cateterización cardiaca(Cournand, Baldwin, Darling, \& Richards, 1941). 

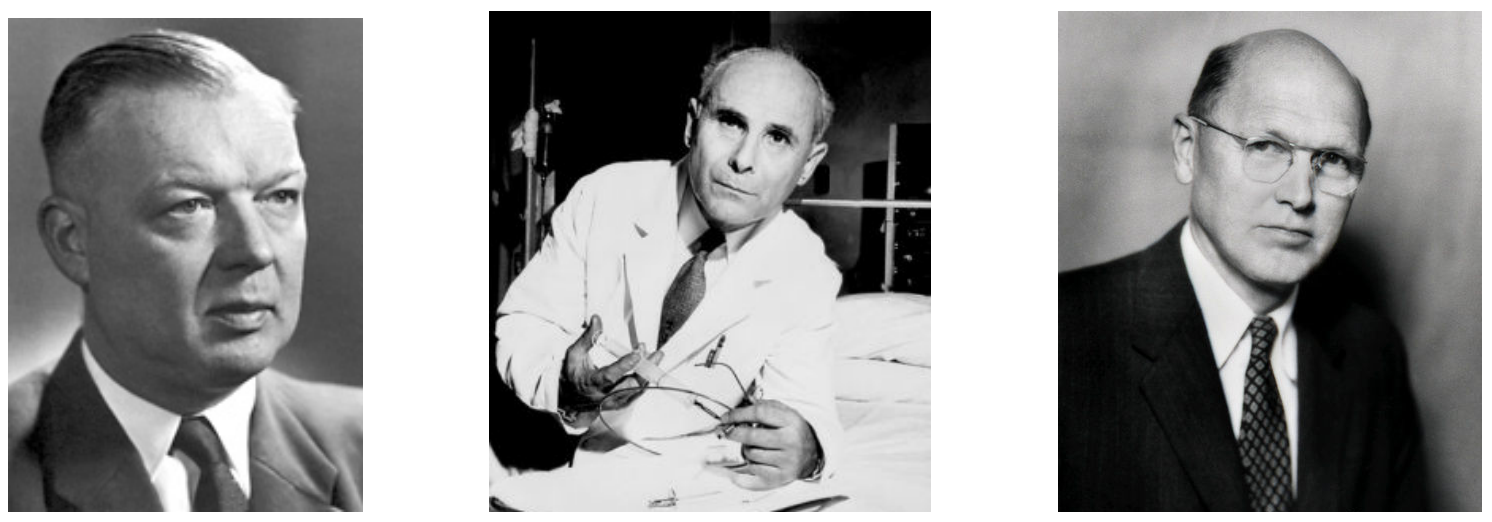

Figura 4: Fotografías de Werner Forssman, André Cournand y Dickinson Richards.

Los tres, Forssmann, Cournand y Richards (Figura 4), compartieron el Premio Nobel de Medicina en 1956 por su trabajo, lo cual no deja de ser una anécdota curiosa teniendo en cuenta que Forssmann fue expulsado del hospital de Eberswalde por haber realizado el experimento sin la autorización de sus superiores.

Una vez logrado alcanzar las cavidades cardiacas con catéteres, el siguiente avance en el conocimiento y manejo de la enfermedad coronaria fue la cateterización selectiva de las estas arterias y su visualización mediante la inyección de contraste, la coronariografía de contraste, lo que fue comunicado por primera vez por Mason Sones en 1958(Sones, 1958).

Una vez obtenidas y desarrolladas las herramientas diagnósticas intracoronarias, el siguiente paso fue lograr una reparación o remodelación de las lesiones ateromatosas encontradas en la enfermedad coronaria. El concepto de angioplastia transluminal percutánea es introducido por Charles Dotter en 1964(Dotter \& Judkins, 1964), dando lugar al origen de la Cardiología Intervencionista, pero es a finales de los años 70 cuando se produce la verdadera revolución en el intervencionismo coronario percutáneo: la primera angioplastia con balón expandible, realizada por Andreas Gruntzig en 1977(Gruntzig \& Schneider, 1977) en San Francisco y posteriormente desarrollada en Zurich sobre pacientes sin anestesia general.
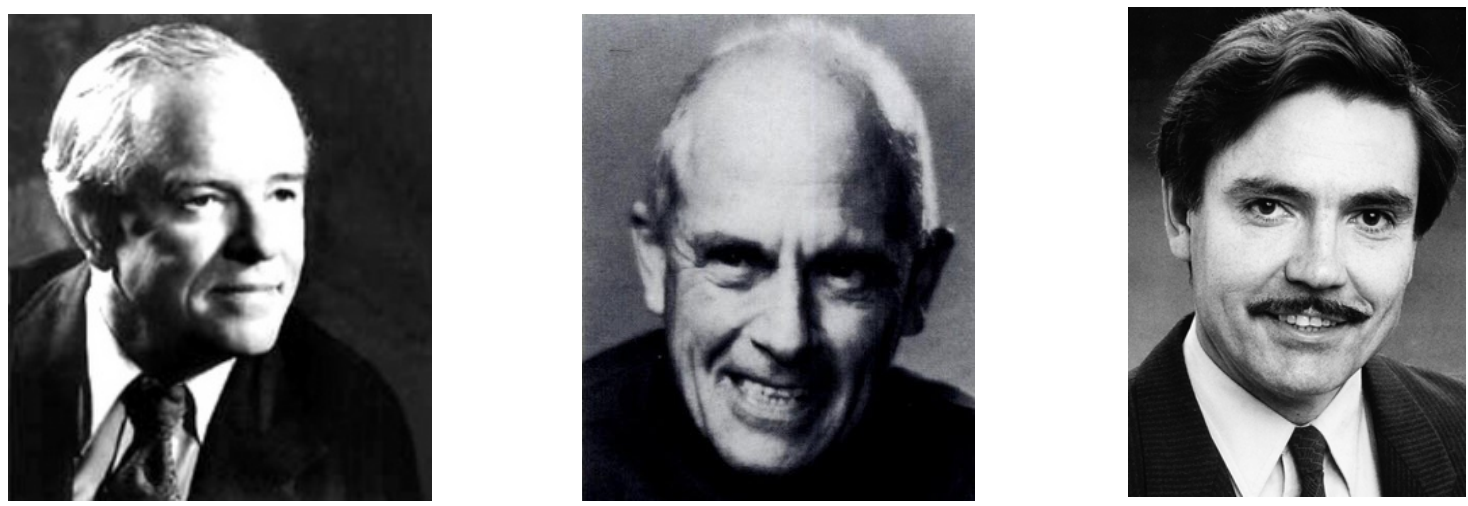

Figura 5: Fotografías de Mason Sones, Charles Dotter y Andreas Grntzig. 
Desde entonces hasta ahora, se han producido grandes avances técnicos en el intervencionismo coronario, entre los que cabe destacar la aparición de los stents coronarios (el primero de ellos desarrollado por Sigwart en 1987(Sigwart, Puel, Mirkovitch, Joffre, \& Kappenberger, 1987)). Debido a la gran importancia de este dispositivo, se le dedica a continuación una sección específica.

\subsection{DEFINICIÓN UNIVERSAL DEL INFARTO AGUDO DE MIOCARDIO}

El infarto agudo de miocardio es un proceso patológico que incluye un conjunto de entidades con determinadas características clínicas, electrocardiográficas, bioquímicas y patológicas. Recientemente se ha elaborado una definición universal de gran importancia a la hora de homogeneizar los criterios necesarios para su diagnóstico(Thygesen et al., 2007). El presente estudio se centra en aquellos pacientes que presentan síntomas isquémicos y una elevación persistente del segmento ST en el electrocardiograma, el llamado infarto agudo con elevación del ST(IAMCEST) o también síndrome coronario agudo con elevación del ST, y que engloba el concepto más tradicional de infarto agudo de miocardio y tiene como causa fundamental la oclusión trombótica aguda de una arteria coronaria debida a la rotura de una placa inestable de ateroma.

\subsection{BIOLOGÍA DE LA ATEROMATOSIS CORONARIA Y EL INFARTO DE MIOCARDIO}

Hasta hace aproximadamente un siglo, los médicos y biólogos consideraban a las arterias cormo meros conductos inanimados, y a la ateromatosis como una rara enfermedad degenerativa. Fue a partir de las investigaciones de Virchow que se reconoció la participación celular en la aterogénesis, originándose una importante controversia entre su visión proliferativa(Virchow, 1989) y la que defendía que su origen procedía de la resorción de trombos, defendida por Rokitansky(Rokitansky, 1855). Tras esto, a comienzos del S. XX Anitschkow y Chalatow utilizaron un modelo de modificación dietética para producir lesiones grasas en las arterias de conejos y lograron identificar al colesterol como culpable final("Classics in arteriosclerosis research: On experimental cholesterin steatosis and its significance in the origin of some pathological processes by N. Anitschkow and S. Chalatow, translated by Mary Z. Pelias, 1913," 1983).

\subsubsection{INICIO DE LA ATEROSCLEROSIS}

A) Acumulación de lípidos extracelulares: las primeras etapas de la aterogénesis en humanos están aún sujetas a teorías, sin embargo se admite que ésta tiene comienzo durante la segunda o la tercer década de la vida(McGill et al., 2000; Stamler et al., 2000) comenzando como una acumulación de pequeñas partículas lipoproteicas en la capa íntima de las arterias(Kruth, 1997). La unión de estas partículas a los proteoglicanos de la íntima captura y retiene estas partículas y les confiere una susceptibilidad especial aumentada a la oxidación y a otras modificaciones químicas consideradas por muchos como un componente 
fundamental de la patogénesis de la aterosclerosis temprana(Camejo, Hurt-Camejo, Wiklund, \& Bondjers, 1998; Rong et al., 1998; Tabas, 1999; Witztum \& Berliner, 1998) mientras que otros estudios sugieren que la permeabilidad a las lipoproteínas de bajaw densidad (LDL) está incrementada en los sitios predilectos de formación de la lesión(Ushio-Fukai, Alexander, Akers, \& Griendling, 1998).

B) Reclutamiento de leucocitos: el segundo acontecimiento morfológicamente definible en el comienzo del ateroma sería el reclutamiento y acumulación de leucocitos. En modelos animales se ha advertido que muy poco después del inicio de la hipercolesterolemia los leucocitos se adhieren al endotelio y se mueven por diapédesis entre las uniones de las células endoteliales hasta penetrar en la íntima, donde comienzan a acumular lípidos y a transformarse en células espumosas(Gimbrone, Cybulsky, Kume, Collins, \& Resnick, 1995). Además de monocitos, estas lesiones tienden también a la acumulación de linfocitos T(Emeson \& Robertson, 1988).

La expresión de ciertas moléculas de adhesión de los leucocitos sobre la superficie de las células endoteliales regula la adhesión de los monocitos y de las células $\mathrm{T}$ al endotelio. Existen dos amplias gamas de moléculas de adhesión leucocitaria(Frenette \& Wagner, 1996). Los miembros de la superfamilia de las inmunoglobulinas incluyen estructuras como la molécula 1 de adhesión a la célula vascular (VCAM-1)(Cybulsky \& Gimbrone, 1991). Esta molécula de adhesión tiene un interés particular en el contexto del comienzo de la aterogénesis porque interactúa con una integrina (antígeno muy tardío [VLA-4]) expresada de forma característica sólo por aquellas clases de leucocitos que se acumulan en el ateroma naciente, en los monocitos y en las células T. Además, los estudios en conejos y ratones han mostrado la expresión de VCAM-1 sobre las células endoteliales que cubren las lesiones ateromatosas muy tempranas(Li, Cybulsky, Gimbrone, \& Libby, 1993).

Otra molécula de la familia de las inmunoglobulinas sería la molécula 1 de adhesión intercelular (ICAM-1)(Poston, Haskard, Coucher, Gall, \& Johnson-Tidey, 1992), mucho más "promiscua" que la anterior ya que puede unirse a muchas clases diferentes de leucocitos.

Las selectinas constituyen la otra gran gama de moléculas de adhesión leucocitaria(Davies, Gordon, et al., 1993; Dong et al., 1998; Vora et al., 1997). La selectina prototipo, la selectina-E (E de endotelio, el tipo de célula que expresa selectivamente este tipo particular de familia), probablemente tiene poco papel en el comienzo de la aterogénesis. Esta selectina recluta preferentemente leucocitos polimorfonoucleares, de un tipo celular que se encuentra raramente en el comienzo del ateroma, pero que juega un papel esencial en la inflamación aguda y los procesos de inestabilización de la placa. Otros miembros de esta familia, incluyendo la selectina-P ( $\mathrm{P}$ de plaqueta) pueden representar un papel más importante en el reclutamiento de leucocitos por el ateroma debido a que células endoteliales que hay encima del ateroma humano expresa esta molécula.

Una vez que los leucocitos se han adherido a la pared vascular deben recibir una señal que les haga penetrar en el interior de la pared arterial. El concepto actual de migración dirigida de los leucocitos implica la acción de moléculas proteicas conocidas como citoquinas quimiotaxinas o quimioquinas(Luster, 1998). Dentro 
de este grupo de moléculas cabe destacar la proteína 1 quimioatractiva de leucocitos (MCP-1), producida por el endotelio en respuesta a las lipoproteínas oxidadas y a otros estímulos. Las células intrínsecas de la arteria normal pueden producir esta quimioquina cuando son estimuladas por mediadores inflamatorios, La MCP-1 origina selectivamente la migración dirigida o quimiotaxis de los monocitos.

Las lesiones ateroscleróticas humanas expresan concentraciones aumentadas de MCP-1 comparadas con los vasos no implicados(Nelken, Coughlin, Gordon, \& Wilcox, 1991). Así, la MCP-1 aparece causalmente relacionada con el reclutamiento de monocitos durante al aterogénesis in vivo.

Otro grupo de quimiocinas puede aumentar la acumulación de linfocitos en la placa de ateroma; éstas son la proteína 10 inducible por interferón (IP-10), el factor quimiotáctico alfa de las células T inducible por interferón (I-TAC) y la monoquina inducida por interferón-gamma (MIG).

C) Focalidad en la formación de la lesión: la explicación de la heterogeneidad espacial de la aterosclerosis ha mostrado ser un desafío en términos mecanicistas. Las concentraciones iguales de factores de riesgo portados en la sangre, así como de lipoproteínas, atacan el endotelio en toda la vasculatura. La localización de los sitios predilectos de la lesión en las porciones proximales de las arterias después de los puntos de ramificación o en las bifurcaciones sugiere una base hidrodinámica para del desarrollo de las lesiones precoces, las arterias sin muchas ramificaciones (por ejemplo la arteria mamaria interna o la arteria radial) tienden a no desarrollar aterosclerosis. Últimamente se han descrito numerosos estudios que relacionan las fueras de estrés hidrodinámico sobre el endotelio vascular, desarrollando zonas de discontinuidad del mismo y acumulación de células inflamatorias con incremento de la presencia de elastasas y la mayor probabilidad así de desarrollar lesiones ateromatosas vulnerables precisamente en las regiones de estrés más reducido(Chatzizisis et al., 2011; Papafaklis, Koskinas, Chatzizisis, Stone, \& Feldman, 2010).

D)Complicaciones de la aterosclerosis: una vez que la masa de la placa excede la capacidad de remodelación hacia el exterior de la arteria comienza la ocupación de la luz arteria con la subsiguiente estenosis y restricción al flujo sanguíneo. Generalmente esta fase suele manifestarse desde el punto de vista clínico como angina estable, aunque en muchos casos puede pasar desapercibida. En esta fase, el crecimiento de la placa tiene lugar de forma discontinua, con periodos de relativa quiescencia salpicados de episodios de rápida progresión como parece evidenciarse en estudios angiográficos(Bruschke et al., 1989; Yokoya et al., 1999).

Ahora es aceptado que esta progresión parcheada se debe generalmente a eventos de inestabilización con ruptura de la cápsula fibrosa de la placa y trombosis secundaria.

Esta evolución en nuestra visión de la patogénesis de los síndromes coronarios agudos pone de nuevo énfasis en la trombosis como mecanismo de transición crítico de la ateromatosis crónica a la aguda. En la década pasada se observó un considerable progreso en el conocimiento de los mecanismos de la trombosis 
coronaria. Actualmente se comprende que la rotura física de la palca aterosclerótica produce habitualmente trombosis aguda.

Dos formas principales de rotura de la placa producen la mayoría de los trombos coronarios. El primer mecanismo, que incluye a los dos tercios de los infartos agudos de miocardio, implica una fractura de la cubierta fibrosa de la placa(Falk, Shah, \& Fuster, 1995). El segundo mecanismo implica una erosión superficial de la íntima e incluye hasta un cuarto de los infartos agudos de miocardio en casos descritos por médicos que han estudiado individuos que han sufrido una muerte súbita(Farb et al., 1996). Esta erosión superficial aparece con mayor frecuencia en mujeres que en hombres(Burke et al., 1998; Burke et al., 1997).

Son muchos los factores que modulan la resistencia de la cápsula fibrosa de la placa a las fuerzas de cizallamiento que contribuyen a su ruptura. El aumento de la resistencia viene determinado por la síntesis del colágeno y las alteraciones de la misma a la que contribuyen en gran medida la degranulación de las plaquetas (con sustancias como el TGF- $\beta$ y el PDGF que refuerzan la estructura colágena).

Los factores que la debilitan se resumen en los procesos catabólicos por parte de las células lisas. Las mismas enzimas que degradan la matriz extracelular que permite la migración de las células musculares lisas ya la remodelación arterial contribuyen también al debilitamiento de la cápsula fibrosa con el correspondiente riesgo de rotura(Dollery, McEwan, \& Henney, 1995; Libby, 1995).

Los macrófagos de los ateromas humano sobreexpresan metaloproteinasas de la matriz y catepsinas elastolíticas que pueden degradar el colágeno y la elastina de la matriz extracelular arterial(Galis, Sukhova, Lark, \& Libby, 1994; Henney et al., 1991; Sukhova, Shi, Simon, Chapman, \& Libby, 1998). Así, la resistencia de la cápsula fibrosa se encuentra regulada de forma dinámica, uniendo la respuesta inflamatoria de la íntima con los determinantes moleculares de la estabilidad de la placa $\mathrm{y}$, por tanto, de las complicaciones trombóticas de la misma. El adelgazamiento de la cápsula fibrosa, resultado de la reducción de la síntesis de colágeno y de su degradación aumentada, explica la morfología de las denominadas placas vulnerables junto a la relativa ausencia de células musculares lisas y abundante núcleo lipídico necrótico(Davies, Richardson, Woolf, Katz, \& Mann, 1993). En resumen, los mediadores de la inflamación, tanto solubles como asociados a los linfocitos $\mathrm{T}$ de superficie, pueden producir la apoptosis de las células musculares lisas. Como estas células son la fuente de la génesis de novo de las fibras de colágeno, necesario para reparar y mantener la cápsula fibrosa la falta relativa de las mismas contribuye al debilitamiento de la placa. La acumulación de lípidos y macrófagos es el tercer elemento definitorio de placa de ateroma vulnerable. Desde un punto de vista mecánico, la gran reserva de lípidos puede servir para concentrar las fuerzas biomecánicas en las regiones traseras de la placa, que son las zonas donde habitualmente se produce la ruptura de las mismas(Cheng, Loree, Kamm, Fishbein, \& Lee, 1993; Loree et al., 1994). Desde un punto de vista metabólico, los macrófagos activados característicos de la zona nuclear de la placa producen las citoquinas proinflamatorias y las enzimas degradantes de la matriz que se piensa que regulan aspectos del catabolismo de ésta y de la apoptosis de las células musculares lisas. 


\section{FIBRINOLISIS: FARMACOLOGÍA, INDICACIONES Y USO ACTUAL}

\subsection{EVIDENCIA DEL BENEFICIO DEL TRATAMIENTO FIBRINOLÍTICO}

El beneficio del tratamiento fibrinolítico está bien establecido. Se previenen aproximadamente 30 muertes precoces por cada 1000 pacientes tratados en las primeras horas y 20 en aquellos tratados entre las 6 y 12 horas tras el inicio de los síntomas ("Indications for fibrinolytic therapy in suspected acute myocardial infarction: collaborative overview of early mortality and major morbidity results from all randomised trials of more than 1000 patients. Fibrinolytic Therapy Trialists' (FTT) Collaborative Group," 1994).

El mayor determinante del beneficio de este tratamiento es el tiempo de evolución desde el inicio de los síntomas. Así, cuando la estrategia de reperfusión elegida sea ésta, el fármaco debe ser administrado de forma lo más precoz posible, por lo que actualmente la mayoría de las áreas de salud cuentan con un programa de fibrinolisis extrahospitalaria en el que esta medicación es administrada por el médico que realiza el primer contacto con el paciente, generalmente en consenso con el Servicio de Cardiología de referencia.

Los beneficios del tratamiento fibrinolítico sobre el intervencionismo coronario percutáneo (ICP) primario se extienden a su facilidad de uso, que no requiere ni de la infraestructura específica ni del personal altamente especializado necesario para el segundo, y de la posibilidad única de ser ofrecido con mucha más precocidad.

La mayor limitación a la hora de aplicar el tratamiento fibrinolítico es el riesgo de sangrados mayores, especialmente de hemorragia cerebral. Los factores que con mayor frecuencia se asocian a esta complicación son la edad avanzada, el bajo peso, el sexo femenino, la enfermedad cerebrovascular previa y elevadas cifras de presión arterial al ingreso (Gore et al., 1995).

En cuanto a la comparación con el ICP primario, la preferencia por una u otra estrategia de reperfusión urgente será tratada en el capítulo correspondiente.

\subsection{FARMACOLOGÍA}

Los fármacos fibrinolíticos constituyen una familia de moléculas de origen natural (a pesar de que los más modernos sean derivados mutantes de los originales) que tienen en común la capacidad de activar el plasminógeno para producir plasmina, la enzima natural encargada de la disolución de los mallas de fibrina que constituyen el trombo.

Al tratarse de moléculas complejas, su administración debe ser siempre parenteral. Se han utilizado de forma intravenosa y de forma intracoronaria directa para tratar de disolver el trombo intracoronario. 
Su mecanismo de acción implica el conocimiento de que al mismo tiempo que son fármacos trombolíticos, tienen en contraposición capacidad procoagulante y proagregante, lo que constituye la justificación central de esta tesis.

\subsubsection{ESTREPTOQUINASA}

La estreptoquinasa o estreptocinasa, como se ha descrito en el apartado de introducción histórica, fue el primer fármaco fibrinolítico descubierto y utilizado en la práctica clínica(Fletcher et al., 1958; Tillett et al., 1934), pero gracias a su gran eficacia y seguridad sigue siendo una molécula de gran utilidad y que suele estar disponible en la mayoría de los centros hospitalarios.

Se trata de un fibrinolítico sin selectividad por la fibrina, a diferencia con el resto de fibrinolíticos comercializados, que ejerce su acción por medio de una unión indirecta al plasminógeno, transformándose en enzima activa que transforma el plasminógeno en plasmina(H. V. Anderson \& Willerson, 1993). Este mecanismo de acción tiene también la ventaja de que eleva la concentración en sangre de proteína $C$ activada, lo que puede favorecer la lisis del trombo(Gruber, Pal, Kiss, Sas, \& Griffin, 1993).

La dosis habitual para su uso durante el infarto de miocardio es de 1,5 millones de UI diluidas en 100 c.c. de suero fisiológico a pasar en perfusión continua durante 30-60 minutos("ISIS-3: a randomised comparison of streptokinase vs tissue plasminogen activator vs anistreplase and of aspirin plus heparin vs aspirin alone among 41,299 cases of suspected acute myocardial infarction. ISIS-3 (Third International Study of Infarct Survival) Collaborative Group," 1992). La dosificación para indicaciones diferentes suele ser menor.

La utilización conjunta de heparina sódica durante la infusión de estreptoquinasa es una cuestión controvertida. Se acepta que el tiempo de tromboplastina parcial activado (TTPA) debe encontrarse entre 50 y 70 segundos a las 12 horas de la administración del fármaco, de acuerdo con la información sobre mortalidad obtenida a partir del estudio GUSTO-1(Granger et al., 1996), lo que requiere la utilización de heparina o hirudina, pero en pacientes ancianos, el grupo de pacientes donde este medicamente es más utilizado, no suele recomendarse para evitar el riesgo de sagrado(Rich, 1998).

\subsubsection{ALTEPLASA (ACTIVADOR TISULAR DEL PLASMINÓGENO)}

La alteplasa o activador tisular del plasminógeno, conocido más frecuentemente por sus siglas en inglés (tPA) es una enzima natural que se une a la fibrina y tiene gran afinidad por la estreptoquinasa o la uroquinasa. Una vez unida, inicia el proceso de transformación del plasminógeno en plasmina sobre la superficie de fibrina. Por este motivo es relativamente selectivo y a dosis clínicas produce escasos efectos sistémicos.

Su vida media es muy breve, lo que hace indispensable su administración simultánea con heparina intravenosa para evitar la recurrencia trombótica. 
La dosis habitual de administración es de 100mg, repartidos en forma de un primer bolo de $15 \mathrm{mg}$, seguidos de $50 \mathrm{mg}$ en perfusión durante media hora posteriormente $35 \mathrm{mg}$ en una hora.

Además de esta dosificación algo compleja, la mayor desventaja del tPA con respecto a la estreptoquinasa está en su precio, cinco veces superior.

\subsubsection{RETEPLASA}

La reteplasa es una delección mutante de la alteplasa que se caracteriza por la eliminación de diferentes dominios, principalmente cadenas laterales de algunos carbohidratos. La molécula originada tiene una eliminación plasmática más prolongada, por lo que puede usarse en un esquema de doble bolo (10 UI + $10 \mathrm{UI}$, cada uno de ellos en 10 minutos y con 30 minutos de diferencia entre uno y otro) y evitar la perfusión continua.

Los estudios INJECT y GUSTO-III demostraron su valor similar al de la estreptoquinasa y la alteplasa respectivamente.

\subsubsection{TENECTEPLASA (TNK-TPA)}

Se trata de una molécula obtenida por medio de ingeniería genética a partir del activador tisular del plasminógeno natural que se distingue por la sustitución de aminoácidos en tres puntos de su cadena. Esta nueva molécula tiene una vida media mayor que las previas, un aumento de la especificidad por la fibrina y una mayor resistencia al inhibidor del activador del plasminógeno (PAI-1) (Figura 6).

Su administración se realiza en la cómoda forma de un bolo único, a dosis de $0,5 \mathrm{mg}$ por Kg de peso del paciente $\mathrm{y}$, con respecto a su efectividad, reduce la mortalidad del infarto de forma similar a la de alteplasa con un menor riesgo de sangrado grave según el estudio ASSENT-2(Van De Werf et al., 1999).

Las características farmacocinéticas y su efectividad clínica hacen que la tenecteplasa se haya convertido en el fármaco fibrinolítico más utilizado, especialmente por la facilidad que su administración en bolo único permite la realización del tratamiento de manera precoz pre-hospitalaria (Figura 7). 


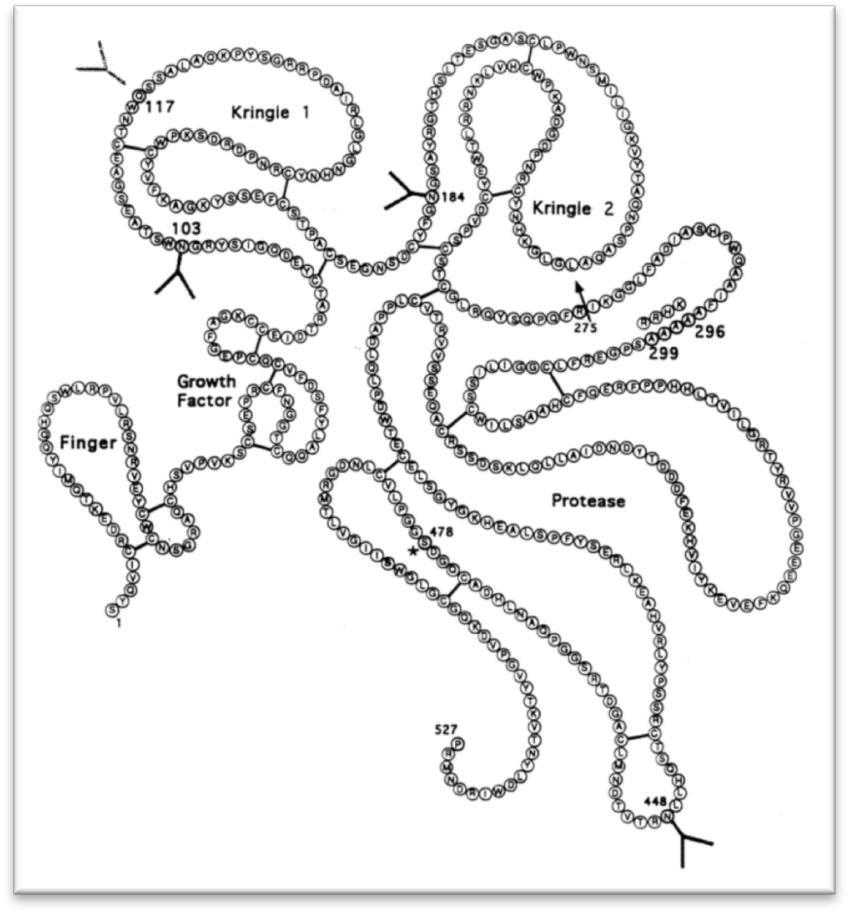

Figura 6: Molécula del TNK-tPA

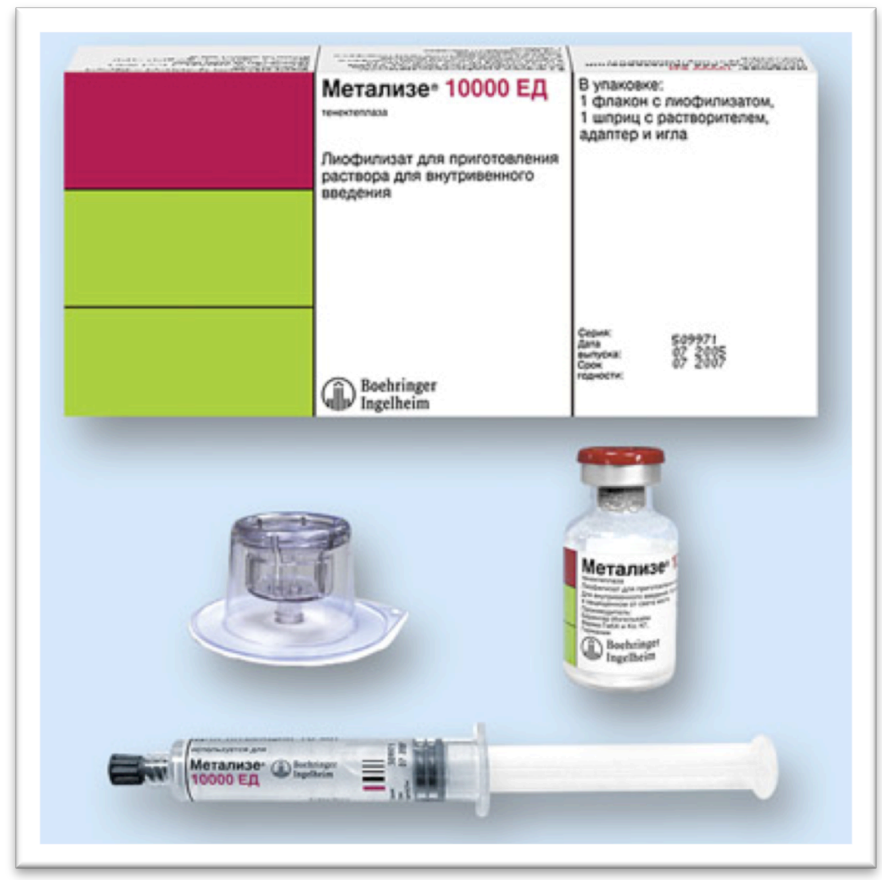

Figura 7: Envase comercial del TNK-tPA (Metalyse ${ }^{\circledR}$ ) 


\subsubsection{UROQUINASA}

La uroquinasa es una molécula natural similar a la estreptoquinasa y que tiene efectos similares, pero al ser sintetizada a partir del cultivo de células renales humanas las reacciones alérgicas en comparación con la estreptoquinasa son mínimas. De todos modos, a pesar de que su uso ha sido aprobado para muchas situaciones clínicas, no ha demostrado reducir la mortalidad del infarto de miocardio, por lo que su uso no está aprobado para esta indicación.

\subsection{INDICACIONES Y CONTRAINDICACIONES}

Las últimas guías de práctica clínica para el manejo del IAMCEST establecen la necesidad de estrategia de reperfusión urgente en los casos en los que se presente el dolor y las alteraciones electrocardiográficas características, cuando esta terapia puede ser aplicada dentro de las primeras 12 horas desde el inicio de los síntomas, e incluso más allá de este plazo si existe evidencia de isquemia en curso (Van de Werf et al., 2009).

Su uso deberá ser acompañado en todo caso de una estrategia antitrombótica asociada y de un tratamiento antiagregante.

\section{Tabla 1: Indicaciones del tratamiento fibrinolítico.}

\section{Recomendación}

\begin{tabular}{|c|c|c|}
\hline $\begin{array}{l}\text { Está indicada la terapia de reperfusión en todos los pacientes con historia } \\
\text { de angina/malestar de menos de } 12 \mathrm{~h} \text { y con elevación persistente del } \\
\text { segmento ST o nuevo (sospecha) bloqueo completo de rama izquierda }\end{array}$ & I & A \\
\hline $\begin{array}{l}\text { Se considerará la terapia de reperfusión en caso de evidencia clínica y/o } \\
\text { electrocardiográfica de isquemia, incluso cuando, según el paciente, los } \\
\text { síntomas hayan comenzado más de } 12 \text { h antes }\end{array}$ & IIa & $\mathrm{C}$ \\
\hline $\begin{array}{l}\text { Se considerará la reperfusión con ICP en pacientes estables que se } \\
\text { presentan más de } 12 \text { y hasta } 24 \text { h tras la aparición de los síntomas }\end{array}$ & IIb & B \\
\hline $\begin{array}{l}\text { El tratamiento fibrinolítico está recomendado en ausencia de } \\
\text { contraindicaciones* y cuando no se pueda realizar una ICP dentro de los } \\
\text { plazos recomendados** }\end{array}$ & I & A \\
\hline Se administrará un agente específico de la fibrina & I & B \\
\hline $\begin{array}{l}\text { Se iniciará el tratamiento de forma prehospitalaria cuando sea posible y } \\
\text { esté indicado }\end{array}$ & IIa & A \\
\hline \multicolumn{3}{|l|}{ Tratamiento antiplaquetario adjunto } \\
\hline $\begin{array}{l}\text { Dosis adicional de aspirina i.v. u oral si el paciente no está en tratamiento } \\
\text { oral con la misma }\end{array}$ & I & B \\
\hline Dosis de carga oral de clopidogrel en pacientes de edad $\leq 75$ años & I & B \\
\hline $\begin{array}{l}\text { Iniciar con dosis oral de mantenimiento de clopidogrel en pacientes de } \\
\text { edad } \geq 75 \text { años }\end{array}$ & IIa & B \\
\hline \multicolumn{3}{|l|}{ Tratamiento antitrombótico adjunto } \\
\hline $\begin{array}{l}\text { Con alteplasa, reteplasa y tenecteplasa: } \\
\text { bolo i.v. de enoxaparina seguido a los } 15 \text { min por la primera dosis s.c.; en } \\
\text { pacientes mayores de } 75 \text { años, no administrar bolo i.v. y comenzar con la } \\
\text { primera dosis s.c. reducida }\end{array}$ & I & A \\
\hline $\begin{array}{l}\text { Si no se dispone de enoxaparina, administrar un bolo ajustado al peso de } \\
\text { heparina i.v. seguida de infusión i.v. ajustada al peso con el primer control } \\
\text { TTPA a las } 3 \mathrm{~h}\end{array}$ & I & A \\
\hline
\end{tabular}




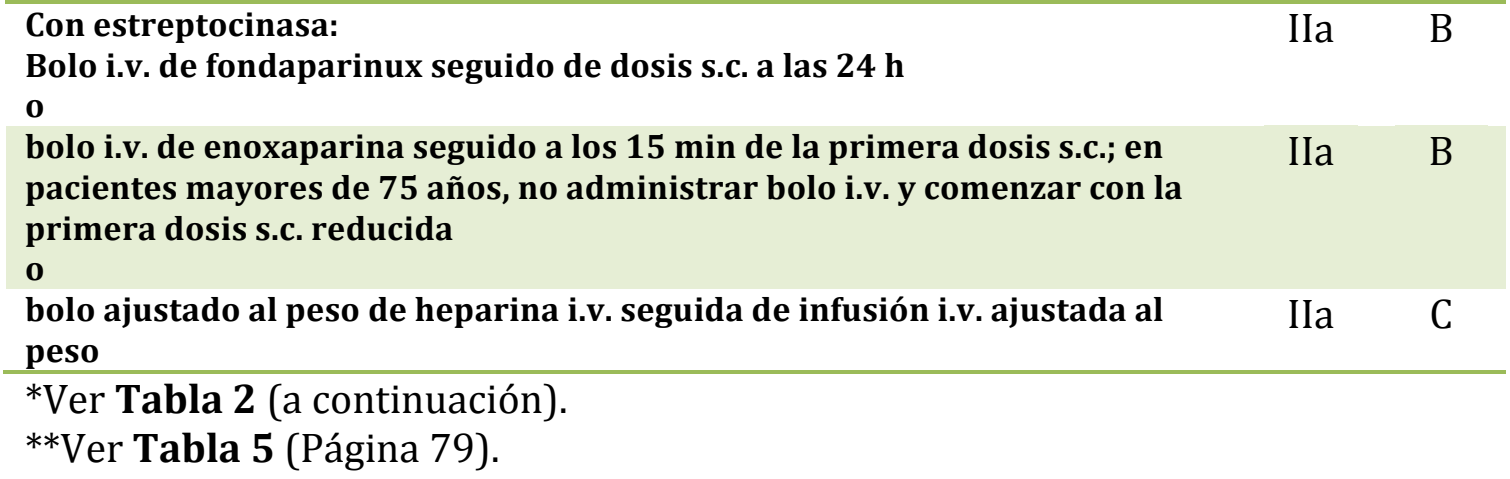

\section{Tabla 2: Contraindicaciones al tratamiento fibrinolítico.}

Contraindicaciones absolutas

ACV hemorrágico o ACV de origen desconocido en cualquier momento

ACV isquémico en los 6 meses precedentes

Traumatismo/cirugía/daño encefálico reciente importante (durante las 3 semanas precedentes)

Sangrado gastrointestinal durante el último mes

Alteración hemorrágica conocida

Disección aórtica

Punciones no compresibles (como biopsia hepática, punción lumbar)

Contraindicaciones relativas

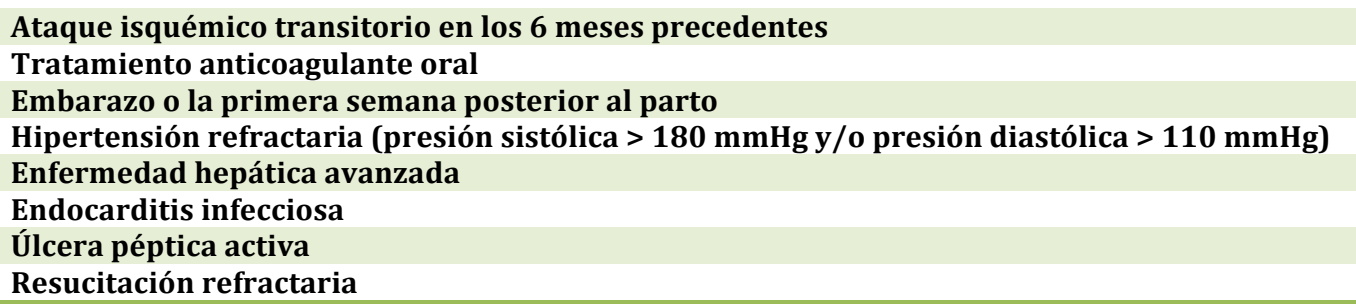

\subsection{USO ACTUAL DEL TRATAMIENTO FIBRINOLÍTICO}

Como se detalla en el apartado correspondiente a las distintas estrategias de reperfusión, en la actualidad el ICP primario ha demostrado mejores resultados globales que el tratamiento fibrinolítico, pero esto es así sólo cuando se cumplan ciertas premisas: fundamentalmente, que el ICP sea realizado por un equipo experto, dentro de un programa de alerta intervencionista permanente y con un volumen no inferior a 75 angioplastias anuales por equipo y 25 procedimientos anuales por operador(Kolh \& Wijns, 2011). Además, el tiempo estimado para poder realizar la reperfusión efectiva del vaso responsable debe ser inferior a 90 minutos desde el primer contacto médico, por lo que los tiempos de traslado deben ser evaluados con sumo cuidado.

Estas condiciones hacen que el tratamiento percutáneo no esté disponible con facilidad para la mayoría de los pacientes afectos de un IAMCEST. En nuestro país, los datos extraídos de los registros PRIAMHO II (Aros et al., 2003) y MASCARA (Ferreira-Gonzalez et al., 2008) muestran un incremento en las terapias de reperfusión en el tratamiento del IAMCST, que ha conseguido una disminución en 
cuanto a mortalidad del 12,3 al 6\% entre los años 2000 y 2005, pero aún es el tratamiento fibrinolítico la estrategia más empleada de las dos, un $89 \%$ de los casos en 2000 y un $63 \%$ en 2005 , de todos los pacientes a los que se les ofrece cualquier estrategia de reperfusión(Aros et al., 2011).

Por lo tanto, el tratamiento fibrinolítico no sólo aún está vigente sino que es el tratamiento de reperfusión urgente más utilizado en nuestro medio. En las últimas guías se recomienda que los pacientes que reciben tratamiento fibrinolítico de forma extrahospitalaria o en centros sin laboratorio de hemodinámica, sean trasladados posteriormente de forma más o menos sistematizada a un centro de referencia para completar la estrategia de reperfusión con un procedimiento percutáneo, ampliando así el número de casos que se benefician de lo que ahora conocemos como estrategias combinadas. 


\section{FISIOPATOLOGÍA PLAQUETARIA EN EL INFARTO DE MIOCARDIO}

La plaqueta es una célula sanguínea anucleada de $2-4 \mu \mathrm{m}$ de diámetro originada a partir de la fragmentación de los megacariocitos de la médula ósea(Chang, Bluteau, Debili, \& Vainchenker, 2007; Deutsch \& Tomer, 2006). Su producción está regulada fundamentalmente por una citoquina: la trombopoyetina, y su liberación depende de diversas señales fisiológicas, pero debe destacarse el hecho de que algunos estados patológicos, como el inflamatorio, aumentan la producción de la misma, lo que debe tenerse en cuenta a la hora de calcular el tiempo de recuperación de la función plaquetaria.

Las plaquetas en estado basal son unas células discoides y de superficie lisa que poseen un sistema canalicular abierto y un glucocálix exterior(Levin, 2007). Sus depósitos intracelulares están repletos de calcio y éste es liberado al citoplasma con la activación de la plaqueta por agonistas. El calcio liberado juega un papel principal como mediador en las respuestas de la plaqueta activada(Rosado, Jenner, \& Sage, 2000). En el citoplasma de la plaqueta encontramos tres tipos diferentes de gránulos, llamados $\alpha$-gránulos, gránulos densos y lisosomas. Los $\alpha$-gránulos son los más abundantes y contienen un gran número de proteínas, la mayoría de las cuales poseen importantes funciones reguladoras del equilibrio entre trombosis y fibrinolisis, tales como la $\alpha 2$-antiplasmina y el inhibidor del activador del plasminógeno-1 (PAI-1)(Harrison \& Cramer, 1993). Las membranas de los $\alpha$ gránulos también contienen proteínas que se expresan en la superficie celular después de la activación de la plaqueta, que incluyen la glicoproteína IIb/IIIa $\left(\alpha_{\text {IIb }} \beta_{3}\right)$ y la P-selectina (CD62P), las moléculas más importantes en la agregación y adhesión plaquetaria. Los gránulos densos contienen depósitos concentrados de ADP, ATP, pirofosfato, calcio iónico y 5HT, todas ellas sustancias que contribuyen a su vez en la activación plaquetaria(McNicol \& Israels, 1999). Los lisosomas contienen numerosas ácidohidrolasas que son secretadas por las plaquetas únicamente en respuesta a una estimulación intensa por un agonista. La activación plaquetaria conduce a la fusión de los gránulos con el sistema canalicular abierto y la liberación del contenido de los mismos. Tras la activación el citoesqueleto plaquetario constituido por microtúbulos y microfilamentos se reorganiza, lo que conlleva un cambio de morfología, transformándose las plaquetas en esféricas y extendiendo unas extensiones citoplasmáticas filiformes conocidas como pseudópodos (Figura 8). 


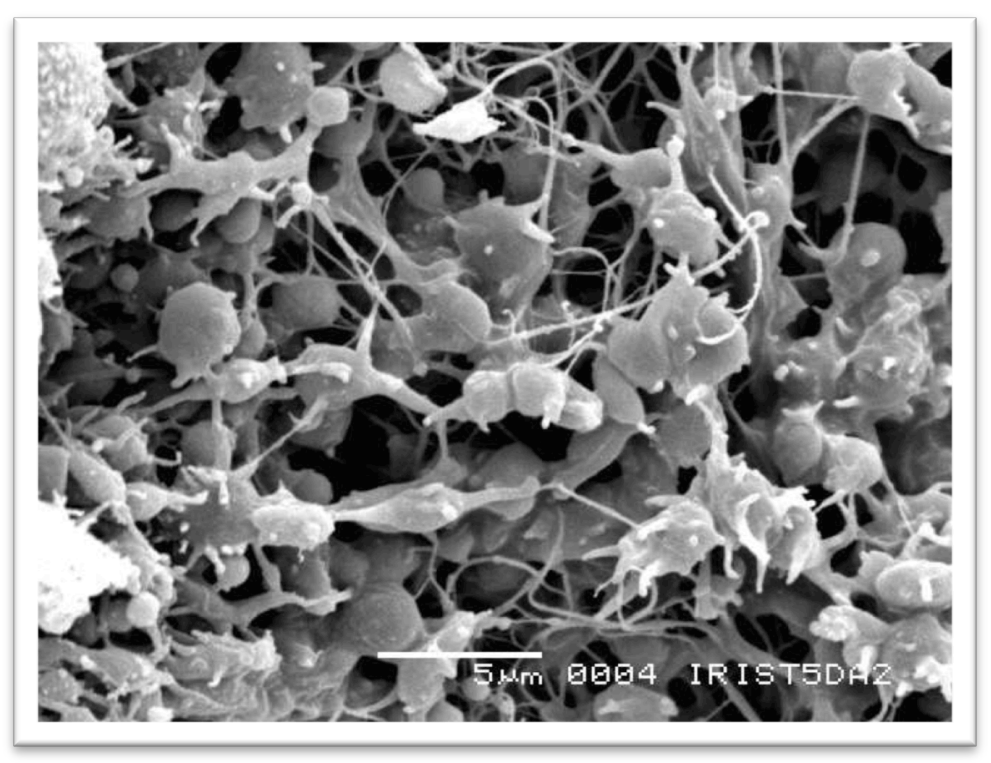

Figura 8: Imagen de microscopía electrónica de barrido en la que se muestran plaquetas activadas formando una red de pseudópodos.

\subsection{RECEPTORES PLAQUETARIOS}

\subsubsection{EL COMPLEJO GLICOPROTEÍNA IIB/IIIA (GP IIB/IIIA)}

También conocida como integrina $\alpha$ IIb $\beta 3$, el complejo GP IIb/IIIa es un receptor de membrana perteneciente a la superfamilia de genes de la integrina, y como otras integrinas, es un heterodímero constituido por una subunidad $\alpha$ y una subunidad $\beta$, ambas transmembrana(Shattil, 1995). Entre 40.000 y 80.000 complejos IIb/IIIa están presentes en la superficie de cada plaqueta en estado de reposo, y este número aumenta rápidamente tras la activación plaquetaria. La activación no sólo incrementa el número, sino que cambia la conformación espacial de la molécula y permite su unión al fibrinógeno, al factor von Willebrand (FvW) o a la fibronectina, mientras que en estado de reposo sólo presenta un poder débil para unirse al fibrinógeno (Figura 9). La molécula de fibrinógeno posee dos regiones de unión a la GP IIb/IIIa que actúan como ligandos bivalentes de gran fuerza que forman puentes cruzados entre las plaquetas activadas dando lugar a la agregación de las mismas. De este modo, el complejo GPIIb/IIIa/fibrinógeno forma la denominada "vía final común" de agregación plaquetaria, independiente de los diferentes estímulos que pueden condicionar la activación de la plaqueta. 


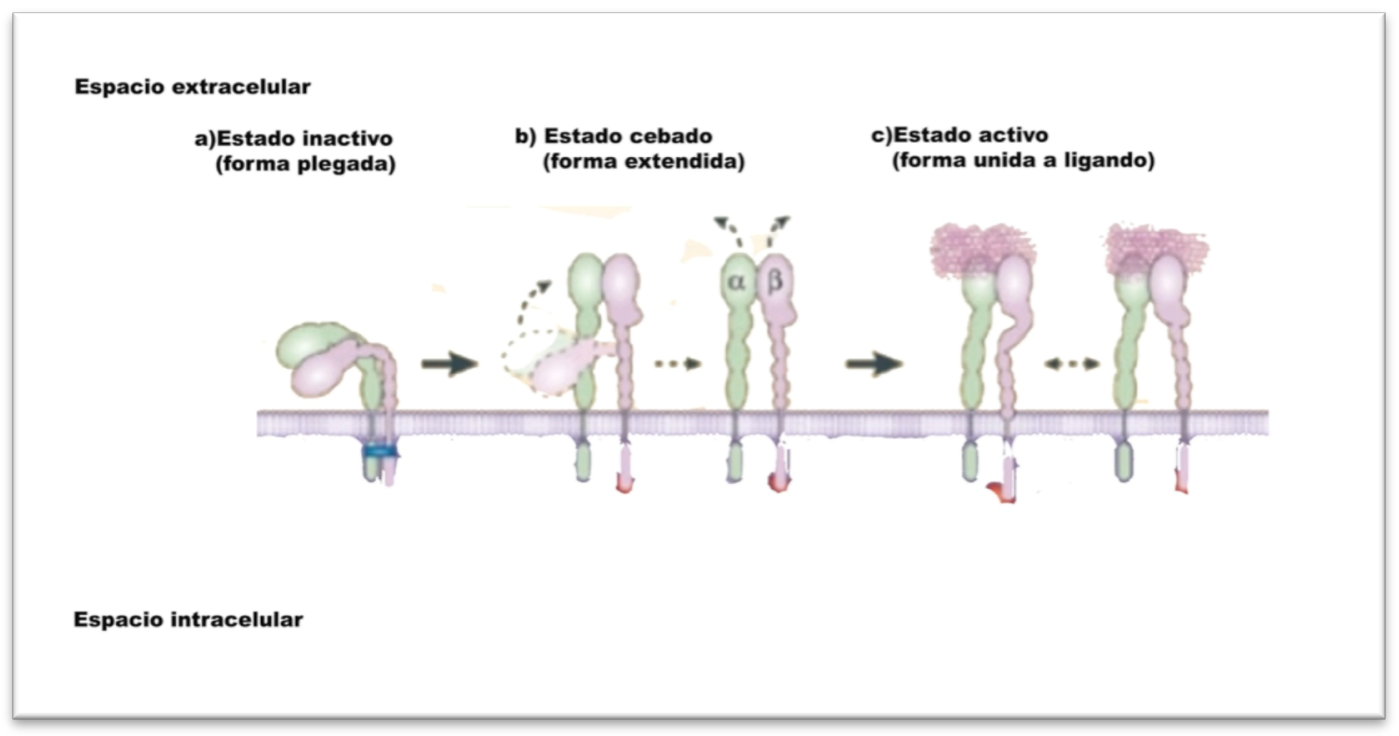

Figura 9: Estructura de la integrina $\alpha \operatorname{IIb} \beta 3$ (modificado de Nature Reviews(C).

\subsubsection{ADHESIÓN PLAQUETARIA E INICIO DE LA FORMACIÓN DEL TROMBO}

En el momento en que el colágeno del subendotelio queda expuesto al torrente sanguíneo, el factor von Willebrand plasmático puede unirse a él y seguidamente se produce la adhesión plaquetaria por medio de la glicoproteína Ib $\alpha$, formándose el complejo GP Ib $\alpha$-IX-V(Ruggeri \& Mendolicchio, 2007). Tras esta primera unión, otros complejos como la GPVI y el complejo $\alpha 2 \beta 1$ refuerzan la unión de las plaquetas a la matriz colágena del subendotelio y, fundamentalmente, por la unión del FvW a la GP IIb/IIIa. La interacción de estas uniones da lugar a una potente activación de las plaquetas en cadena favorecida por la liberación del contenido de los gránulos densos (ADP, ATP, serotonina), activación de la fosfolipasa A2, formación y liberación del tromboxano A2 y la activación conjunta de la cascada de la coagulación por medio de la formación de trombina, que a su vez inicia la formación del coágulo trombínico con el reclutamiento y activación subsiguientes de un mayor número de plaquetas.

\subsubsection{LA VÍA DEL ÁCIDO ARAQUIDÓNICO Y EL TROMBOXANO A2}

El ácido araquidónico es el producto de la acción de un grupo de fosfolipasas, conocidas de forma colectiva como fosfolipasa A2 (PLA2) sobre los fosfolípidos de membrana como la fosfatidilcolina y la fosfatidilserina, y es uno de los estimulantes plaquetarios más conocidos(Moncada \& Vane, 1979; RittenhouseSimmons, 1981). El ácido araquidónico es rápidamente transformado por la ciclooxigenasa (COX) en prostaglandina G2, la cual se convierte a su vez en prostaglandina $\mathrm{H} 2$ mediante la peroxidasa y ésta en tromboxano A2 por acción de la tromboxanosintetasa. Tanto PGH2 como TXA2, aunque lábiles, son potentes activadores plaquetarios que pueden difundir a través de la membrana plasmática y unirse a receptores específicos ligados a proteína G(Brass, Hoxie, \& Manning, 1993). El primer fármaco utilizado con éxito como antiplaquetario fue el ácido 
acetil salicílico que mediante la acetilación de la COX inhibía de forma irreversible esta vía de activación.

\subsubsection{RECEPTORES PLAQUETARIOS P2}

Existen tres tipos de receptores en esta familia: $\mathrm{P}_{2} \mathrm{X}_{1}, \mathrm{P}_{2} \mathrm{Y}_{1}$ y $\mathrm{P}_{2} \mathrm{Y}_{12}$ (Hechler, Cattaneo, \& Gachet, 2005) (Figura 10). El P2X1 es un canal iónico activado por ATP que interviene en el cambio de forma de la plaqueta y la activación inducida por el colágeno. El P2Y1y el P2Y12 son receptores acoplados a proteína G y activados por ADP (Figura 11). El estímulo del ADP supone la primera activación del receptor P2Y1 ligado a la proteína Gq y esta activación es mantenida y amplificada por el P2Y12, acoplado a la proteína Gi y con una potencia biológica mucho mayor, ya que estimula la secreción de los gránulos plaquetarios y la activación procoagulante de la plaqueta(Storey et al., 2000), lo que explica la base de la importancia de este receptor y el éxito terapéutico que sus agonistas han mostrado en la inhibición de la función plaquetaria(Storey, 2006).

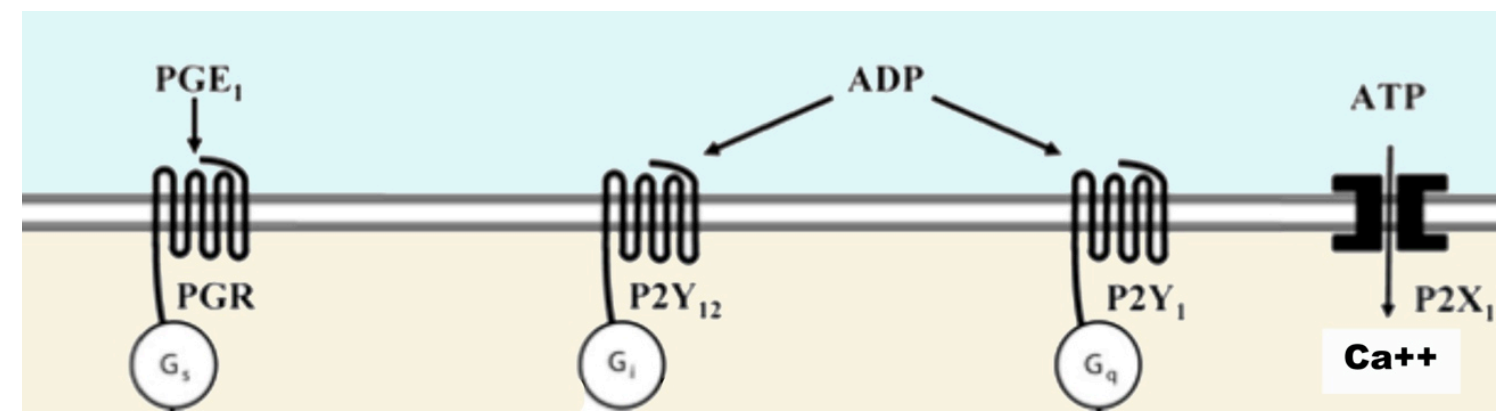

Figura 10: Familia de los receptores plaquetarios P2 (modificado de Medscape(C).

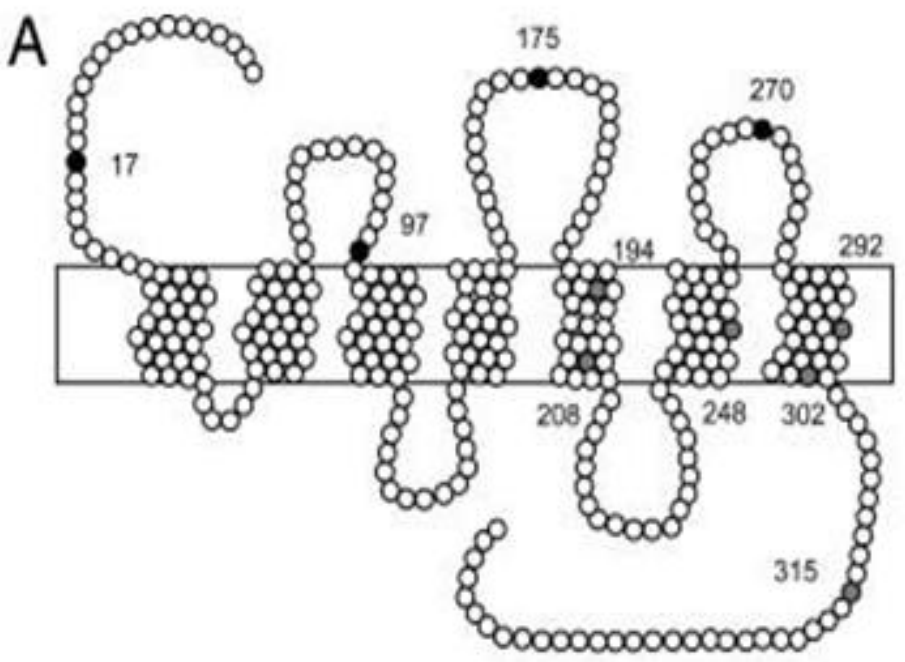

Figura 11: Estructura molecular del receptor P2Y12 humano. 


\subsubsection{RECEPTORES PLAQUETARIOS ACTIVADOS POR PROTEASA (PAR) Y TROMBINA}

Los receptores PAR1 y PAR4 se expresan en las plaquetas humanas, siendo el PAR1 el que probablemente tenga un papel más destacado al activarse a bajas concentraciones de trombina, mientras que el PAR4 requiere mayores concentraciones(Coughlin, 2005). La trombina escinde el dominio N-terminal de los receptores PAR, dando lugar a un péptido ligando que activa el receptor, procesa lo que puede ser imitado por los péptidos de trombina activadores del receptor o TRAP(Coughlin, 2005). La importancia que estos receptores podrían tener es la presencia de los mismos en células involucradas en la respuesta inflamatoria, por lo que podrían servir como dianas terapéuticas para los procesos inflamatorios que cursan con manifestaciones trombóticas asociadas.

\subsubsection{VÍAS MEDIADAS POR RECEPTOR QUE INHIBEN LA ACTIVACIÓN PLAQUETARIA}

La estructura más involucrada en la inhibición de la función plaquetaria por medio de mantener su estado "quiescente" o no activado es el endotelio vascular. Esta función es desempeñada fundamentalmente por la producción de óxido nítrico (NO) y prostaciclina (PGI2), molécula que actúan directamente sobre las vías de activación de la plaqueta además de poseer un efecto vasodilatador intrínseco(Cines et al., 1998). El NO activa la guanidilciclasa plaquetaria, aumentando los niveles de GMP cíclico que inhiben a su vez el aumento de los niveles de calcio citoplasmático inducido por los agonistas(Loscalzo, 2001; Mendelsohn, O'Neill, George, \& Loscalzo, 1990). El NO derivado de las plaquetas también parece inhibir la formación de trombo por parte de las proteínas del sistema de coagulación(Vilahur, Segales, Salas, \& Badimon, 2004).

La COX y la prostaglandina G/H sintetasa-2 (conocidas como COX-1 y COX-2) endoteliales intervienen en la producción de PGI2, la cual disminuye la actividad plaquetaria por la ruta del aumento del AMP cíclico intracitoplasmático(Boie et al., 1994). La inhibición de estas enzimas por el uso de antiinflamatorios no esteroideos puede producir un descenso en los niveles plasmáticos de PGI2 que pueden explicar los efectos cardiovasculares adversos que este tipo de fármacos parecen tener(Grosser, Fries, \& FitzGerald, 2006).

Otro metabolito de la COX, la PGE2, posee efectos contradictorios sobre la actividad plaquetaria. A bajas concentraciones y actuando a través de los receptores EP3 puede aumentar las respuestas de la plaqueta, oponiéndose al incremento del AMP cíclico que produce la PGI2(Fabre et al., 2001). La liberación de PGE2 por parte de la pared vascular inflamada puede tener responsabilidad en los fenómenos trombóticos subsiguientes a la inflamación de la placa ateromatosa(Gross, Tilly, Hentsch, Vonesch, \& Fabre, 2007).

Otra molécula con importante efecto inhibidor sobre la función plaquetaria es la adenosina, actuando a través de los receptores $\mathrm{A}_{2 \mathrm{~A}} \mathrm{y}$ aumentando los nieles de AMP cíclico(Gessi, Varani, Merighi, Ongini, \& Borea, 2000). La adenosina sería 
liberada al torrente sanguíneo durante los episodios de hipoxia o isquemia, aumentando lo suficiente como para activar estos receptores y dando explicación a su involucración en los fenómenos de pre y poscondicionamiento isquémico. Los efectos antiplaquetarios del dipiridamol dependen de la inhibición de la captación de la adenosina por las células sanguíneas, aumentando así sus niveles plasmáticos(Schaper, 2005).

\subsection{PAPEL DE LA PLAQUETA EN LA ATEROTROMBOSIS CORONARIA Y EN EL INTERVENCIONISMO CORONARIO PERCUTÁNEO}

La aterotrombosis se refiere al proceso mediante el cual la progresión de la ateromatosis coronaria conduce a la ruptura y erosión de la placa de ateroma y a la formación de trombo intravascular.

Las denominadas placas vulnerables o de alto riesgo, placas de ateroma con un contenido alto de lípidos y células inflamatorias y una cápsula fibrosa fina parece que son las más relacionadas con la génesis del infarto de miocardio, aunque esta relación es muy difícilmente demostrable y está aún siendo evaluada(Maseri \& Fuster, 2003).

La exposición de las plaquetas al colágeno, el factor de von Willebrand y la fibronectina del subendotelio que siguen a la ruptura de una de estas placas produce la activación plaquetaria directa, pero además de ello, el abundante contenido de factor tisular que se haya en el core lipídico de ellas también activa la cascada de la coagulación, generando trombina que a su vez incrementa la activación plaquetaria.

En resumen, podemos afirmar que si la célula espumosa y otras células de la inflamación son las responsables del inicio y mantenimiento del proceso de la ateromatosis, la plaqueta es la células más íntimamente implicada en el proceso de inestabilización de la placa y de iniciador de los síndromes coronarios agudos como estadio final de este proceso patológico. Por este motivo, si las medidas antiinflamatorias e hipolipemiantes son las más eficaces para frenar la progresión de la enfermedad en sus fases iniciales, durante la fase aguda de presentación del infarto de miocardio los esfuerzos se concentran en inhibir la actividad plaquetaria y el sistema de la coagulación.

En cuanto al intervencionismo coronario percutáneo, los motivos por los que la plaqueta ejerce un papel determinante pueden ser muy similares a los previos. Al fin y al cabo, la intervención sobre las placas de ateroma de las arterias coronarias, no por el hecho de realizarse en un ambiente controlado deja de ser una agresión que conduce a la rotura de las mismas, con la presentación del material subendotelial al flujo sanguíneo y la subsiguiente activación plaquetaria. De hecho, los requerimientos de terapia antiagregante durante el intervencionismo coronario percutáneo son incluso más exigentes que durante el infarto de miocardio debido a la extensión del daño vascular y denudación endotelial que se produce. 
A su vez, en el periodo posterior a la intervención, las plaquetas pueden contribuir también a la proliferación celular del músculo liso vascular que da lugar a la reestenosis posterior al intervencionismo(Weber \& Schror, 1999).

\subsection{FARMACOLOGÍA ANTIPLAQUETARIA}

\subsubsection{INHIBIDORES DE LA CICLOOXIGENASA}

Las propiedades antiinflamatorias y antipiréticas del primer inhibidor de la ciclooxigenasa (COX), el ácido acetilsalicílico (AAS) son conocidas desde la antigüedad. La sustancia forma parte de la corteza del sauce blanco (Salix alba) y era administrada en forma de infusión o cerveza para aliviar los síntomas de los procesos febriles, posiblemente desde tiempos inmemoriales pero al menos descrito así en el Corpus Hippocraticum. Pero no fue hasta 1971 cuando John R. Vane descubrió sus propiedades antiagregantes a través de la capacidad que poseía de inhibir la producción de prostaglandinas y tromboxanos(Vane, 1971). A partir de ese momento se abrieron las posibilidades de aplicación en la enfermedad cardiovascular. Su repercusión y difusión fue tan amplia que es uno de los pocos ejemplos en los que el nombre comercial acuñado por Bayer, aspirina, se convierte en nombre genérico (Figura 12).

En 1974 se demuestra su capacidad para reducir la mortalidad administrada a los pacientes tras sufrir un infarto de miocardio(Elwood et al., 1974). Posteriormente, los estudios AMIS("The aspirin myocardial infarction study: final results. The Aspirin Myocardial Infarction Study research group," 1980) y luego el ISIS-2("Randomised trial of intravenous streptokinase, oral aspirin, both, or neither among 17,187 cases of suspected acute myocardial infarction: ISIS-2. ISIS-2 (Second International Study of Infarct Survival) Collaborative Group," 1988) confirmaron y cuantificaron este beneficio, consiguiendo reducciones de mortalidad de hasta un $43 \%$ asociada a estreptoquinasa.

La dosis inicial habitual es entre 162 y 325mg, seguida de una dosis de mantenimiento de entre 75 y $162 \mathrm{mg}$ que debe ser mantenida de por vida en ausencia de contraindicaciones. Esta dosis es tan eficaz como dosis mayores y presenta menos toxicidad("Collaborative meta-analysis of randomised trials of antiplatelet therapy for prevention of death, myocardial infarction, and stroke in high risk patients," 2002).

Las dos principales isoformas de la COX son la COX-1 y la COX-2, también denominadas PGH2 sintetasa 1 y 2 respectivamente, están constituidas por tres unidades plegables independientes, que constituyen un dominio tipo factor de crecimiento epidérmico, una región transmembrana y un dominio enzimático(Picot, Loll, \& Garavito, 1994).

Tiene un papel crucial en el metabolismo del ácido araquidónico (AA). Éste es liberado desde los fosfolípidos de membrana por la fosfolipasa A2. La COX oxida al 
AA para formar prostaglandina (PG) G2 y PGH2. La PGH2 es catalizada posteriormente por sintetasas específicas para formar las prostaglandinas D2, E2, F2 $\alpha$ e I2 (prostacliclina) y tromboxano A2 (TXA2), todos ellos con funciones celulares específicas(Raju, 2009).

La COX-1 se expresa de forma constitutiva en casi todas las células y tiene función primordial para mantener las necesidades propias de la célula que incluyen la protección gástrica y la función plaquetaria(Awtry \& Loscalzo, 2000).

La COX-2 se expresa sólo en respuesta a determinados estímulos inflamatorios y factores de crecimiento como respuesta al daño tisular(Smith, Garavito, \& DeWitt, 1996).

Las plaquetas nuevas expresan ambas isoformas de la enzima mientras que las maduras sólo la COX-1. La plaqueta procesa la transformación de PGH2 en TXA2, el cual interactúa con su receptor de membrana para activar las plaquetas, dando lugar a una agregación irreversible(Raju, 2009). A su vez, el TXA2 tiene otros efectos cardiovasculares como son la vasoconstricción y la proliferación del músculo liso vascular(Patrono, Garcia Rodriguez, Landolfi, \& Baigent, 2005).

El endotelio, por el contrario, procesa la transformación de pGH2 en prostaciclina (PGI2), la cual inhibe la agregación plaquetaria y la proliferación del músculo liso y causa vasodilatación y protege al miocardio ante el estrés oxidativo(Patrono et al., 2005).

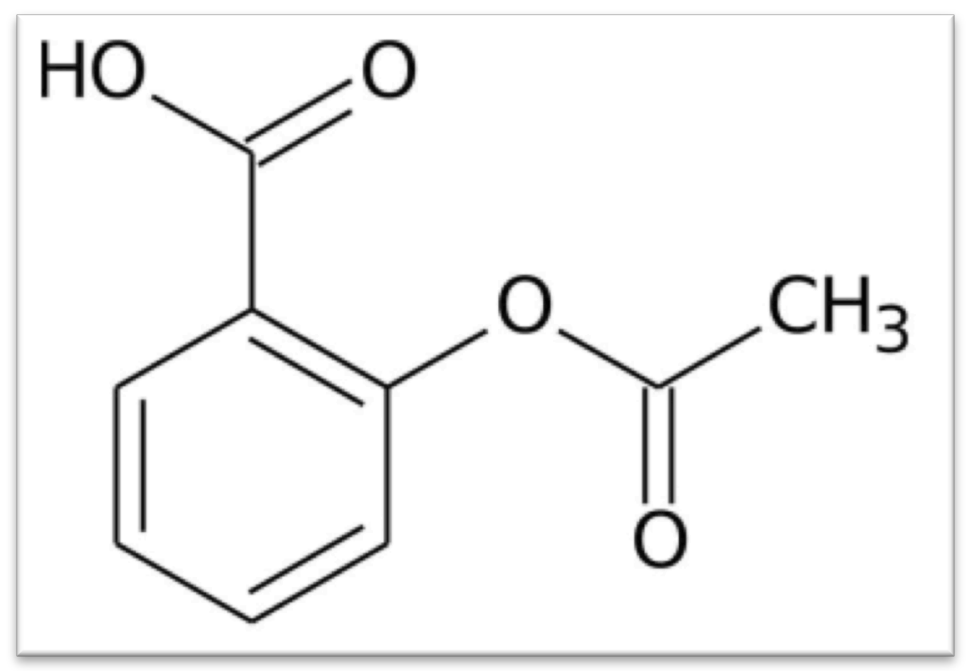

Figura 12: Fórmula del ácido acetil-salicílico (aspirina)

El AAS tiene una vida media de 15 a 20 minutos, aunque únicamente es necesario una dosis diaria ya que inhibe la COX-1 de forma irreversible y las plaquetas no son capaces de sintetizar enzima adicional al no poseer núcleo. De hecho, el efecto inhibidor sobre las plaquetas se prolonga durante 5 a 10 días(Raju, 2009).

El AAS inhibe de forma irreversible el paso inicial de la biosíntesis de prostanoides al evitar la conversión de AA a PGG2 por la COX-1 y la COX-2, pero su capacidad para inhibir la primera es 170 veces más potente que para inhibir la 
COX-2, de manera que se requieren dosis mucho más elevadas para alcanzar efectividad antiinflamatoria.

Uno de los efectos adversos más temidos ante la utilización de AAS es la hemorragia gastrointestinal. La COX-1 es la isoforma predominante en la mucosa gástrica y su inhibición por el AAS suprime la producción de PGE2, la cual tiene una función citoprotectora en el estómago. La presencia de síntomas gastrointestinales leves entre los paciente que toman AAS es frecuente, pero la incidencia de hemorragias graves no lo es tanto(Patrono et al., 2001). De todos modos, cuando se emplea para prevenir la enfermedad cardiovascular, el AAS debe ser administrado a la dosis mínima efectiva con el fin de minimizar el riesgo de hemorragia, $y$ en muchas en muchas ocasiones se administra de forma concomitante con protectores gástricos, a pesar de que esta medida es todavía controvertida en ausencia de antecedentes de sangrado digestivo.

Otros efectos adversos como son la toxicidad renal, la ototoxicidad y las reacciones de hipersensibilidad son muy raros a las dosis recomendadas para profilaxis secundaria de la enfermedad coronaria y por lo tanto quedan fuera de los objetivos de esta tesis.

\section{Variabilidad de la respuesta a la aspirina}

La aspirina es el fármaco antiplaquetario más utilizado en la prevención secundaria de la enfermedad coronaria. De todos modos, a pesar del tratamiento adecuado, se calcula que entre el 10 y el $20 \%$ de los pacientes pueden sufrir una recurrencia de eventos isquémicos, lo que sugiere que los efectos de la aspirina podrían no ser iguales en todos los enfermos. Además, las medidas de agregación plaquetaria de laboratorio han mostrado una gran variabilidad interindividual en los resultados obtenidos(Grotemeyer, Scharafinski, \& Husstedt, 1993; Gum, Kottke-Marchant, Welsh, White, \& Topol, 2003; Pappas, Westengard, \& Bull, 1994).

A su vez, recientes estudios han demostrado la existencia de una relación entre la respuesta a la aspirina en los tests in vitro de agregación plaquetaria y los eventos clínicos en el seguimiento(Hobikoglu et al., 2007; Marcucci et al., 2006). De todos modos, como ya se ha dicho, ya que las dosis mayores de aspirina no mejoran su efectividad y sólo incrementan el riesgo de efectos adversos, las medidas posibles ante la resistencia a la aspirina pasan por la utilización de otros antiplaquetarios orales, fundamentalmente el clopidogrel. De hecho el primer estudio randomizado que evalúa los eventos clínicos en los pacientes resistentes a la aspirina lo hace mediante el cambio a clopidogrel de mantenimiento(Pettersen, Seljeflot, Abdelnoor, \& Arnesen, 2004), aunque sus resultados no han sido publicados.

Por estos motivos, presenta mayor repercusión clínica y mayores posibilidades terapéuticas la resistencia al clopidogrel, el fármaco utilizado no sólo como alternativa a la aspirina sino especialmente, como tratamiento adyuvante precisamente en las situaciones en las que los requerimientos de eficacia antiagregante sean más exigentes (como lo son la fase posterior al infarto de miocardio y el intervencionismo coronario percutáneo, las dos situaciones 
implicadas en el desarrollo de esta tesis doctoral). Por este motivo pasamos a definir los conceptos de resistencia a los fármacos antiagregante y sus implicaciones clínicas en el siguiente apartado, referente a las tienopiridinas.

\subsubsection{INHIBIDORES DEL ADP}

\subsubsection{Tienopiridinas de primera y segunda generación: Ticlopidina y Clopidogrel}

Los antiagregantes tienopiridínicos, ticlopidina y clopidogrel, interfieren en la agregación plaquetaria mediante la inhibición selectiva e irreversible del receptor P2Y12 para el ADP(Savi et al., 2000). Ambos fármacos son inactivos in Vitro y requieren la administración in vivo para presentar su efecto antiagregante tras una metabolización hepática del profármaco mediante el citocromo P450(Savi et al., 1994). Ambos fármacos (Figuras 13 y 14) presentan el mismo efecto y potencia antiagregante, sin embargo, debido a la relativamente alta frecuencia de reacciones adversas graves como neutropenia y púrpura trombocitopénica inducidas por la ticlopidina(Page et al., 1991; Szto, Linnemeier, \& Ball, 1999), ésta ha pasado a un segundo plano, siendo el clopidogrel el principal derivado ticlopidínico utilizado en la práctica clínica habitual.

Tras su aparición en los años noventa, el clopidogrel fue utilizado primeramente como sustituto de la aspirina en pacientes alérgicos o con intolerancia gástrica a la misma. Los primeros estudios comparativos entre AAS y clopidogrel mostraron que ambos eran igual de eficaces en la reducción de episodios isquémicos vasculares en pacientes que habían sufrido recientemente un infarto de miocardio o un ictus isquémico, pero en pacientes con vasculopatía periférica, el clopidogrel se mostró más eficaz en la prevención de nuevos episodios isquémicos("A randomised, blinded, trial of clopidogrel versus aspirin in patients at risk of ischaemic events (CAPRIE). CAPRIE Steering Committee," 1996).

La generalización del uso del clopidogrel en el contexto del síndrome coronario agudo comenzó tras la publicación del estudio CURE, que demostró el beneficio clínico de su adición al tratamiento antiagregante con AAS durante el síndrome coronario agudo sin elevación del segmento ST(Mehta \& Yusuf, 2000). Este beneficio, como demostró el subanálisis PCI-CURE, resultó ser mucho más acusado en los pacientes sometidos a intervencionismo coronario percutáneo con implantación de stent(Mehta et al., 2001).

Posiblemente el miedo a complicaciones hemorrágicas graves hizo que su aplicación en el infarto agudo de miocardio con elevación del segmento ST fuera más tardía, debido al tratamiento fibrinolítico habitual para este proceso. Con la publicación de los hallazgos de los estudios COMMIT(Chen et al., 2005) y CLARITY(Sabatine et al., 2005), quedó establecida su valía como tratamiento antiagregante adyuvante a la aspirina en el infarto fibrinolisado sin que se produjera un incremento de las hemorragias graves.

En resumen, durante los últimos años hemos sido testigos de cómo esta molécula ha pasado de un uso marginal en la enfermedad cardiovascular a presentarse como fármaco de cabecera asociado a la aspirina en todas las 
situaciones de alto riesgo: los síndromes coronarios agudos sin elevación del segmento ST (angina inestable e infarto sin elevación del segmento ST), el propio IAMCEST y todo proceso que lleve asociado un intervencionismo coronario percutáneo con implante de stent.

De esta forma, sea cual sea el tratamiento de reperfusión indicado en un infarto de miocardio con elevación del segmento ST, el clopidogrel se ha establecido como tratamiento fundamental, ya sea asociado a la aspirina como antiplaquetario durante la fibrinolisis, ya sea asociado al implante de stent durante la angioplastia. Así, la inmensa mayoría de los pacientes admitidos a un hospital por un infarto de miocardio, recibirán clopidogrel durante el ingreso y especialmente durante las primeras horas y días del mismo.

En un escenario en el que el techo terapéutico de la aspirina parece encontrado y en el que todavía parece que la investigación sobre el receptor P2Y12 puede dar frutos futuros, nos centramos en la descripción del funcionamiento de este receptor y en los mecanismos de resistencia a las tienopiridinas a la hora de plantear avances en la terapia antiagregante asociada al tratamiento del infarto de miocardio.

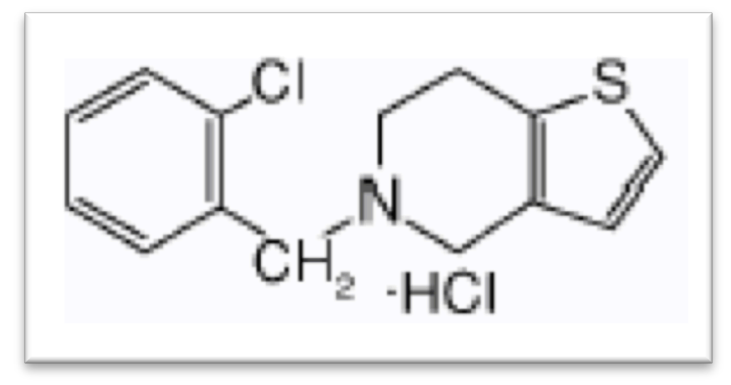

Figura 13: Fórmula de la ticlopidina.

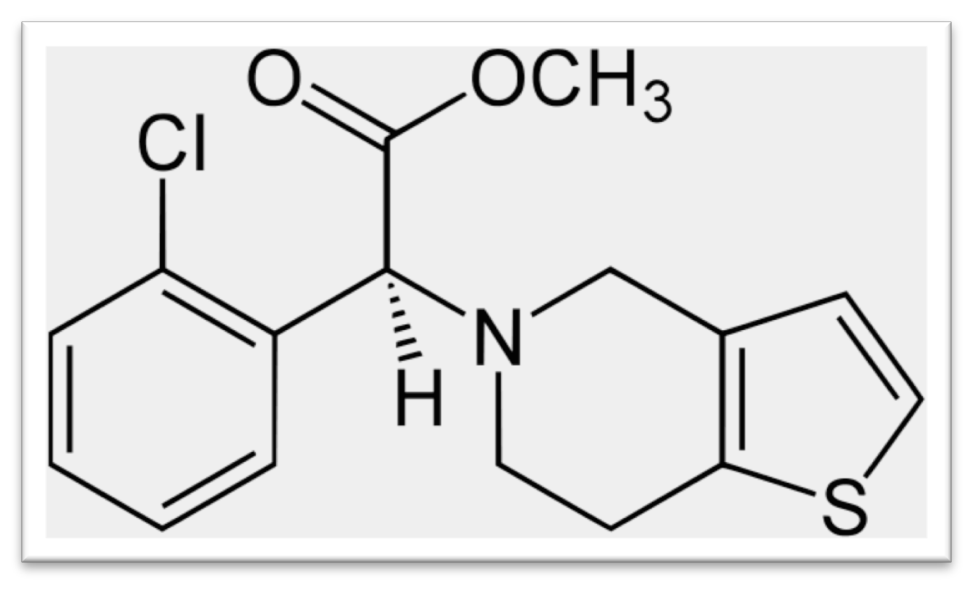

Figura 14: Fórmula del clopidogrel. 


\section{Farmacocinética}

El inicio de acción del clopidogrel se empieza a apreciar pasadas dos horas desde su administración, aunque el estado de equilibrio del efecto de inhibición plaquetaria se alcanza entre tres y siete días tras el inicio del tratamiento (de acuerdo con la información del fabricante). La cinética del clopidogrel no es lineal y se caracteriza por una notoria disminución de su excreción después de suministrar varias dosis. Dado que su unión con el receptor es de carácter irreversible, al igual que sucede con la aspirina son necesarios cinco días para que desaparezcan sus efectos una vez cesado el tratamiento(HD White, 2001).

\section{Variabilidad de la respuesta a las tienopiridinas: resistencia al clopidogrel}

Por la especial trascendencia que este concepto tiene en la justificación y diseño de esta tesis doctoral, la siguiente sección de este capítulo (3.4) se dedica específicamente a esta cuestión.

\subsubsection{Tienopiridinas de tercera generación: Prasugrel}

Se trata de una tienopiridina de tercera generación que bloquea de forma irreversible y selectiva el receptor P2Y12 plaquetario para el ADP. Esta molécula no requiere de la doble metabolización hepática que requiere el clopidogrel sino sólo una metabolización de primer paso, por lo que el inicio del efecto tras su administración oral es mucho más rápido y permite niveles mucho más estables de droga en plasma gracias a su relativa independencia del sistema de citocromo P450(Payne et al., 2007).

Una dosis de carga de $60 \mathrm{mg}$ de prasugrel seguida de $10 \mathrm{mg}$ diarios de mantenimiento, comparada con $600 \mathrm{mg}$ de clopidogrel seguida de $75 \mathrm{mg}$ diarios(Wallentin et al., 2008) o de $150 \mathrm{mg}$ diarios(Wiviott, Trenk, et al., 2007), ), ha demostrado que proporciona un inicio de acción más rápido, valores de inhibición plaquetaria superiores y menor variabilidad interindividual. Este efecto puede ser explicado fundamentalmente por su rápida absorción que permite valores plasmáticos máximos a los 30 minutos de su administración.

Otras ventajas que presenta esta molécula sobre el clopidogrel son la no influencia del genotipo CYP en las propiedades farmacocinéticas $\mathrm{y}$ farmacodinámicas y la mucho menor, y la práctica ausencia de pacientes con valores de antiagregación subóptima.

El estudio clínico que ha avalado la utilización del prasugrel es el TRITON-TIMI 38. Este ensayo clínico de gran tamaño estudió a una población de pacientes con SCA con o sin elevación del ST derivados a ICP. Los pacientes eran asignados de forma randomizada a recibir prasugrel (60mg de carga más $10 \mathrm{mg}$ diarios) o clopidogrel (300mg de carga seguidos de 75mg diarios). Se comprobó una reducción estadísticamente significativa del objetivo primario del estudio, que era una combinación de muerte de causa cardiovascular, infarto no fatal e ictus 
isquémico. Eso sí, a costa de un incremento en los eventos hemorrágicos mayores que contrarrestó el beneficio clínico neto(Wiviott, Braunwald, et al., 2007).

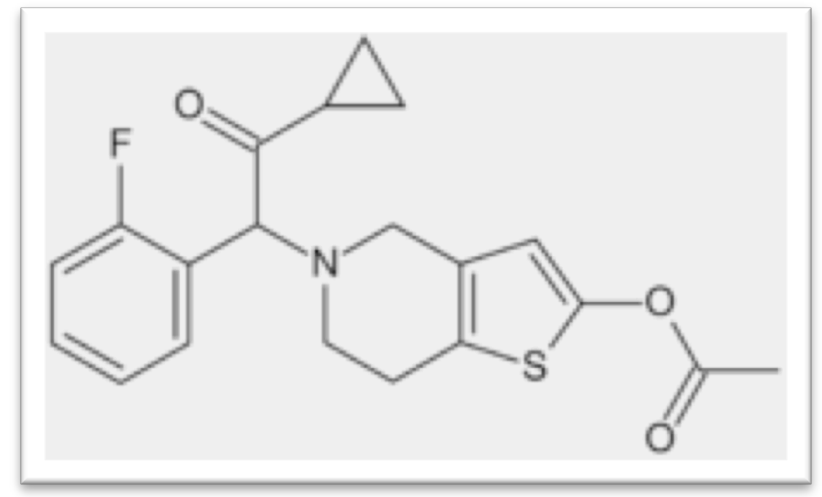

Figura 15: Fórmula del prasugrel.

\subsubsection{Inhibidores del ADP no tienopiridínicos: Ticagrelor y Cangrelor}

El ticagrelor (Figura 16), previamente conocido como AZD6140, es una molécula que pertenece a la nueva familia de las ciclopentil-triazol-pirimidinas. No se trata pues de una tienopiridina. Es un inhibidor oral directo del receptor P2Y12 que presenta la gran ventaja con respecto a las tienopiridinas de que su unión al receptor P2Y12 es reversible y sin necesidad de metabolización hepática. De esta manera, el ticagrelor produce una inhibición más rápida y más consistente del receptor P2Y12 que el clopidogrel(Husted et al., 2006).

La seguridad, tolerabilidad y eficacia del fármaco añadido a la aspirina fue evaluada en el estudio DISPERSE-2(Cannon et al., 2007) en el que no se encontraron diferencias en la incidencia de sangrados mayores pero sí un aumento importante de sangrados menores comparadas las pautas de $90 \mathrm{mg}$ día de ticagrelor frente a la de $75 \mathrm{mg}$ diarios de clopidogrel.

El estudio PLATO(Wallentin et al., 2009) se trata de un gran ensayo clínico fase III que reclutó a más de 18000 pacientes con SCA con o sin elevación del segmento ST para ser asignados de forma randomizada a ticagrelor $180 \mathrm{mg}$ de dosis de carga seguidos de $90 \mathrm{mg}$ cada doce horas) o a clopidogrel (300-600mg de dosis de carga seguidos de $75 \mathrm{mg}$ diarios de mantenimiento). Tras un año de seguimiento, el objetivo primario del estudio (un objetivo compuesto de muerte vascular, infarto de miocardio y ACV) ocurrió en el 9,8\% de los pacientes tratados con ticagrelor frente al $11,7 \%$ de los pacientes tratados con clopidogrel. Las hemorragias en este estudio no mostraron diferencias gracias a una reducción de los sangrados relacionados con la cirugía cardiaca, aunque sí que se encontró un incremento significativo de los sangrados mayores no relacionados con la cirugía.

Otros efectos secundarios propios del ticagrelor son el encontrar tasas superiores de disnea entre los paciente tratados. Este efecto secundario requirió la suspensión del tratamiento en aproximadamente un 1\% de los pacientes y hubo un incremento en pausas cardiacas superiores a 3 segundos sin que se apreciaran diferencias significativas en cuanto a síncope o requerimientos de marcapasos 
permanente, así como en elevación de las cifras de creatinina y ácido úrico plasmáticos.

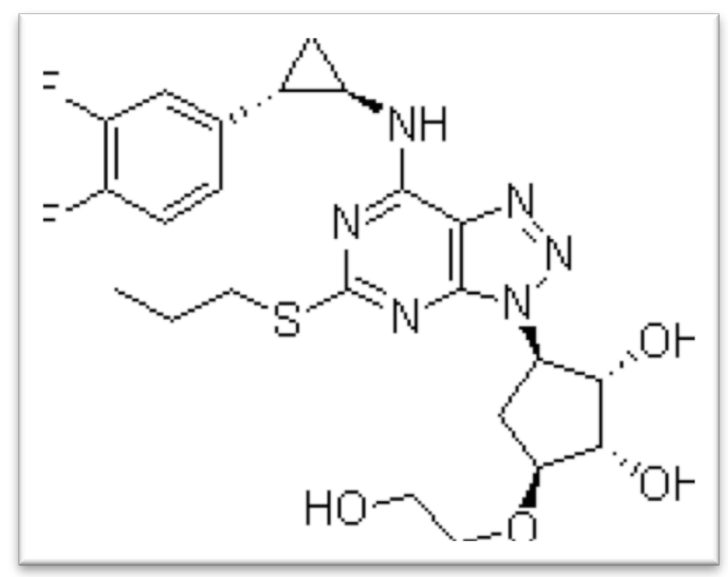

Figura 16: Fórmula del ticagrelor.

El cangrelor (Figura 17) es un análogo del ATP no tienopiridínico que actúa como potente inhibidor selectivo del receptor P2Y12 para el ADP. Esta molécula no requiere conversión a metabolito activo y por lo tanto es efectiva de forma inmediata tras su infusión intravenosa. Tiene una vida media de 3 a 6 minutos y sus efectos cesan tras 30-60 minutos de la suspensión de la perfusión. La necesidad de administración intravenosa del fármaco tiene ventajas e inconvenientes; entre estos últimos, quizá el más importante sea la imposibilidad de ser utilizado como fármaco habitual de forma ambulatoria.

La potencia de este fármaco es comparable a la obtenida con el abciximab, inhibidor directo de la glicoproteína IIb/IIIa y posiblemente el fármaco antiplaquetario más potente, lográndose una inhibición completa de la actividad plaquetaria a los pocos minutos de iniciada su administración, pero tras el cese de la infusión y debido a la naturaleza reversible de su unión al receptor, la reactividad plaquetaria retorna a valores normales a mucha más velocidad que con la administración de abciximab (que actúa mediante una unión irreversible al receptor IIb/IIIa).

Se han realizado dos ensayos clínicos fase III de gran tamaño (CAHAMPION-PCI y CHAMPION PLATFORM) para comparar el cangrelor con el clopidogrel durante el ICP en pacientes con síndrome coronario agudo sin que se encontraran diferencias significativas en cuanto a eventos clínicos en el seguimiento con excepción de tasa de trombosis del stent(Bhatt et al., 2009; Harrington et al., 2009), por lo que el reclutamiento fue suspendido. 


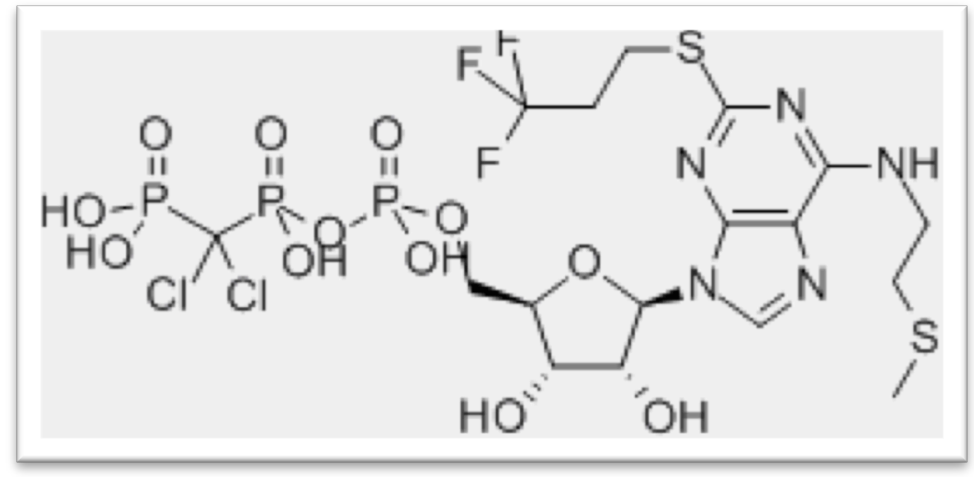

Figura 17: Fórmula del cangrelor.

\subsubsection{INHIBIDORES DE LA GP IIB/IIIA}

En el apartado de introducción dedicado a la fisiología plaquetaria ya se describió el complejo transmembrana IIb/IIIa, molécula responsable de la agregación final plaquetaria al realizar los puentes IIb/IIIa-fibrinógeno-IIb/IIIa, como se muestra en la Figura 18.

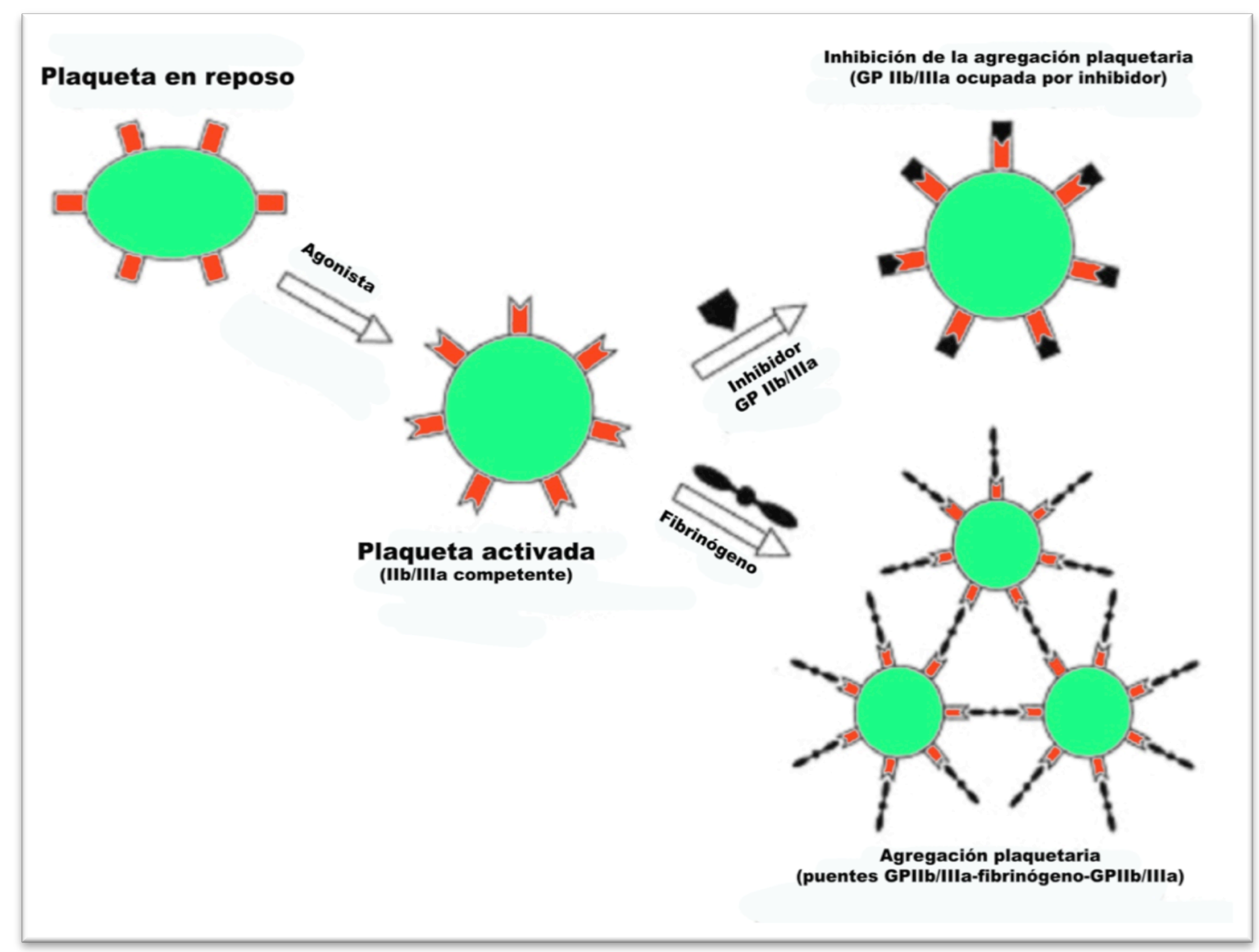

Figura 18: Agregación plaquetaria mediante puentes GP IIb/IIIa-fibrinógeno (modificado de Medscape(C). 
Lo más destacable de este complejo es que se trata de la ruta final de agregación plaquetaria, una vez que se ha producido la activación plaquetaria por otras vías bioquímicas. Así pues, la inhibición de la función de este receptor suprimirá completamente la capacidad de agregación plaquetaria (no otras funciones plaquetarias como la adhesión, que depende de la glicoproteína Ib $\alpha$ ).

Los primeros fármacos capaces de inhibir al receptor IIb/IIla se trataban de anticuerpos monoclonales murinos modificados. Posteriormente se encontraron las propiedades inhibidoras de este receptor en los venenos de diferentes serpientes, que centraban su capacidad inhibitoria en la secuencia RGD peptídica. No han podido ser utilizados de forma directa por su potente inmunegicidad, pero han servido de modelo para el desarrollo de nuevas moléculas de síntesis.

\subsubsection{Abciximab}

El abciximab es el primer inhibidor de la GP IIb/IIIa aprobado por la FDA y uno de los más usados todavía en la actualidad. Se trata de una molécula de gran tamaño ( $>50 \mathrm{KD}$ ) obtenida mediante la modificación de un anticuerpo monoclonal murino al que se adhiere a su fragmento Fab una inmunoglobulina humana para minimizar su potencial inmunógeno(Blankenship, 2009).

El sitio de unión del abciximab está localizado en la cadena $\beta$ del receptor y se trata de un sitio grande (50KD). Impide estéricamente la unión de otros ligandos a la molécula de forma irreversible. Un bolus estándar de abciximab de 0,25 mg/Kg produce un bloqueo superior al $80 \%$ de los receptores y reduce la agregación palquetaria a menos del $20 \%$ de forma rápida.: el $50 \%$ de las moléculas de abciximab se une a las plaquetas a los 10 minutos de infusión. La vida media de disolución del abciximab es de 4 horas, pero debido a su alta afinidad por los receptores y a una disociación muy lenta, hasta el 13\% de los receptores todavía se encuentran inhibidos tras 15 días de su administración y es detectable en las plaquetas circulantes hasta pasados 21(Casserly \& Topol, 2002).

Su efectividad a la hora de mejorar las variables angiográficas y la función ventricular de los pacientes sometido a ICP primario por IAMCEST ha sido demostrada(Gibson et al., 2001), así como la mejoría del pronóstico clínico(Montalescot et al., 2001), siempre en el contexto del infarto agudo de miocardio, lo que distingue a esta molécula del resto de inhibidores de la GPIIb/IIIa, sólo testados en otros contextos menos protrombóticos.

En general se admite que el uso de abciximab durante el ICP relacionado con el infarto de miocardio permite reducir la mortalidad de los pacientes hasta en un $32 \%$ en el primer mes sin aumentar de forma significativa los sangrados graves(De Luca et al., 2005), por lo que las últimas guías de actuación clínica dan recomendación de nivel IIa y nivel de evidencia A su utilización sistematizada durante el angioplastia primaria(Van de Werf et al., 2009), aunque su beneficio en el intervencionismo electivo es menos definitivo y es recomendado con nivel de evidencia B. 


\subsubsection{Eptifibatida}

Esta molécula, de menor tamaño que el abciximab, es sintetizada basándose en el veneno de la serpiente de cascabel Sistrurus m. barbouri. Es altamente selectiva para el receptor IIb/IIIa y su menor tamaño le confiere una inmunogenicidad casi nula. Tiene una vida media de 2,5 horas y es excretada mayoritariamente por orina sin transformar.

Los estudios ex vivo que comprobaron su potencia utilizaban tubos citratados para la extracción de las muestras sanguíneas y esto dio lugar a una sobreestimación de la potencia del fármaco, por lo que los primeros estudios realizados in vivo no mostraron un beneficio clínico relevante y evidenciaron una potencia inhibidora de la agregación plaquetaria no superior al 50$60 \%$ ("Randomised placebo-controlled trial of effect of eptifibatide on complications of percutaneous coronary intervention: IMPACT-II. Integrilin to Minimise Platelet Aggregation and Coronary Thrombosis-II," 1997; Schneider \& Aggarwal, 2004). Posteriormente, la dosis utilizada fue incrementada tanto en bolus como en perfusión continua y el estudio ESPRIT("Novel dosing regimen of eptifibatide in planned coronary stent implantation (ESPRIT): a randomised, placebo-controlled trial," 2000) demostró el beneficio de su utilización durante el intervencionismo coronario percutáneo. De todos modos, esta molécula aún no ha sido adecuadamente probada en el contexto más agudo del infarto de miocardio y en el caso de su administración precoz en el síndrome coronario agudo sin elevación del segmento ST, su administración precoz no mostró beneficios y sí mayor riesgo hemorrágico(Giugliano et al., 2009).

\subsubsection{Tirofibán}

El tirofiban es una molécula no peptídica denominada como peptidomimética por la cualidad de imitar la secuencia de aminoácidos de un péptido inhibidor con la secuencia RGD. Su farmacocinética es similar a la de la eptifibatida y su efecto inhibidor es dosis y concentración dependiente. Tras el cese de su infusión, la agregabilidad plaquetaria retorna a estado basal el en el $90 \%$ de los pacientes en un plazo de 4 a 8 horas.

Su utilización en el contexto de la angina inestable y el IAM sin elevación del ST ha sido probada("Inhibition of the platelet glycoprotein IIb/IIIa receptor with tirofiban in unstable angina and non-Q-wave myocardial infarction. Platelet Receptor Inhibition in Ischemic Syndrome Management in Patients Limited by Unstable Signs and Symptoms (PRISM-PLUS) Study Investigators," 1998) pero no se recomienda en el contexto del IAMCEST.

\section{Efectos adversos de los inhibidores de la GP IIb/IIIa}

Lógicamente, teniendo en cuenta su potencia antipalquetaria, el efecto adverso más temido de la utilización de estos fármacos es la hemorragia, especialmente en el contexto del ICP y el acceso vascular. 
Durante la última década se han realizado avances importantes en el control del riesgo hemorrágico asociado al uso de estas moléculas, que incluyen ajustes de dosis de heparina según el peso, retirada precoz de introductores arteriales así como el uso de introductores de menor tamaño, todas ella medidas adoptadas de forma general.

Otros avances más recientes, como la utilización de dispositivos de cierre percutáneo y la preferencia de la vía radial como ruta de acceso vascular parece que también ayudarán a controlar este problema. Como hemos comentado previamente, los últimos metaanálisis defienden la utilización del abciximab sin demostrar un incremento de las hemorragias mayores(De Luca et al., 2005).

Otro problema relativamente frecuente es la aparición de trombocitopenia. Todos los inhibidores de la GP IIb/IIIa pueden producir trombocitopenia en mayor o menor medida, sin embargo, el abciximab la produce con más frecuencia y en grado más severo en comparación con los inhibidores de la GP IIb/IIIa de molécula pequeña(Blankenship, 2009). Esta trombocitopenia aparece generalmente a las 24 horas de la administración del fármaco y tiene como mecanismo más probable la aparición de anticuerpos inducidos por una exposición previa a las secuencias murinas que forman parte de la molécula de abciximab.

Por el resultado de los estudios clínicos arriba mencionados y ante los riesgos inherentes a su utilización, en las últimas guías de actuación clínica en el manejo del SCA sin elevación del segmento ST, la indicación para utilizar estas moléculas ha quedado desplazada a situaciones muy marginales, posiblemente influenciado también por la aparición de las más potentes inhibidores modernos del ADP, prasugrel y ticagrelor, y por la más exigente precocidad a la hora de realizar las intervenciones coronarias electivas(Hamm et al., 2011). Esta medida afecta fundamentalmente al uso de eptifibatida y tirofiban, ya que la indicación en el ICP relacionado con el contexto mucho más trombogénico del IAMCEST se sigue manteniendo para el uso de abciximab.

\subsection{VARIABILIDAD DE LA RESPUESTA A LAS TIENOPIRIDINAS: RESISTENCIA AL CLOPIDOGREL}

A pesar del beneficio que la adición del clopidogrel ha supuesto en todos estos escenarios, uno de los principales problemas es que no todos los individuos responden con la misma intensidad a su administración, de tal forma que una proporción no desdeñable de pacientes presentan recurrencia de eventos clínicos a pesar de tratamiento activo con clopidogrel. Esta variabilidad en la respuesta ha sido descrita de forma exhaustiva en diferentes marcos clínicos y se ha llegado a utilizar el término de resistencia al clopidogrel para definir esta situación, aunque el término es ciertamente impreciso y no plenamente aceptado por toda la comunidad científica. 
No existe una definición estandarizada de resistencia al clopidogrel. De hecho, la prevalencia de este fenómeno es desconocida precisamente debido a la falta de homogeneidad en los criterios utilizados para referirse a él. En diferentes estudios clínicos se han comunicado porcentajes que varían entre el 5 y el 44\%(Angiolillo et al., 2005; Gurbel, Bliden, Hayes, et al., 2005; Jaremo, Lindahl, Fransson, \& Richter, 2002; Lepantalo, Virtanen, Heikkila, Wartiovaara, \& Lassila, 2004; Lev et al., 2006; Matetzky et al., 2004; Mobley et al., 2004; Muller et al., 2003). Estos porcentajes tan dispares dependen fundamentalmente de que se sigan criterios bioquímicos o clínicos.

\section{DEFINICIÓN CLÍNICA}

Los criterios clínicos de resistencia al clopidogrel se centran en el fracaso en evitar la recurrencia de eventos isquémicos a pesar de tratamiento activo con la droga. Existe una extensa evidencia de que la baja respuesta al clopidogrel se relaciona con la aparición de eventos isquémicos en el seguimiento de pacientes que han sufrido un síndrome coronario agudo(Cuisset et al., 2006; de Miguel Castro, 2010; Geisler et al., 2006), pero dados los múltiples determinantes de la etiopatogenia del proceso aterotrombótico, es posible que centrar la definición de la resistencia al clopidogrel exclusivamente en la presencia de estos eventos recurrentes sea inadecuado, o al menos impreciso. Desde este punto de vista clínico, el término de "resistencia al clopidogrel" debería ser evitado, aunque sí podría utilizarse, y de hecho se hace, el término "fracaso del tratamiento".

\section{DEFINICIÓN BIOQUÍMICA}

La definición bioquímica se centra en el fracaso de la molécula en conseguir cifras adecuadas de efecto inhibitorio en los tests de función plaquetaria de laboratorio. Este efecto inhibitorio se ha definido como la diferencia entre los valores pre y post tratamiento determinado por diferentes métodos de agregometría, el porcentaje de inhibición de actividad plaquetaria (\%IAP). De todos modos, las respuestas de los pacientes a estos diferentes tests de laboratorio no muestran poblaciones separadas de respuesta, sino que la respuesta que suele verse en todos los estudios sigue una distribución normal (un fenómeno equivalente a lo que puede observarse en el efecto causado por casi cualquier droga). De esta manera, la respuesta al clopidogrel no debe verse como un fenómeno dicotómico sino como una variable continua, con una distribución que sigue una forma de campana de Gauss y que por lo tanto presentará unos valores más extremos en ambos sentidos progresivamente menos frecuentes a medida que nos alejemos de los valores centrales. Así, pueden establecerse valores arbitrarios que definan lo que la comunidad científica entiende por "extremos". Siguiendo las definiciones de otros procesos, estos valores se han establecido generalmente en el $5 \%$ o en \pm 2 desviaciones estándar(Serebruany et al., 2005). La magnitud de la respuesta al clopidogrel puede además, y de hecho lo hace, presentar una variabilidad intraindividual (esto es, en el mismo sujeto), de forma que esta respuesta se presenta como un fenómeno dinámico que varía a lo largo del tiempo en los tratamientos a largo plazo. Incluso más importante, como ya hemos 
mencionado, esta respuesta insuficiente o "resistencia" cuantificada de forma analítica ha presentado rangos de definición diferentes en muchos de los ensayos clínicos que la han estudiado.

Por todos estos motivos es posible que más que "resistencia al clopidogrel", teniendo en cuenta que la respuesta que presenta sigue una distribución normal y que esto es similar a lo que sucede con la mayoría de los medicamentos que son administrados a los pacientes reales, el término más adecuado para hacer referencia a este fenómeno sea "variabilidad de la respuesta", y que un paciente sea denominado como "resistente" tras múltiples determinaciones analíticas por debajo de los límites normales y que además presente recurrencia clínica de eventos isquémicos.

Algunos estudios han demostrado además que el valor de actividad plaquetaria postratamiento es más preciso para determinar el riesgo trombótico de los pacientes que el \%IAP(Bliden et al., 2007; Campo et al., 2006; Cuisset et al., 2006; de Miguel Castro et al., 2009; Gurbel, Bliden, Guyer, et al., 2005; Hochholzer et al., 2006; Samara, Bliden, Tantry, \& Gurbel, 2005), dado que este porcentaje no tiene en cuenta el valor absoluto de la actividad plaquetaria residual. Una vez considerado esto, incluso la definición de resistencia puede ser más confusa ya que pacientes considerados como no-respondedores por un \%IAP bajo pueden presentar valores absolutos de actividad plaquetaria postratamiento muy bajos y algunos pacientes con una respuesta medida en \%IAP normal pueden presentar valores de actividad plaquetaria residual muy elevados(Gurbel, Bliden, Hayes, et al., 2005) al proceder de contextos clínicos con una mayor actividad pretratamiento.

Otro factor importante a tener en cuenta en la determinación tanto del \%IAP como de la reactividad postratamiento es el hecho de que en muchos de los pacientes la determinación del valor de reactividad pretratamiento no es exactamente la misma que en condiciones basales y esta reactividad "basal" es prácticamente imposible de realizar, ya que la mayoría de los contextos clínicos en los que estos pacientes se presentan, como el infarto de miocardio, están relacionados con estados de hiperagregabilidad plaquetaria y/o trombofilia que impide conocer el estado "normal" de actividad plaquetaria de ese paciente específico antes de la presentación del episodio agudo.

Otro factor limitante de la definición analítica o bioquímica de la resistencia al clopidogrel es la existencia de múltiples tests para el análisis de la función plaquetaria (cada uno de ellos con sus propias limitaciones), el uso de diversos agonistas y dosis para la estimulación de la agregación plaquetaria en estos tests y los diferentes puntos de corte y ventanas temporales para la realización de las determinaciones.

A tener en cuenta es el hecho de que el impacto que puede tener una determinación de laboratorio de la función plaquetaria aún no es bien comprendido, ya que la relación existente entre la respuesta al clopidogrel (o la no-respuesta) y los eventos clínicos es heterogénea y aún no se han planteado actuaciones terapéuticas específicas al respecto.

Tras la aparición del concepto de resistencia al clopidogrel, no tardó en aparecer el de resistencia a la aspirina y, de forma similar a lo que sucedió con el 
clopidogrel, recientes metaanálisis han demostrado, sin embargo, que la prevalencia de esta resistencia a la aspirina depende fundamentalmente del método de medición empleado(Hovens et al., 2007), variando entre el 6 y el 26\%, lo que pone en evidencia de nuevo la dificultad a la hora de establecer estándares analíticos que sirvan de definición y establecimiento de un sistema de referencia o patrón oro.

Por otro lado, el nivel óptimo de inhibición de la función plaquetaria depende del contexto clínico de cada paciente, de forma que nadie aún se ha adelantado a dar un valor específico de \%IAP y/o reactividad postratamiento que pueda servir como punto de corte que identifique a pacientes con mayor riesgo de recurrencia trombótica, pero parece ser que un punto de corte entre 175 y 208 unidades de reactividad plaquetaria (URP) medido con el sistema VerifyNow® puede ser el más prometedor(de Miguel Castro et al., 2009; Price, Angiolillo, et al., 2011). Los ensayos clínicos que ahora están en marcha pretenden evaluar si la caracterización de determinados pacientes dentro de este grupo de alto riesgo (utilizando distintos puntos de corte) puede llevar a beneficio de medidas terapéuticas más agresivas, ya sea mediante incremento de dosis de los antiagregantes utilizados hasta ahora o mediante la utilización de nuevos agentes terapéuticos. Estos estudios proporcionarán la información crítica que hasta ahora nos falta sobre la capacidad de estas medidas a la hora de mejorar el pronóstico de los pacientes con un tipo de terapia individualizada en función de la monitorización de la actividad plaquetaria.

De todos modos, hasta la fecha y debido a todas estas limitaciones, las guías de actuación clínica todavía no recomiendan ningún tipo de determinación analítica para estudiar la actividad plaquetaria de los pacientes de forma rutinaria y realizar un tratamiento "guiado"(J. L. Anderson et al., 2007; Bassand et al., 2007; King et al., 2008).

En la mayoría de las situaciones clínicas en las que el paciente es admitido en un hospital, la evaluación del valor real de actividad plaquetaria basal es pues imposible de determinar, no por defectos en la técnica en sí sino debido a la propia naturaleza del evento agudo, ya que son precisamente los procesos patológicos que motivan la necesidad de este tipo de tratamiento lo que impide conocer los verdaderos valores de función plaquetaria previos a la aparición de la condición patológica y que nos pudiera servir de referencia.

\section{Mecanismos de la respuesta variable o resistencia al clopidogrel}

La variabilidad interindividual de la respuesta al clopidogrel es de origen multifactorial y todos los mecanismos implicados aún no han sido correctamente identificados. Estos mecanismo pueden dividirse en farmacocinéticos (fracaso a la hora de obtener o mantener unos niveles sanguíneos adecuados de droga activa) o farmacodinámicos (incapacidad para conseguir función adecuada a pesar de niveles plasmáticos adecuados). 
A su vez, factores clínicos, ambientales, celulares y genéticos también juegan un papel determinante en la actividad final que pueda ejercer el fármacos sobre las plaquetas del paciente.

Las potenciales causas de respuesta variable o resistencia la clopidogrel se resumen en la Tabla 3.

Tabla 3: Mecanismos potenciales de respuesta variable al clopidogrel.

\section{Biodisponibilidad reducida}

No adherencia al tratamiento

Dosificación inadecuada

Malabsorción

Interacciones medicamentosas implicado al citocromo P450

\section{Variabilidad genética}

Polimorfismos del receptor P2Y12

Polimorfismos del citocromo P450

Polimorfismos de la glicoproteína Ia

Polimorfismos de la glicoproteína IIb/IIIa

\section{Liberación incrementada de ADP}

\section{Aumento de receptores P2Y12}

\section{Factores clínicos que determinan actividad pretratamiento incrementada}

Síndromes coronarios agudos

Diabetes mellitus

Índice de masa corporal elevado

6. Sobreactivación de vías independientes del sistema P2Y12

Trombina

Tromboxano A2

Colágeno

Epinefrina

7. Estado de hiperregeneración plaquetaria

Una actividad plaquetaria basal incrementada durante determinadas condiciones clínicas patológicas es, como hemos mencionado previamente, un factor contribuyente fundamental en la baja respuesta a los fármacos antiagregantes. El clopidogrel ejerce su efecto inhibidor a través exclusivamente de una de las múltiples rutas de activación de la plaqueta, la activación a través del receptor P2Y12 para el ADP. De esta forma, la mayoría de las situaciones clínicas que produzcan una mayor estimulación de las plaquetas lo harán utilizando múltiples vías distintas, por lo que la inhibición de sólo una de ellas puede no ser suficiente en muchos casos para lograr una disminución efectiva de la actividad plaquetaria total. Además, el clopidogrel no inhibe la respuesta plaquetaria a agonistas de la agregación tan potentes como la trombina, la epinefrina o el colágeno. En las situaciones clínicas de alto riesgo, como el síndrome coronario 
agudo y especialmente el síndrome coronario agudo con elevación del segmento ST, caracterizados por una elevada carga de trombina en el torrente sanguíneo coronario, es posible que se requieran estrategias más potentes que el clopidogrel para lograr una reducción de las complicaciones trombóticas. De todos modos, incluso esto puede que no fuese suficiente, ya que existen numerosos ensayos clínicos que tras evaluar el efecto de inhibidores plaquetarios infinitamente más potentes como son los inhibidores de la glicoproteína IIB/IIIA no siempre han encontrado un beneficio clínico asociado al descenso radical en la actividad plaquetaria. Estos ensayos han llegado a estas conclusiones tanto en el contexto del SCA sin elevación del ST(Simoons, 2001) como en el SCA con elevación del segmento ST(Topol, 2001), lo que hace suponer que existen otros muchos determinantes además de la actividad plaquetaria que determinan los eventos clínicos adversos en el seguimiento de este tipo de pacientes.

\section{a) Polimorfismos genéticos:}

El clopidogrel es una prodroga que requiere, una vez es absorbido en la mucosa intestinal, de una doble metabolización hepática antes de ser convertido en molécula activa. Específicamente se requieren dos pasos consecutivas de oxidación a través del sistema del citocromo P450. Una gran variedad de enzimas de este complejo sistema están involucradas en este proceso.

El primer paso metabólico, que transforma el clopidogrel en 2-oxo-clopidogrel, depende de 3 enzimas (CYP1A2, CYP2B6 y CYP2C19) y el segundo paso, que culmina en la producción del metabolito activo, involucra al actividad de otras cuatro enzimas (CYP2B6, CYP2C9, CYP2C19 y CYP3A4).

Existen múltiples estudios farmacogenéticos que han demostrado las diferencias en los polimorfismos para los genes que codifican todo este complejo sistema de proteínas enzimáticas y que pueden contribuir así a la variabilidad interindividual en la respuesta biológica obtenida con una misma dosis de clopidogrel. Entre todos estos no sólo aquellos genes que codifican para las enzimas de metabolización hepática sino también en genes que codifican proteínas relacionadas con la absorción intestinal, y proteínas de membrana plaquetaria.

De entre todos estos polimorfismos genéticos, quizá uno de los más determinantes en la variabilidad de la respuesta al clopidogrel sean los polimorfismos para el gen codificante de la enzima CYP2C19(Brandt et al., 2007), involucrada en los dos pasos de metabolización hepática. De manera importante, además de la modulación en las propiedades farmacodinámicas y farmacocinéticas, este polimorfismo se ha relacionado de manera independiente con la aparición de eventos isquémicos(Trenk et al., 2008), ), incluida la trombosis del stent tras intervencionismo coronario percutáneo(Mega et al., 2009). Estos hallazgos han sugerido la posible necesidad de realizar análisis genético a los pacientes sometidos a ICP para descartar este polimorfismo como medida para identificar a los pacientes con mayor riesgo de recurrencia isquémica. Actualmente se están desarrollando los primeros dispositivos para el análisis genético a pie de cama de este tipo de polimorfismos. 
b) Interacciones entre fármacos:

Uno de los factores modificables más importantes que determinan la variabilidad de la respuesta al clopidogrel es la interacción con diversos fármacos, muchos de ellos parte del tratamiento habitual de los pacientes que sufren un síndrome coronario agudo. Como hemos descrito previamente, el clopidogrel es un profármaco que requiere dos procesos de oxidación enzimática hepática antes de ser transformado en su metabolito activo. De esta forma todas la moléculas que sean metabolizadas por este mismo sistema de enzimas pueden potencialmente interferir con el grado de transformación de clopidogrel hasta su metabolito activo y así modificar la respuesta biológica a nivel del receptor plaquetario. Entre todas estas drogas, quizá las más característicamente relacionadas con este problema sean los inhibidores de la hidroxi-metilglutaril coenzima A reductasa, más comúnmente llamados estatinas, los inhibidores de la bomba de protones y los inhibidores de los canales de calcio.

\section{Estatinas}

Las estatinas son fármacos utilizados para reducir los niveles de colesterol, especialmente de su fracción LDL. Estas moléculas no sólo han demostrado su valor en la prevención primaria por su efecto directo en la mejora del perfil lipídico de los pacientes, sino que han demostrado una reducción directa de la mortalidad administradas durante la fase aguda de los síndromes coronarios agudos, especialmente la atorvastatina(Ahsan, Shah, \& Ezekowitz, 2001), por lo que su uso es recomendado para todo pacientes tras sufrir un infarto agudo de miocardio en ausencia de contraindicación(Van de Werf et al., 2009). Los estudios preliminares de la interacción que puedan tener estas moléculas con los fármacos antiagregantes parecen sugerir que las estatinas lipofílicas, como la atorvastatina, la lovastatina y la simvastatina, al requerir metabolización por el sistema CYP3A4, puedan disminuir la capacidad antiagregante del clopidogrel(Lau et al., 2003; Neubauer, Gunesdogan, Hanefeld, Spiecker, \& Mugge, 2003), pero los últimos estudios al respecto parecen desmentir estos hallazgos preliminares(Gorchakova et al., 2004; Mitsios et al., 2004), por lo que a pesar de la plausibilidad biológica de esta interacción, no ha quedado suficientemente aclarado el papel de las estatinas en la respuesta al clopidogrel y no se han realizado modificaciones al respecto a su uso en las guías de práctica clínica que mantienen la recomendación tipo I(Van de Werf et al., 2009).

\section{Inhibidores de la bomba de protones}

Los inhibidores de la bomba de protones son un grupo de fármacos gastroprotectores encaminados a disminuir la producción ácida del estómago. La utilización de fármacos antiplaquetarios potencialmente lesivos para la mucosa gástrica como el ácido acetil salicílico, han hecho que este tipo de fármacos sean recomendados para evitar las complicaciones derivadas de este tratamiento, especialmente la hemorragia digestiva alta. Las guías actuales de práctica clínica 
recomiendan el uso de inhibidores de la bomba de protones en todos aquellos pacientes que estén tratados con doble terapia antiagregante con AAS y clopidogrel(Bhatt et al., 2008). La metabolización hepática de este tipo de fármacos también depende del citocromo P450 y por ello se ha planteado la hipótesis de que el uso concomitante de inhibidores de la bomba de protones y clopidogrel pueda disminuir la potencia antiagregante de este último.

Esta alarma quedó corroborada tras un estudio realizado recientemente en el que a 124 pacientes consecutivos dirigidos a intervencionismo coronario y que recibían clopidogrel y aspirina a dosis habituales se les administró omeprazol 20 $\mathrm{mg}$ /día o placebo(Gilard et al., 2008). La determinación de la actividad del clopidogrel medida mediante la determinación de la fosforilación de la proteína estimulada por vasodilatación (VASP) mostró una diferencia estadísticamente significativa entre ambos grupos, con una proporción de pacientes con baja respuesta mayor en el grupo de tratamiento con omeprazol $(26,7 \%$ vs $60,9 \%$, $\mathrm{p}<0,0001$ ). La odds ratio para ser considerado no respondedor al clopidogrel era de 4.31 comparado el grupo de tratamiento con omeprazol con el placebo. De todos modos, el impacto clínico que esto pudiera tener no fue evaluado en este estudio.

Estudios más recientes han confirmado la atenuación de la respuesta al clopidogrel con el tratamiento con omeprazol pero no con el tratamiento con pantoprazol(Cuisset et al., 2009; Sibbing et al., 2009), lo que hace suponer que este efecto inhibidor de respuesta puede no ser observado por igual para todos los inhibidores de la bomba de protones.

De todos modos, esta relación parece ser lo suficientemente importante como para que el tratamiento concomitante con clopidogrel e inhibidores de la bomba de protones haya mostrado un incremento en el riesgo de eventos cardiovasculares tanto en poblaciones de pacientes sometidos a ICP(Gaglia et al., 2010) como en pacientes con síndrome coronario agudo(Ho et al., 2009).

El estudio COGENT fue diseñado para dar respuesta a esta cuestión, randomizando a un gran número de pacientes a recibir tratamiento con omeprazol o placebo. Los pacientes que requerían tomar clopidogrel por un periodo mínimo de doce meses (típicamente pacientes con síndrome coronario agudo con o sin elevación del ST y pacientes con implante de stent coronario liberador de fármaco) no mostraron diferencias en cuanto a eventos cardiovasculares mayores en función de la administración o no de omeprazol(Bhatt et al., 2010).

Considerando toda la evidencia científica disponible hasta la fecha en este momento, las sociedades científicas siguen recomendando la administración de inhibidores de la bomba de protones a los pacientes que presenten indicación y requieren doble terapia antiagregante.

\section{Inhibidores de los canales de calcio}

Los inhibidores de los canales de calcio son fármacos ampliamente utilizados entre los pacientes con enfermedades cardiovasculares, con propiedades dirigidas fundamentalmente a la disminución del consumo miocárdico de oxígeno, 
diminución de la tensión arterial, reducción de la frecuencia cardiaca y prevención y control de determinadas arritmias cardiacas. Estas drogas son metabolizadas también a través del complejo P450-CYP3A4.

Dos estudios observacionales prospectivos han descrito la influencia del tratamiento con este tipo de fármacos en pacientes que requieren el uso de clopidogrel(Gremmel et al., 2010; Siller-Matula, Lang, Christ, \& Jilma, 2008). En ambos estudios se encontró una atenuación en la actividad antiplaquetaria del fármaco. De hecho, la utilización de este tipo de moléculas se relacionó con un peor pronóstico en el seguimiento, relacionado fundamentalmente con una mayor necesidad de revascularización. Debido a tamaños muestrales reducidos, diferencias en las características basales de los grupos y la naturaleza observacional del diseño de estos estudios, las conclusiones no pueden extrapolarse a la población general y se requieren estudios randomizados para aclarar definitivamente la cuestión, pero hasta entonces es posible suponer que la administración concomitante de inhibidores de los canales de calcio y clopidogrel pueda tener potenciales interacciones que reduzcan la efectividad antiplaquetaria del clopidogrel.

\section{En resumen:}

La actividad inhibitoria del clopidogrel sobre el receptor P2Y12 parece depender de muchos factores. Los determinantes más importantes de este fenómeno radican en la necesidad de doble metabolización hepática que condiciona una biodisponibilidad por vía oral de apenas un $5 \%$. Las nuevas moléculas inhibidoras de este receptor, al tener una biodisponibilidad del $70 \%$ en el caso del prasugrel y de prácticamente el $100 \%$ en el caso del ticagrelor, presentan una consistencia de potencia inhibitoria mucho más homogénea y se ven influenciadas en mucha menor medida por factores externos(Storey et al., 2009; Weerakkody et al., 2007).

\subsection{MONITORIZACIÓN DE LA FUNCIÓN PLAQUETARIA}

Hemos visto previamente la extraordinaria importancia de la variabilidad en la respuesta a los antiagregantes plaquetarios, especialmente ante el clopidogrel y otros inhibidores del receptor P2Y12.

Se enumeran a continuación las diferentes herramientas de que disponen en al actualidad los centros clínicos y de investigación para la evaluación de esta respuesta.

A medida que la investigación farmacológica ha ido produciendo moléculas de mayor patencia antiplaquetaria y antitrombótica, la aparición de hemorragias mayores como complicación de estos tratamiento ha ido creciendo en importancia. 
Por este motivo, la mejor comprensión de los mecanismos que modulan la respuesta individual ante estos fármacos y la monitorización personalizada en busca de la dosis óptima y combinación de medicamentos más adecuada es uno de los objetivos más ambiciosos de la medicina cardiovascular en estos momentos. Aquí es donde los diferentes tests y medidas de la función plaquetaria cobran una mayor importancia.

\subsubsection{IN VIVO}

\subsubsection{El tiempo de sangría}

Se trata de la primera prueba descrita para evaluar la función plaquetaria, desarrollada a principios del S. XX por el médico francés Milian(Milian, 1901) y que se basa en la medición del tiempo que tarda en cesar el sangrado de una herida estandarizada. Aunque el tiempo de sangría constituye una prueba relevante, desde el punto de vista fisiológico tiene muchos inconvenientes: falta de especificidad y sensibilidad, elevada variabilidad interoperador y la frecuente formación de cicatriz, por lo que en la actualidad es una prueba ya obsoleta excepto en circunstancias clínicas excepcionales.

\subsubsection{IN VITRO}

\subsubsection{Agregometría plaquetaria}

Esta prueba desarrollada por Born en 1962(Born, 1962) ha sido considerada como el patrón oro para la evaluación de la actividad plaquetaria desde su introducción, especialmente en los ensayos clínicos. Se trata de un sistema in vitro que cuantifica la respuesta a un agonista en un plasma rico en plaquetas mediante turbidometría o en sangre entera a través de la impedancia eléctrica. Cuantifica de manera eficaz la agregación plaquetaria de la GP IIb/IIIa.

$\mathrm{Su}$ ventaja fundamental es que ha demostrado su capacidad para predecir eventos cardiovasculares adversos en diferentes ensayos clínicos(Gum et al., 2003; Matetzky et al., 2004; Mueller et al., 1997).

Las principales desventajas de este método incluyen el alto volumen de muestra necesario, la necesidad de preparación de la muestra (no utiliza sangre entera), el tiempo de análisis y la necesidad de un técnico altamente cualificado y con experiencia(Jennings, 2007).

\subsubsection{TEG® PlateletMapping ${ }^{T M}$ System}

El tromboelastógrafo no es un sistema nuevo: fue inventado hace más de 50 años, pero ha sido actualizado recientemente como el TEG PlateletMapping ${ }^{\mathrm{TM}}$ System (Haemoscope, Niles, IL). En este dispositivo se genera un coágulo débil en sangre heparinizada mediante la adición de reptilasa y factor XIII. $\mathrm{Al}$ añador un agonista de las plaquetas (ácido araquidónico o ADP) el coágulo se 
fortalece, lo que confiere a esta prueba sensibilidad en la inhibición de la función plaquetaria(Harrison, 2007), pero todavía no ha demostrado de manera estable su relación con los eventos clínicos, por lo que, pese a sus ventajas (utilización de sangre entera, rapidez), no es uno de los métodos favoritos. Además, la necesidad de pipetear lo convierte en un dispositivo más engorroso que el VerifyNow®(Michelson, 2009).

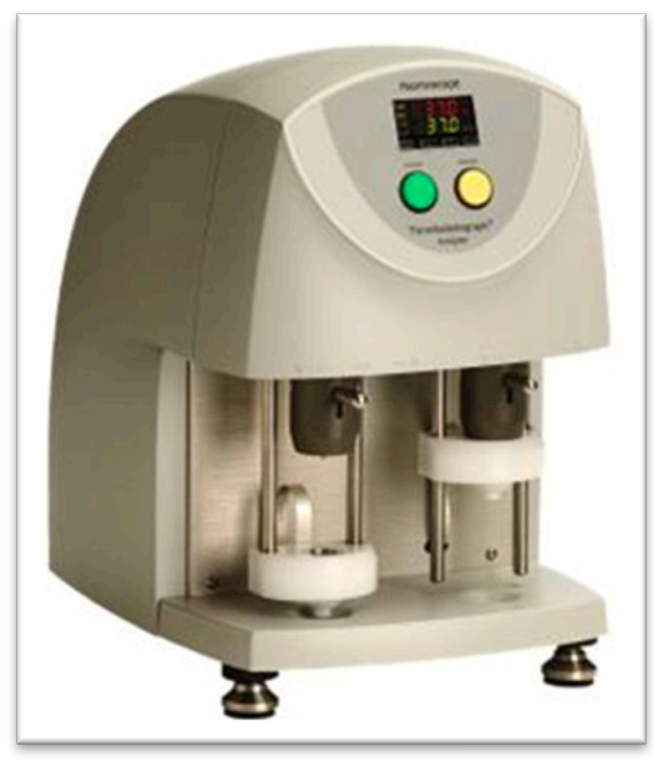

Figura 19: Fotografía del sistema TEG® PlateletMapping ${ }^{\mathrm{TM} S y s t e m .}$

\subsubsection{Impact-R® cone and plate(let) analyzer}

El Impact-R ${ }^{\circledR}$ cone and plate(let) analyzer (Diamed, Cressier, Swtitzerland) es un sistema en el que la sangre entera es expuesta a un cizallamiento uniforme mediante el centrifugado de un cono en una cubeta estandarizada(Varon, 2007). Tras una tinción automatizada, la adhesión plaquetaria en la cubeta es evaluada con un programa informático de análisis de imágenes. Las ventajas de este dispositivo incluyen el diagnóstico inmediato ( a pesar de que requiere pipeteo de la muestra), simplicidad y volumen bajo de muestra. Este dispositivo de todos modos, es útil para evaluar la función del receptor IIb/IIIa pero la adición ex vivo de ácido araquidónico o ADP impide que pueda ser utilizado para la evaluación de la respuesta a la aspirina o a las tienopiridinas(Michelson, 2009). 


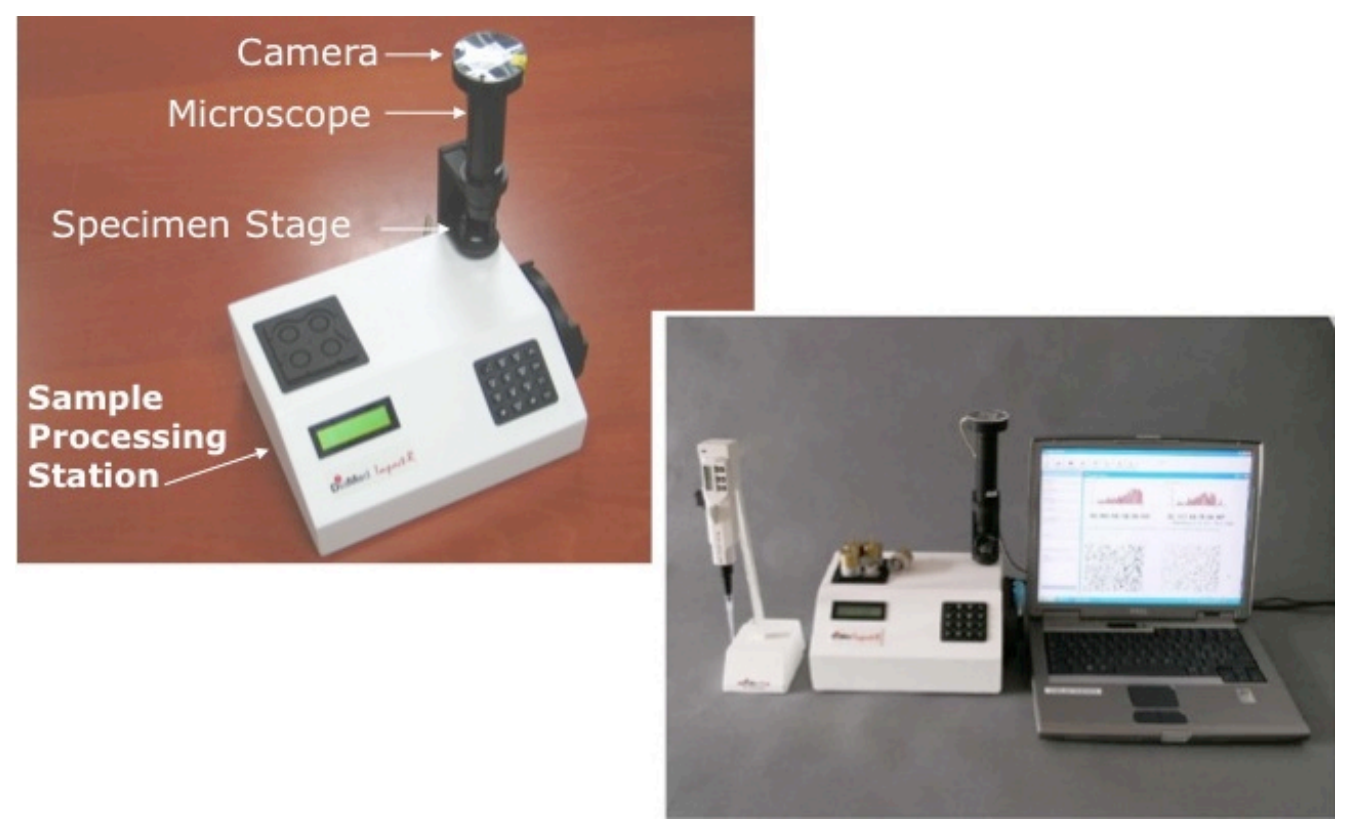

Figura 20: Fotografía del analizador Impact-R cone and plate.

\subsubsection{PFA-100®}

El platelet function analyzer 100 (PFA-100® assay, Dade Behring, Newark, DE) se trata de un dispositivo rápido de evaluación de la función plaquetaria mediante el sistema de someter a las plaquetas a un sistema de cizallamiento por medio de hacer pasar la muestra a través de una apertura recubierta de colágeno de $150 \mu \mathrm{m}$ de diámetro en presencia de ADP o adrenalina. El dispositivo determina el tiempo empelado por la muestra en ocluir esta apertura (tiempo de cierre)(Francis, 2007). Entre las ventajas del PFA-100 destacan su simplicidad, rapidez, volumen de muestra pequeño, cizallamiento alto fisiológicamente relevante, la no necesidad de preparación de la muestra (aunque sí que requiere pipeteo) y sistema de sangre entera.

Utilizando este dispositivo se han publicado estudios que relacionan la respuesta plaquetaria con los resultados clínicos en pacientes sometidos a ICP(Campo et al., 2006), y con la extensión del infarto en pacientes con IAMCEST(Frossard et al., 2004), pero su utilidad parece más limitada a la evaluación de la resistencia a la aspirina y no se recomienda para evaluar la respuesta al clopidogrel u otras tienopiridinas(Hayward, Harrison, Cattaneo, Ortel, \& Rao, 2006). 

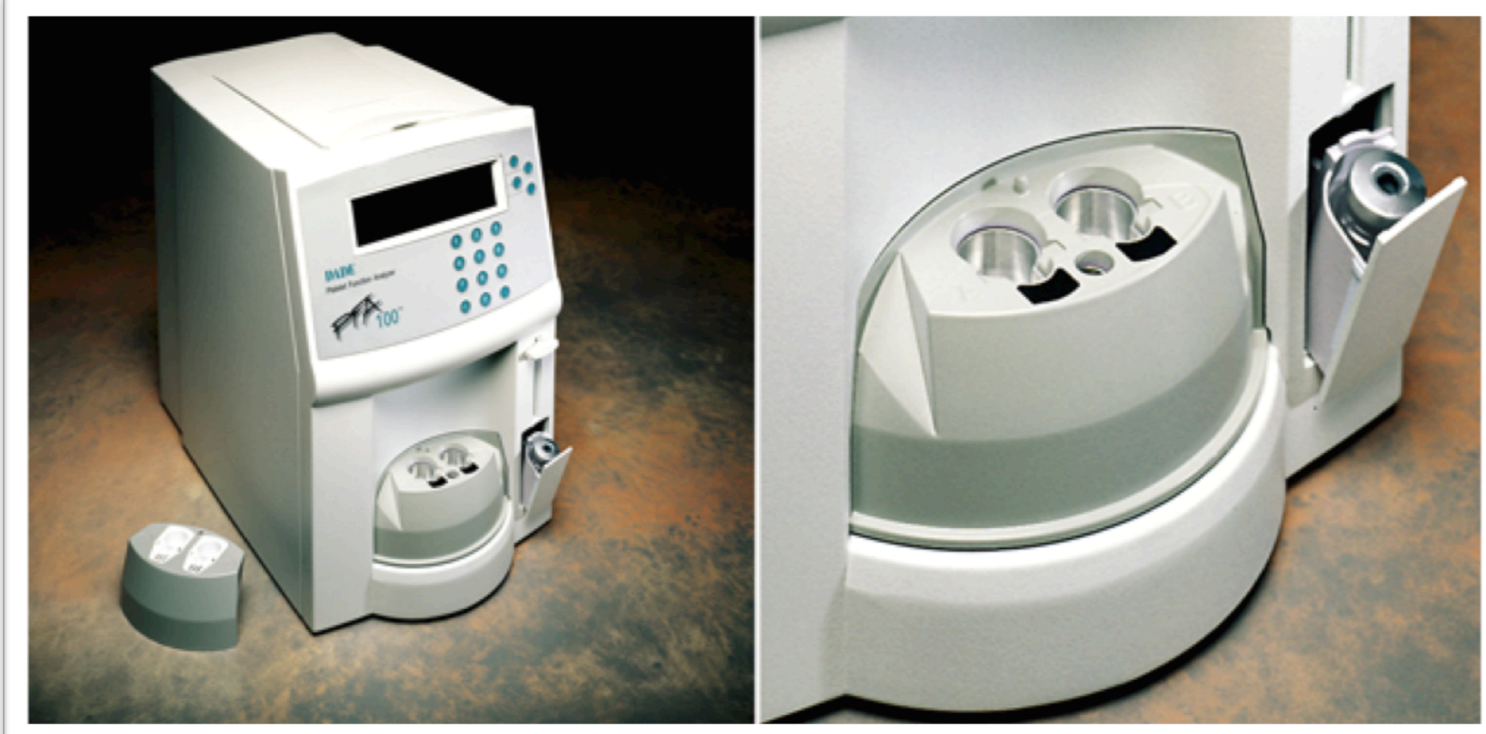

Figura 21: Sistema PFA-100®.

\subsubsection{Citometría de flujo de sangre entera}

Al igual que VerifyNow®P2Y12 que se presenta en el siguiente apartado, este sistema utiliza de forma combinada ADP y PGE1 para determinar la función específica del receptor P2Y12(Aleil et al., 2005). Ante estos agonistas, la fosforilación de la VASP (fosfoproteína estimulada por vasodilatadores), identificada por medio de anticuerpos monoclonales, es directamente proporcional a la inhibición del receptor P2Y12(Schwarz, Geiger, Walter, \& Eigenthaler, 1999). Este sistema también ha demostrado su excelente especificidad para determinar la función de las tienopiridinas y sus valores se han relacionado con eventos cardiovasculares adversos, más concretamente, con eventos isquémicos tras ICP(Kabbani et al., 2003) y con la temida trombosis subaguda del stent(Gurbel, Bliden, Samara, et al., 2005).

La citometría de flujo de sangre entera tiene las ventajas de que las plaquetas son analizadas en su entorno fisiológico y de que las muestras pueden prepararse en tubos citratados y almacenadas a temperatura ambiente hasta 72 horas, lo que permite que sean transportadas y analizadas por un laboratorio central que aglutine la experiencia. Las desventajas fundamentalmente se centran en la dificultad de la técnica que requiere una experiencia considerable.

\subsubsection{VerifyNow ${ }^{\circledR}$}

El sistema VerifyNow ${ }^{\circledR}$ (Accuemtrics, San Diego, CA), antes llamado Ultegra rapid platelet function analyzer (RPFA), es un sistema portátil de análisis que nació con la idea de resolver las desventajas de la agregometría plaquetaria clásica, ya que: 1) utiliza una muestra sanguínea pequeña, 2)no requiere procesamiento de la 
muestra ni técnico especializado y 3) presenta los resultados en cuestión de escasos minutos.

Estas características lo convierten en la elección ideal para el estudio de esta tesis doctoral. Se presenta en el siguiente apartado una descripción detallada de este dispositivo y de sus ventajas para proyectos de investigación clínica como el que nos ocupa.

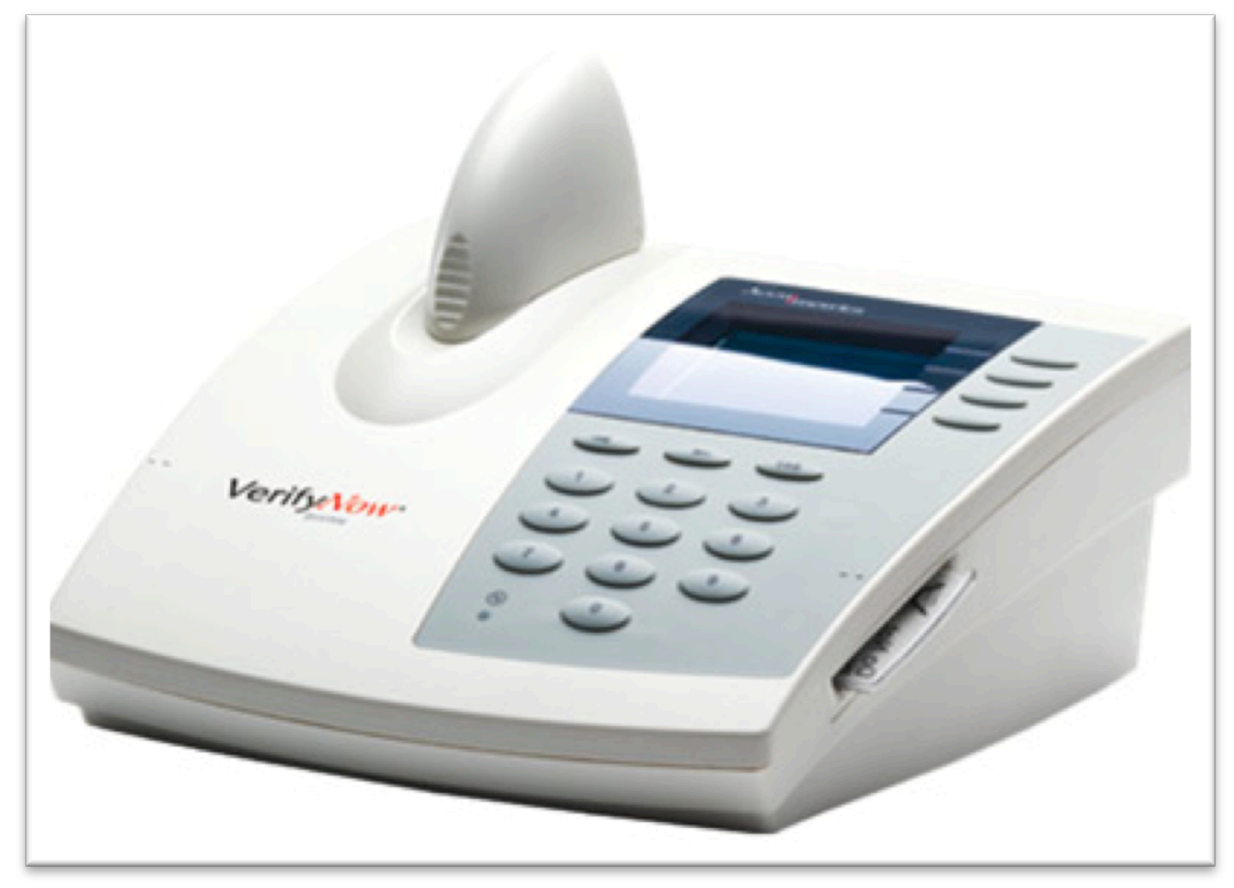

Figura 22: Fotografía del dispositivo VerifyNow®.

\subsubsection{Utilización de las pruebas de función plaquetaria en la práctica clínica}

Desde la comercialización de los distintos métodos específicos para cuantificar la actividad plaquetaria y hasta el último año, los resultados obtenidos han sido considerados como hallazgos de investigación y todas las publicaciones realizadas especificaban que, dado que estos sistemas no estaban aprobados para su uso en la clínica habitual, los resultados debían ser evaluados con cautela y no debían realizarse variaciones en las pautas aprobadas de tratamiento antiplaquetario en función de los mismos. Esto último ha cambiado en el último año. Los resultados de los ensayos clínicos han sido tan contundentes que las sociedades científicas más importantes han incluido ya estos dispositivos en la evaluación clínica, al menos entre pacientes seleccionados.

La ACCF/AHA otorga recomendación clase IIb con nivel de evidencia B a la realización de test de función plaquetaria para pacientes que van a ser sometidos a ICP de alto riesgo(Wright et al., 2011).

El comité de expertos para la conservación de sangre de las sociedades americanas de Anestesiología y de Cirugía Torácica y Cardiaca promueven la utilización de los dispositivos de análisis rápido a pie de cama de la actividad del 
receptor P2Y12 para todos aquello pacientes que hayan recibido tratamiento con clopidogrel y puedan beneficiarse de una intervención más precoz, con una indicación clase IIb, nivel de evidencia C(Ferraris et al., 2011)

Por último, la Sociedad Europea de Cardiología, en sus últimas guías de manejo del SCASEST también confiere recomendación clase IIb, nivel de evidencia B a la adecuación de la pauta de tratamiento antiagregante en función de los resultados de los test de función plaquetaria para pacientes seleccionados(Hamm et al., 2011).

Así pues, los tests de función plaquetaria no deben ser considerados por más tiempo como meras herramientas de investigación, sino que se incorporan ya al conjunto de pruebas complementarias que permiten individualizar el tratamiento de los pacientes coronarios.

Las recomendaciones realizadas por estas sociedades se centran en el subgrupo de pacientes afectos de SCASEST y especialmente en aquellos que reciben intervencionismo coronario percutáneo, dado que es el grupo de pacientes en los que se ha llevado a cabo un mayor número de estudios clínicos. En el caso del IAMCEST, no existen recomendaciones por ausencia de ensayos clínicos que nos permitan obtener conclusiones al respecto, pero al tratarse de un síndrome con una carga trombótica mucho mayor, será especialmente crucial el conocimiento preciso del estado de reactividad plaquetaria por las importantes consecuencias que ésta puede tener tanto en el seguimiento clínico como en el resultado del intervencionismo coronario percutáneo realizado en este contexto.

\subsection{EL SISTEMA VERIFYNOW ${ }^{\circledR}$}

Muy pocas medidas terapéuticas han logrado una penetración en el tratamiento habitual de los pacientes con enfermedades cardiovasculares como lo han hecho los antiagregantes plaquetarios desde los años 70 .

Curiosamente, a pesar de su amplia utilización, los antiplaquetarios son administrados casi siempre en forma de dosis fija, sin titulación de dosis ni monitorización del efecto. Esta práctica es radicalmente contraria a la forma habitual de administración de fármacos en terapias cardiovasculares, en las que la dosis de los fármacos se ajustan a un efecto clínico determinado (ej: antihipertensivos y cifras de TA) o a una determinación analítica estandarizada (Ej: hipolipemiantes y cifras de LDL-col).

Una de las posibles explicaciones a este hecho sea la ausencia, al menos durante la fase de desarrollo de estas moléculas, de una prueba consistente, reproducible, fiable y clínicamente relevante de medición de la función plaquetaria in vivo.

Ya se ha descrito brevemente en el punto anterior las técnicas más usadas para determinar la función plaquetaria, y se han expuesto las ventajas y desventajas de 
cada una de ellas. El problema más importante que todas ellas presentan es la falta de correlación adecuada con los eventos clínicos en el seguimiento de los pacientes.

El sistema VerifyNow, anteriormente conocido como Ultegra Rapid Platelet Function Assay nació como un sistema preparado para admitir sangre entera a pie de cama del paciente, con lo que pretendía proporcionar una medida fiable de la reactividad plaquetaria que pudiera conseguirse con relativa sencillez y rapidez en cualquier contexto de presentación clínica. Inicialmente se ideó para monitorizar la actividad de los inhibidores de la GP IIb/IIIa, pero posteriormente se refinaron los sistemas específicos para analizar la actividad dependiente del TXA2 y del receptor P2Y12.

Pero lo que de verdad proporciona a este sistema una ventaja inigualable sobre el resto de determinaciones analíticas es la consistencia de su correlación con los eventos clínicos de los pacientes en ensayos clínicos a gran escala.

Por este motivo, y por la larga experiencia que nuestro equipo había desarrollado con este sistema tanto en el estudio del infarto con elevación del ST como en el síndrome sin elevación del ST, fue el sistema elegido para determinar la actividad plaquetaria durante la fase aguda del infarto en este proyecto de tesis doctoral.

\subsubsection{MECANISMO DE ACCIÓN}

Este aparato de análisis funciona mediante la utilización de micropartículas de poliestireno recubiertas de fibrinógeno que se aglutinan al ser mezcladas con un agonista plaquetario específico y sangre completa, en una proporción directa a las plaquetas activadas y por tanto al número de receptores IIb/IIIa activos que se presenten.

La inhibición de la actividad de la glicoproteína IIb/IIIa, ya sea utilizando antagonistas directos de este receptor o utilizando inhibidores de la ruta del ácido araquidónico o del ADP, disminuye la aglutinación de estas micropartículas en una proporción igual al grado de inhibición plaquetaria conseguido en ese paciente.

Las muestras de sangre deben ser obtenidas en tubos citratados y el tubo se inserta en un cartucho específico. La sangre es mezclada por efecto del movimiento de una pequeña esfera de acero dirigida por un microprocesador y posteriormente es impulsada hacia un sistema de contenedores con los distintos agentes activos del analizador: el agonista plaquetario específico para la ruta que se desee explorar y las micropartículas cubiertas de fibrinógeno.

La absorbancia lumínica de la mezcla se mide con un detector automatizado que realiza 16 determinaciones por segundo. A medida que las plaquetas interactúan con las micropartículas produciendo su aglutinación, la transmisión lumínica se incrementa. El grado de aglutinación se cuantifica mediante la curva de cambio de absorbancia sobre un periodo de tiempo prefijado y medida en milivoltios por 10 segundos. El dispositivo proporciona finalmente un valor en función de medidas específicas de agonista. 
Existen tres tipos diferentes de cartuchos comercializados: VerifyNow IIb/IIIa Assay, VerifyNow Aspirin Assay y VerifyNow P2Y12 Assay. Se presenta a continuación una descripción detallada del funcionamiento de este último, el utilizado para determinar la inhibición plaquetaria lograda por el clopidogrel en este estudio.

\subsubsection{FUNCIONAMIENTO DEL CARTUCHO ESPECÍFICO VERIFYNOW P2Y12}

El agonista que utiliza el analizador específico para las tienopiridinas es el ADP a una concentración de $20 \mu \mathrm{M}$. Para mejorar la especificidad sobre el receptor P2Y12, se añade un canal con prostaglandina E1 que suprime los niveles de calcio libre intracelular y así reduce la contribución a la activación plaquetaria que pueda tener la unión del ADP al receptor P2Y1. De esta forma, cuando una muestra es estimulada con ADP, el grado de aglutinación de las micropartículas recubiertas de fibrinógeno está determinado principalmente por el grado de inhibición de la actividad del receptor P2Y12, y el valor final es expresado en unidades de reactividad P2Y12 (URP).

Los estudios sobre pacientes sanos antes y después de la toma de clopidogrel mostraron una gran variabilidad en los resultados pero una separación consistente entre los valores preclopdiogrel y posclopidogrel, tanto a las 24 horas de una dosis de carga de $450 \mathrm{mg}$ como tras 7 días de $75 \mathrm{mg}$ diarios(S. Steinhubl, 2007).

La respuesta al clopidogrel es frecuentemente expresada en forma de porcentaje sobre la reactividad plaquetaria basal (\%IAP). Teniendo en cuenta que en la mayoría de los contextos clínicos la obtención de una muestra de sangre pretratamiento no es posible, el VerifyNow P2Y12 presenta un sistema único para determinar este porcentaje: se trata de un canal independiente en el que el agonista utilizado es iso-TRAP (thrombin-activated peptide). Teniendo en cuenta que su efecto es independeinte de la presencia o no de inhibidores del ADP, la reactividad conseguida en este canal, denominada BASE, se considera equivalente a la reactividad plaquetaria basal total pretratamiento. Así, la respuesta a los inhibidores del ADP se expresa como porcentaje de inhibición de la actividad plaquetaria (\%IPA): (1 - [RPP / BASE]) x 100.

La especificidad de este sistema ha sido probada determinando la agregabilidad plaquetaria in vitro inducida por ADP o por ADP+PGE1 en presencia 2-metiltioAMP, un inhibidor específico del receptor P2Y12. En presencia de este inhibidor, la agregabilidad residual obtenida fue del 27\% para el ADP y del 5\% para el ADP+PGE1. Además, se encontró una fuerte correlación entre la agregometría con ADP+PGE1 y el test con VerifyNow P2Y12 Assay, con un coeficiente de variación menor al 8\% y sin que las lecturas de este sistema presentaran modificaciones en función de la edad de los pacientes, el contaje total plaquetario, el hematocrito, el fibrinógeno o los niveles plasmáticos de colesterol o triglicéridos.

Por todas estas cuestiones el VerifyNow se considera la herramienta ideal para determinar in vivo y de forma rápida y sencilla la respuesta a los antiplaquetarios que tienen como diana la inhibición del receptor P2Y12. 
Como único inconveniente estaría la imposibilidad de su utilización en presencia de inhibidores del receptor IIb/IIIa, ya que este receptor es la molécula que debe interactuar con las micropartículas recubiertas de fibrinógeno.

Como último apunto de su funcionamiento, es necesario comentar que las muestras deben permanecer en reposo en el tubo antes de ser analizadas un mínimo de 10 minutos (pero no más de 4 horas) para que la sangre se equilibre con el tampón citratado.

\subsubsection{CORRELACIÓN CON OTROS SISTEMAS DE MEDIDA DE LA ACTIVIDAD PLAQUETARIA}

La correlación entre este sistema y la agregometría turbidométrica clásica, considerada el gold-standard para este tipo de test, fue evaluada en un estudio clínico sobre pacientes con enfermedad coronaria, el ISAR-CHOICE(von Beckerath et al., 2005), en el que se la reactividad plaquetaria mediante agregometría clásica, inmediatamente antes y a las 4 horas de distintas dosis de carga, 300, 600 y 900 mg. En un subgrupo de 30 pacientes también se evaluó la reactividad plaquetaria mediante el sistema VerifyNow p2Y12. Se encontró una fuerte correlación tanto para los valores de URP como para los valores de porcentaje de \%IPA, con valores de $\mathrm{R}=0.85$ y 0.84 respectivamente. Como se puede observar en las gráficas de este estudio, la correlación parecía ser pobre para los valores extremos de baja URP o muy alta \%IPA. Esto ha sido atribuido a la no discriminación de la estimulación del receptor P2Y1 durante el estudio con agregometría clásica, efecto que se previene con el canal de PGE1 que incorpora el sistema VerifyNow P2Y12.

Fuera de ensayos clínicos, también se ha demostrado una correlación excelente entre este sistema y la determinación de la fosforilación de la fosfoproteína estimulada por vasodilatadores (VASP) mediante citometría de flujo de sangre entera(Aleil et al., 2005).

\subsubsection{ASOCIACIÓN DE LOS RESULTADOS CON EVENTOS CLÍNICOS}

El primer estudio prospectivo diseñado para analizar la relación entre las variables proporcionadas por este dispositivo y el resultado clínico de los pacientes reales fue el estudio GOLD (AU-Assessing Ultegra)(S. R. Steinhubl et al., 2001) que demostró una mayor incidencia de eventos cardiovasculares mayores (MACE por sus siglas en inglés: major adverse cardiac events) en los pacientes con una inhibición del recpetor IIb/IIIa inferior al 95\% a los 10 minutos de infusión de abciximab.

Tras esta primera publicación que sugirió las posibilidades de este dispositivo para la práctica clínica, y tras la alarma ante el fenómeno de la resistencia al clopidogrel que surgió a mediados de la década del 2000, se han sucedido una gran cantidad de estudios que han evaluado el kit específico para el receptor P2Y12 y su relación con los eventos clínicos en el seguimiento. 
El estudio POPULAR realizó una comparación de los distintos test para medición de la reactividad plaquetaria dependiente del receptor P2Y12 en un contexto clínico real. Los resultados del mismo(Breet et al., 2010) mostraron una relación del la reactividad plaquetaria postratamietno con clopidogrel determinada con agregometría clásica, VerifyNow y Plateletworks, no así con los sistemas Impact-R o el PFA-100.

De forma específica con el VerifyNow P2Y12 Assay, Price et al describieron en 2008 la relación de la RPP con los eventos clínicos tras intervencionismo coronario percutáneo con implante de stent farmacoactivo(Price et al., 2008). Posteriormente se han sucedido una serie de estudios similares, recogidos en un reciente metaanálisis que demuestra esta relación entre la RPP y los eventos cardiovasculares durante el seguimiento tras ICP(Brar et al., 2011).

Entre los eventos cardiovasculares más particularmente relacionados con el intervencionismo coronario percutáneo, la RPP determinada con el sistema VerifyNow ha demostrado su utilidad para predecir tanto los pacientes con riesgo de trombosis subaguda del stent(Gurbel, Bliden, Samara, et al., 2005) y de mionecrosis tras la intervención(Cuisset et al., 2007).

Nuestro grupo ha desarrollado desde hace años una línea de investigación específica para estudiar las posibilidades de este dispositivo en los diferentes contextos clínicos de la enfermedad coronaria inestable, especialmente en sus formas de presentación más protrombóticas como son el infarto con y sin elevación del ST. Así, en 2006 publicamos la relación entre la inhibición plaquetaria del receptor IIb/IIIa lograda con abciximab durante el ICP primario en el tratamietno del IAM con elevación del ST y los parámetros de reperfusión miocárdica(Perez de Prado et al., 2006), y con el VerifyNow P2Y12, ya en el contexto del SCA sin elevación del segmento ST con una elevada proporción de infarto de miocardio sin onda Q demostramos la relación de la RPP tanto con el daño miocárdico posintervención(Perez de Prado et al., 2009) como con los eventos cardiovasculares mayores en el seguimiento clínico a largo plazo(de Miguel Castro et al., 2009)

\section{En conclusión:}

El sistema VerifyNow ofrece múltiples ventajas con respecto al resto de sistemas para determinar la reactividad plaquetaria, especialmente a la hora de analizar la funcionalidad del receptor P2Y12. Estas ventajas incluyen: (1) la utilización de sangre entera, evitando la necesidad de procesado, (2) funcionamiento semiautomatizado, lo que previene errores dependiente de operador y variabilidad subjetiva interobservador, (3) test rápido que ofrece los resultados en menos de 5 minutos, (4) digitalización de los datos y (5) alta especificidad por el receptor estudiado.

A estas ventajas debería ser añadido la experiencia con este dispositivo con la que cuenta nuestro grupo en particular, lo que facilita en gran medida la disminución de los errores técnicos y de la variabilidad interoperador. 
La comparación con el resto de sistemas disponibles en el mercado para determinar la reactividad plaquetaria y la respuesta al clopidogrel se presenta en la siguiente tabla.

Tabla 4: Organigrama de ventajas e inconvenientes de cada una de las pruebas de análisis de función plaquetaria.

\begin{tabular}{|c|c|c|c|c|c|c|}
\hline & Sencillez* & $\begin{array}{c}\text { Velocidad } \\
\text { test }\end{array}$ & $\begin{array}{c}\text { Pie de } \\
\text { cama }\end{array}$ & Especificidad & $\begin{array}{c}\text { Experiencia } \\
\text { operador }\end{array}$ & $\begin{array}{c}\text { Correlación } \\
\text { resultados } \\
\text { clínicos }\end{array}$ \\
\hline $\begin{array}{c}\text { Agregometría } \\
\text { clásica }\end{array}$ & - & - & - & +++ & - & ++ \\
\hline TEG & + & + & - & - & - & - \\
\hline Impact-Cone & - & + & - & - & - & - \\
\hline PFA-100 & + & + & + & - & + & + \\
\hline VASP & + & - & - & +++ & - & +++ \\
\hline VerifyNow & ++ & + & + & +++ & +++ & +++ \\
\hline
\end{tabular}

*Sencillez: -:necesidad de procesado de la muestra; +: sangre entera pero necesidad de pipeteo; ++: sangre entera sin necesidad de pipeteo.

\subsection{HIPERREACTIVIDAD PLAQUETARIA INDUCIDA POR TRATAMIENTO FIBRINOLÍTICO}

La propia fisiopatología del infarto de miocardio involucra la activación plaquetaria desde su misma génesis, con la rotura de la placa ateromatosa vulnerable y la exposición al torrente sanguíneo del contenido subendotelial rico en moléculas de LDL oxidadas, factor tisular y otros factores protrombóticos.

Este hecho, que activa las plaquetas a través de sus moléculas de adhesión, actúa como disparador de la activación y agregación plaquetaria a través de la vía común final de la glicoproteína IIb/IIIa y la formación de los complejos GP IIb/IIIafibrinógeno característicos del trombo blanco. De todos modos, la adhesión plaquetaria es sólo el primero de los estímulos que desencadenan este proceso. Existe una multitud de co-factores favorecedores y multiplicadores de la agregación plaquetaria interrelacionados en esta situación clínica: incremento de las catecolaminas circulantes, aumento de la viscosidad sanguínea, incremento de la presión arterial sistólica y de las fuerzas de cizallamiento intravascular, etc... todos estos factores pueden suceder tanto como factor desencadenante de la rotura de la placa como ser consecuencia de la isquemia miocárdica durante las primeras fases del síndrome. 
Añadido a estos factores y como eje central sobre el que se construye este estudio, sabemos que la administración de fármacos fibrinolíticos, a pesar de producir la lisis del coágulo que obstruye la arteria y permitir resolver la isquemia miocárdica, tiene asociado un efecto procoagulante y proagregante de manera intrínseca que incrementa el riesgo de retrombosis y reoclusión del vaso.

Se ha demostrado que el pico de este efecto se produce aproximadamente a las 24 horas de la administración de estos fármacos(Gurbel et al., 1998), lo que puede explicar el repunte de eventos isquémicos en el seguimiento de estos infartos y que complica hasta el $10 \%$ de los casos durante la fase hospitalaria(Hudson et al., 2001) y hasta el 30\% de los casos durante el primer mes(White et al., 1995). Esta recurrencia de eventos isquémicos es responsable de un incremento significativo de la mortalidad(Bauters et al., 1999) y es la razón por la que se ha requerido la asociación al fibrinolítico de agentes antitrombóticos y antiplaquetarios adyuvantes para tratar de disminuir esta complicación.

Se ha postulado que el incremento de la actividad plaquetaria inducida por los fármacos fibrinolíticos dependa de una activación por parte de la plasmina circulante de los receptores plaquetarios para la trombina(Eisenberg \& Miletich, 1989) o por disparar la formación de trombina a través de la activación del factor V(Lee \& Mann, 1989).

La fibrinolisis efectiva del trombo coronario de fibrina tiene como consecuencia inmediata la exposición intravascular de trombina en forma soluble que puede inducir la generación masiva de trombina por autocatálisis y producir efectos muy acentuados sobre la activación plaquetaria(Zeymer, Mateblowski, \& Neuhaus, 1998).

La trombina es una de las moléculas con mayor potencia proagregante, y una vez unida a sus receptores plaquetarios específicos, incrementa la liberación plaquetaria de serotonina y de TXA2. A mayores, la trombina produce la transformación del factor $\mathrm{V}$ a factor $\mathrm{Va}$, lo que produce la formación de más cantidad de trombina a través del complejo de la potrombinasa (hasta 300 veces más cantidad de la generada exclusivamente a través de la activación del factor X), lo que conlleva el repunte de la agregabilidad plaquetaria en un contexto ya de por sí protrombótico y de ahí el aumento de las posibilidades de reoclusión arterial.

De todos modos, la suposición de que los fármacos fibrinolíticos actúan exclusivamente a un solo nivel no tiene base si se tiene en cuenta la complejidad del sistema de la coagulación y el sistema fibrinolítico y sus interacciones con la fisiología plaquetaria y con el sistema de la inflamación.

Así, teniendo en cuenta que la administración de fármacos trombolíticos combina una activación del sistema de la fibrinolisis dependiente de la activación del plasminógeno con un efecto protrombótico y proagregante, su mayor o menor eficacia depende de su capacidad para alterar el equilibrio entre estas dos facetas opuestas de la homeostasis sanguínea. 0 lo que es lo mismo, el éxito de la terapia fibrinolítica depende de la posibilidad de obtener un adecuado balance entre la actividad fibrinolítica y la propia actividad procoagulante. 
Independientemente del valor relativo de cada una de las rutas de activación, casi la totalidad de los autores coinciden en que la hiperactividad plaquetaria en este contexto se produce por un complejo mecanismo de retroalimentación que implica a una gran diversidad de cofactores y estímulos con efecto sumatorio y entre los cuales resulta difícil discernir un punto común de convergencia.

A pesar de ello, se ha demostrado que la trombina es una de las moléculas con mayor poder para activar la agregabilidad plaquetaria(Coughlin, 2005) mientras que la activación plaquetaria dependiente de la plasmina se obtiene sólo a altas concentraciones. Concretamente, al comparar el valor relativo de la estimulación de la agregación plaquetaria tras tratameitno fibrinolítico entre la plasmina y la trombina, esta segunda demuestra tener una potencia muy superior a la primera(Winters, Santoro, Miletich, \& Eisenberg, 1991)

El efecto proagregante inducido por la administración de fibrinolíticos ha sido ampliamente demostrado, pero mediante la utilización de marcadores inespecíficos de activación plaquetaria(Bihour, Durrieu-Jais, Besse, Nurden, \& Nurden, 1995; Fitzgerald, Catella, Roy, \& FitzGerald, 1988; Frandsen, Winther, Pedersen, Christiansen, \& McNair, 1996; Moser et al., 1999; Rasmanis, Vesterqvist, Green, Edhag, \& Henriksson, 1992). En esta situación, si bien es esperable que la ruta del ADP y la implicación específica del receptor P2Y12 también se hallen afectadas, ningún estudio se ha dedicado de forma concreta a la actividad de este receptor hasta la fecha. Receptor que, como se ha expuesto, presenta una importancia central en la actualidad debido a ser la diana terapéutica sobre la que se están realizando los mayores avances durante la última década en terapia farmacológica y por ser una de las rutas más importantes en cuanto a lo que se refiere al intervencionismo coronario percutáneo. 


\section{ESTRATEGIAS DE REPERFUSIÓN EN EL INFARTO DE MIOCARDIO}

Ante un episodio de dolor torácico prolongado de características isquémicas, la realización de un electrocardiograma es imprescindible y debe realizarse lo antes posible con el fin de determinar si el paciente cumple criterios de infarto agudo de miocardio con elevación del ST. La realización del electrocardiograma en fase precoz no sólo es fundamental para el diagnóstico, sino que determina la actuación médica inmediata que debe ser activada, ya que lo prioritario ante un cuadro de estas características es determinar si es candidato a recibir tratamiento de reperfusión urgente.

El objetivo de la restauración del flujo sanguíneo a la zona isquémica del miocardio es limitar el tamaño final de la necrosis y evitar así la pérdida de función contráctil, además de disminuir significativamente el riesgo de complicaciones eléctricas y mecánicas inmediatas y mejorar la supervivencia("Indications for fibrinolytic therapy in suspected acute myocardial infarction: collaborative overview of early mortality and major morbidity results from all randomised trials of more than 1000 patients. Fibrinolytic Therapy Trialists' (FTT) Collaborative Group," 1994).

Durante muchos años, el único tratamiento disponible para tratar de restaurar el flujo sanguíneo a través de la arteria coronaria obstruida era la disolución del mismo mediante fármacos fibrinolíticos, pero con los avances de la cardiología intervencionista apareció el concepto de angioplastia primaria (ahora más conocido como intervencionismo coronario percutáneo primario). Durante muchos años ha sido un debate clásico cuál de estas dos estrategias era preferible en términos de beneficio clínico. Actualmente se acepta que, siempre y cuando sea realizada por equipos experimentados y dentro de los límites de tiempo especificados, la angioplastia primaria es superior al tratamiento fibrinolítico(Itoh et al., 2010; Keeley, Boura, \& Grines, 2003). De todos modos, la terapia fibrinolítica sigue siendo una herramienta útil y ampliamente utilizada, especialmente cuando no se dispone de un laboratorio de cardiología intervencionista en el centro o cuando el infarto de miocardio lleva muy poco tiempo de evolución, por lo que las guías de actuación clínica siguen recomendando su uso en determinadas circunstancias y abogan por una evaluación individualizada de la estrategia en función de las características clínicas del paciente y de las facilidades e infraestructura del punto donde se realice el primer contacto médico(Van de Werf et al., 2009).

Se han realizado muchas comparaciones de estas dos estrategias consideradas generalmente como opciones competitivas con poca consideración de una interrelación entre ellas, pero lo que ha quedado demostrado es que, más que el tipo de reperfusión recibida, es la permeabilidad sostenida y completa de la arteria responsable del infarto el factor que en mayor medida se relaciona con el pronóstico a largo plazo de estos pacientes, independientemente de si ésta se consigue con fibrinolisis(Boersma, Maas, Deckers, \& Simoons, 1996) o por medio de angioplastia primaria(De Luca, Suryapranata, Ottervanger, \& Antman, 2004)). 
Por lo tanto debe hacerse el mayor esfuerzo posible en instaurar las medidas necesarias para realizar la estrategia que permita una reperfusión más rápida en función de la localización del paciente y de los medios disponibles en la zona.

Teniendo en cuenta que el tratamiento fibrinolítico tarda una media de 60 minutos en lograr la reperfusión(HD White, 2001), se considera que la estrategia más adecuada será aquella que consiga instaurar tratamiento fibrinolítico antes de transcurridos 30 minutos desde el contacto médico o angioplastia primaria antes de transcurridos 90 minutos(Van de Werf et al., 2009). De todos modos, el margen de tiempo en el que la angioplastia primaria puede presentar resultados superiores a la fibrinólisis puede variar en función de determinadas características, fundamentalmente la edad del paciente, la localización del mismo y el tiempo de evolución de los síntomas(Pinto et al., 2006), y puede variar desde menos de una hora en caso de menores de 65 años con infarto anterior de menos de una hora de evolución hasta casi 3 horas en el caso de mayores de 65 años con infartos no anteriores de más de 2 horas de evolución de los síntomas.

Estos datos indican que un enfoque individualizado de la estrategia de reperfusión puede ser beneficioso en vez de asumir una estrategia protocolizada general para todo tipo de IAMCEST.

Seguidamente pasamos a describir ambas técnicas.

\subsection{FIBRINOLISIS}

El tratamiento de reperfusión urgente mediante la administración de fármacos fibrinolíticos se ha descrito ya en los capítulos 1 y 2 de esta sección, por lo que se evitará repetir la información ya proporcionada.

Los beneficios ya se han explicado, así como que el subgrupo de pacientes en los que su uso tiene un mayor impacto sobre la supervivencia es precisamente el de pacientes de mayor riesgo al ingreso. De todos modos, dado que precisamente este subgrupo es también el que más se beneficia del ICP primario, y teniendo en cuenta que ésta última es la estrategia de elección en la actualidad si está disponible, el tratamiento fibrinolítico ha quedado reservado, siempre hablando en términos generales, para aquellos pacientes que no pueden acceder a ICP primario por cualquier motivo o para aquellos que se presentan con un perfil de menor riesgo, y especialmente aquellos que se presentan con menos de 2 horas de evolución. Esto quedó especialmente establecido tras los resultados del estudio CAPTIM que demostró una mayor supervivencia mediante lisis prehospitalaria que con traslado para ICP primario en este grupo de pacientes(Steg et al., 2003). Resultados que además han quedado reforzados tras completarse el seguimiento a cinco años de los pacientes incluidos en este estudio(Bonnefoy et al., 2009). 


\subsection{INTERVENCIONISMO CORONARIO PERCUTÁNEO PRIMARIO (TAMBIÉN ANGIOPLASTIA PRIMARIA)}

El intervencionismo coronario percutáneo primario se define como la angioplastia con o sin implantación de stent coronario sin asociar tratamiento fibrinolítico previo o simultáneo que se realiza de forma inmediata una vez realizado el diagnóstico de IAMCEST según los criterios establecidos.

Para que la angioplastia primaria sea efectiva en el objetivo de mejorar el pronóstico de los pacientes con un infarto, ésta debe ser realizada por un equipo experimentado y en un centro que disponga de las facilidades para instaurar un programa de atención continuada durante $24 \mathrm{~h} / 7$ días a la semana. La necesidad d estos equipos altamente especializados y con servicio de alerta localizada $24 \mathrm{~h}$ son imprescindibles para obtener resultados adecuados ya que, por un lado, se ha demostrado que los centros con experiencia presentan menores tasas de mortalidad y complicaciones(Canto et al., 2000; Spaulding, Morice, et al., 2006), y ya que debe realizarse el intervencionismo en un tiempo lo más corto posible ya que el retraso en obtener la reperfusión también se ha relacionado también con un peor pronóstico(De Luca et al., 2003; Nallamothu et al., 2007).

La Tabla 5 resume los requerimientos aceptados para la realización de ICP primario como estrategia de reperfusión urgente de elección sobre otras estrategias como fibrinolisis o estrategias combinadas(Kolh \& Wijns, 2011).

\section{Tabla 5: Requerimientos ICP primario como 1 elección.}

\section{Del operador}

Experiencia de $>75$ procedimientos ICP electivos/año

Experiencia de $>11$ procedimientos de ICP primario/año

\section{Del centro}

Volumen $>400$ ICP electivos/año

Volumen >36 ICP primarios/año

\section{Sobre pacientes que llegan directamente a centro con programa ICP}

\section{primaria $24 / 7$}

Tiempo llegada a urgencias-balón $<60$ minutos

\section{Pacientes que llegan a centro sin programa ICP}

Traslado a centro con programa ICP si el tiempo esperado entre inicio de síntomas y balón es $<2$ horas.

Si tiempo estimado de revascularización $>2$ horas se recomienda fibrinolisis y traslado para realizar ICP electiva entre 3 y 24 horas tras la fibrinolisis

El ICP primario consiste en la cateterización de las arterias coronarias mediante los procedimientos habituales y posterior identificación del vaso responsable. Una vez logrado esto, se realiza el avance de una guía de angioplastia y se restablece el flujo coronario mediante la utilización de distintos dispositivos. En conjunto el ICP primario permite una reperfusión efectiva, entendida como la recuperación del flujo coronario en el vaso responsable del infarto y el mantenimiento de la permeabilidad del mismo de manera efectiva. 
La cuestión de si debe implantarse o no stent de forma sistemática y qué tipo de stent es una cuestión en debate, ya que el implante sistemático de stent son se relaciona con la supervivencia a largo plazo aunque sí lo hace con la necesidad de repetir procedimiento(Grines et al., 1999), por lo que suele implantarse siempre que, una vez restaurado el flujo anterógrado normal, se aprecie una lesión coronaria con estenosis significativa que sea identificable como responsable del episodio de trombosis intracoronaria, pero teniendo en cuenta que esto sucede en la gran mayoría de las ocasiones y que la estrategia de implante directo de stent, esto es sin predilatación de la lesión responsable, disminuye la mortalidad a largo plazo(Mockel et al., 2011), la estrategia más recomendada en la actualidad es implante de stent coronario, de forma directa siempre que las características angiográficas parezcan favorables(Lozano, Avanzas, \& Rondan, 2010).

La utilización así mismo de los diferentes tipos de stent (recubiertos de fármacos o no) también tiene implicaciones en la incidencia de reestenosis y necesidades de repetir procedimientos de revascularización, pero parece que no así en la supervivencia global, ni en las tasas de trombosis tardía y/o muerte en el seguimiento(Kastrati et al., 2007; Laarman et al., 2006; Spaulding, Henry, et al., 2006). A pesar de estos resultados, de todos modos parece ser que pudiera existir un efecto de clase y que los stents liberadores de fármacos derivados del sirolimus sí pudieran presentar beneficio en cuanto a mortalidad a largo plazo(Simsek et al., 2011)

La utilización de dispositivos de trombectomía con el fin de minimizar el riesgo de complicaciones embólicas y fenómeno de no reflujo era una cuestión que quedaba de forma tradicional a criterio del operador, pero desde la publicación del estudio TAPAS(Vlaar et al., 2008), el uso de los dispositivos de aspiración de trombo también parece recomendable.

En conclusión, la angioplastia primaria tal y como se entiende en la actualidad consiste en la rápida cateterización de la arteria culpable con el fin de avanzar una guía y reperfundir la arteria con la menor agresión posible sobre la lesión responsable para minimizar el riesgo de no reflujo. Para ello parece recomendable la técnica de implante directo del stent tras tromboaspiración.

\subsection{EL TALÓN DE AQUILES: EL DAÑO POR REPERFUSIÓN}

Aun cuando la fibrinolisis o la angioplastia primaria tengan éxito en la restauración del flujo en la arteria del infarto, puede seguir habiendo un deterioro de la perfusión de la zona del infarto por una combinación de diversos factores: embolización microvascular de residuos trombóticos o partículas de la placa de ateroma, por daño inducido por la reperfusión propiamente dicha, daño microvascular, disfunción endotelial, inflamación y edema miocárdico(Ito, Okamura, et al., 1996; Kaul \& Ito, 2004; Yellon \& Hausenloy, 2007). Esta complicación es denominada también fenómeno de no reflujo(Ito, Maruyama, et al., 1996) y se objetiva, en función de diferentes estudios y de la técnica empleada en la reperfusión, entre el 10 y el 40\% de los pacientes(Ito, Maruyama, et al., 1996; Ito et al., 1992; Kelly, Cohen, Runge, \& Stouffer, 2004; Maes et al., 1995) y se asocia con 
importancias complicaciones como persistencia de la isquemia, arritmias graves, deterioro hemodinámico y muerte(Sorajja et al., 2005).

La lesión por reperfusión produce edema celular, formación de radicales libres, sobrecarga de calcio y aceleración de la apoptosis. Además, la activación de las citocinas en la zona del infarto da lugar a la acumulación de un gran número de células inflamatorias que contribuyen a la lesión hística. Por lo tanto, son necesarios tratamientos complementarios auxiliares que minimicen la magnitud de la lesión microvascular y que también protejan la zona del infarto de miocardio en peligro para obtener una reperfusión más eficaz a nivel tisular.

Como acabamos de ver, la mayoría de los pacientes que sufren un infarto de miocardio tienen problemas para recibir el tratamiento idóneo, la angioplastia primaria, ya que deben darse una combinación de circunstancias muy específica para que ésta sea efectiva: primero y ante todo, que esté tipo de terapia esté disponible el centro al que el paciente llega; segundo, que el equipo de hemodinámica de ese centro tenga la experiencia necesaria y un programa de alerta 24 horas; tercero, que la intervención pueda ser realizada en un plazo de tiempo ideal inferior a 90 minutos.

Debido a la lógica dificultad de que se den estos tres requisitos en todos los casos, y teniendo en cuenta la facilidad de transporte a cualquier lugar y la sencillez de administración de un fármaco fibrinolítico (especialmente la tenecteplasa), desde hace tiempo se vienen evaluando las alternativas para poder extender el mejor tipo de terapia de reperfusión al máximo porcentaje posible de población. Esta idea se basa en lograr una reperfusión farmacológica lo más precoz posible, incluso en domicilio, para luego estabilizar mecánicamente la lesión responsable con un procedimiento invasivo.

En este punto es donde nacen las estrategias combinadas de reperfusión.

En principio estas estrategias podrían tener una ventaja añadida a su posibilidad de extensión a toda la población, y es el hecho de que la disminución de la carga trombótica que pudiera lograr la fibrinolisis debería disminuir el riesgo de no reflujo durante el ICP primario.

\subsection{ESTRATEGIAS COMBINADAS}

Dentro de las denominadas estrategias combinadas de reperfusión se definen tres: la angioplastia de rescate, la angioplastia electiva y la angioplastia facilitada.

\subsubsection{ANGIOPLASTIA DE RESCATE}

El concepto de angioplastia de rescate corresponde al ICP indicado con motivo de fracaso de la terapia fibrinolítica en conseguir criterios de reperfusión a los 90 minutos de iniciada la administración. Identificar los casos en los que el fibrinolítico no ha sido efectivo por medios no invasivos puede ser algo complicado, pero se admiten para su evaluación los criterios clínicos de desaparición del dolor 
y electrocardiográficos de reducción de la desnivelación del ST $>50 \%$ sobre las derivaciones más alteradas y la aparición de arritmias de reperfusión.

Esta estrategia ante el fracaso de la lisis ha demostrado ser superior a otras alternativas como la repetición del tratamiento fibrinolítico o el tratamiento conservador en términos de supervivencia y de incidencia de insuficiencia cardiaca a pesar de que presenta un mayor riesgo de ACV y de hemorragias(Gershlick et al., 2005; Wijeysundera et al., 2007).

La angioplastia de rescate debe considerarse entonces siempre que tras un tratamiento fibrinolítico no se alcancen criterios de reperfusión y siempre y cuando ésta pueda realizarse con un margen de tiempo razonable(Van de Werf et al., 2009). De todos modos, teniendo en cuenta que no es una estrategia programada sino la consecuencia del fracaso de una de las dos terapia principales, la población en la que se evalúa estos tratamientos es de un perfil mucho peor que la normal con IAMEST y por lo tanto la angioplastia de rescate no debe compararse con las estrategias que dependen de la elección del médico.

\subsubsection{ANGIOPLASTIA ELECTIVA TRAS FIBRINOLISIS}

Basándose en lo descrito previamente, la teoría de la angioplastia electiva resulta muy atractiva: realización de una reperfusión farmacológica por parte del médico del primer contacto, generalmente la unidad de emergencias móvil, y posterior traslado a un centro con servicio hemodinámica para realizar la coronariografía y una eventual revascularización mecánica que estabilice la lesión y disminuya así el riesgo de reoclusión precoz.

Esta estrategia se corresponde entonces con el complementario a la angioplastia de rescate, es decir, tras la administración del tratamiento fibrinolítico, una vez logrados los criterios de reperfusión, enviar a todos los pacientes para realización de coronariografía independientemente de su situación clínica.

En la era previa al stent coronario esta estrategia no mostró beneficio, pero más recientemente, los estudios GRACIA-1(Fernandez-Aviles et al., 2004) y WEST(Armstrong, 2006) lograron demostrar una reducción de eventos isquémicos y necesidad de revascularización y fundamentan la recomendación de esta estrategia en grado IA(Van de Werf et al., 2009).

La ventana temporal utilizada en estos estudios se estableció de forma arbitraria en las 24 horas posteriores a la administración del fármaco fibrinolítico. Lógicamente, la siguiente pregunta era evaluar si la realización de la angiografía de manera inmediata, acortando este tiempo, podía ofrecer un beneficio añadido.

Es de esta forma como nace el concepto de angioplastia facilitada. 


\subsubsection{ANGIOPLASTIA FACILITADA}

La angioplastia de rescate y la angioplastia electiva comparten la utilización de los criterios clínico y ECG para la evaluación del éxito o no del tratamiento fibrinolítico. El concepto de la angioplastia facilitada se centra en la indicación de coronariografía inmediata tras la administración del fármaco lítico, independientemente del resultado, con el fin de disminuir al máximo el tiempo de demora hasta la revascularización mecánica.

De esta forma, los estudios CARESS-in-AMI(Di Mario et al., 2008), SIAM III(Scheller et al., 2003) y CAPITAL-AMI(Le May et al., 2005) parecieron demostrar posibles beneficios añadidos, y dos grandes estudios multicéntricos fueron coordinados para la evaluación de esta estrategia: los estudios FINESSE(Ellis et al., 2008) y ASSENT-4("Primary versus tenecteplase-facilitated percutaneous coronary intervention in patients with ST-segment elevation acute myocardial infarction (ASSENT-4 PCI): randomised trial," 2006). Ninguno de los dos logró demostrar un beneficio con ninguna de las terapias propuestas, que incluían diferentes combinaciones de fármacos pre-angiografía. De hecho, el estudio ASSENT-4 tuvo que ser suspendido precozmente por aumento de la mortalidad en la rama de fibrinolisis más ICP con respecto a la que recibía ICP primario; mortalidad que se debía, en contra de los primeramente imaginado, a un incremento en los eventos isquémicos, que no hemorrágicos.

Debido a estos hallazgos, la Sociedad Europea de Cardiología en sus últimas guías de actuación clínica(Van de Werf et al., 2009) cierra la puerta a las posibilidades de angioplastia facilitada y recuerda el periodo de actividad protrombótica y proagregante que se sucede tras la administración de fármacos fibrinolíticos y que debe ser responsable de los efectos deletéreos que supone realizar la ICP inmediatamente tras la fibrinolisis, por lo que mantiene la recomendación de realizar angioplastia electiva dejando un lapso mínimo de tiempo de entre 3 y 24 horas antes de la realización de la misma.

Esta tesis centró su objetivo principal precisamente en evaluar la respuesta del receptor P2Y12 durante esta estrategia, con el fin de caracterizar el patrón temporal del estado proagregante inmediatamente posterior al tratamiento fibrinolítico. 

HIPÓTESIS Y OBJETIVOS 



\section{HIPÓTESIS Y OBJETIVOS}

Una vez presentada la revisión sobre el estado actual del tema, queda delimitado el campo de trabajo y puede plantearse la HIPÓTESIS INICAL, DE PARTIDA O DE TRABAJO:

"La utilización de fármacos fibrinolíticos como tratamiento de reperfusión en el infarto de miocardio induce un estado de hiperagregabilidad plaquetaria que disminuye la eficacia de los fármacos antiplaquetarios durante la angioplastia electiva."

Formulada así la hipótesis inicial como una afirmación de campo teórico que debe ser contrastada para ser admitida o rechazada, y sin olvidarnos de ella y de lo que significa, preferimos no obstante de forma pragmática y reduccionista hablar de OBJETIVOS a conseguir, uno como principal o general y otros específicos u operativos entendidos éstos como peldaños o escalones o etapas a conseguir para alcanzar el objetivo general.

\section{OBJETIVO GENERAL:}

Demostrar el déficit de inhibición adecuada del receptor P2Y12 durante la coronariografía electiva tras la administración de dosis aprobadas de clopidogrel en pacientes afectos de infarto agudo de miocardio sometidos a tratamiento fibrinolítico.

\section{OBJETIVOS OPERATIVOS}

1. Medir la actividad del receptor P2Y12 en condiciones basales previa a la administración de fármacos antiplaquetarios o antitrombóticos durante la fase aguda o de presentación del infarto de miocardio.

2. Estudiar la evolución temporal de la actividad del receptor P2Y12 tras la administración de dosis de carga de clopidogrel durante los primeros días y hasta el momento de la coronariografía electiva e intervencionismo coronario percutáneo en su caso.

3. Cuantificar la respuesta al abciximab durante el intervencionismo coronario percutáneo.

4. Evaluar la relación entre la actividad plaquetaria y los eventos clínicos en el seguimiento de los pacientes.

5. Determinar las variables angiográficas y hemodinámicas de este grupo de pacientes.

6. Realizar un modelo predictivo para determinar las variables más relacionadas con el daño miocárdico periprocedimiento. 
7. Realizar un modelo predictivo para determinar las variables más relacionadas con la actividad plaquetaria postratamiento.

Para dar respuesta a los objetivos e hipótesis planteados diseñamos un plan de investigación tipo:

Estudio observacional descriptivo prospectivo con asignación consecutiva de casos estudio como unidades experimentales.

Y que a través de todas sus etapas y en especial de la estrategia de recogida de datos nos permita admitir o rechazar la hipótesis inicial. 
MATERIAL Y MÉTODO 



\section{MATERIAL Y MÉTODO}

\section{DISEÑO DEL ESTUDIO}

Con el fin de hacer más comprensible el diseño del estudio efectuado, en el presente apartado se resumen las distintas etapas que se llevarán a cabo durante la investigación.

\subsection{SELECCIÓN DEL TIPO DE ESTUDIO}

El imperativo principal de cualquier estudio sobre sujetos humanos determina que el tratamiento recibido haya sido aprobado y se realice según las normas de actuación clínica.

Teniendo en cuenta que el tratamiento antiagregante, tanto la aspirina como el clopidogrel, ha probado su efectividad en el tratamiento del infarto agudo de miocardio mejorando la supervivencia de los enfermos("The aspirin myocardial infarction study: final results. The Aspirin Myocardial Infarction Study research group," 1980; Chen et al., 2005; Sabatine et al., 2005), el diseño de un estudio randomizado hacia tratamiento con elemento activo o placebo no cumpliría con los requisitos éticos. Por este motivo se diseña un estudio observacional prospectivo en el que, con el fin de aproximar los resultados a la población real, se incluyen de manera consecutiva a todos los pacientes que cumplien los requisitos de infarto agudo de miocardio con elevación del segmento ST e indicación de tratamiento fibrinolítico.

\subsection{SELECCIÓN DE LA MUESTRA}

Para la realización de este estudio se realizó una evaluación de todos los pacientes aceptados en el Servicio de Urgencias del Complejo Asistencial Universitario de León con el fin de determinar si cumplían los siguientes

\section{Criterios de inclusión:}

-Pacientes mayores de 18 años ingresados por IAMCEST, según definición estándar aceptada:

*Dolor torácico de características anginosas prolongado a lo largo de un periodo igual o superior a 30 minutos.

*Elevación del segmento ST del trazado electrocardiográfico en al menos dos derivaciones contiguas. 
*Indicación de tratamiento urgente de reperfusión mediante la administración de un fibrinolítico intravenoso, según sus propias indicaciones y contraindicaciones.

* Posibilidad de extracción de muestra sanguínea en tubo citratado al $3,2 \%$ previa a la administración del fibrinolítico o en los diez minutos inmediatamente posteriores a su administración.

La posibilidad de extracción de la muestra basal es quizá el criterio más importante ya que la hipótesis del estudio pretende comparar la actividad plaquetaria basal, entendida ésta como actividad en ausencia de tratamiento en condiciones basales patológicas y no fisiológicas, antes de la administración de medicación con su evolución temporal una vez administrados el clopidogrel y el fibrinolítico. Teniendo en cuenta el efecto prácticamente inmediato de la administración intravenosa del fibrinolítico, el margen temporal para la extracción de esta muestra era muy escaso (10 min teniendo en cuenta la semivida de tenekteplasa y estreptoquinasa). La otra dificultad que entrañaba este punto se centraba en la necesidad de obtener la muestra sanguínea en tubo citratado, no en los tubos de EDTA normalmente utilizados en el centro para la realización del hemograma, requisito fundamental para la determinación de la reactividad plaquetaria con el dispositivo P2Y12-VerifyNow®. A este efecto, los residentes de Cardiología de guardia fueron provistos de tubos especiales autorellenables citratados al 3,2\% que debían llevar consigo ante un aviso IAMCEST.

Una vez comprobados los criterios de inclusión, y antes de la administración de la medicación habitual, se procedió a determinar que los pacientes no presentaran ninguno de los criterios de exclusión

\section{Criterios de exclusión:}

*Contraindicación para la utilización de medicación antiagregante o antitrombótica.

*Alergia a aspirina o clopidogrel.

*Administración prehospitalaria de fármacos fibrinolítico.

*Administración prehospitalaria de fármacos inhibidores de la glicoproteína IIb/IIIa.

*Ausencia de criterios de reperfusión y subsiguiente necesidad de realización de angioplastia de rescate.

La explicación de los criterios de exclusión se centra en que la utilización de fibrinólisis prehospitalaria, muy frecuente cuando los pacientes deben ser trasladados desde largas distancias hasta el centro hospitalario, impide la extracción de sangre en condiciones basales o pre-tratamiento requeridas para la determinación de la actividad plaquetaria basal.

De la misma forma, el uso de inhibidores de la GP IIb/IIIa interfiere con la reactividad proporcionada por el canal BASE, dependiente de este recptor como se 
ha expuesto previamente, por lo que la medida de la actividad plaquetaria en estas condiciones queda falseada.

Por último, la angioplastia de rescate es realizada cuando el fibrinolítico no logra restaurar un mínimo flujo sanguíneo a la zona de miocardio en riesgo tras un periodo de 90 minutos En estas circunstancias no se espera a la realización de coronariografía electiva sino que se procede a la realización de una coronariografía urgente y por este motivo, estos pacientes no tiempo de recibir las sucesivas dosis de clopidogrel que permitan evaluar la efectividad del tratamiento antiagregante.

\subsection{ADMINISTRACIÓN DE TRATAMIENTO FIBRINOLÍTICO}

Una vez determinadas la presencia de todos los criterios de inclusión y la ausencia de cualquiera de los criterios de exclusión se procedía a la administración de tratamiento fibrinolítico. Durante el periodo de inclusión de pacientes en el estudio, las dos moléculas que estaban disponibles en el Complejo Asistencial Universitario de León eran la tenecteplasa (Metalyse ${ }^{\circledR}$, Boehringer-Igelheim S.A, Alemania.) y la estreptoquinasa (Streptase ${ }^{\circledR}$, CSL-Behring ltd, USA). La elección de uno de los dos era realizada a criterio del médico de guardia que atendiera al paciente.

\subsection{ADMINISTRACIÓN DE MEDICACIÓN ANTIAGREGANTE}

Todos los pacientes recibieron tratamiento antiagregante según las guías de recomendación clínica de la Sociedad Española de Cardiología y de la Sociedad Europea de Cardiología. Se realizaban dosis de carga de aspirina con $250 \mathrm{mg}$ administrados de forma intravenosa y dosis de carga de clopidogrel de $300 \mathrm{mg}$ administrados de forma oral en el momento del ingreso. Posteriormente se prosiguieron con dosis de mantenimiento de $100 \mathrm{mg}$ orales de aspirina y de $75 \mathrm{mg}$ de clopidogrel de forma oral. La administración de clopidogrel de mantenimiento era realizada, según criterios del estudio, siempre a las 8:00 horas con el fin de realizar más fácilmente una curva tiempo de administración-efectividad antiagregante.

\subsection{ELECTROCARDIOGRAMA Y CRITERIOS DE REPERFUSIÓN}

A todos los pacientes les fueron realizados un mínimo de dos electrocardiogramas en los primeros momentos de su ingreso: electrocardiograma basal o al ingreso para definir las alteraciones características del IAMCEST y un electrocardiograma a los 90 minutos de la administración del fibrinolítico para determinar los criterios de reperfusión.

Se definió la variable Suma ST al ingreso como la suma en milímetros de la desnivelación del segmento ST en todas las derivaciones afectadas y siempre y cuando fueran correspondientes a la presentación del infarto, evaluado sobre un 
electrocardiograma realizado a una velocidad de $25 \mathrm{~mm} / \mathrm{seg}$ y una amplitud de 10 $\mathrm{mV} / \mathrm{cm}$.

La variable Máxima ST corresponde a los milímetros de desviación del segmento ST en la derivación con mayor alteración identificada.

Dentro de las variables electrocardiográficas se evaluaron también la aparición de RIVAs (ritmo idioventricular acelerado) u otras arritmias de reperfusión como criterio de reperfusión efectiva mediada por el tratamiento fibrinolítico. Los RIVAs se definieron como ritmo de frecuencia constante entre 70 y 120 por minuto de QRS ancho y eje eléctrico diferente al presente en ritmo sinusal y que no condicionase inestabilidad hemodinámica. Otros criterios de reperfusión fueron considerados la reducción de la desnivelación máxima del ST en un valor $>50 \%$ con respecto a la desnivelación basal y la desaparición del dolor característico.

\subsection{OTRAS PRUEBAS COMPLEMENTARIAS BÁSICAS}

A todos los pacientes les fueron extraídas muestras sanguíneas para la realización de análisis de bioquímica básica y hemograma. Teniendo en cuenta que una de las variables más relacionadas con la resistencia al clopidogrel parece ser la presencia de diabetes mellitus, para estudiar la presencia de alteraciones basales en el metabolismo de los hidratos de carbono no previamente diagnosticadas, se incluyeron como variables de estudio los valores de glucemia plasmática al ingreso y en la primera determinación realizada en situación de ayuno.

Se incluyeron a su vez como variables analíticas los valores de $\mathrm{Hb}$, contaje total plaquetario y de $\mathrm{Cr}$ antes y después de la coronariografía ya que es el momento más relacionado tanto con sangrados mayores como con plaquetopenia 0 disfunción renal aguda (nefropatía inducida por contraste).

Para cuantificar el tamaño del infarto se realizaron análisis seriados cada seis horas con determinación de enzimas de daño cardiaco creatinquinasa y su fracción MB (CK y CK-MB) así como troponina T. Estos análisis se repitieron también en caso de ICP tras el mismo para determinar el daño miocárdico periprocedimiento. Se definió infarto periprocedimiento como un incremento superior al doble de los valores previos de CK-MB y/o troponina T tras el intervencionismo.

\subsection{DETERMINACIÓN DE LA ACTIVIDAD PLAQUETARIA}

Las extracciones de muestras sanguíneas para la realización de los test de función plaquetaria se realizaron mediante punción de vena periférica según técnica habitual. Las muestras se obtuvieron en el momento de la administración del fibrinolítico (determinación basal), de forma diaria durante las primeras 48 horas de ingreso a las 8:00 horas (determinaciones Día +1 y Día +2) e inmediatamente antes de la coronariografía electiva (determinación coronariografía). Todas las muestras fueron obtenidas en tubos citratados al 3,2\% $\mathrm{y}$, siguiendo las instrucciones del fabricante, fueron almacenadas a temperatura 
ambiente durante un mínimo de 30 minutos y un máximo de 3 horas antes de su análisis.

El análisis de la reactividad plaquetaria se realizó utilizando el dispositivo VerifyNow® (Accumetrics, San Diego, California, USA). Su utilidad para medir el grado de reactividad plaquetaria ya ha sido descrito previamente(S. R. Steinhubl et al., 2001). Este dispositivo proporciona los datos en unidades de reactividad plaquetaria (URP) y la correlación con la agregometría óptica, considerada como el estándar-oro, es excelente(van Werkum, van der Stelt, Seesing, Hackeng, \& ten Berg, 2006; von Beckerath et al., 2006).

Se trata de un dispositivo portátil de cuantificación a pie de cama que utiliza los mismo principios de la agregometría óptica clásica, cuantificando los cambios en la transmisión de luz óptica a través de la muestra, pero que determina la aglutinación de micropartículas recubiertas de fibrinógeno ante sangre total estimulada mediante adenosin-difosfato (ADP). Cada kit específico está compuesto por tres canales. El primero de ellos determina la adhesión de las plaquetas a las micropartículas mediada por estimulación con iso-TRAP, un sistema que depende directamente de la vía final de agregación mediante el receptor IIb/IIIa y es independiente de la presencia o no de agonistas de la vía del ADP. Este valor es el que el sistema utiliza como valor de agregabilidad total de referencia.

El segundo canal utiliza la estimulación máxima mediante ADP a una concentración de 20 micromolar para cuantificar la reactividad dependiente de esta ruta. Un tercer canal de Prostaglandina E1 se utiliza para contrarrestar el receptor P2Y1. De esta forma, este sistema nos permite conocer exactamente la reactividad plaquetaria residual dependiente del receptor P2Y12 que persiste una vez iniciado el tratamiento, también conocida como reactividad plaquetaria postratamiento.

El tercer valor que nos proporciona el dispositivo VerifyNow® es un valor indirecto derivado de los dos previos: el porcentaje de inhibición de la actividad plaquetaria (\%IAP), considerado clásicamente como el valor de referencia para cuantificar la efectividad de los fármacos antiagregantes. Este valor se obtiene mediante la fórmula: (1 - [RPP / BASE]) x 100 y es expresado en porcentaje de inhibición con respecto al valor de reactividad basal (reactividad plaquetaria dependiente del receptor P2Y12 postratamiento respecto a la reactividad vía final IIb/IIIa cuantificada mediante estimulación iso-TRAP).

No obstante, recientemente se ha demostrado que el valor de reactividad plaquetaria postratamiento (RPP) tiene mejor correlación con los eventos clínicos que el \%IAP en la población de pacientes afectos de síndrome coronario agudo sin elevación del segmento ST(de Miguel Castro et al., 2009), por lo que este estudio se diseñó teniendo en cuenta la RPP como variable principal para cuantificar la reactividad plaquetaria dependiente del receptor P2Y12.

Se valorará a su vez, para la RPP, la proporción de pacientes dentro de los distintos puntos de corte propuestos como mejores predictores de eventos en el seguimiento de 175(de Miguel Castro et al., 2009), 208(Price, Angiolillo, et al., 2011) y 235(Price et al., 2008)URP. 


\subsection{CORONARIOGRAFÍA Y ACTITUD TERAPÉUTICA}

La coronariografía electiva fue programada según el funcionamiento habitual de la Unidad Coronaria y la Sección de Hemodinámica y Cardiología Intervencionista del Complejo Asistencial Universitario del León para aproximar la muestra el máximo posible a la actividad real en un hospital terciario.

Se recogieran de forma sistematizada los tiempos de espera entre la llegada al Servicio de Urgencias, la administración de la medicación y la realización de la coronariografía, de forma que pudiera diseñarse una tabla de evolución temporal de la respuesta a los fármacos antiagregantes.

Se recogieron las variables sobre la información anatómica de la lesión responsable del infarto: diámetro de referencia, diámetro luminal mínimo y flujo TIMI en arteria responsable.

Una vez realizada la coronariografía y en función de las lesiones encontradas y de las características clínicas de los pacientes se decidió actitud terapéutica a seguir. Aquellos pacientes que no presentaban lesiones susceptibles de recibir tratamiento de revascularización se seguían exclusivamente con tratamiento médico a criterio de su cardiólogo responsable. En el caso de que las lesiones encontradas y las características clínicas del paciente fueran candidatas a revascularización quirúrgica (enfermedad de tres vasos o tronco coronario izquierdo en conjunción con diabetes mellitus y/o mala función ventricular izquierda), los pacientes eran presentados en sesión médico/quirúrgica y la intervención se realizaba mediante la rutina habitual de Servicio de Cirugía Cardiaca.

En caso de encontrarse lesiones candidatas a revascularización mediante intervencionismo coronario percutáneo, éste era realizado inmediatamente después de la coronariografía, en consenso con el cardiólogo responsable y una vez informados el paciente y familiares de los riesgos y beneficios esperables para cada caso. La elección de diferentes plataformas o modelos de stents, así como la utilización de medicación adyuvante durante el procedimiento quedaron a criterio del operador. Se recogieron los datos correspondientes a las variables del ICP: éxito del procedimiento como diámetro y longitud del stent, implante directo o tras predilatación, sobredilatación del stent, flujo TIMI tras ICP, así como la aparición de complicaciones.

(Definiciones detalladas en Apéndice II).

\subsection{ABCIXIMAB DURANTE EL ICP Y MONITORIZACIÓN DE SU EFECTIVIDAD}

En el caso de que el abciximab, antiagregante plaquetario de la familia de los inhibidores de la glicoproteína IIb/IIIa, fuera utilizado durante el ICP, se realizaban nuevas extracciones sanguíneas en tubos citratados al 3,2\% para monitorizar la efectividad de esta droga también con el dispositivo VerifyNow®, en esta ocasión con kits específicos para el receptor IIb/IIIa. Los valores proporcionados en esta ocasión se presentan en unidades PAU, por sus siglas en inglés (Platelet Activity Units), y en este caso la referencia se realiza mediante la extracción basal 
preadministración del fármaco y una extracción al final de la intervención para determinar la reactividad plaquetaria residual postratamiento dependiente del receptor IIb/IIIa (ruta final de agregación plaquetaria).

\subsection{SEGUIMIENTO CLÍNICO}

Durante el periodo intrahospitalario se definió la recurrencia isquémica como la presencia de dolor torácico de características isquémicas asociado a cambios electrocardiográficos de aparición posterior a la obtención de criterios de reperfusión tras la administración del fibrinolítico.

Se determinó a su vez el grado máximo de insuficiencia cardiaca izquierda según la clasificación de Killip-Kimball(Killip \& Kimball, 1967).

Una vez dados de alta, los pacientes eran seguidos en consulta externo o de forma telefónica, si lo previo no era posible, con el fin de registrar cualquier tipo de evento cardiovascular o hemorrágico. Este seguimiento se realizó al mes, los seis meses y un año.

Los eventos cardiovasculares mayores se definieron como muerte, infarto de miocardio, necesidad de nueva revascularización o ictus.

En cuanto a objetivos de seguridad, se definieron eventos hemorrágicos según la clasificación TIMI(Rao et al., 1988). 


\section{ALGUNAS TÉCNICAS EMPLEADAS PARA LA REALIZACIÓN DE LA ESTADÍSTICA DESCRIPTIVA.}

Tal y como es bien conocido dentro del ámbito de la investigación, la estadística descriptiva es una parte de la estadística que se dedica a analizar y representar los datos(Yadolah, 2003). En el presente proyecto de tesis doctoral, se ha llevado a cabo un análisis por medio de estadística descriptiva de todas las variables características de cada uno de los pacientes. En este proceso de caracterización se han calculado medias, medianas, intervalos de confianza, desviaciones típicas, etc. A pesar de que todas las técnicas aplicadas son bien conocidas en el presente apartado se realiza una breve explicación de dos herramientas básicas: los diagramas de boxplot o de cajas y el test de Anderson-Darling.

\subsection{DIAGRAMAS DE BOXPLOT}

Los diagramas de boxplot, también denominados en español diagramas de caja, son una forma de representación gráfica basada en cuartiles que sirven para la visualización de distribuciones de datos. Fueron inventados por el matemático norteamericano John Tukey y en la actualidad son ampliamente utilizados en los más diversos campos de aplicación de la estadística(Murrel, 2005).

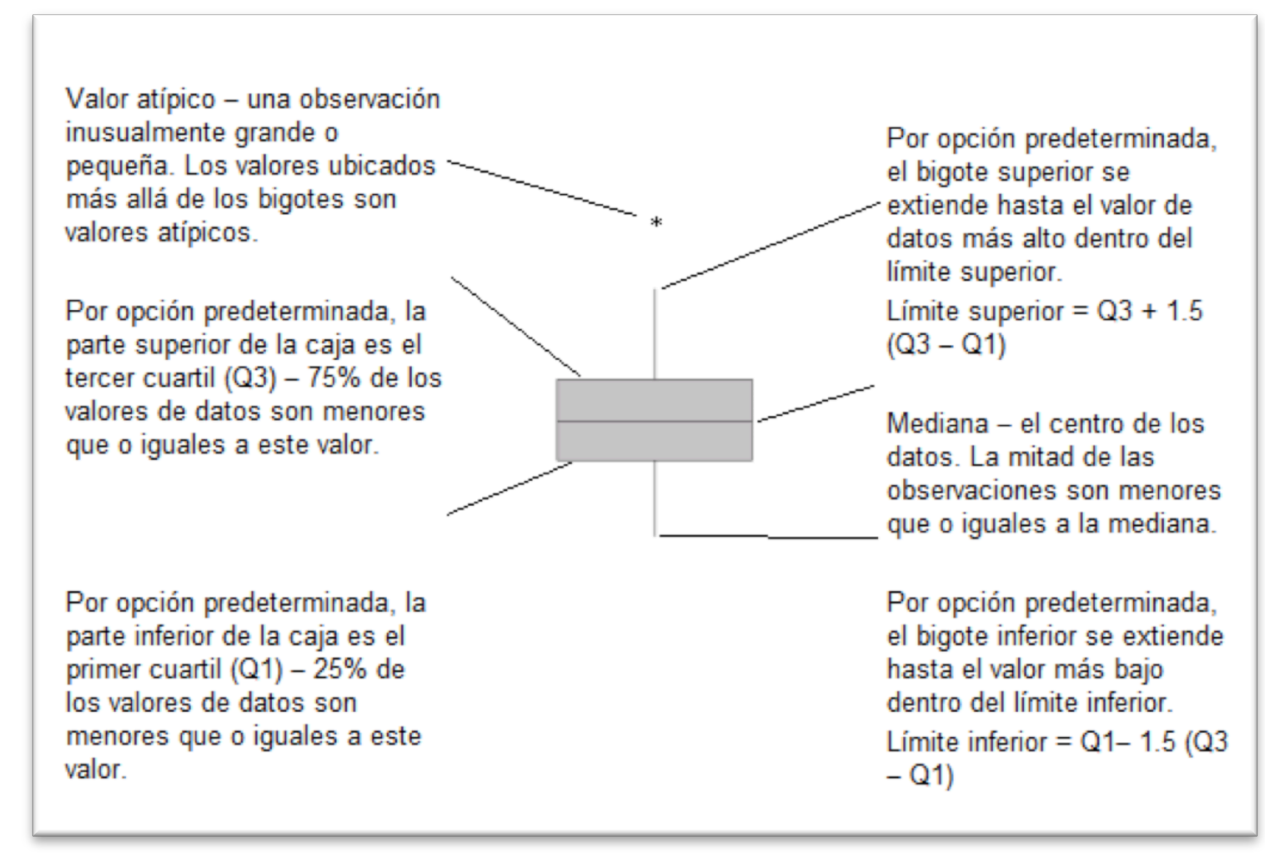

Figura 23: Interpretación de un diagrama de boxplot.

En la Figura 23 se muestra a modo de ejemplo una representación gráfica de un diagrama de boxplot acompañada de su correspondiente interpretación estadística. 


\subsection{EL TEST DE ANDERSON-DARLING}

El test Anderson-Darling recibe este nombre en honor a T.W. Anderson y D.A. Darling quienes fueron sus inventores(T. D. Anderson, DA, 1952). Dicho test mide en qué grado los datos siguen una distribución particular. En el caso del presente trabajo la comparación se ha realizado con una distribución normal. Mientras mejor se ajuste la distribución a los datos, menor será este estadístico. El estadístico de Anderson-Darling se utiliza para comparar el ajuste de varias distribuciones a fin de determinar cuál es la mejor o probar si una muestra de datos proviene de una población con una distribución específica.

Las hipótesis para la prueba de Anderson-Darling son:

- $\mathrm{H}_{0}$ : Los datos siguen una distribución especificada.

- $\mathrm{H}_{1}$ : Los datos no siguen una distribución especificada.

Si el valor p (cuando está disponible) para la prueba de Anderson-Darling es inferior al nivel de significación seleccionado (generalmente 0.05 ó 0.10) se puede concluir que los datos no siguen la distribución especificada.

\subsection{TÉCNICAS FUNDAMENTALES APLICADAS PARA LA REALIZACIÓN DE LA ESTADÍSTICA INFERENCIAL}

En la actualidad, se define como inferencia estadística o estadística inferencial una parte de la Estadística que comprende los métodos y procedimientos para deducir propiedades (hacer inferencias) de una población, a partir de una muestra de la misma(Asadoorian, 2008). En el presente apartado se presentan de forma resumida los fundamentos metodológicos de las técnicas inferenciales fundamentales que se emplearon el presente proyecto de investigación. Estas fueron: el test de análisis de la varianza, el test de la chi-cuadrado y las curvas de Kaplan-Meier.

\subsubsection{TEST DE ANÁLISIS DE LA VARIANZA DE UNA VÍA}

El análisis de varianza (ANOVA) es una técnica estadística que se emplea para investigar y modelar la relación entre una variable de respuesta y una o más variables predictoras(Johnson, 1992). En el caso del ANOVA de una vía, que es el utilizado en el presente trabajo, el número de variables predictoras queda restringido a uno. Aunque un análisis de regresión también permite estudiar las relaciones existentes entre dos variables, el análisis de la varianza se diferencia de la regresión en dos aspectos fundamentales: las variables predictoras son cualitativas (categóricas) y no se parte de ningún supuesto acerca de la naturaleza de la relación (es decir, el modelo no incluye coeficientes para las variables). En efecto, el análisis de varianza amplía la prueba t de dos muestras(Bechhofer, 1988) para probar la igualdad de las medias de dos poblaciones a una hipótesis nula en la 
que se compara la igualdad de más de dos medias con el hecho de que no todas sean iguales.

\subsubsection{TEST DE LA CHI-CUADRADO}

En el presente trabajo, con el fin de poder analizar si la proporción de pacientes con una determinada característica en un grupo era igual a la que poseía otro grupo de pacientes (por ejemplo: si la proporción de hombres con HTA era equivalente a la de mujeres), se ha empleado el test de la chi-cuadrado de Pearson(Pearson, 1900). En estadística, la distribución chi-cuadrado de Pearson es una distribución de probabilidad continua con un parámetro $k$ que representa los grados de libertad de la variable aleatoria.

\subsubsection{CURVAS DE KAPLAN-MEIER}

Con el fin de poder tener una representación gráfica de la existencia de eventos cardiovasculares de mayores (por sus siglas en inglés Major Adverse Cardiovascular Events), definidos en este estudio como la aparición de muerte, reinfarto, ictus isquémico o necesidad de nueva revascularización, durante el seguimiento de los pacientes de la muestra, se recurrió al uso de curvas de supervivencia. En el caso del presente estudio las curvas empleadas han sido las de Kaplan-Meier(Kaplan, 1958). Las curvas de Kaplan-Meier son un método para estimar, para cada tiempo, la probabilidad de que un evento ocurra después. El evento en estudio puede ser muerte (de ahí el nombre de curvas de supervivencia) o bien otro evento de interés para el paciente. En el caso del presente trabajo este ha sido la ocurrencia o no de un evento cardiovascular según la definición previa. Una de las ventajas de las Curvas de Kaplan-Meier es que la medida de los eventos no se realiza a intervalos fijos de tiempo, siendo esto ventajoso dado que los resultados no dependen de la elección de los intervalos. Así, Las curvas de KaplanMeier estiman la probabilidad de que ocurra el evento para cada tiempo, junto con el correspondiente error estándar. También se representa el número de casos expuestos al riesgo en cada momento.

Finalmente, nos gustaría señalar que si bien existen métodos que permiten comparar desde un punto de vista analítico curvas correspondientes a distintos grupos de pacientes en el presente trabajo y dada la no existencia de MACE en ninguna de las mujeres de la muestra no se ha recurrido al empleo de dichos tales como el de Hosmer-Lemeshow ni el de Mantel-Haenszel.

\subsection{TÉCNICAS ASOCIADAS A LOS MODELOS PREDICTIVOS}

En el presente apartado se presenta el último gran bloque de técnicas matemáticas empleadas en este proyecto de tesis doctoral. Se incluye aquí la descripción matemática de los modelos empleados (modelos multivariantes adaptativos de regresión por medio de splines) junto con la de las técnicas auxiliares que se emplearon, que en este caso fueron el análisis de componentes 
principales, la selección de variables por medio de la determinación del mejor subconjunto posible para la realización de un modelo lineal y finalmente una técnica de validación cruzada exhaustiva que permitió comprobar el rendimiento de los modelos obtenidos. Si bien en el presente proyecto de tesis doctoral se ha restringido al mínimo el contenido matemático primando siempre la funcionalidad de las diferentes técnicas sobre su fundamento teórico, en el caso de los modelos multivariantes adaptativos de regresión por medio de splines (MARS) se ha optado por exponer de manera breve su desarrollo matemático dado que si bien se trata de una técnica que ha sido aplicada con éxito en otros campos de la medicina y de otras ciencias pretendemos contribuir a su difusión dentro del campo de la cardiología.

\subsubsection{MODELOS ADAPTATIVOS DE REGRESIÓN POR MEDIO DE SPLINES (MARS)}

Un problema común en muchas disciplinas es la adecuada aproximación de funciones de muchas variables, conocido únicamente el valor de dicha función en un grupo reducido de puntos del espacio de la variable independiente y, a menudo, perturbado por el ruido. El objetivo es encontrar el modelo de dependencia entre la variable respuesta y las variables de entrada $x_{i}, \ldots, x_{n}$ una vez que se ha realizado un muestreo $\left\{y_{i}, x_{i}, \ldots, x_{n}\right\}_{1}^{N}$.

El sistema que genera los datos se puede describir como $y=f\left(x_{1}, \ldots, x_{n}\right)+\varepsilon$ sobre un dominio $\left(x_{1}, K, x_{n}\right) \in D \subset R^{n}$, el cual, contiene los datos.

La función f relaciona la variable de salida con las variables de entrada y $\varepsilon$ es el ruido estocástico. El objetivo del análisis de regresión es encontrar una función $\widetilde{f}\left(x_{1}, L, x_{n}\right)$ que sirva como aproximación de $f\left(x_{1}, \Lambda, x_{n}\right)$ sobre el dominio D.

Para ello se considera un tipo de funciones denominadas funciones básicas $B_{m}$ de la forma:

$$
B_{m}(x)=I\left[x \in R_{m}\right]
$$

Donde I es una función que toma el valor 1 si el argumento es cierto y 0 en caso contrario. Los $\left\{a_{m}\right\}_{1}^{M}$ son los coeficientes de expansión cuyos valores son ajustados para obtener una buena adaptación a los datos. Los $\left\{R_{m}\right\}_{1}^{M}$ son las subregiones del espacio donde está definida la función. Si estas subregiones son disjuntas, sólo una función básica es distinta de 0 para cada $\mathrm{x}$.

La principal limitación del método anterior es su falta de continuidad entre subregiones vecinas. Esta falta de continuidad limita la precisión de la adaptación. Para conseguir modelos continuos, con derivadas continuas, se desarrolló el método de splines regresivos adaptativos (Multivariable Adaptative Regressive Splines, MARS)(Friedman \& Roosen, 1995).

El único aspecto que introduce discontinuidades en el modelo es la función escalón. Si se reemplaza esta función por otra que sea continua, el algoritmo 1 
debería de producir modelos continuos. La función elegida para reemplazar a la función escalón es un spline.

Las dos partes de la división de la función básica tienen la forma:

$$
b_{q}^{ \pm}\left(x-t^{n}\right)=\left[ \pm\left(x-t^{n}\right)\right]_{+}^{a_{S}}
$$

donde $t^{n}$ es la localización del nodo, $q_{S}$ es el orden del spline, y el subíndice indica la parte positiva del argumento.

Para $q_{S}>0$ la aproximación por splines es continua, y con $q_{S}-1$ derivadas continuas.

Las funciones escalón son un caso particular en que los splines son de grado cero, $q_{S}=0$.

Este método produce unas funciones básicas que son el producto de splines univariantes. Dichas funciones básicas tienen la forma:

$$
B_{m}^{(q)}(x)=\prod_{K=1}^{K_{m}}\left[S_{k m} \cdot\left(x_{v(k, m)}-t_{k m}\right)\right]
$$

Es decir, reemplazando las funciones escalón por splines de grado $q_{S}$, se consiguen modelos continuos, con $q_{S}-1$ derivadas continuas.

El modelo MARS se escribe de la siguiente forma:

$$
\tilde{f}(x)=a_{0}+\sum_{K_{m}=1} f_{i}\left(x_{i}\right)+\sum_{K_{m}=2} f_{i j}\left(x_{i}, x_{j}\right)+\sum_{K_{m}=3} f_{i j k}\left(x_{i}, x_{j}, x_{k}\right)+L
$$

El primer sumatorio contiene todas aquellas funciones que dependen de una sola variable. El segundo contiene las funciones básicas que dependen de dos variables, y representa las interacciones entre dos variables. El tercer sumatorio representa la contribución de las interacciones entre tres variables, y así sucesivamente.

Sea $V(m)=\{v(k, m)\}_{1}^{K m}$ el conjunto de variables asociada con la función básica m, $B_{m}(x)$. Cada función del primer sumatorio puede ser expresada como:

$$
f_{i}\left(x_{i}\right)=\sum_{\substack{k_{m}=1 \\ i \boxminus(m)}} a_{m} B_{m}\left(x_{i}\right)
$$

La ecuación anterior representa la suma de todas las funciones básicas que envuelven solamente la variable ${ }^{x_{i}} \mathrm{y}$ es el spline que representa la función univariante correspondiente.

Cada función bivariante del segundo sumatorio puede ser expresarse como: 


$$
f_{i}\left(x_{i}, x_{j}\right)=\sum_{\substack{K_{m}=2 \\(i, j) \in(m)}} a_{m} B_{m}\left(x_{i}, x_{j}\right)
$$

Lo cual representa la suma de todas las funciones básicas que envuelven un determinado par de variables $x_{i} \mathrm{y}_{j}$. Sumándole la correspondiente contribución univariante para esas mismas variables se tendrá:

$$
f_{i j}^{*}\left(x_{i}, x_{j}\right)=f_{i}\left(x_{i}\right)+f_{j}\left(x_{j}\right)+f_{i j}\left(x_{i}, x_{j}\right)
$$

que representa el conjunto de la contribución bivariante de $x_{i}$ y $x_{j}$ al modelo. Procediendo de la misma manera se obtienes las contribuciones de los términos correspondientes a grupos de tres o más variables.

El método MARS combina los métodos de proyección activa y proyección recursiva, utilizando regresión multivariante adaptativa con splines. El modelo utilizado por el MARS es el mismo que en proyección recursiva pero con distintas funciones base. Las funciones base utilizadas por el MARS son splines multivariantes, es decir, el producto tensorial de splines de una dimensión.

Con el fin de conocer la importancia de las variables que forman parte de un modelo MARS, el algoritmo muestra los resultados correspondientes a tres criterios. Estos son:

- El criterio de nsubsets: este criterio cuenta el número de subconjuntos de modelos en el que se ha incluido cierta variable. Aquellas variables que se han incluido en un mayor número de subconjuntos de modelos son consideradas de mayor importancia. En este contexto, debe tenerse en cuenta que se denomina subconjunto a cada subconjunto de términos generado por el algoritmo en cada una de sus pasadas de poda. Es decir, existe un subconjunto para cada uno de los posibles tamaños del modelo, partiendo de una variable y llegando hasta el número final de variables que es elegido por el modelo. Es decir, la estimación se realiza tomando en cuenta solo aquellos modelos de tamaño menor o igual que el del modelo final.

- El criterio rss: este criterio calcula el valor de la ecuación RSS para cada uno de los subconjuntos. Así, las variables cuya eliminación contribuyen de manera más significativa a la reducción del RSS son consideradas como las más importantes para el modelo final.

- Finalmente, el criterio gcv es análogo al del rss pero empleando esta vez la ecuación de GCV en vez de la del RSS.

\subsubsection{METODOLOGÍA PARA LA VALORACIÓN CRUZADA EXHAUSTIVA DE LOS MODELOS}

Dado que en el presente trabajo de investigación se dispone de una muestra de pacientes de un tamaño relativamente reducido, es muy importante aplicar metodologías que aseguren la capacidad de generalización de los resultados alcanzados por todos aquellos modelos que se generen. Para el caso del presente 
proyecto de tesis doctoral se ha optado por una metodología consistente en la validación cruzada exhaustiva de los modelos.

Así, para la realización de dicha validación la muestra se dividirá en dos subconjuntos, de tal modo que el modelo inicialmente se entrena con la información proporcionada por uno de ellos, mientras que el otro subconjunto es empleado para ver si el modelo realizado presenta un buen ajuste. Para nuestro problema y debido al pequeño número de casos disponibles (número que denominaremos $\mathrm{n}$ ) se ha optado por aplicar la validación cruzada $\mathrm{n}$ veces. Es decir, el subconjunto de validación consta de un solo paciente (validación extrema) Para ello se ha aplicado el algoritmo que se representa en la Figura 24.

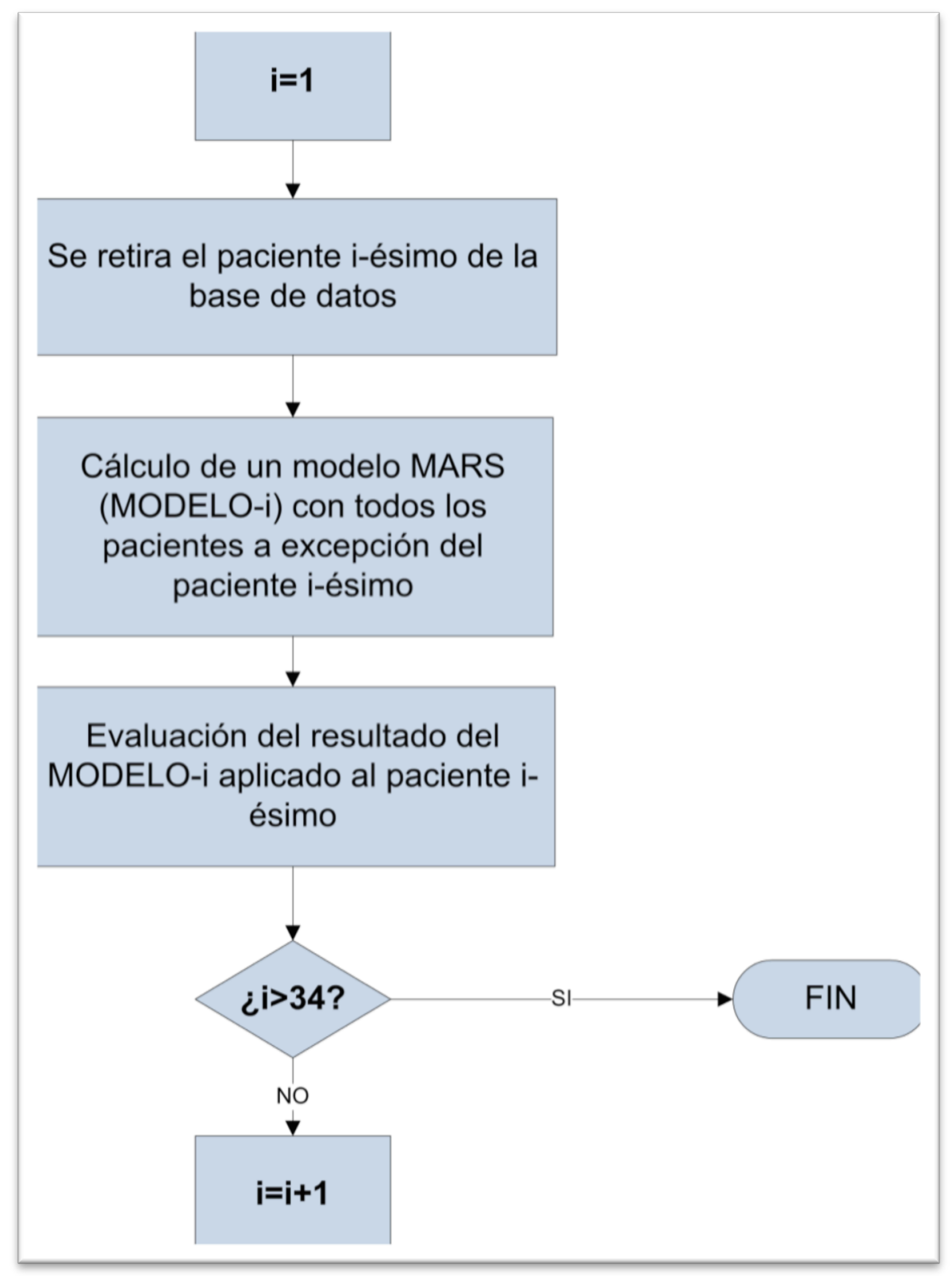

Figura 24: Algoritmo empleado para la aplicación de la de la validación cruzada.

El algoritmo de validación cruzada presentado en la figura anterior se puede resumir de la siguiente manera: se realizan $\mathrm{n}$ modelos (en nuestro caso 
materializados en los 34 pacientes), empleando para el entrenamiento de cada uno de ellos a los otros 33 pacientes. En cada caso, el paciente que no ha sido empleado para la construcción del modelo (paciente i-ésimo) es utilizado para su validación.

\subsubsection{EL MÉTODO DE LAS COMPONENTES PRINCIPALES}

Un problema central en el análisis de datos multivariantes es la reducción de la dimensionalidad. La meta del análisis de los componentes principales consiste en explicar la cantidad máxima de varianza con el menor número de componentes principales(Jollife, 2002). Si es posible describir con precisión los valores de $p$ variables por medio de un subconjunto $r<p$ de ellas, se habrá reducido la dimensión del problema a costa de una pequeña pérdida de información.

La técnica de componentes principales es debida a Hotelling aunque sus orígenes se encuentran en los ajustes ortogonales por mínimos cuadrados introducidos por Karl Pearson en 1901(Pearson, 1901).

El análisis de componentes principales es frecuentemente utilizado como una técnica de reducción dimensional, puesto que permite estimar las orientaciones preferentes de los datos. Es decir, partiendo de un espacio n-dimensional, donde $\mathrm{n}$ representa el número de variables a estudiar, se pretende encontrar un nuevo espacio de dimensiones más reducidas donde esté contenida prácticamente la misma información. Además, el empleo del análisis de direcciones principales permite detectar las variables que más y menos influyen sobre la variable o variables de salida.

Se pueden entender como poco relevantes aquellas variables cuyo grado de participación en las componentes principales que describen el nuevo espacio es mínimo. Las componentes principales serán pues aquellas que definen el sistema de coordenadas del nuevo espacio de dimensión más reducida.

La técnica de Análisis de Componentes Principales transforma el conjunto original de variables correlacionadas en un nuevo conjunto de variables no correlacionadas, llamadas componentes principales(Oja, 1982). Estas nuevas variables son combinaciones lineales de las variables originales y se derivan en orden decreciente de importancia, de manera que la primera componente principal explica tanta variación en los datos originales como sea posible, decreciendo en las sucesivas componentes la proporción de variación de los datos que explica cada una.

Sea:

$$
X^{*}=\left\{x_{i}^{j}\right\}_{\substack{i=1 . n \\ j=1, N}}
$$

La matriz de valores pertenecientes a una muestra de $\boldsymbol{N}$ individuos, cada uno de dimensión $\boldsymbol{n}$. Si se representan los datos en $\boldsymbol{X}^{*}$ como desviaciones de sus correspondientes medias, se obtiene una nueva matriz $\mathbf{X}$, en donde la media de cada columna de datos es cero. Se define entonces la matriz de covarianza, $\mathbf{S}$, como: 


$$
S=\frac{\left(X X^{T}\right)}{N-1}=\left(S_{i}^{j}\right)_{\substack{i=1, N \\ j=1, N}}
$$

El propósito del análisis de la componente principal es transformar la matriz $\mathbf{X}$ de $\boldsymbol{N}$ variables, posiblemente relacionadas, en otra matriz $\boldsymbol{Y}$ de $\boldsymbol{N}$ variables supuestamente sin, cuya varianza decrece de arriba a abajo. Se puede demostrar (Muller, 1977) que la matriz $\boldsymbol{Y}$ se obtiene multiplicando $\boldsymbol{X}$ por una matriz ortogonal $\boldsymbol{U} Y=X \cdot U$, cuyas columnas están formadas por los vectores propios de $\boldsymbol{S}$. Para asegurar el decrecimiento de la varianza, los vectores deben tomarse en orden decreciente según el módulo del valor propio asociado. Puesto que la transformación $\boldsymbol{U}$ es ortogonal, se asegura que las distancias entre los vectores iniciales $\boldsymbol{X}$ se conserva entre sus imágenes $\boldsymbol{Y}$.

\subsubsection{SELECCIÓN DE VARIABLES POR MEDIO DE LA DETERMINACIÓN DEL MEJOR SUBCONJUNTO POSIBLE PARA LA REALIZACIÓN DE UN MODELO LINEAL}

En el presente trabajo de investigación se han empleado modelos de regresión lineal multivariante con el fin de determinar qué variables son las que hacen que se pueda obtener un coeficiente de correlación más elevado. Así, la técnica de regresión de los mejores subconjuntos identifica los modelos de subconjuntos que generan los valores de $\mathrm{R}^{2}$ más altos a partir del conjunto completo de las variables predictoras que se ha especificado, que en este caso han sido todas las disponibles en el presente trabajo. La regresión de los mejores subconjuntos es una manera eficiente de identificar modelos y que sirve de ayuda a la hora de identificar qué variables influyen sobre la salida, que en este caso es el valor de la variable reactividad plaquetaria postratamiento (RPP).

Esta técnica se aplica de la siguiente manera(McCullagh, 1992): el algoritmo examina todos los subconjuntos posibles de los predictores, comenzando con todos los modelos que contienen un predictor, luego, con todos los modelos que contienen dos predictores, y así sucesivamente, mostrándose como resultado de cada etapa los dos mejores modelos para cada número de predictores.

\subsection{EJEMPLO DE PRESENTACIÓN GRÁFICA DE LOS DATOS}

A lo largo de los resultados del presente trabajo de investigación se emplearán gráficos como el que presentamos a continuación con el fin de representar de manera resumida la información estadística de las variables. La interpretación de la información estadística contenida en todas ellas es equivalente. Así, en dichas figuras se muestra en su parte izquierda un histograma en el que se representa la distribución de los datos de todos los pacientes disponibles para la variable en cuestión analizada. Debajo de dicho histograma aparece un diagrama de boxplot (o diagrama de caja) en este tipo de diagramas se representan los mismos datos que aparecen en el histograma pero de una forma distinta. Así, el rectángulo coloreado de gris corresponde a los valores de las medidas que se encuentran recogidos entre el percentil $25 \mathrm{y}$ el percentil 75 de la muestra, correspondiendo la línea vertical que se encuentra entre ambas a la mediana (percentil 50) los valores que 
se representan por medio de aspas son los considerados como espurios de la muestra, mientras que los trazos horizontales a ambos lados de la figura representan los datos comprendidos hasta el percentil 25 (parte izquierda de la figura) y por encima del percentil 75 (parte derecha). Para completar la información contenida en la parte izquierda del gráfico, debajo del boxplot se recogen los intervalos de confianza al 95\% tanto para el valor de la media como para el de la mediana. En la parte derecha de la gráfica se puede observar en primer lugar el valor de la prueba de normalidad de Anderson-Darling. Dicha prueba mide en qué grado los datos siguen una distribución particular, en nuestro caso normal. Cuanto mejor se ajuste la distribución a los datos, menor será este estadístico. En el caso del test que se efectúa en estas gráficas, las hipótesis para la prueba de Anderson-Darling son:

- H0: Los datos siguen una distribución normal.

- H1: Los datos no siguen una distribución normal.

Si el valor p para la prueba de Anderson-Darling es inferior al nivel de significación seleccionado (generalmente 0.05 ó 0.10 ), se puede concluir que los datos no siguen la distribución normal. En aquellos casos en los que el gráfico no muestra un valor p para la prueba de Anderson-Darling, es porque éste no existe.

En estas mismas gráficas, debajo del test de Anderson-Darling, en la parte derecha se pueden observar los valores de la media, desviación estándar, varianza, asimetría (esta medida nos permite identificar si los datos se distribuyen de forma uniforme alrededor del punto central, es decir de la media aritmética), curtosis (esta medida determina el grado de concentración que presentan los valores en la región central de la distribución), número de casos (pacientes) utilizados para el cálculo de los valores, valor mínimo, valor del primer cuartil (percentil 25), valor de la mediana, valor del tercer cuartil (percentil 75) y valor máximo tomado por la variable en los datos de la muestra. Finalmente, se incluyen los valores numéricos de los intervalos de confianza de la media, mediana y desviación estándar.

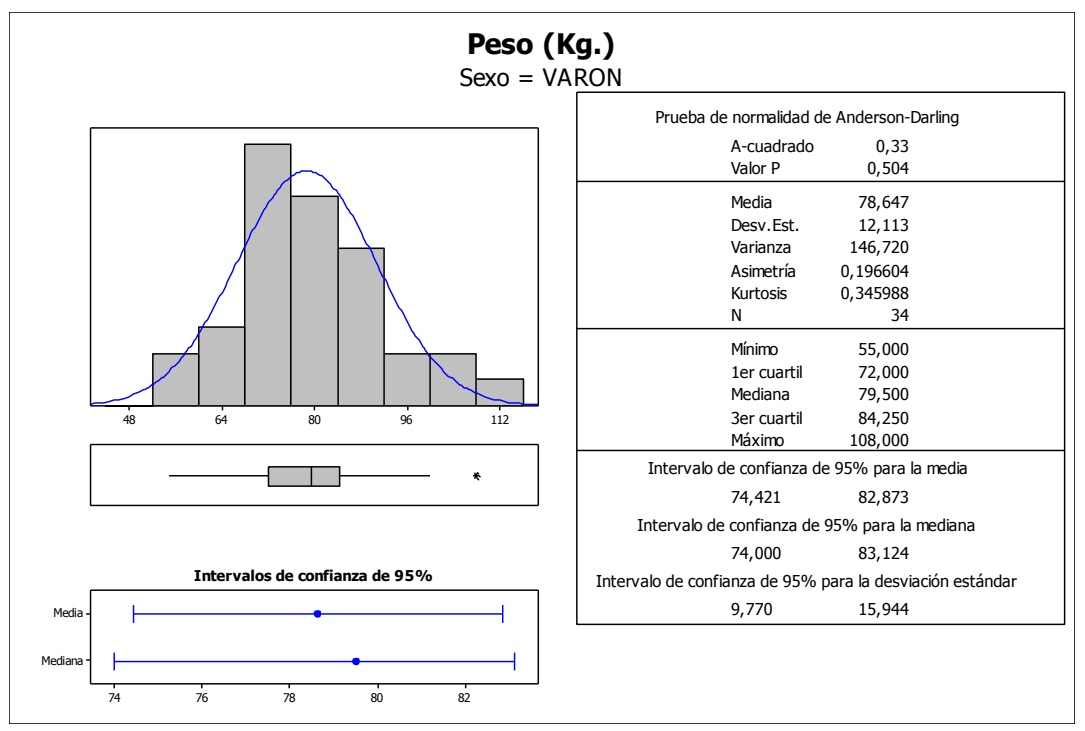

Figura 25: Ejemplo de representación gráfica de variables en forma de histograma con test de Anderson-Darling y datos de distribución asociados. 


\section{PRESENTACIÓN Y FORMATO DE CITACIÓN BIBLIOGRÁFICA}

El presente trabajo de tesis doctoral se presenta en formato electrónico para aprovechar los beneficios ofrecidos por las nuevas tecnologías. De esta forma, además de presentar el texto principal en formato .pdf, se adjunta anexo de datos informáticos con todas las gráficas y análisis estadísticos realizados, hayan sido incluidos o no en el texto final. A su vez se realiza una copia del texto final en formato .epub para su visualización en lectores electrónicos que permita la edición y toma de notas por parte de los miembros del tribunal calificador.

Para el formato de las referencias bibliográficas, en esta ocasión se ha utilizado el sistema propuesto en la sexta actualización de las normas de publicación de la American Psicological Association. 
RESULTADOS 



\section{CARACTERIZACIÓN DE LA MUESTRA}

Durante el periodo de reclutamiento, entre octubre de 2007 y marzo de 2009, se evaluaron para su inclusión los 300 pacientes que ingresaron en el hospital con el diagnóstico inicial de síndrome coronario agudo con elevación del segmento ST. 45 de ellos no recibieron tratamiento urgente de reperfusión por diferentes motivos, la mayoría de las ocasiones por haberse presentado con mucho tiempo de evolución y necrosis establecida en el electrocardiograma.

Se realizó como tratamiento de reperfusión ICP primario en 153 casos y se indicó tratamiento con fibrinólisis en 102. De entre estos últimos, 57 recibieron el tratamiento de forma prehospitalaria, por lo que la muestra sanguínea basal no pudo ser obtenida.

45 pacientes fueron reclutados para el estudio. 4 de ellos no cumplieron criterios de reperfusión tras 90 minutos de fibrinólisis por lo que se realizó ICP de rescate y fueron eliminados para el estudio. Así, finalmente 41 pacientes cumplieron todos los criterios de inclusión para su seguimiento y análisis.

El esquema de reclutamiento se muestra en la Figura 26. 


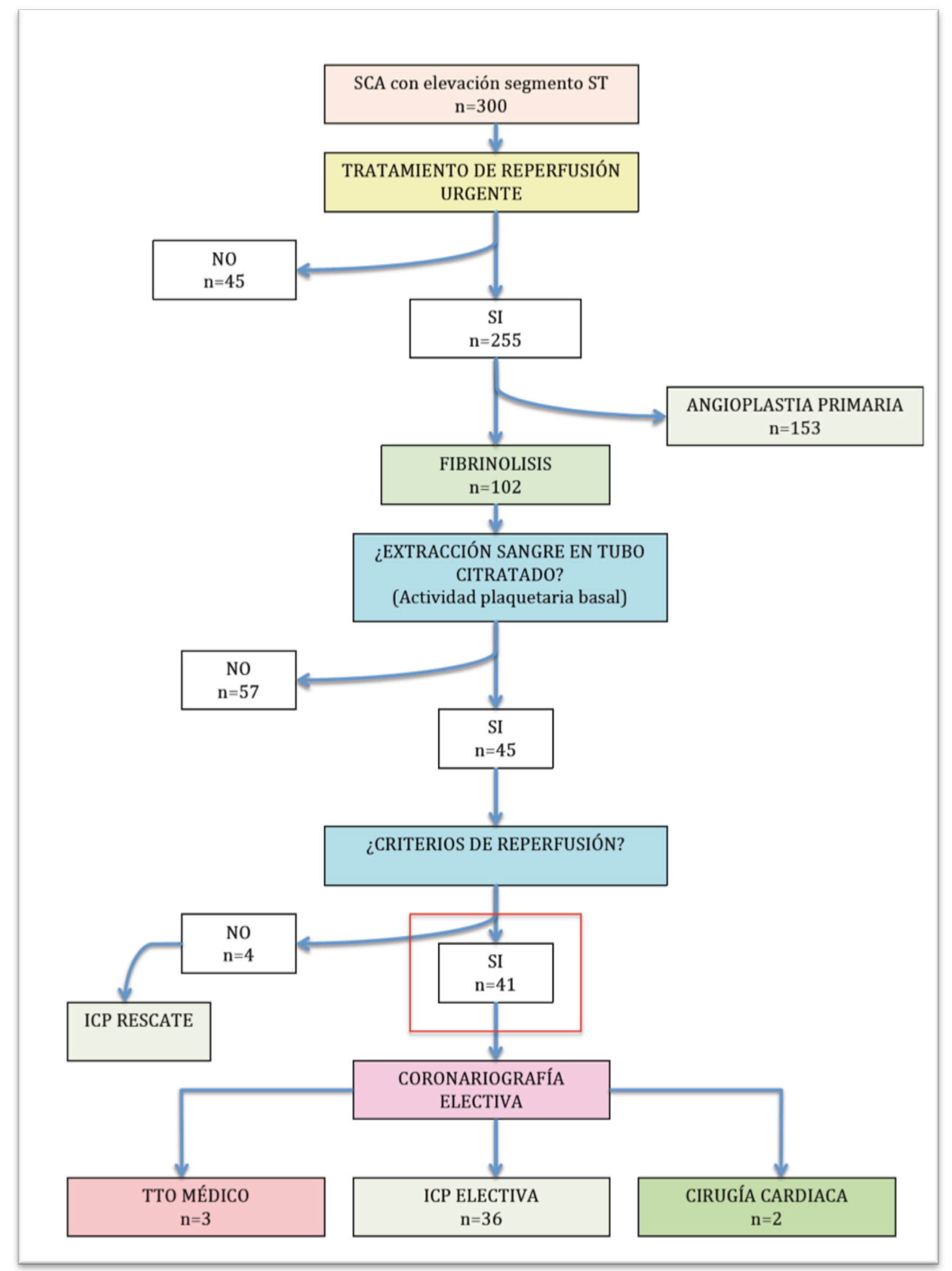

Figura 26: Esquema de selección de pacientes durante el periodo de reclutamiento. El grupo encuadrado en rojo lo forman los pacientes que finalmente cumplieron todos los criterios de inclusión y ninguno de los criterios de exclusión. 


\subsection{AGENTE LÍTICO, CORONARIOGRAFÍA Y ESTRATEGIA INICIAL:}

El tratamiento fibrinolítico fue indicado mediante la utilización de un bolo de tenecteplasa con dosis ajustada por peso según instrucciones del fabricante en todos los casos menos dos, en los que se utilizó estreptoquinasa por edad extrema y mayor riesgo de sangrado intracraneal (85 y 81 años).

Se realizó coronariografía a todos los pacientes, con una mediana de intervalo de 2,5 días (rango intercuartil: 1,8-4,1).

Tras el diagnóstico, dos pacientes fueron enviados para cirugía de revascularización coronaria mediante injertos arterio-coronarios debido a enfermedad severa de tres vasos y mala función ventricular. En otros tres casos ningún tratamiento de revascularización fue indicado debido a ausencia de lesiones coronarias con estenosis significativa.

El intervencionismo coronario percutáneo electivo fue indicado en los 36 pacientes restantes, con implantación de stent coronario en todos ellos menos en un caso (por presentar arteria responsable aneurismática de más de $10 \mathrm{~mm}$ de diámetro y que sólo recibió tratamiento mediante angioplastia con balón).

La Figura 27 muestra el esquema general del estudio detallando los momentos de determinaciones analíticas y la estrategia de revascularización en cada caso. 


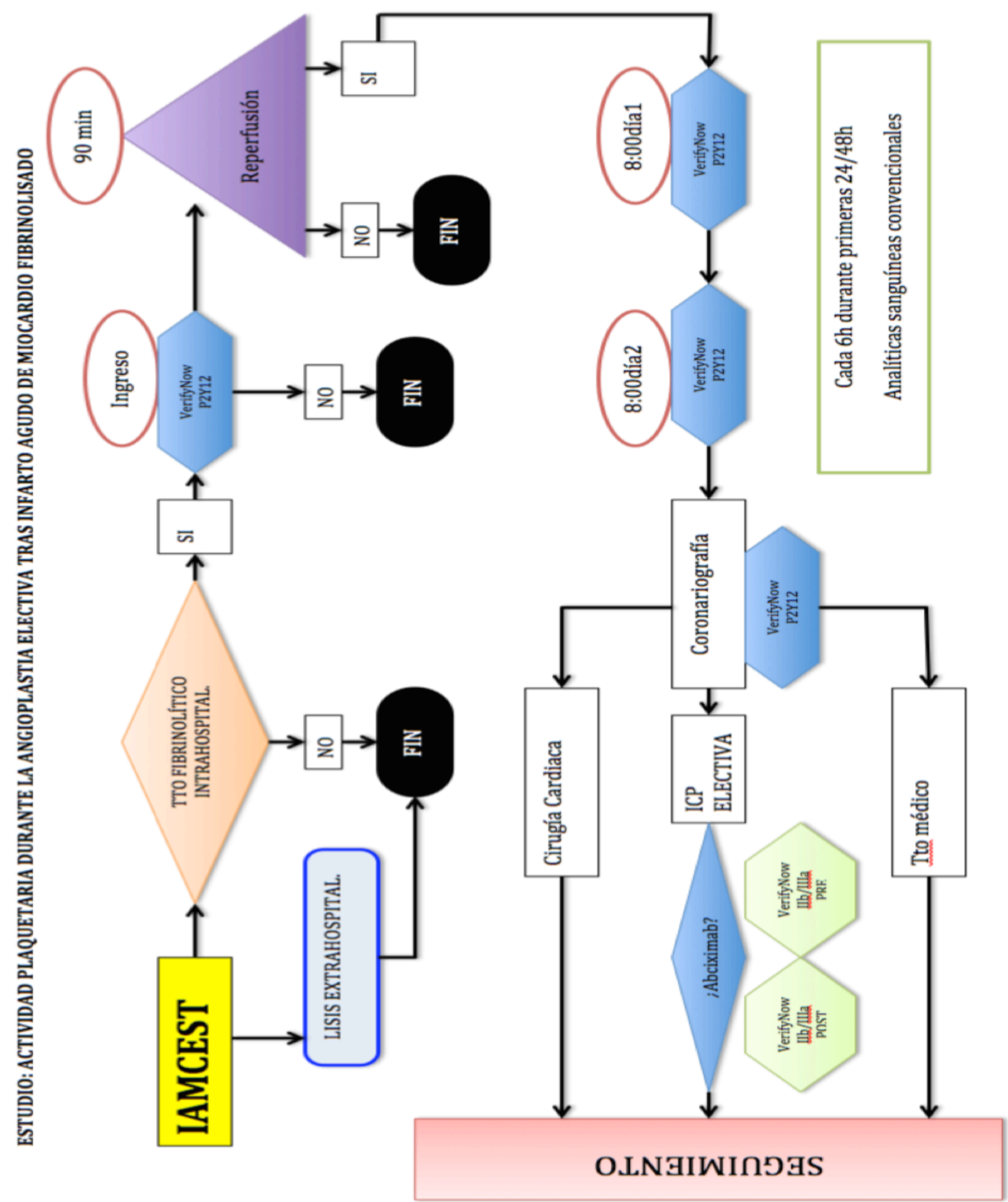

Figura 27: Esquema general del estudio en el que se muestran los criterios de inclusión y las determinaciones analíticas más importantes. 


\section{ESTADÍSTICA DESCRIPTIVA}

\subsection{CARACTERÍSTICAS BASALES}

En este apartado se expone la estadística descriptiva realizada sobre las características basales de los pacientes de la muestra. Dichas variables han sido divididas en cuatro categorías: variables comunes, factores de riesgo cardiovascular, antecedentes cardiológicos y tratamientos previos.

\subsubsection{VARIABLES COMUNES}

\section{División de los pacientes de la muestra por sexo}

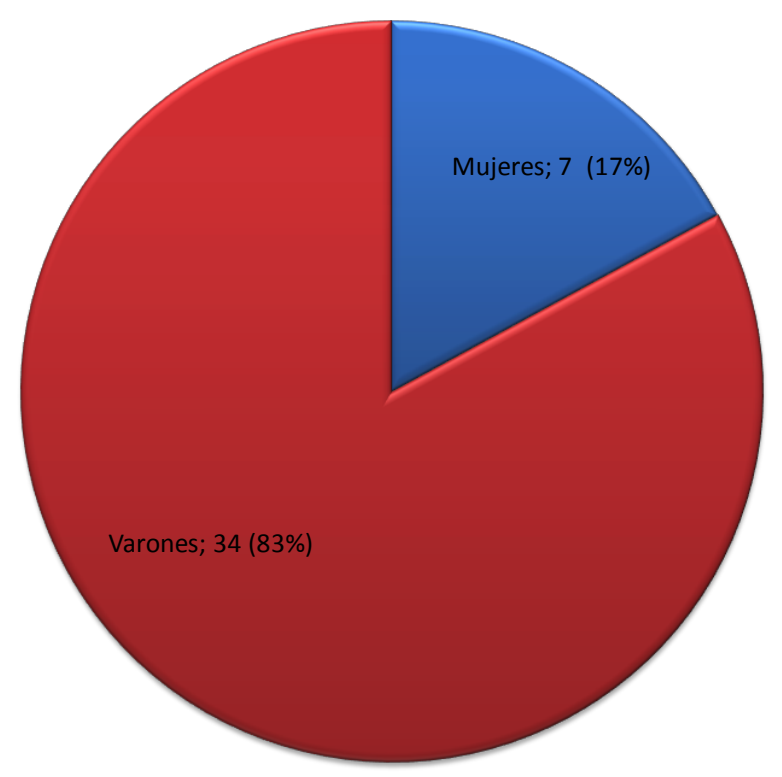

Figura 28: División de los pacientes de la muestra por sexo.

La población final sobre la que se realizaron los análisis estadísticos fue constituida por un total de 41 pacientes. Se presenta la distribución de sexos de la muestra ya que ha sido la característica común utilizada para hacer la mayor parte de las divisiones por grupos, debido a la diferencia en cuanto a distribución de factores de riesgo y variables clínicas que estos dos grupos presentan.

Se presentan a continuación las características basales de la muestra total y divididas en función del sexo. A pesar de que la comparación entre ambos grupos pertenece al apartado de estadística inferencial, los valores $\mathrm{p}$ de las distintas técnicas empeladas para la comparación de estos dos subgrupos se presentan también añadidos a los datos puramente descriptivos para facilitar la comprensión de los mismos. 
Los histogramas de representación de las variables comunes y las tablas de contingencia de los factores de riesgo cardiovascular y antecedentes cardiológicos se aportan en el anexo informático de datos estadísticos.

La Tabla 6 representa en resumen las características basales de la muestra. Las variables comunes (edad, peso, talla) mostraron distribuciones normales. A pesar de las diferencias encontradas en cuanto a peso y talla entre hombres y mujeres, estas diferencias se corrigieron tras ajustar en función del área de superficie corporal. En cuanto al resto de variables incluidas dentro de las características basales: factores de riesgo cardiovascular, antecedentes cardiológicos y tratamientos previos, tampoco se encontraron diferencias significativas.

Tabla 6: Características basales de la muestra.

\begin{tabular}{|c|c|c|c|c|}
\hline & $\begin{array}{l}\text { TOTAL } \\
(\mathrm{n}=41)\end{array}$ & $\begin{array}{l}\text { Varón } \\
(\mathrm{n}=34)\end{array}$ & Mujer (n=7) & $\mathrm{p}$ \\
\hline Edad & $63,12 \pm 12,23$ & $63,06 \pm 12,14$ & $63,43 \pm 13,62$ & 0,94 \\
\hline Peso & $75,23 \pm 14,51$ & $76,65 \pm 12,11$ & $59,14 \pm 8,76$ & 0,002 \\
\hline Talla & $167 \pm 9,7$ & $170 \pm 7,2$ & $154 \pm 5,7$ & 0,0004 \\
\hline \multicolumn{5}{|c|}{ Factores de riesgo } \\
\hline HTA & $15(36,58 \%)$ & $12(35,30)$ & $3(42,86 \%)$ & 0,71 \\
\hline Dislipemia & $14(34,15 \%)$ & $12(35,30 \%)$ & $2(28,58 \%)$ & 0,73 \\
\hline Tabaquismo & $15(36,58 \%)$ & $12(35,30 \%)$ & $3(42,86 \%)$ & 0,71 \\
\hline \multicolumn{5}{|l|}{$D M$} \\
\hline ADO & $3(7,32 \%)$ & $2(5,88 \%)$ & $1(14,29 \%)$ & \\
\hline Dieta & $1(2,44 \%)$ & $1(2,94 \%)$ & 0 & \\
\hline Insulina & 0 & 0 & 0 & 0,68 \\
\hline \multicolumn{5}{|l|}{$\begin{array}{l}\text { Antecedentes } \\
\text { cardiológicos }\end{array}$} \\
\hline IAM previo & $3(7,32 \%)$ & $3(8,82 \%)$ & 0 & 0,41 \\
\hline CABG previa & $1(2,44 \%)$ & $1(2,94 \%)$ & 0 & 0,64 \\
\hline ICP previa & $2(4,88 \%)$ & $2(5,89 \%)$ & 0 & 0,51 \\
\hline \multicolumn{5}{|c|}{ Angina preinfarto* } \\
\hline$<24 \mathrm{~h}$ & $5(12,20 \%)$ & $4(11,76 \%)$ & $1(14,29 \%)$ & \\
\hline $1 d-7 d$ & $6(14,63 \%)$ & $4(11,76 \%)$ & $2(28,58 \%)$ & \\
\hline Total & $11(26,83 \%)$ & $8(23,53 \%)$ & $3(42,86 \%)$ & 0,38 \\
\hline \multicolumn{5}{|c|}{ Tratamiento previo } \\
\hline Estatinas & $6(14,63 \%)$ & $5(14,71 \%)$ & $1(14,21 \%)$ & 0,95 \\
\hline \multicolumn{5}{|c|}{ Antiagregantes } \\
\hline AAS & $6(14,63 \%)$ & $5(14,71 \%)$ & $1(14,29 \%)$ & 0,95 \\
\hline Clopidogrel & $1(2,44 \%)$ & $1(2,94 \%)$ & 0 & 0,64 \\
\hline AAS+Clopi & $1(2,44 \%)$ & $1(2,94 \%)$ & 0 & 0,64 \\
\hline Total & $8(19,51 \%)$ & $7(20,58 \%)$ & $1(14,29 \%)$ & 0,70 \\
\hline
\end{tabular}

*Angina preinfarto: criterios definidos en el Apéndice II. 


\subsection{TIEMPOS}

Teniendo en cuenta la importancia clínica de los intervalos temporales en el manejo agudo de las primeras fases del infarto de miocardio, se presentan a continuación los datos correspondientes al inicio de síntomas, llegada a primer contacto médico (en el caso de los pacientes de la muestra siempre el Servicio de Urgencias del Hospital de León), administración del fibrinolítico y del clopidogrel.

Las Figuras 30-32 muestras el tiempo desde el inicio de los síntomas hasta la llegada al Servicio de Urgencias. La distribución de los datos en este caso es no normal con un apuntamiento hacia la izquierda de la gráfica y una mediana de 120 minutos y los datos de probabilidad acumulada muestran que las mujeres tardan algo más en solicitar asistencia médica, con una mediana de 143 minutos con respecto a los 111 que tardan los varones, a pesar de que estas diferencias no resultaron estadísticamente significativas $(\mathrm{p}=0,34)$.

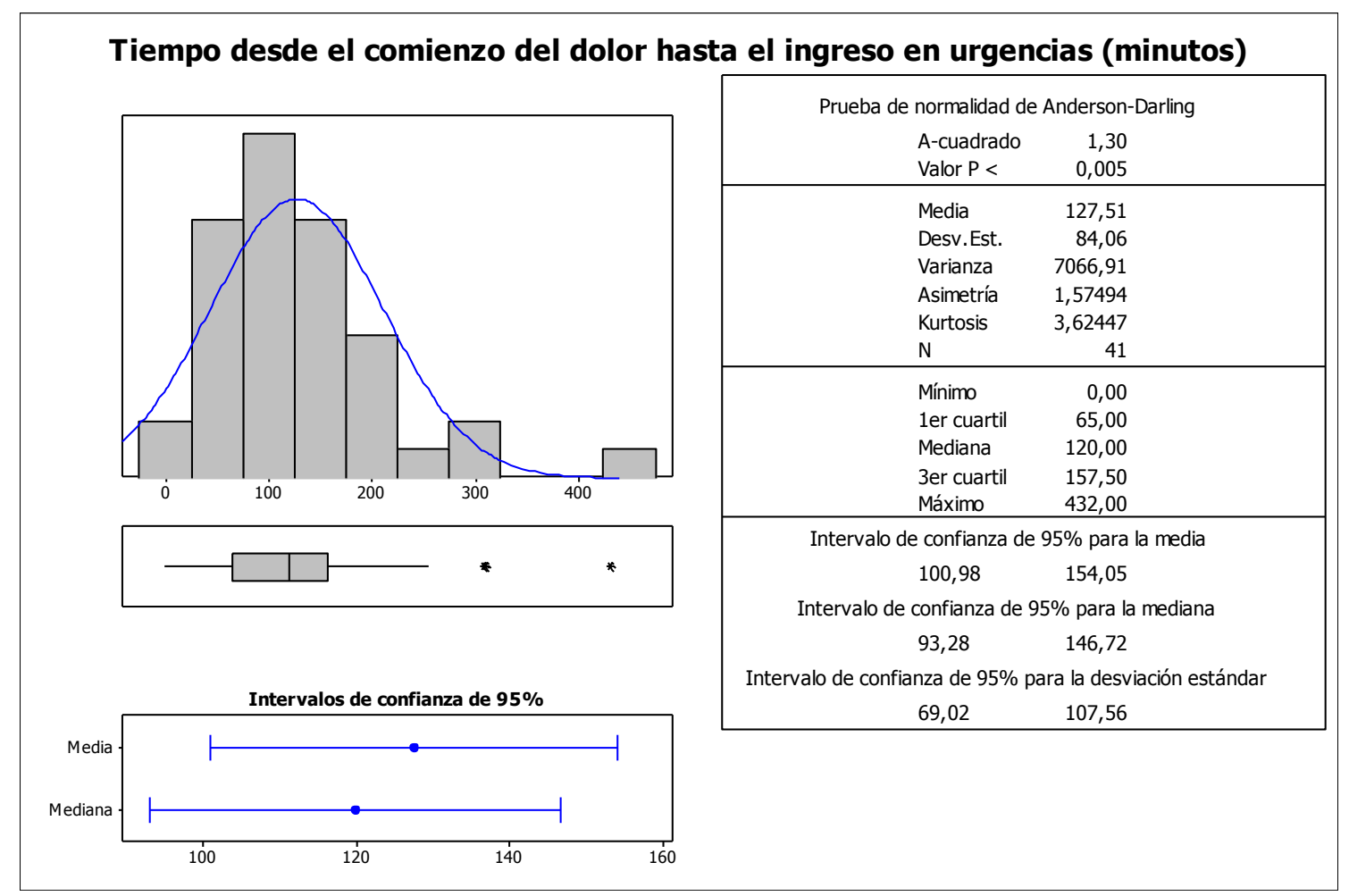

Figura 30: Histograma de distribución de los datos de la variable tiempo desde el comienzo de los síntomas hasta la llegada al Servicio de Urgencias. 


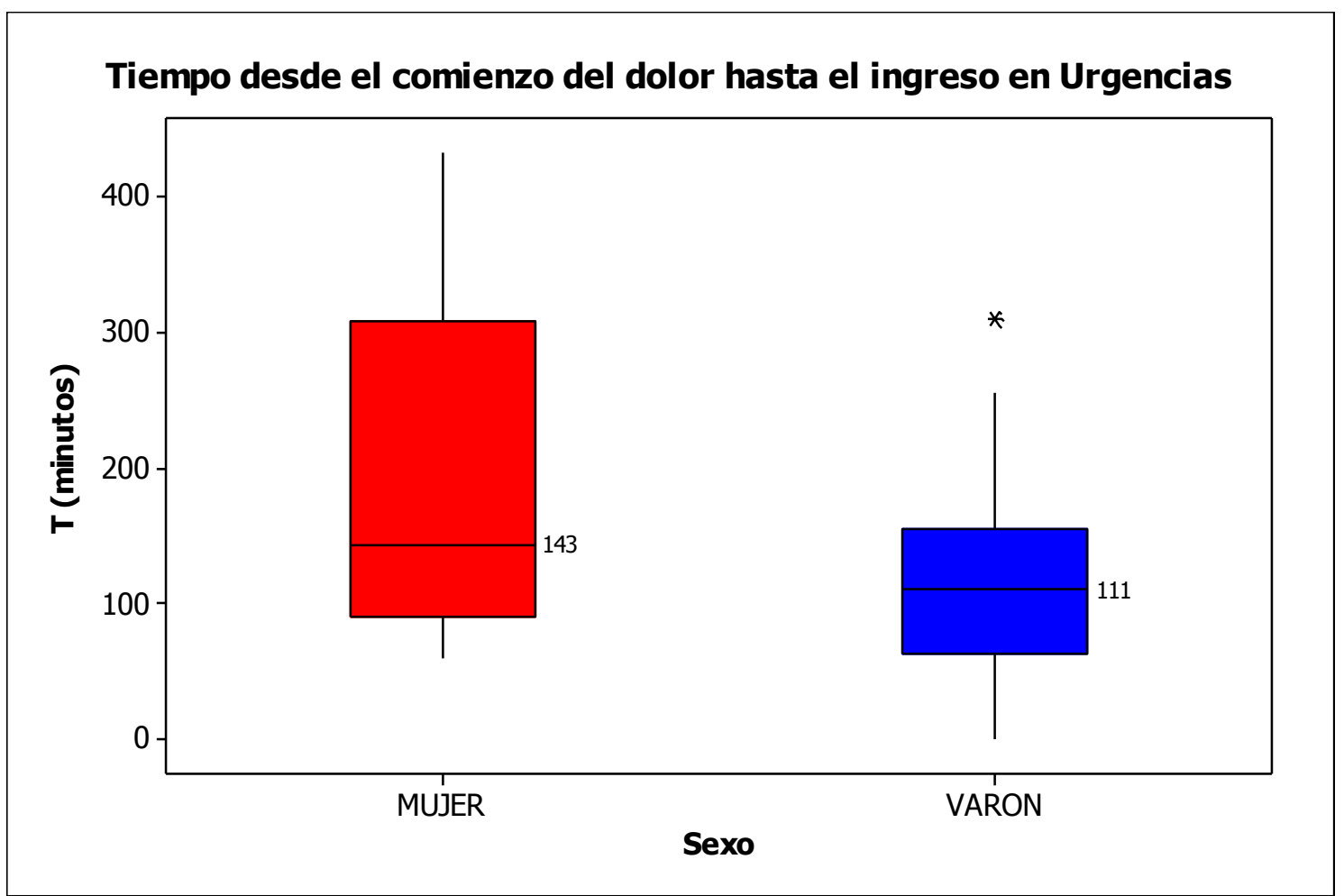

Figura 31: Gráfico de boxplot que muestra la distribución de la variable tiempo desde inicio de los síntomas hasta llegada a urgencias en función del sexo del paciente.

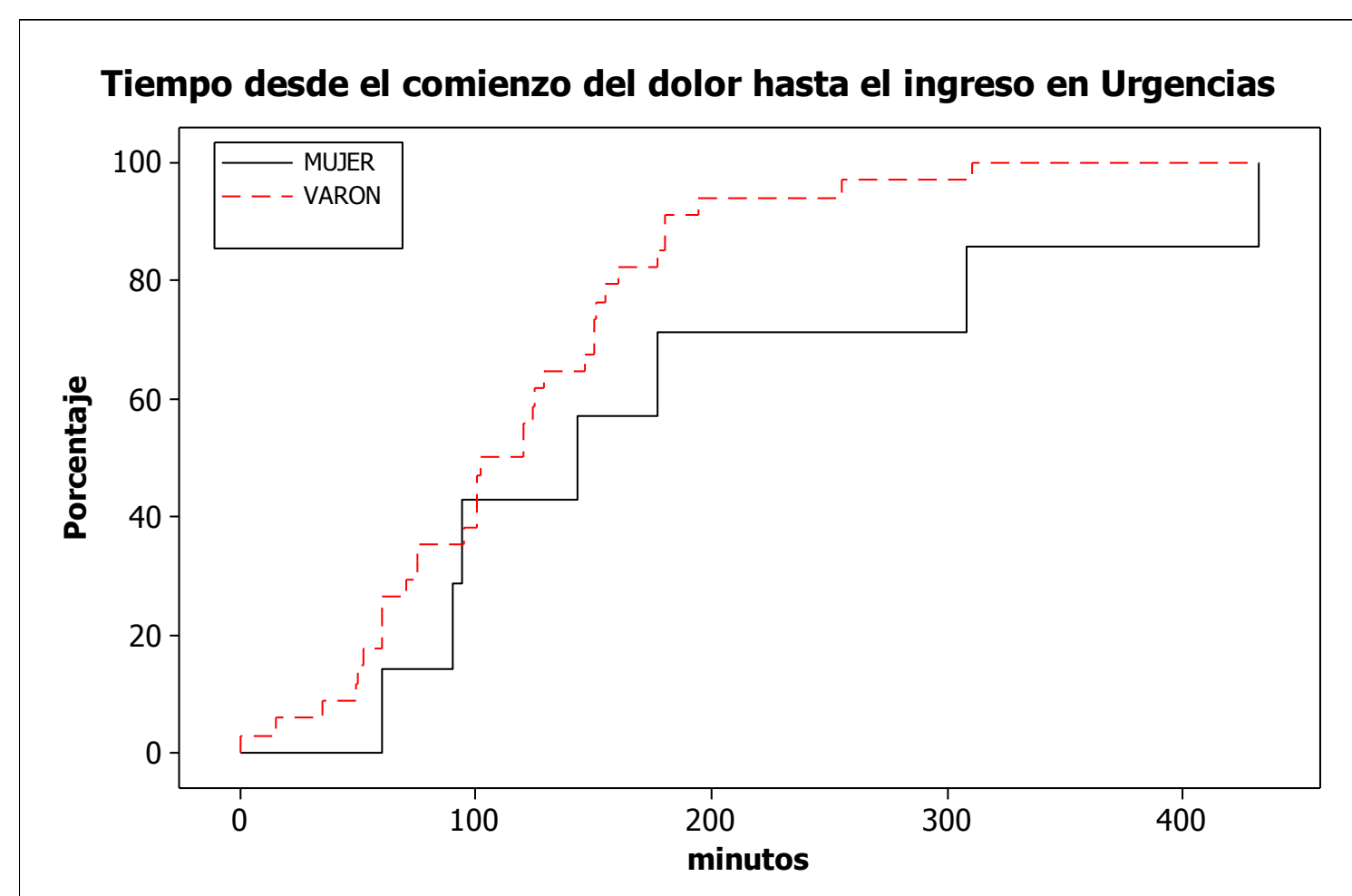

Figura 32: Curvas de densidad acumulada de la variable tiempo desde inicio de los síntomas hasta llegada al Servicio de Urgencias en función del sexo.

En cuanto al tiempo de retraso entre el ingreso y la administración del fibrinolítico, denominado generalmente mediante el anglicismo "door-to-needle", se obtuvieron también datos que muestran una distribución no normal con una 
mediana 15 minutos, y una dispersión de los valores llamativa debido posiblemente a los casos de diagnóstico diferido. A pesar de ello, tanto la mediana como la media se encuentran dentro de los márgenes de excelencia recomendados en las guía de actuación clínica (30 min).

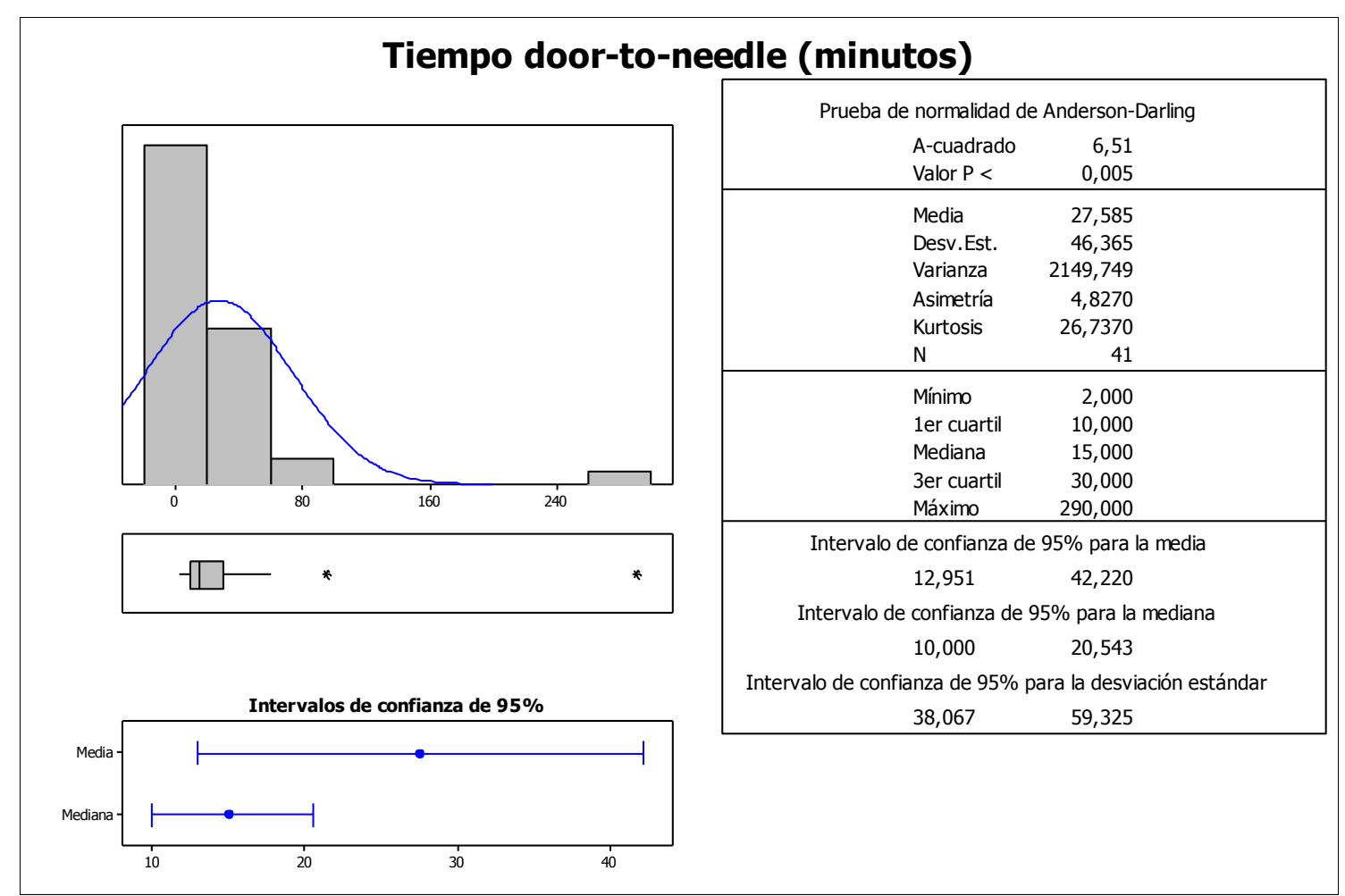

Figura 33: Histograma de distribución de la variable tiempo desde la llegada al Servicio de Urgencias hasta la administración del fibrinolítico.

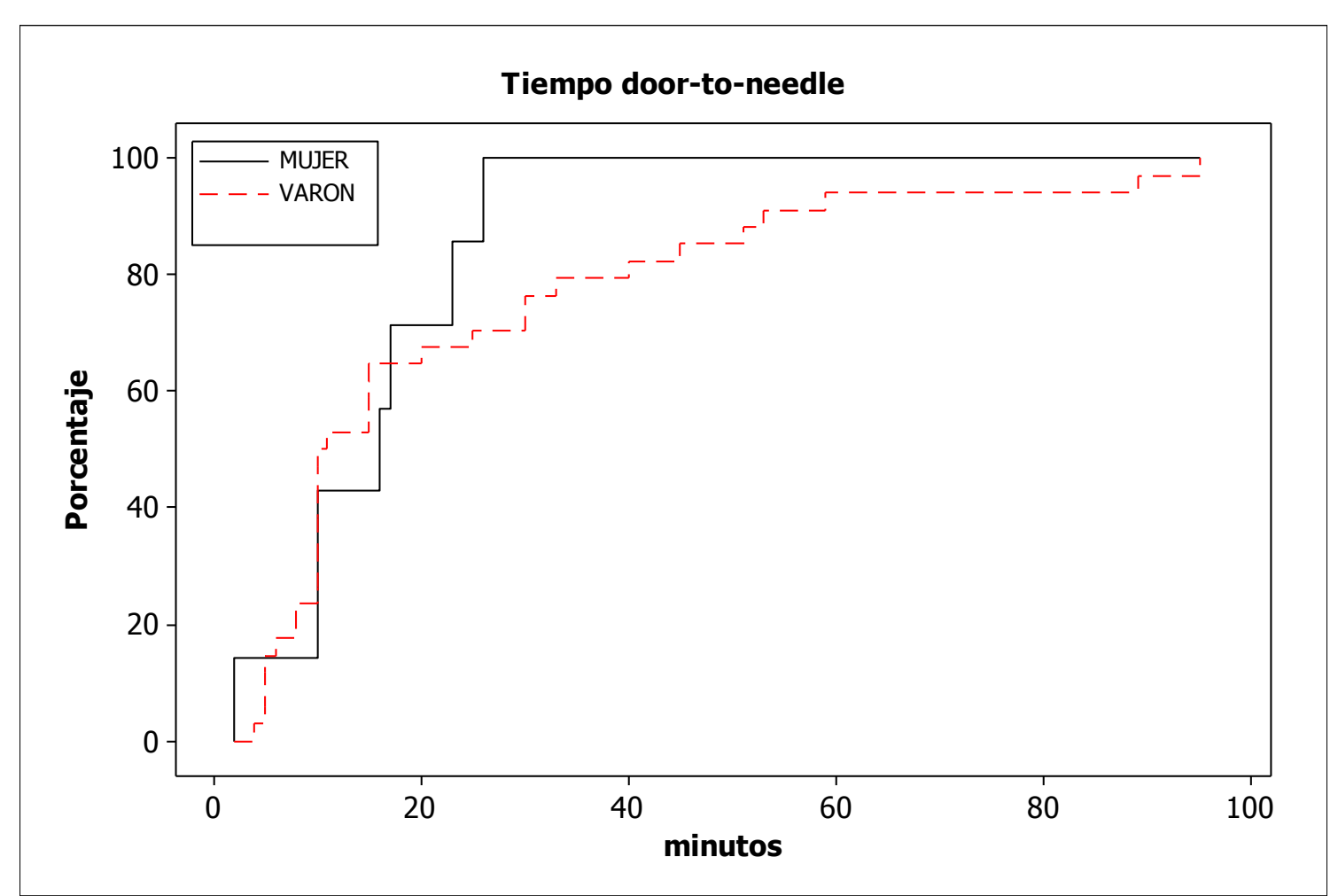

Figura 34: Curvas de densidad acumulada de la variable tiempo desde llegada al Servicio de Urgencias hasta la administración del fibrinolítico en función del sexo. 
Sumando los tiempos anteriores, se obtiene una mediana desde el inicio de lo síntomas hasta la administración de tratamiento fibrinolítico de 138 minutos, y una mediana desde el inicio de los síntomas hasta la administración de la dosis de carga del clopidogrel de 140 minutos (datos proporcionados en anexo informático de datos suplementarios).

\subsection{CARACTERÍSTICAS DEL INFARTO}

En este apartado se presentan las características generales propias del infarto que motiva la inclusión en el estudio. Estas características se corresponden con las propias de infarto de bajo riesgo o de pequeño tamaño, lo que se ajusta a la elección de tratamiento fibrinolítico por parte del cardiólogo de guardia que recibe al paciente. En resumen puede afirmarse que este tipo de infartos son predominante de localización inferior, sin signos de insuficiencia cardiaca en el momento del ingreso y de menos de 3 horas de evolución desde el momento de aparición de los síntomas.

Estos infartos, por ser predominantemente de localización inferior reciben también menos tratamiento vasodilatador y betabloqueante debido al riesgo de presentar complicaciones tipo hipotensión y boqueo aurículo-ventricular.

Tabla 7: Características del infarto.

\begin{tabular}{|c|c|}
\hline \multicolumn{2}{|l|}{ Localización del infarto } \\
\hline Anterior & $11(26,83 \%)$ \\
\hline Inferior & $28(68,29 \%)$ \\
\hline Lateral & $2(4,88 \%)$ \\
\hline \multicolumn{2}{|l|}{$\begin{array}{l}\text { Clasificación de Killip-Kimbal } \\
\text { (ingreso) }\end{array}$} \\
\hline I (no insuficiencia cardiaca) & $36(87,8 \%)$ \\
\hline II (insuficiencia cardiaca leve) & $4(9,76 \%)$ \\
\hline III (edema agudo de pulmón) & $1(2,44 \%)$ \\
\hline IV (shock cardiogénico) & \\
\hline \multicolumn{2}{|l|}{ Fibrinolítico administrado } \\
\hline Tenecteplasa (TNK-rtPA) & $40(97,56 \%)$ \\
\hline Estreptoquinasa (SK) & $1(2,44 \%)$ \\
\hline \multicolumn{2}{|l|}{ Tratamiento antitrombótico } \\
\hline Heparina no fraccionada & $4(9,76 \%)$ \\
\hline Enoxaparina & $37(90,24 \%)$ \\
\hline \multicolumn{2}{|l|}{ Otro tratamiento UCIC } \\
\hline NTG i.v. & $22(53,66 \%)$ \\
\hline Betabloqueantes & $21(51,22 \%)$ \\
\hline IECAs & $20(48,72 \%)$ \\
\hline
\end{tabular}


En este estudio no se realizaron pruebas de imagen específicas, isotópicas o resonancia magnética nuclear, para determinar el tamaño del infarto, ya que no es uno de los objetivos del estudio. Se describen para proporcionar una idea general del tamaño del mismo los estimadores habituales mediante parámetros electrocardiográficos y determinación de fracción MB de la creatinquinasa (CKMB).

\subsubsection{ELECTROCARDIOGRAMA AL INGRESO}

Las variables "Máxima desviación ST" y "Sumatorio ST" trasladan una aproximación a la extensión del infarto cuantificado desde un punto de vista electrocardiográfico. Teniendo en cuenta que ninguna de ellas evalúa el daño final sino el territorio afectado por la isquemia en un momento dado, estas variables nos permiten estimar el área de miocardio en riesgo durante las primeras fases del IAMCEST.

Las curvas de dispersión de los histogramas representados en las Figuras 35 y 36 muestran de nuevo cierto grado de apuntamiento izquierdo, con una mediana de desviación máxima del ST de $3 \mathrm{~mm}$ y un a mediana del sumatorio de desviación de $10 \mathrm{~mm}$, lo que en estos parámetros indica un mayoría de infartos de tamaño relativamente discreto, siendo más raros aquellos infartos de aparición con manifestaciones electrocardiográficas extensas.

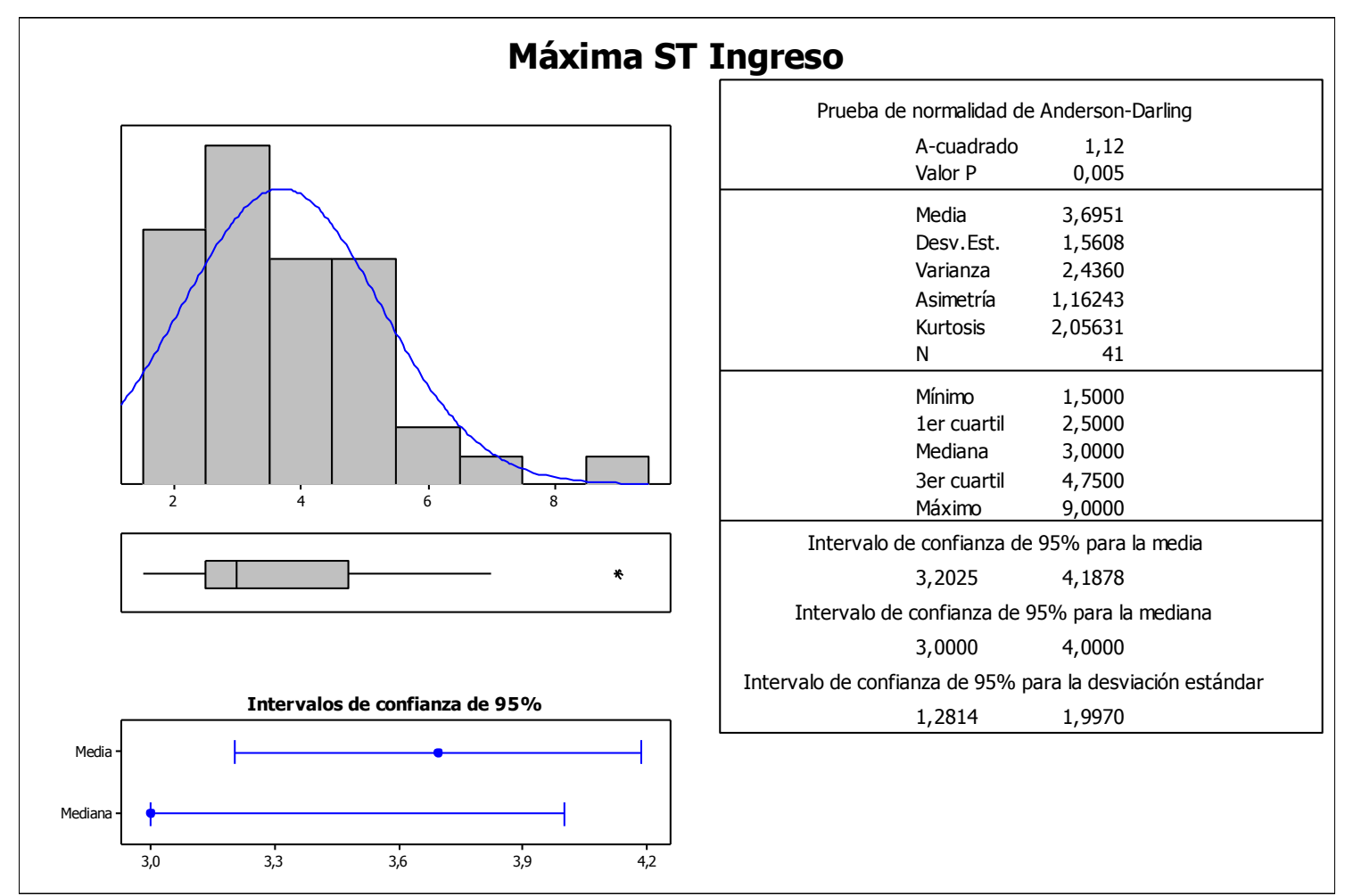

Figura 35: Histograma y distribución de los datos de la variable Máxima desviación del ST en el momento del ingreso. 


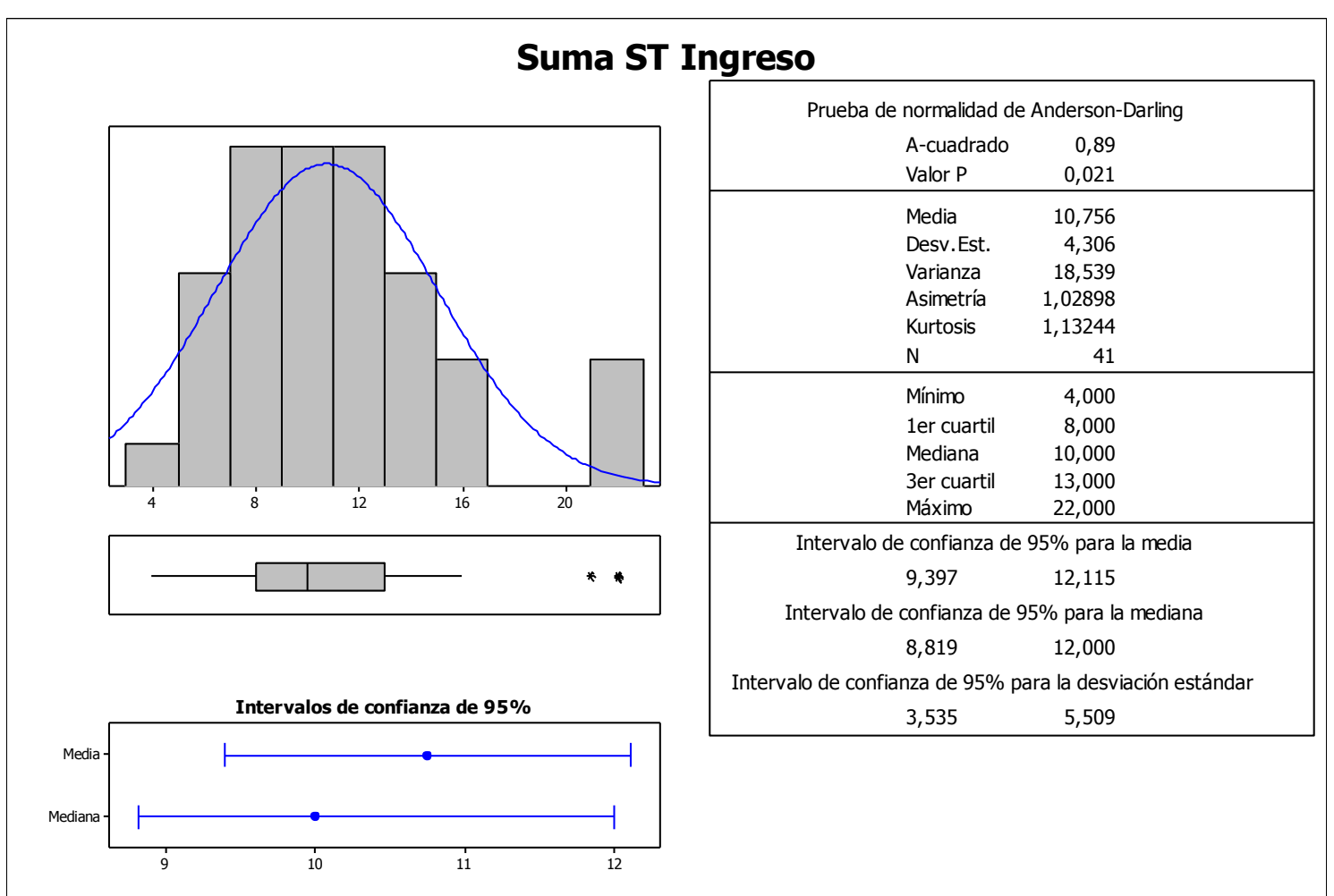

Figura 36: Histograma y distribución de los datos de la variable Sumatorio desviación del ST en el momento del ingreso.

\subsubsection{ELECTROCARDIOGRAMA A LOS 9O MINUTOS}

La importancia de los datos electrocardiográficos a los 90 minutos de la administración del tratamiento fibrinolítico se centra, como hemos definido en el Anexo II, en que constituyen el pilar fundamental para determinar los criterios de reperfusión junto con la desaparición del dolor.

Se exponen a continuación en las Figuras 37 y 38 las variables máxima desviación del ST y sumatorio del ST a los 90 minutos así como la frecuencia de aparición de arritmias de reperfusión del tipo RIVAs (ritmo idioventricular acelerado) en la Tabla 8.

Tabla 8: Presencia documentada de RIVAs durante los primeros 90 minutos tras la administración del fibrinolítico.

RIVAs

\begin{tabular}{llll}
\hline & Varones & Mujeres & Total \\
No & $17(50 \%)$ & $1(14,29 \%)$ & $18(43,90 \%)$ \\
Sí & $17(50 \%)$ & $6(85,71 \%)$ & $23(56,10 \%)$ \\
Total & $34(100 \%)$ & $7(100 \%)$ & $41(100 \%)$ \\
\hline
\end{tabular}




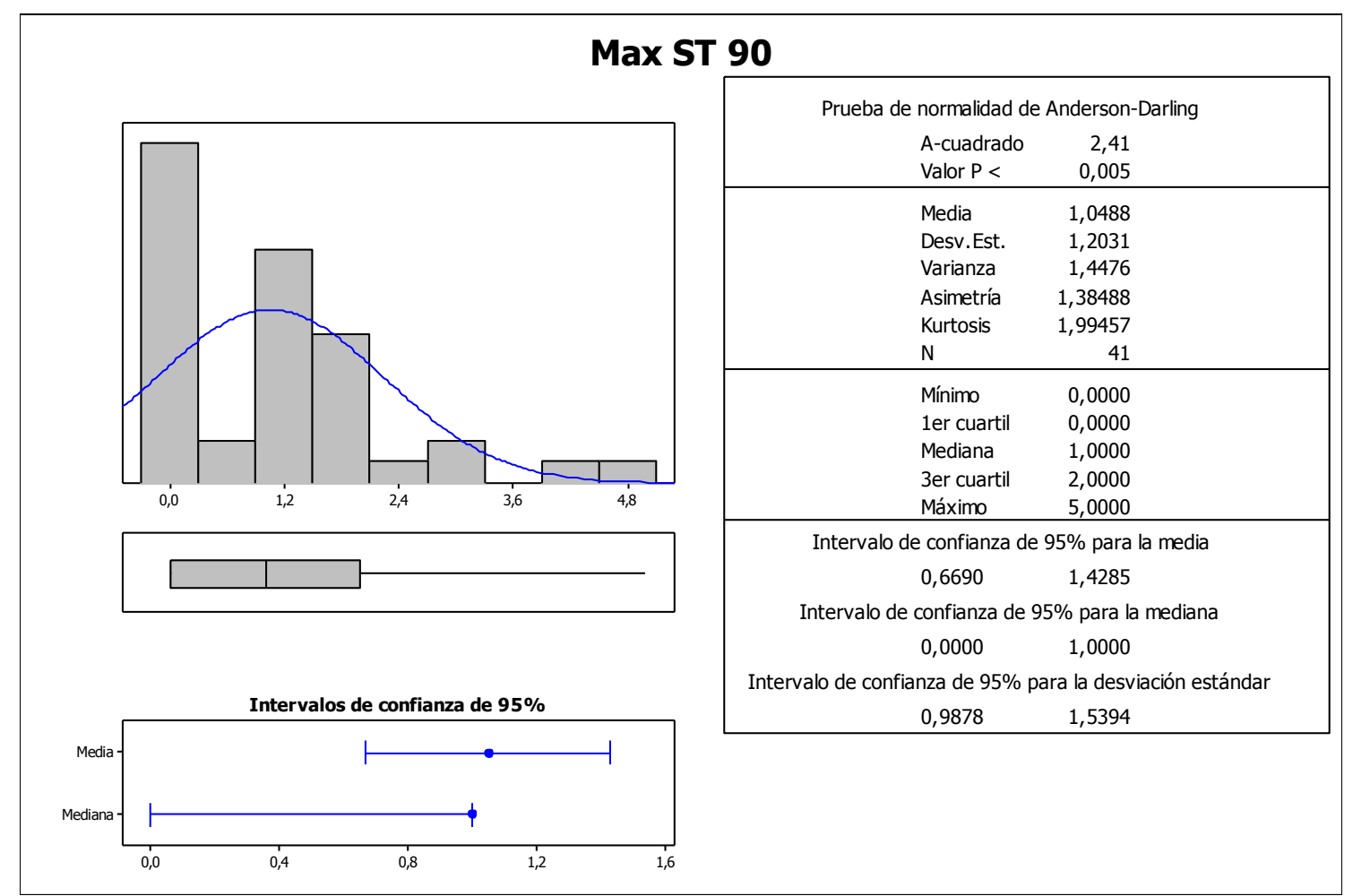

Figura 37: Histograma y distribución de datos de la variable máxima desviación del ST a los 90 minutos de la administración del tratamiento fibrinolítico.

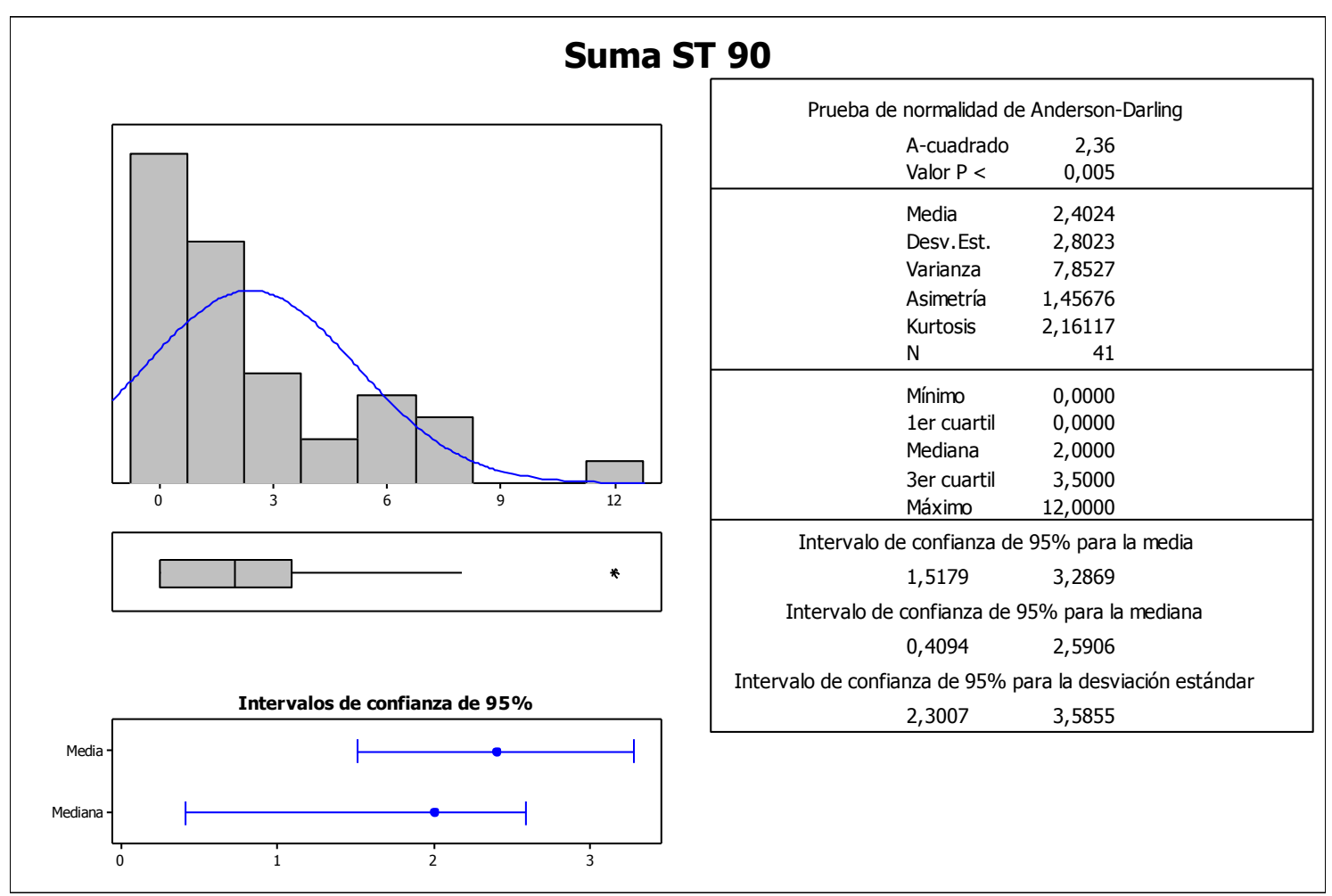

Figura 38: Histograma y distribución de datos de la variable sumatorio de la desviación del ST a los 90 minutos de la administración del fibrinolítico. 


\subsubsection{EVOLUCIÓN DE LAS ALTERACIONES ENZIMÁTICAS:}

Se exponen a continuación los datos de evolución de los valores de la enzima CK-MB, utilizada para estimar el tamaño total del infarto y la consecución o no de reperfusión por la aparición de pico precoz de la misma. Se aprecia así una elevación enzimática correspondiente con infarto de tamaño moderado, correspondiente con los hallazgos electrocardiográficos, y un pico máximo de elevación enzimática alcanzado entre las 6 y 12 horas de la administración del lítico, en consonancia con el hecho de que todos los pacientes debían, para ser incluidos en el análisis, haber alcanzado los criterios clínicos y ECG de reperfusión miocárdica.

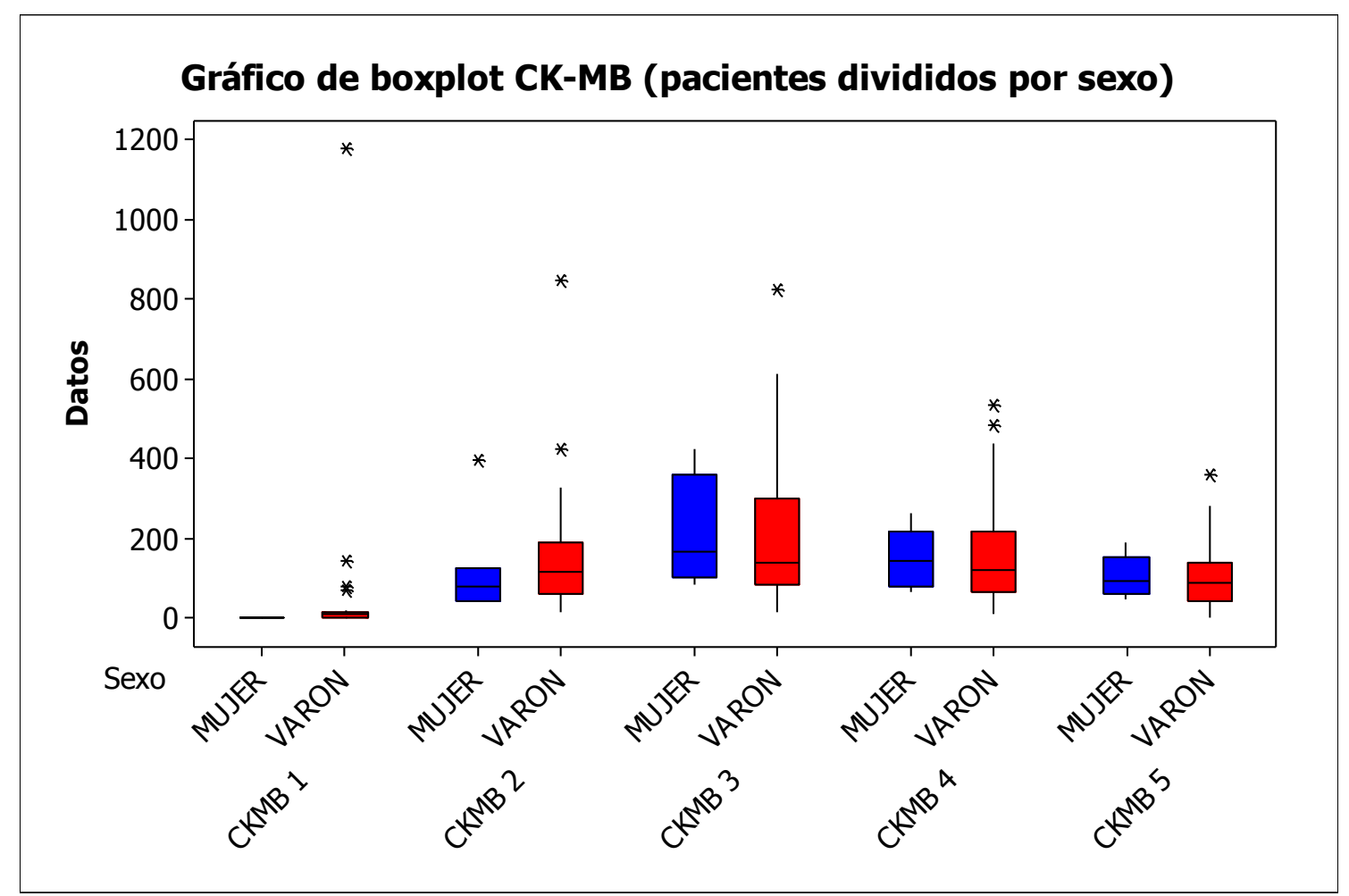

Figura 39: Gráfico de boxplot que muestra los valores de las cinco determinaciones seriadas cada seis horas de la fracción MB de la enzima creatinquinasa (CK-MB). 


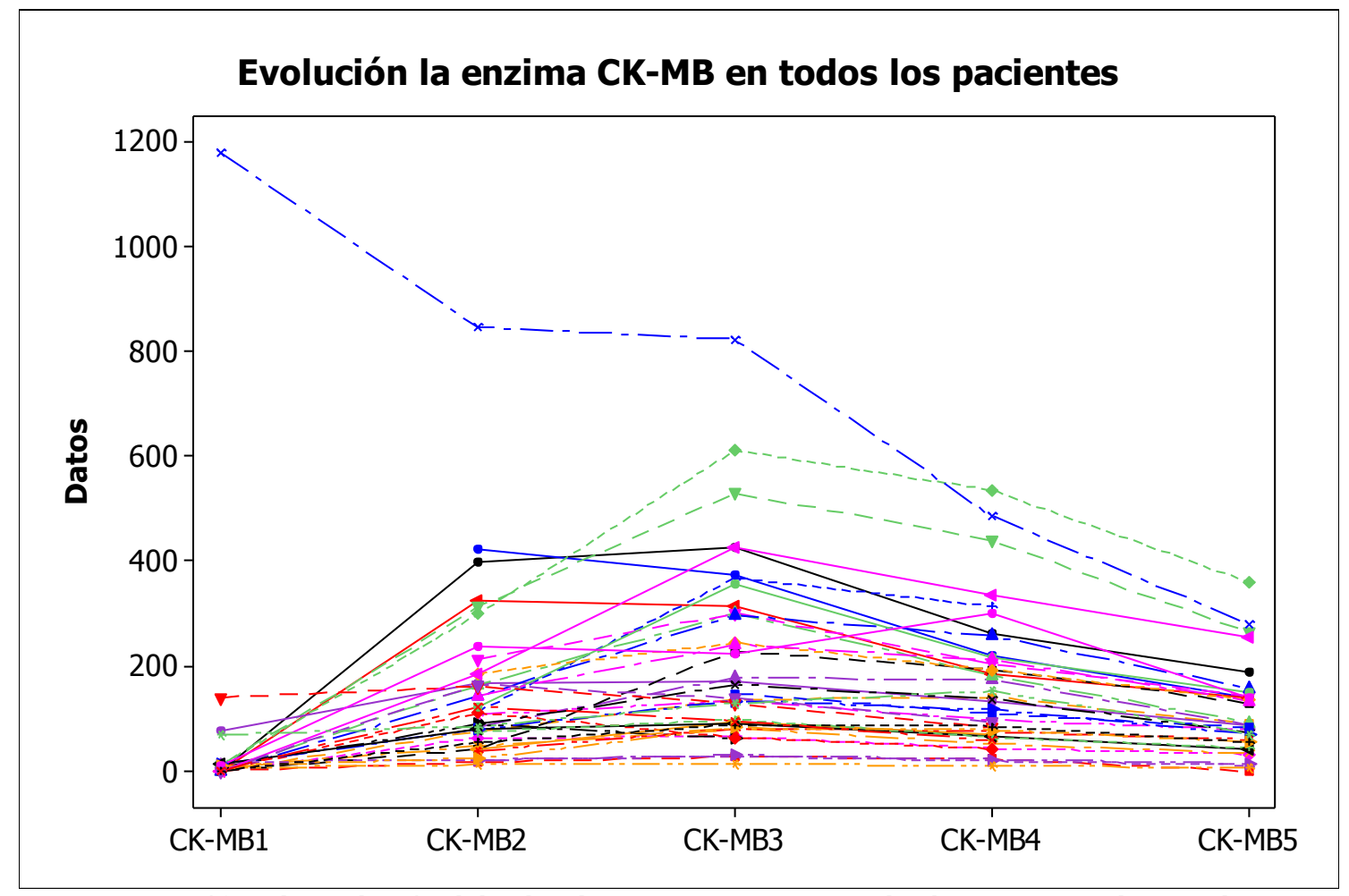

Figura 40: Gráfico de evolución del valor de enzima CK-MB en todos los pacientes durante las cinco determinaciones seriadas cada seis horas tras el ingreso.

Otras determinaciones analíticas que no tienen relación con el tamaño del infarto pero que pueden presentar interés, como los valores de hemoglobina, glucemia o parámetros de función renal, se presentan en el anexo de datos informático.

\subsection{ACTIVIDAD PLAQUETARIA}

En el presente apartado se presenta la información relativa a todas aquellas variables relacionadas con la actividad plaquetaria. Con el fin de facilitar el análisis de las mismas, éstas han sido clasificadas atendiendo al momento temporal en el que fueron determinadas. Así, se crearon las siguientes divisiones: momento 1 (ingreso) correspondiente a la determinación basal pretratamiento, momento 2 (8:00 a.m. del primer día después del ingreso) y presentada como Día +1 , momento 3 (8:00 a.m. del primer segundo día después del ingreso) y presentada como Día +2 y momento 4 (instantes previos a la coronariografía).

Los parámetros de actividad plaquetaria aquí presentados son todos los referentes a la actividad del clopidogrel, es decir, los determinados mediante el test específico para el receptor P2Y12 del sistema VerifyNow® que, como hemos visto en el apartado de Material y Método consta de las variables BASE, correspondiente al valor obtenido mediante estimulación iso-TRAP, el valor de reactividad plaquetaria postratamiento, RPP (estos dos primeros medido en unidades de reactividad plaquetaria URP) y el porcentaje de inhibición de la agregación plaquetaria (\%IAP). 
Los datos se presentan en esta sección de forma totalmente descriptiva. En la siguiente sección, de estadística inferencial univariante, se realizará la comparación entre los valores de evolución temporal de las variables.

\subsubsection{MOMENTO 1 (INGRESO): DETERMINACIÓN BASAL}

La primera determinación realizada en todos los pacientes incluidos en la muestra final del estudio supone el estado de la actividad plaquetaria antes de que se hayan administrado las medidas farmacológicas establecidas, es decir, siguiendo la hipótesis de esta tesis, antes de que el fibrinolítico haya podido incrementar su agregabilidad y antes de que el clopidogrel haya podido inhibir el receptor P2Y12.

Las Figuras 41 y 42 muestran así los valores de reactividad BASE, determinada tras estimulación mediante iso-TRAP, y de RPP. Ambas variables muestran una distribución normal y, como se discutirá posteriormente, presentan unos valores medios muy superiores a los encontrados en otro tipo de poblaciones.

Es necesario destacar que, a pesar de la terminología habitual de reactividad plaquetaria postratamiento (RPP), esta variable muestra de forma específica la actividad dependiente del receptor P2Y12, por lo que esta determinación, anterior a la administración de clopidogrel, es la verdadera reactividad plaquetaria pretratamiento para este receptor, la variable basal que, como se ha comentado, la mayoría de los estudios no puede mostrar por la dificultad para su obtención.

Siendo así la RPP el valor basal antes de la administración de clopidogrel, los valores de \%IAP, mostrados en la Figura 43, son lógicamente en este momento valores próximos a 0\% ya que los valores de BASE y de RPP deberían ser similares antes de la administración de inhibidores del receptor P2Y12. 


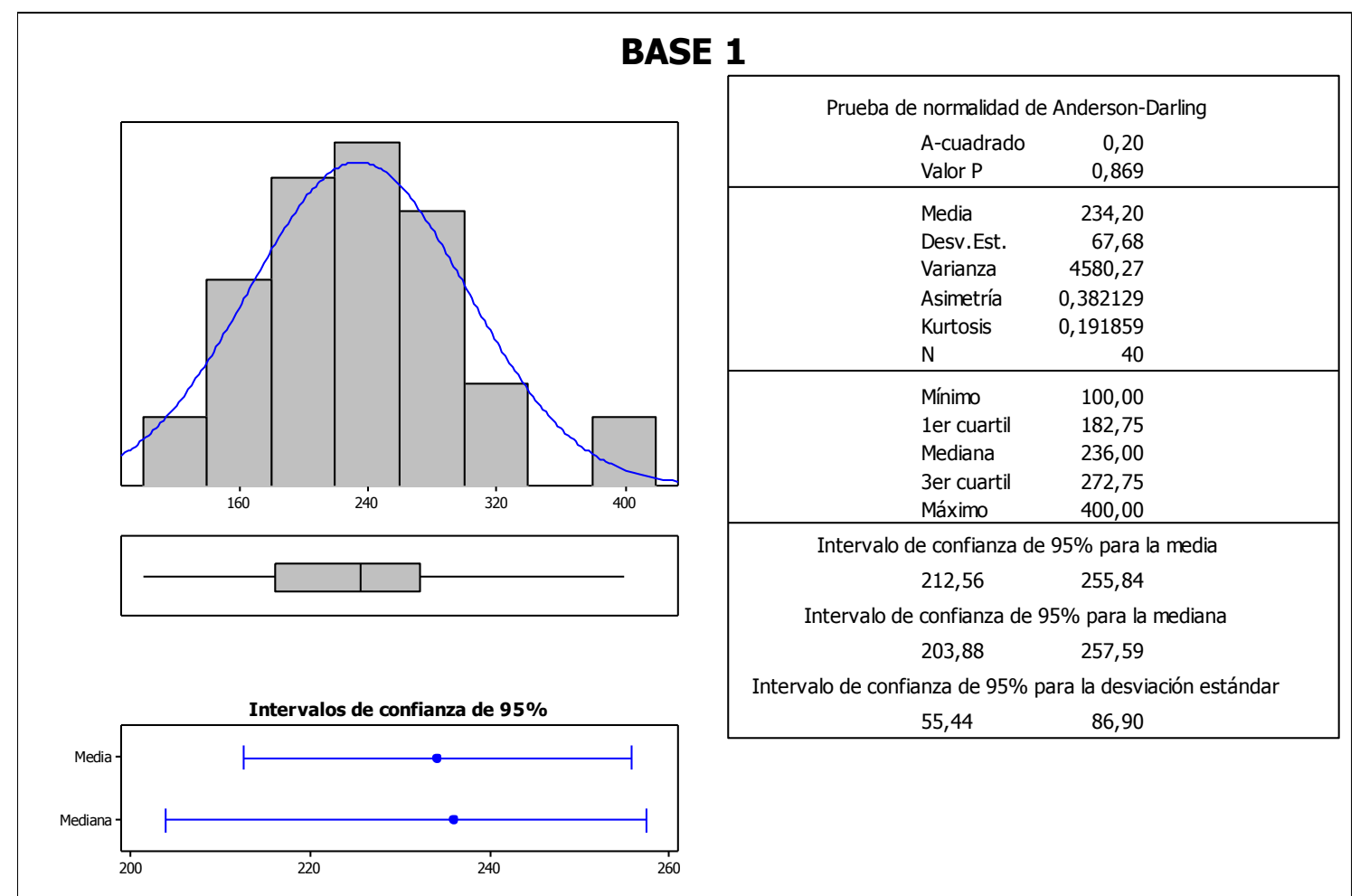

Figura 41: Resumen de la información correspondiente a la variable BASE medida en el momento del ingreso y expresada en unidades de reactividad plaquetaria URP.

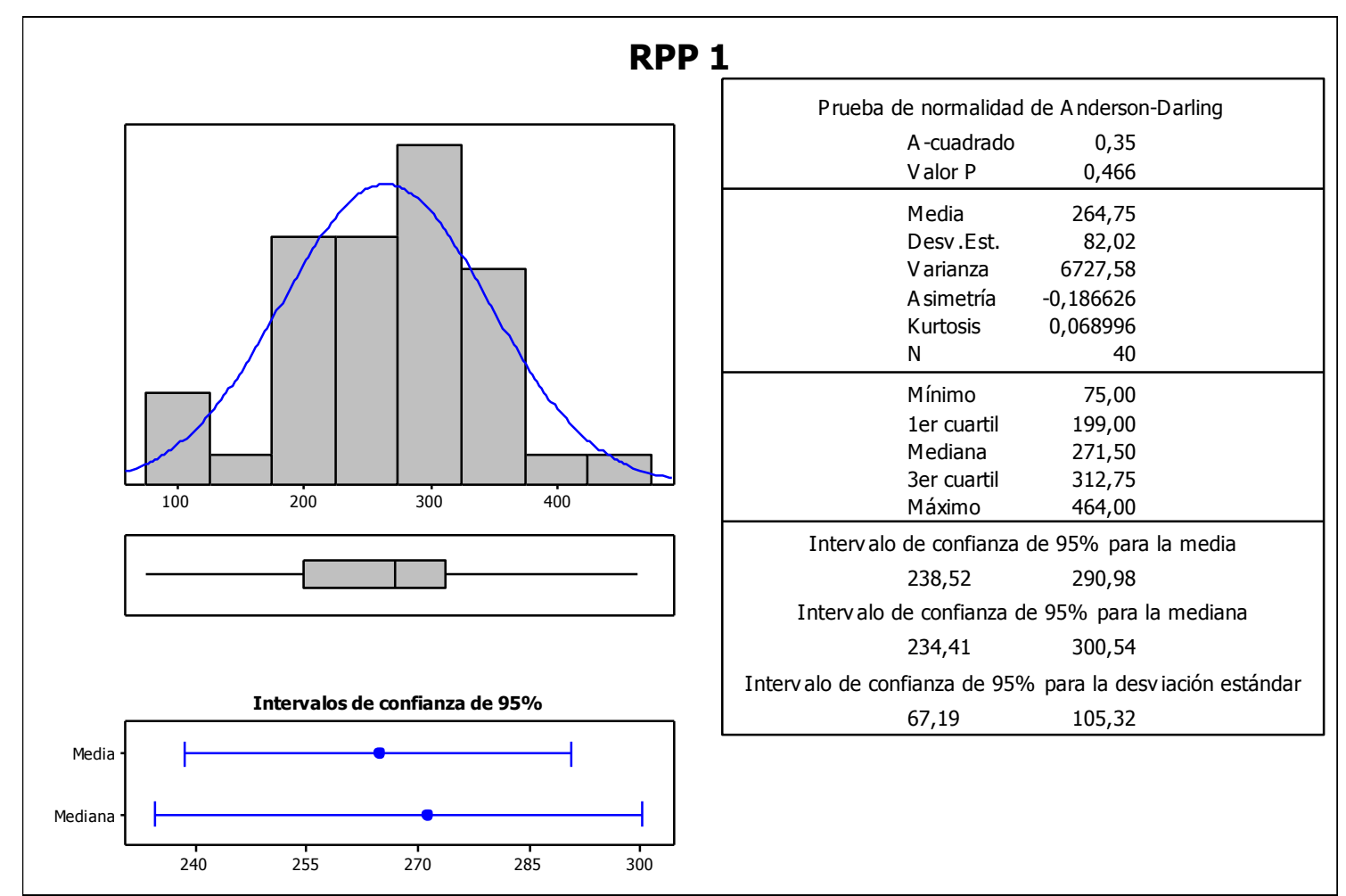

Figura 42: Resumen de la información estadística correspondiente a la variable RPP medida en el momento del ingreso. 


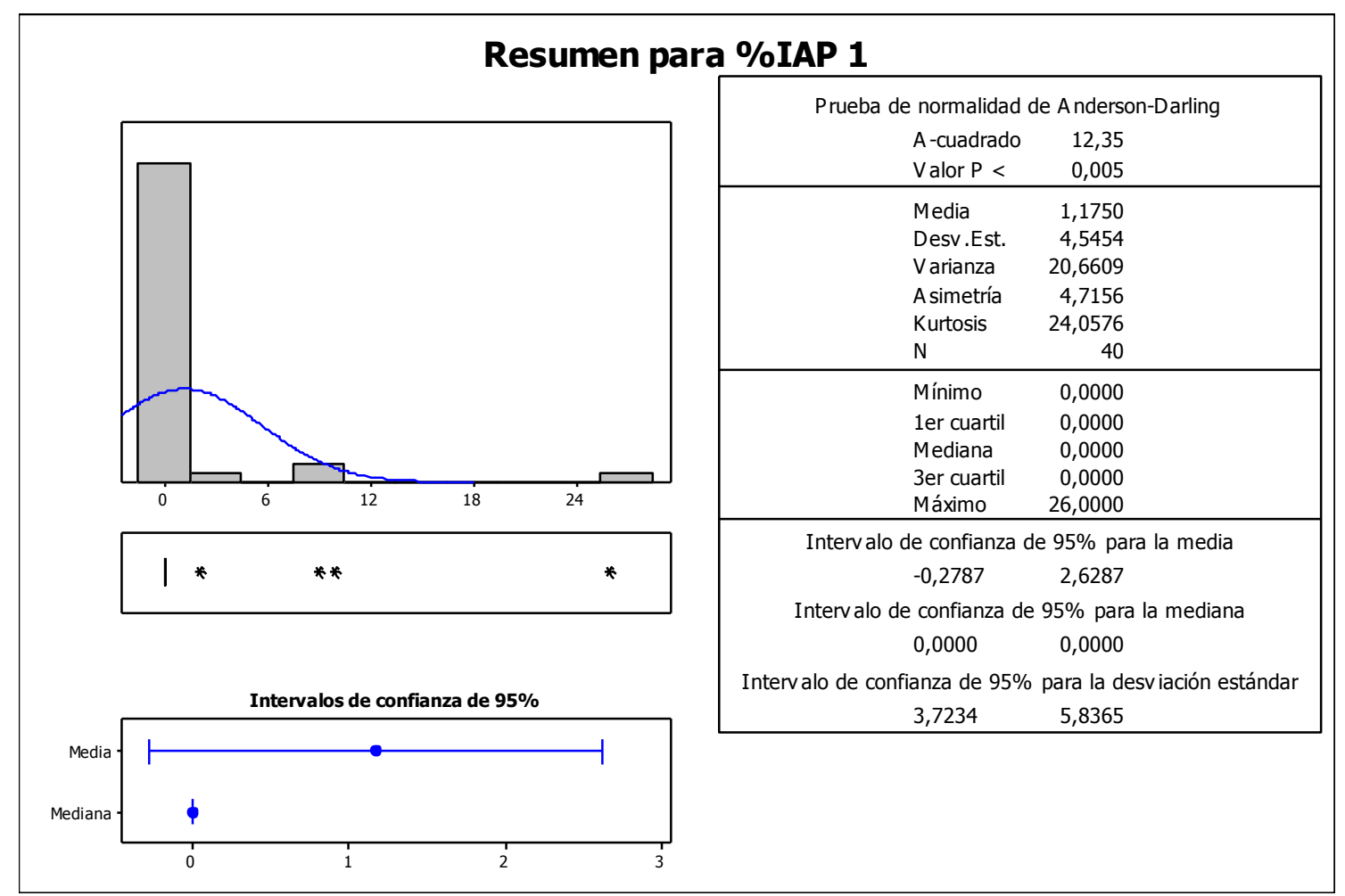

Figura 43: Resumen de la información estadística correspondiente a la variable \%IAP medida en el momento del ingreso.

\subsubsection{MOMENTO 2 (8:00 A.M. DEL PRIMER DÍA DESPUÉS DEL INGRESO)}

Se presentan a continuación las mismas gráficas para las variables BASE, RPP y \%IAP determinadas a las 8:00 horas del primer día tras el ingreso. Se trata del valor temporal más inconstante ya que el tiempo entre la carga de clopidogrel y fibrinolisis y la determinación oscila entre una y varias horas (siempre menos de 24). Se presentan en la Figura 44 los valores de la variable tiempo desde el momento 1 (ingreso) hasta el momento 2 (8:00 a.m. Dia +1). A pesar de ello, los valores resultan muy similares a los de la determinación previa y se mantiene la normalidad para las distribuciones de BASE y RPP. En cuanto al \%IAP, obsérvese que a pesar de que comienza a mostrar valores positivo y la media sube al $5 \%$, la mediana persiste en 0 . 


\section{Tiempo desde el ingreso hasta las 8:00 del día siguiente (minutos)}
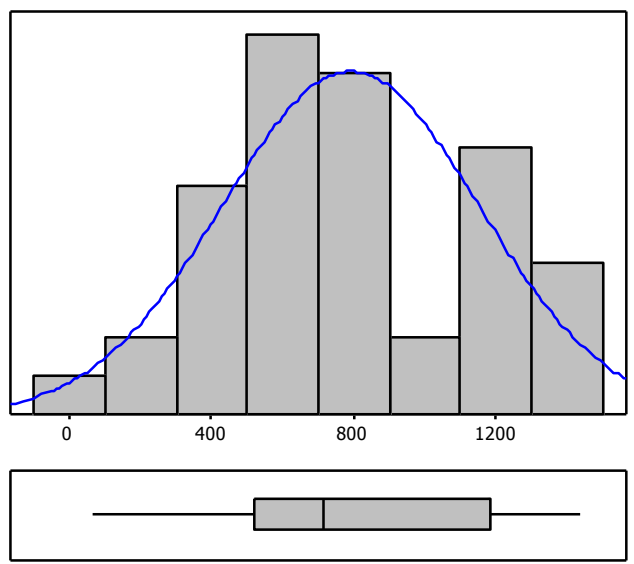

Intervalos de confianza de $95 \%$

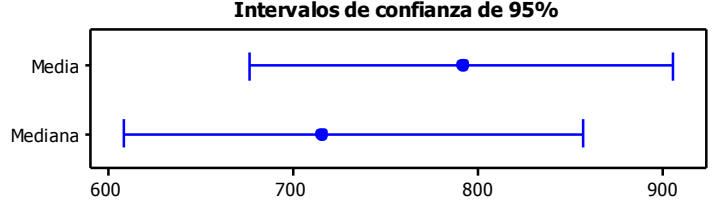

Prueba de normalidad de Anderson-Darling

A-cuadrado $\quad 0,81$

Valor $\mathrm{P} \quad 0,034$

Media $\quad 790,78$

Desv.Est. $\quad 362,58$

V arianza 131464,13

A simetría $\quad 0,303027$

Kurtosis $\quad-0,806229$

$\mathrm{N} \quad 41$

Mínimo $\quad 63,00$

1er cuartil $\quad 523,00$

Mediana $\quad 715,00$

3er cuartil $\quad 1185,00$

Máximo $\quad 1440,00$

Intervalo de confianza de $95 \%$ para la media

$$
\text { 676,34 905,22 }
$$

Intervalo de confianza de $95 \%$ para la mediana $608,19 \quad 856,88$

Intervalo de confianza de $95 \%$ para la desviación estándar 297,68 463,92

Figura 44: Distribución de la variable tiempo entre el momento 1 y momento 2.

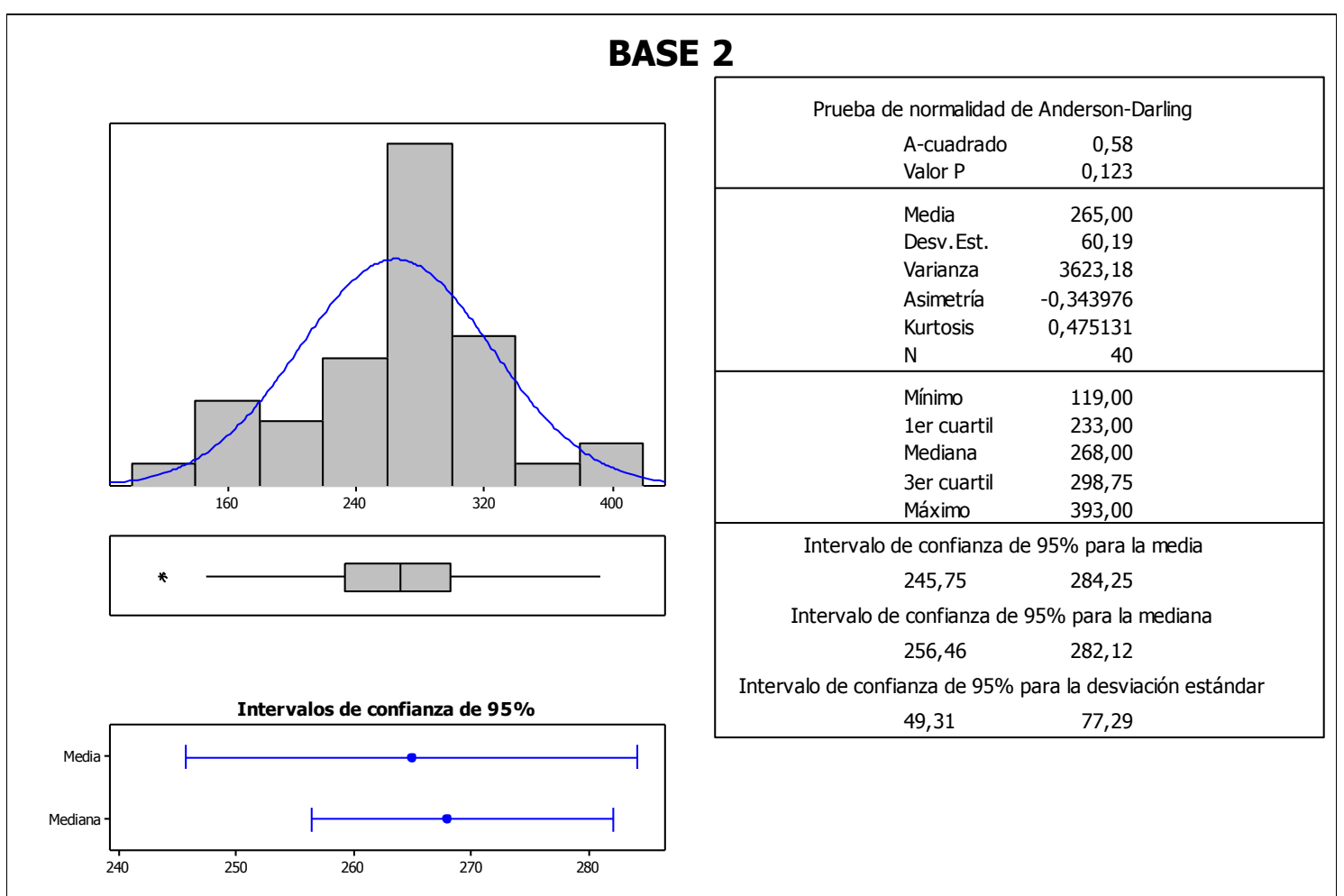

Figura 45: Resumen de la información estadística correspondiente a la variable BASE medida a las 8:00 del primer día después del ingreso. 


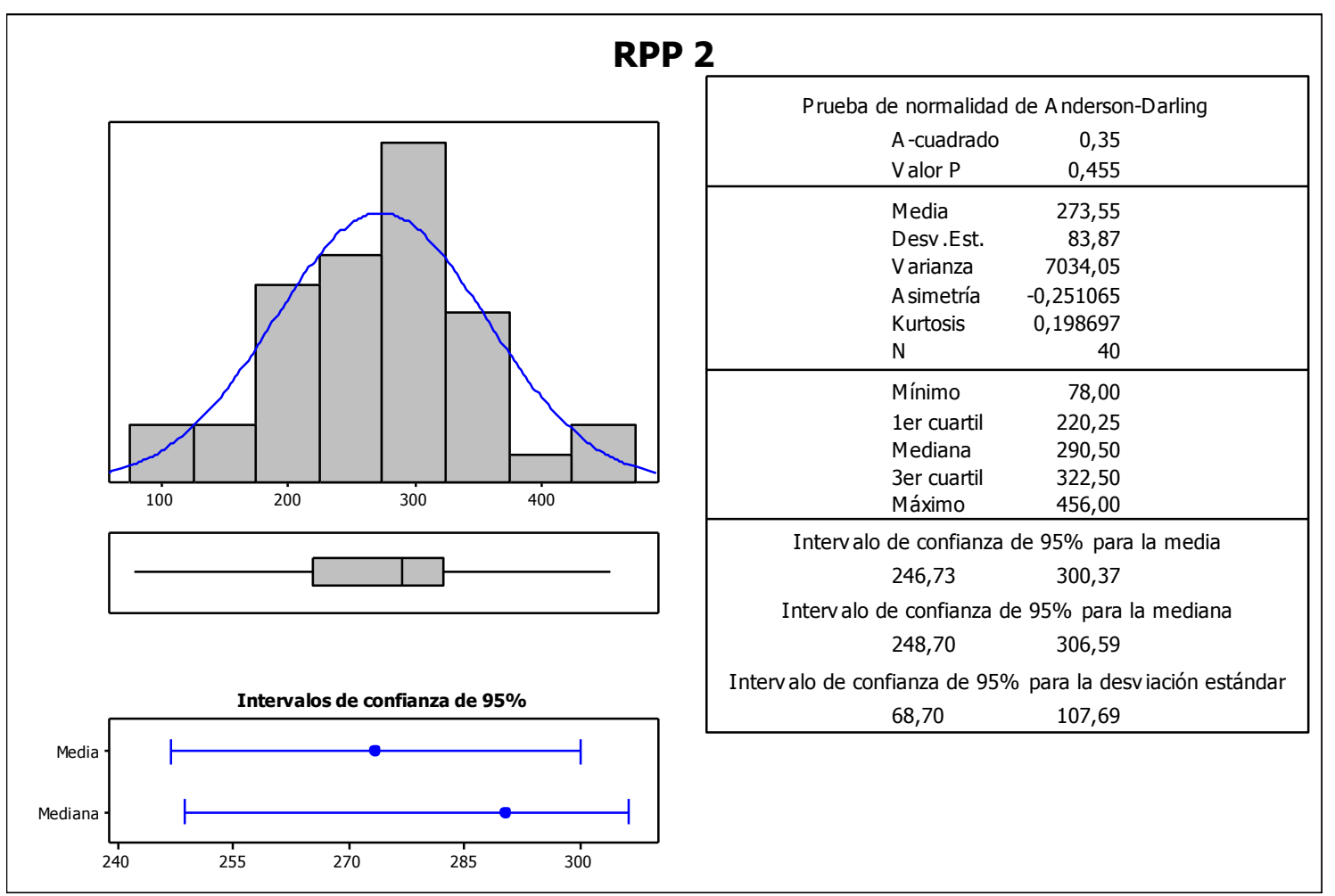

Figura 46: Resumen de la información estadística correspondiente a la variable RPP medida a las 8:00 del primer día tras el ingreso.

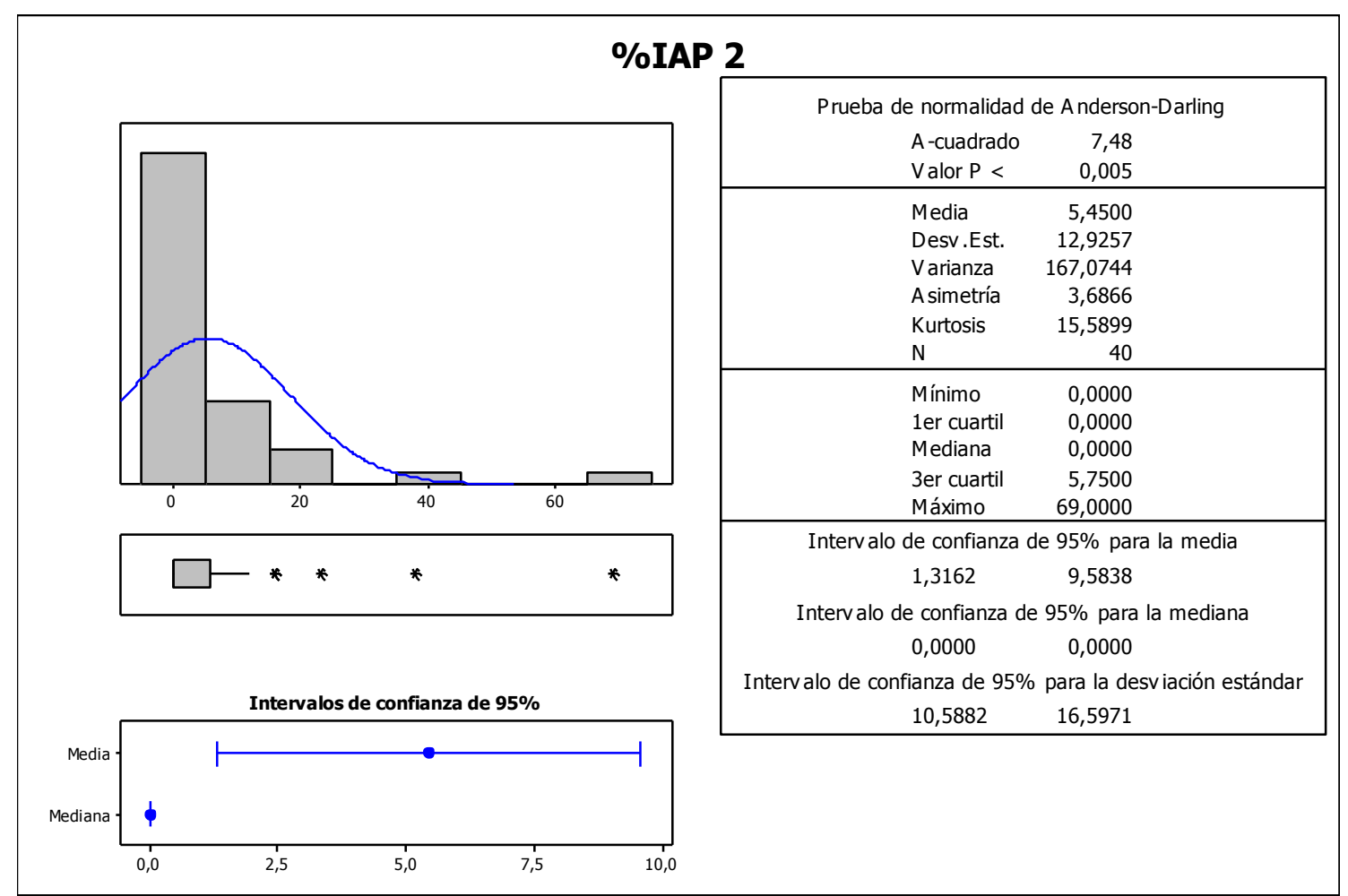

Figura 47: Resumen de la información estadística correspondiente a la variable \%IAP medida a las 8:00 horas del primer día tras el ingreso. 


\subsubsection{MOMENTO 3 (8:00 A.M. DEL SEGUNDO DÍA DESPUÉS DEL INGRESO)}

El momento 3 corresponde con las 8:00 horas del segundo día del ingreso, excepto en los casos en los que la coronariografía se realizara antes de este punto. Las Figuras 48, 49 y 50 muestran cómo los valores de BASE y RPP siguen mostrando distribuciones normales y cómo el \%IAP incrementa la dispersión de sus valores, alcanzando por primera vez valores de mediana superiores a 0 .

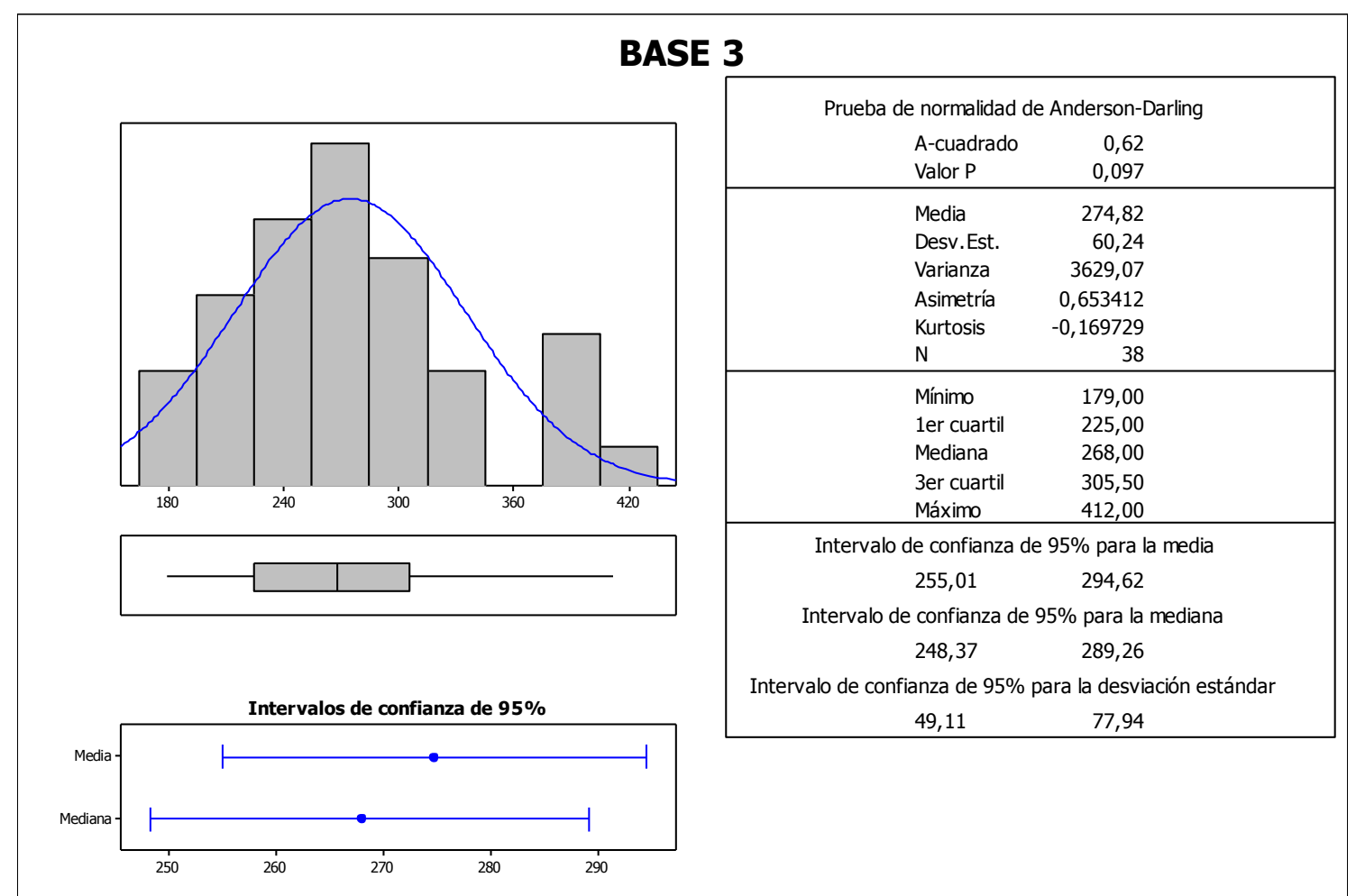

Figura 48: Resumen de la información estadística correspondiente a la variable BASE medida a las 8:00 del segundo día después del ingreso. 


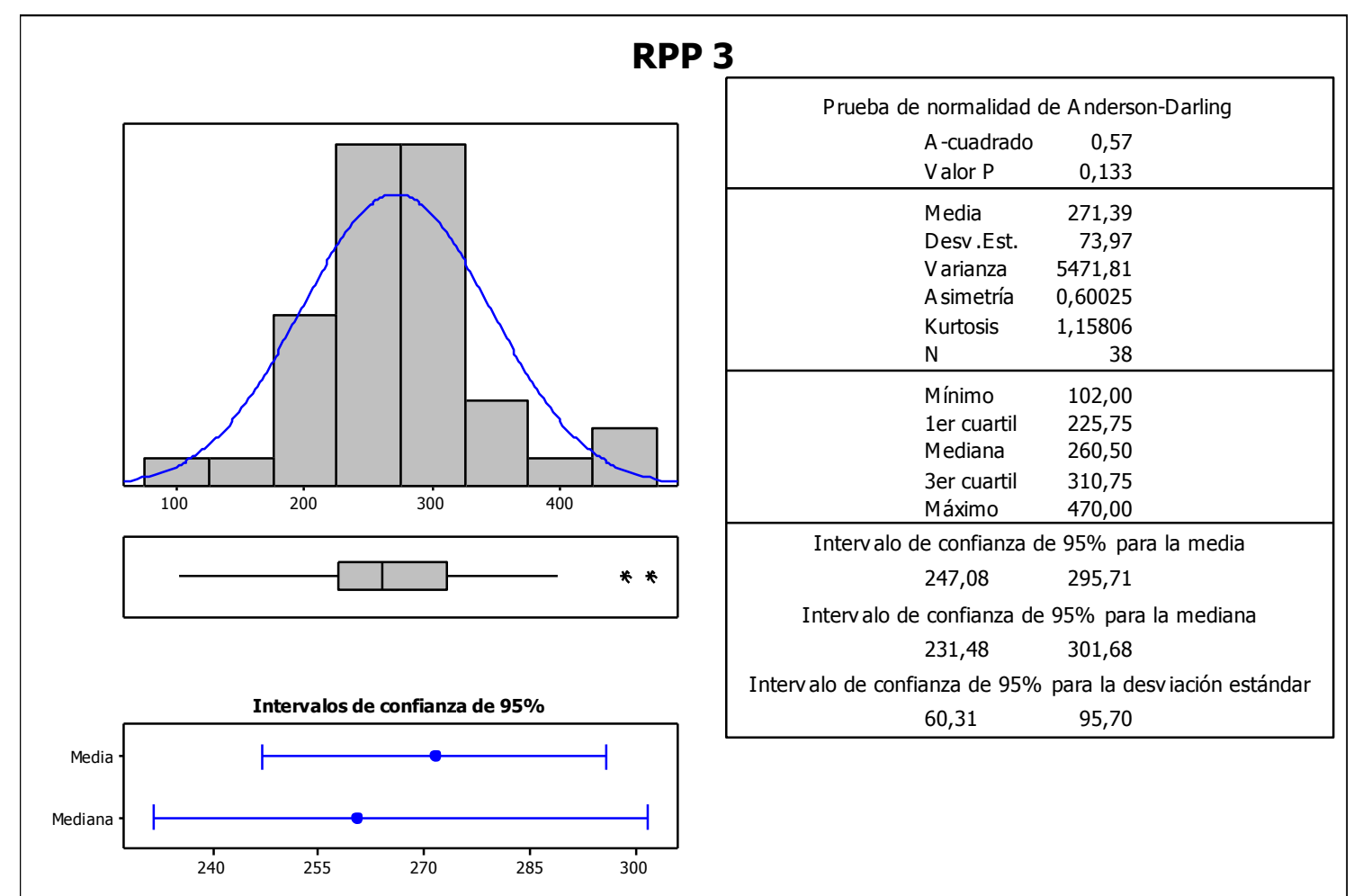

Figura 49: Resumen de la información estadística correspondiente a la variable RPP medida a las 8:00 del segundo día después del ingreso.

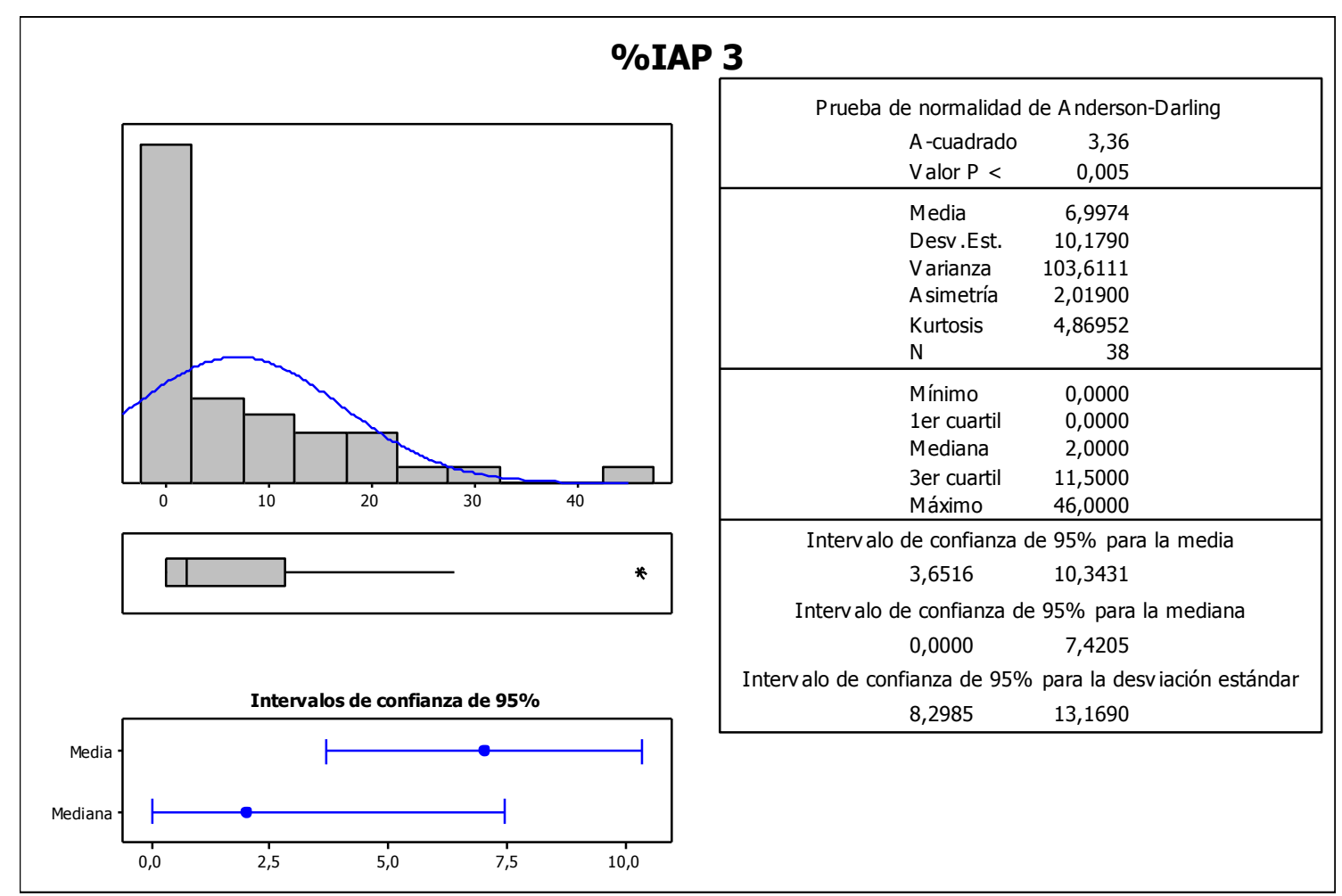

Figura 50: Resumen de la información estadística correspondiente a la variable \%IAP medida a las 8:00 del segundo día después del ingreso. 


\subsubsection{Momento 4 (coronariografía)}

De la misma forma que en los apartados previos se procede a describir la información correspondiente a las variables de función plaquetaria en el momento de la realización de la coronariografía. En este momento se aprecia un ligero descenso de los valores medios de RPP, manteniéndose la reactividad BASE en valores similares a los previos. Los valores de \%IAP comienzan a incrementar su dispersión a pesar de mantener valores todavía muy reducidos.

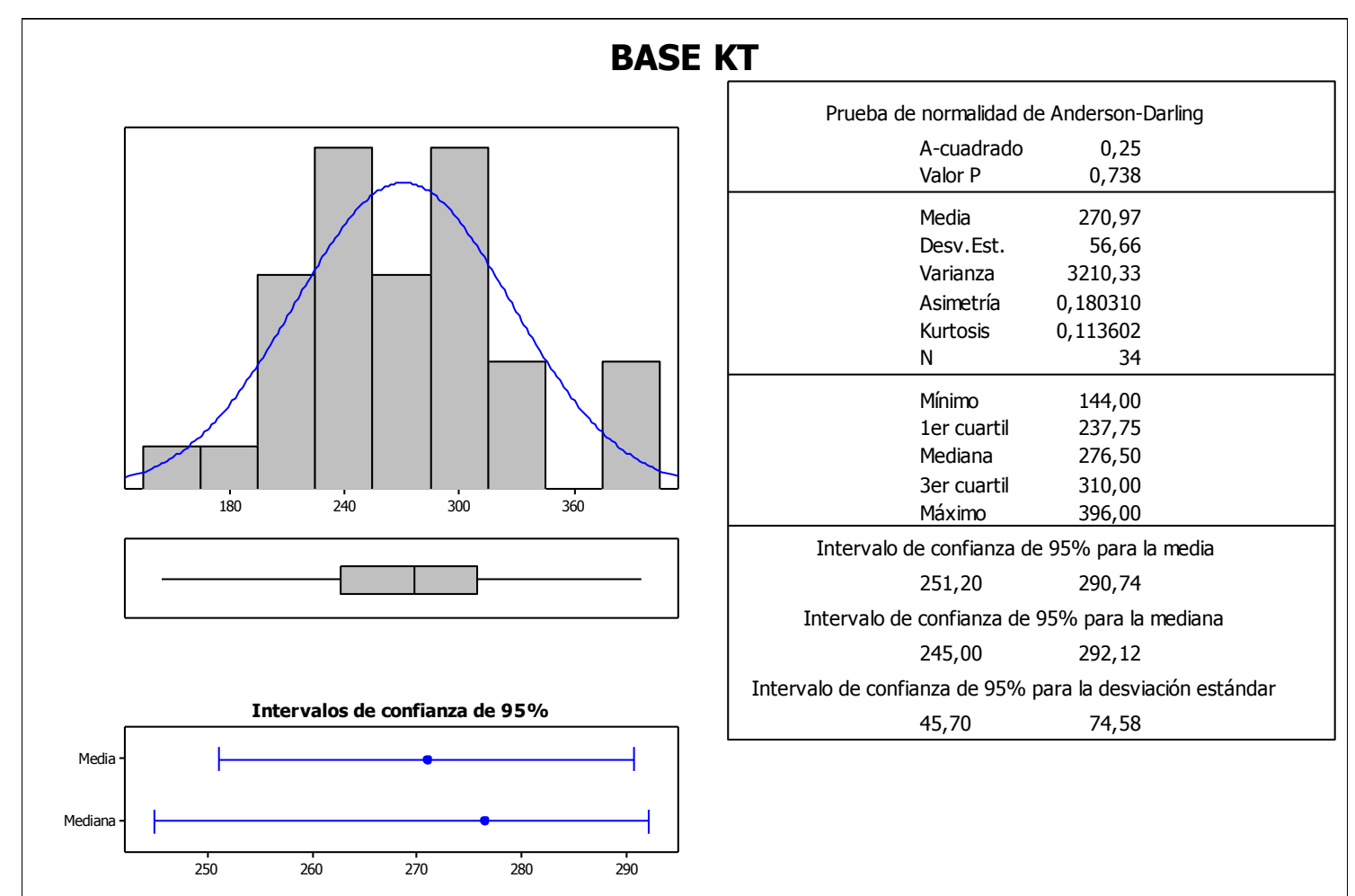

Figura 51: Resumen de la información estadística correspondiente a la variable BASE medida en el momento de la coronariografía. 


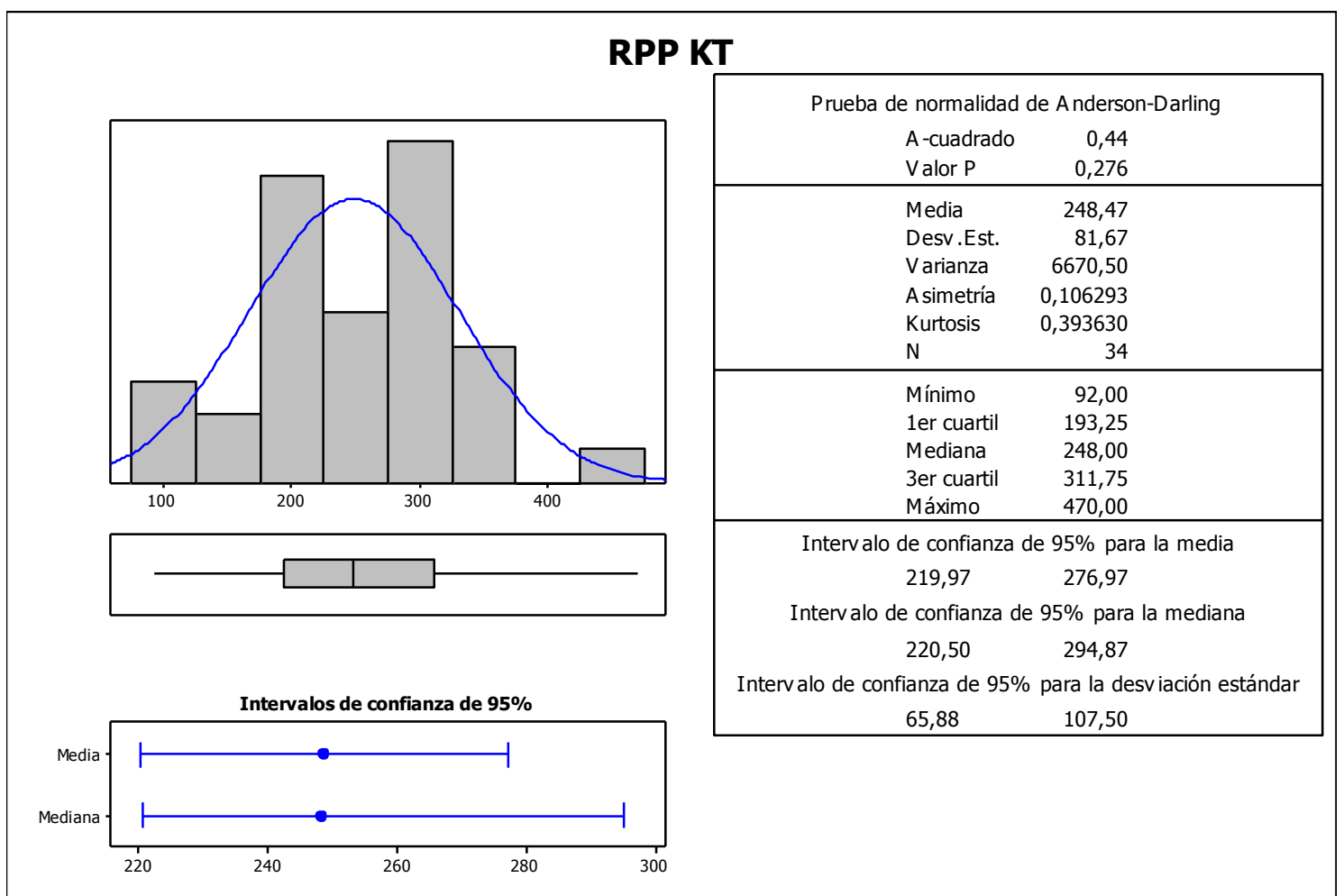

Figura 52: Resumen de la información estadística correspondiente a la variable RPP medida en el momento de la coronariografía.

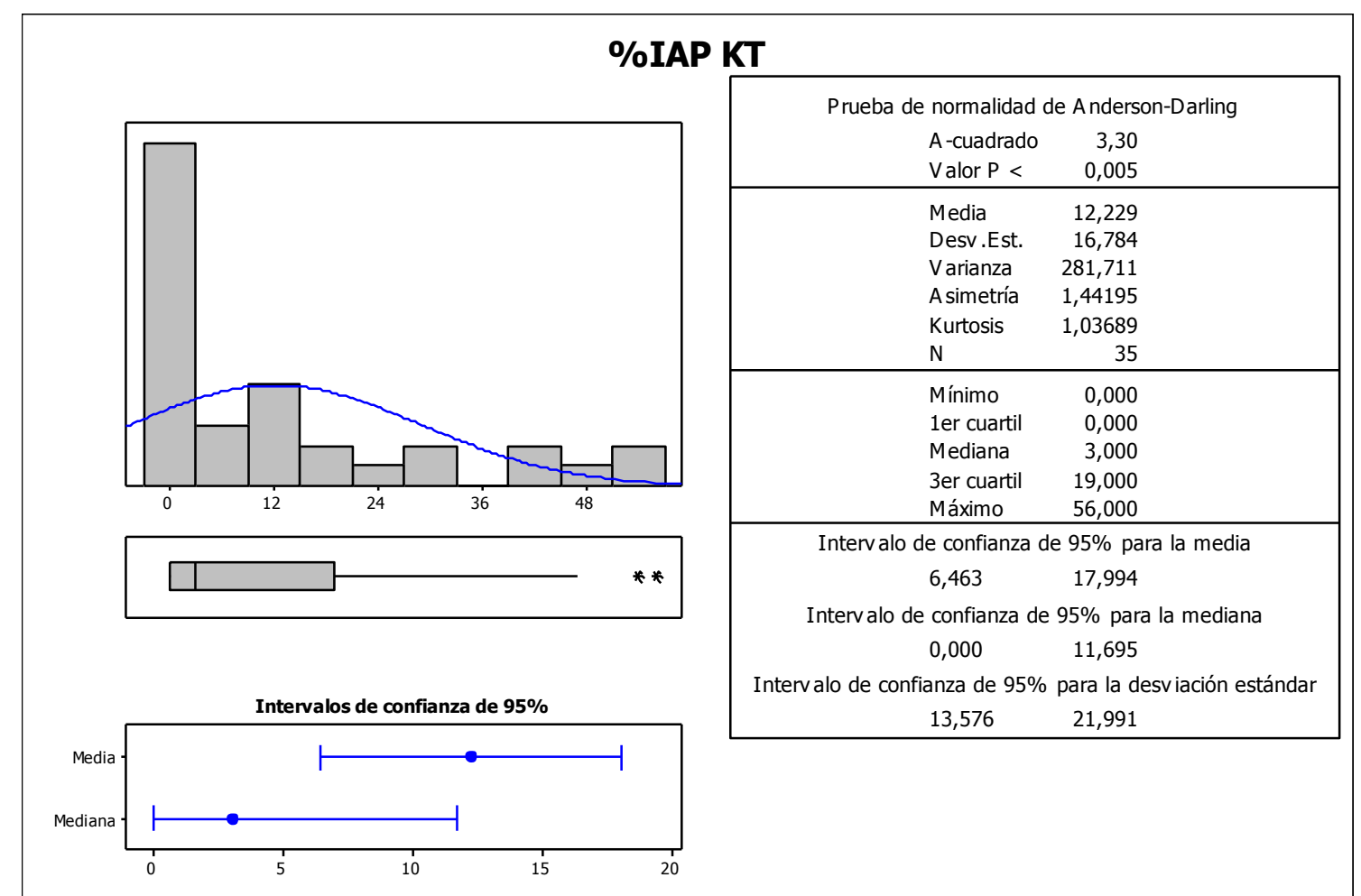

Figura 53: Resumen de la información estadística correspondiente a la variable \%IAP medida en el momento de la coronariografía. 


\subsubsection{RESUMEN, PUNTOS DE CORTE Y DISTRIBUCIÓN POR SEXOS:}

Teniendo en cuanta los puntos de corte de RPP con mejor poder para discriminar eventos clínicos durante el seguimiento, se presentan las gráficas de distribución de pacientes que quedarían incluidos como "no respondedores" según criterio analítico de RPP en función de los puntos de corte publicados de 175URP, 208URP y 235URP.

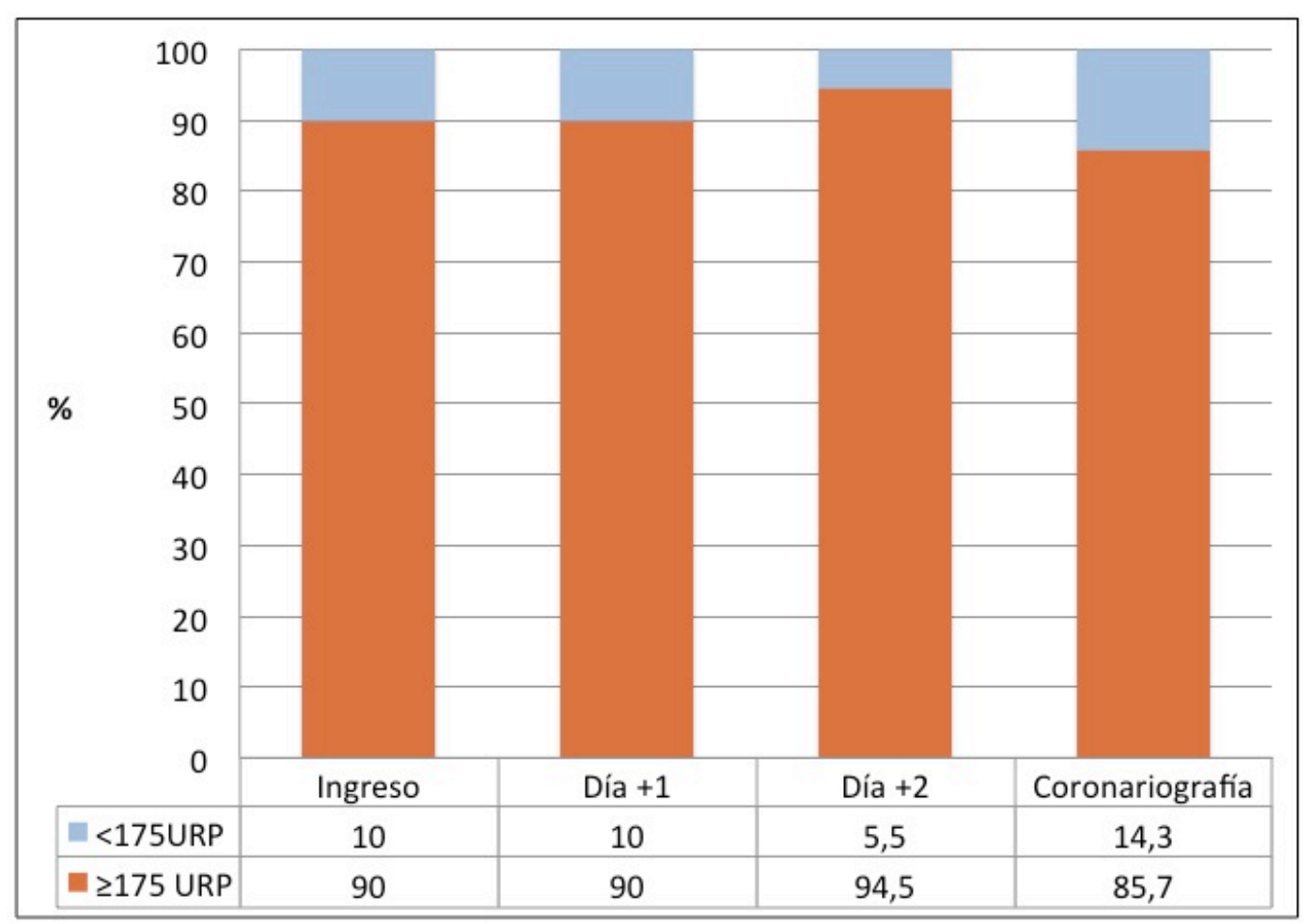

Figura 54: Porcentaje de pacientes de la muestra con reactividad plaquetaria postratamiento igual o superior al punto de corte de 175URP en los diferentes momentos de medición. 


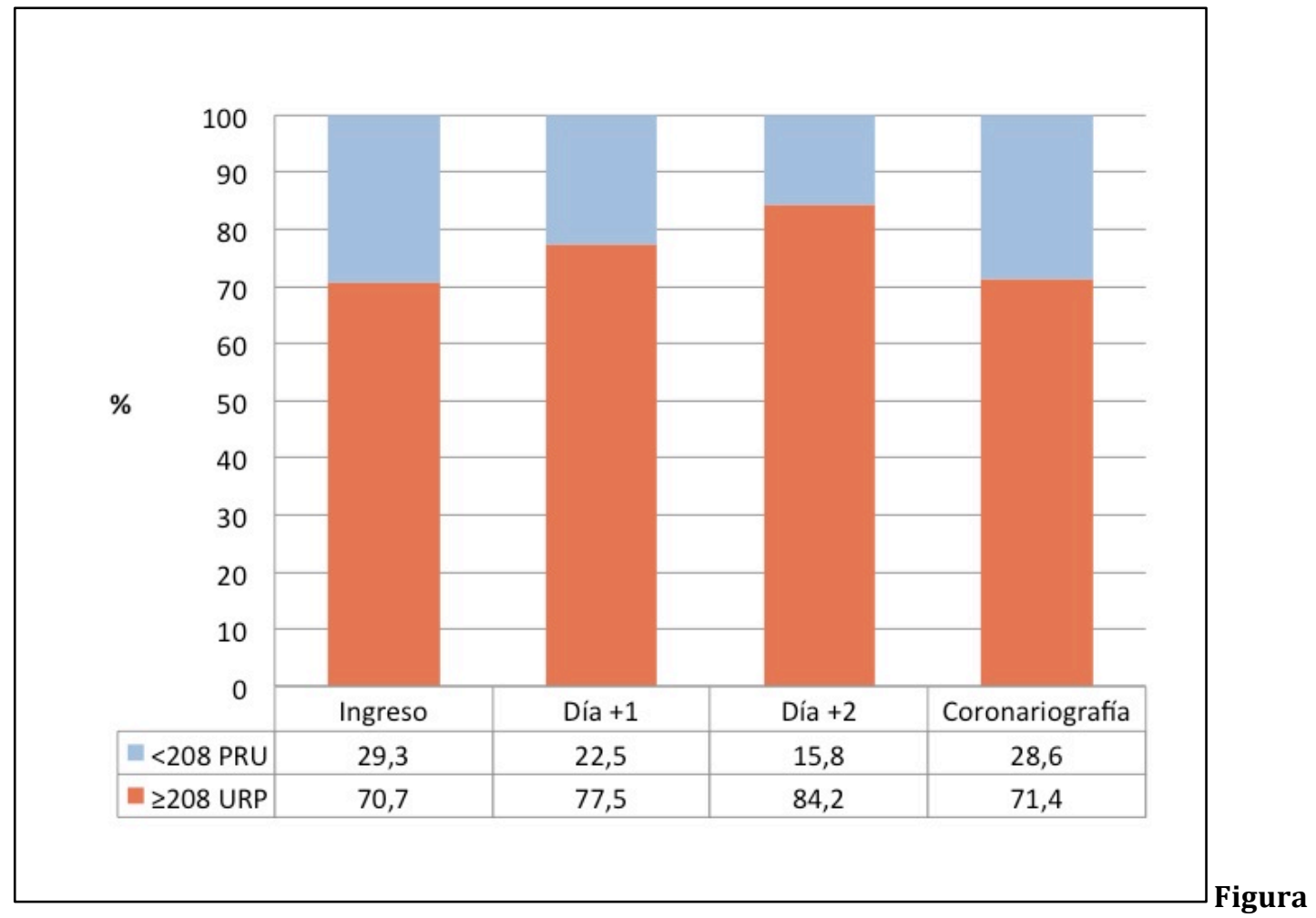

55: Porcentaje de pacientes de la muestra con reactividad plaquetaria postratamiento igual o superior al punto de corte de 208URP en los diferentes momentos de medición.

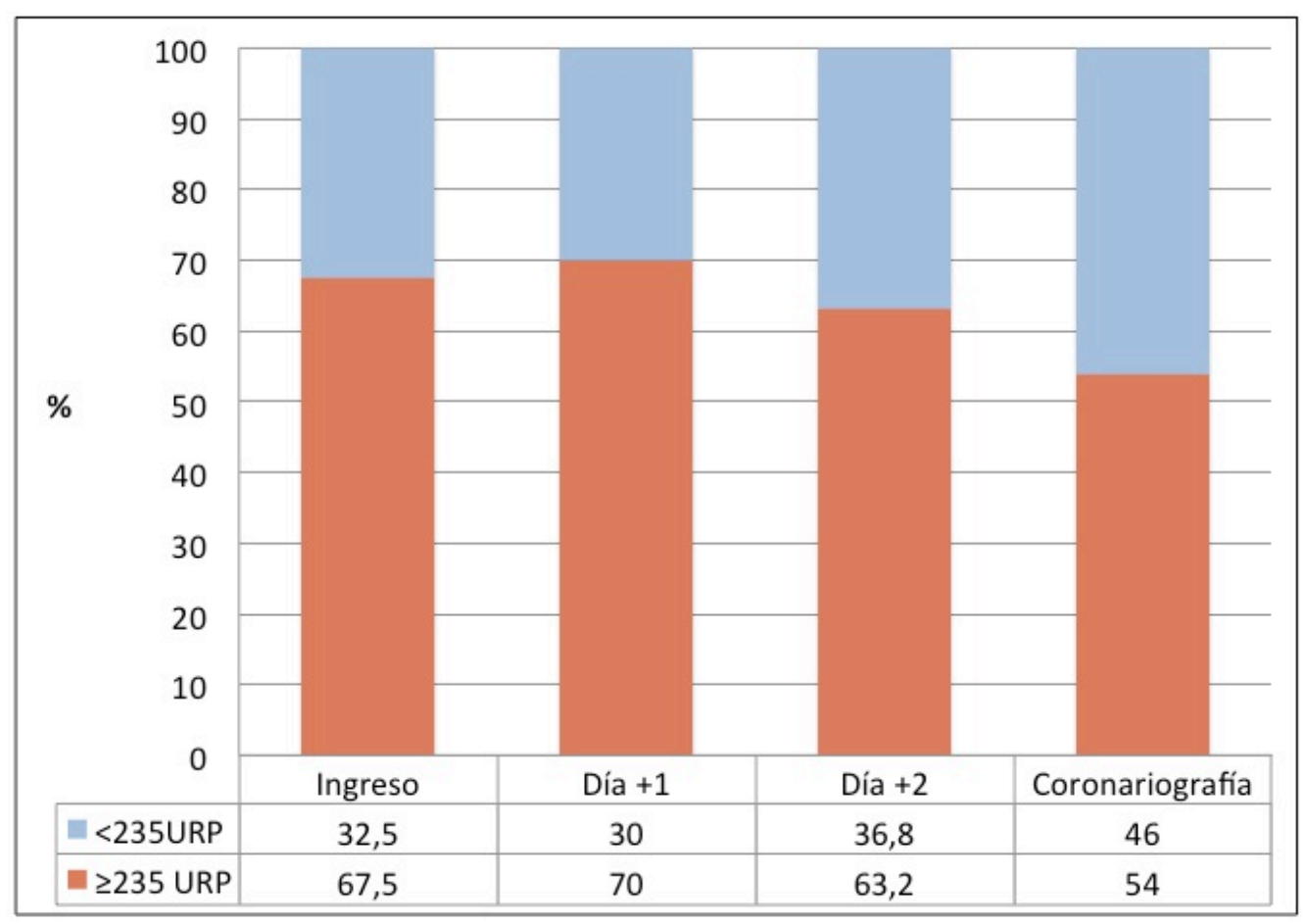

Figura 56: Porcentaje de pacientes de la muestra con reactividad plaquetaria postratamiento igual o superior al punto de corte de 235URP en los diferentes momentos de medición. 
Por último, en la Tabla 9, se muestran los valores de las tres variables de actividad plaquetaria distribuidos por sexos. Los valores de BASE y de RPP mostrados dentro del subgrupo de mujeres son superiores al mostrado entre el grupo de varones. A pesar de que no siempre se alcance diferencias significativas, este hallazgo resulta consistente a lo largo de las 4 determinaciones realizadas.

Tabla 9: Resumen de la evolución temporal de las variables de función plaquetaria.

\section{Actividad plaquetaria}

\begin{tabular}{lllll}
\hline Ingreso & TOTAL & Varones & Mujeres & $\mathrm{p}$ \\
BASE & $234 \pm 67$ & $225 \pm 58$ & $278 \pm 95$ & 0,059 \\
\hline RPP & $265 \pm 82$ & $260 \pm 81$ & $288 \pm 90$ & 0,4 \\
\hline \%IAP & $0(0-0)$ & $0(0-0)$ & $0(0-0)$ & 0,57 \\
Día +1 & & & & \\
BASE & $265 \pm 60$ & $258 \pm 60$ & $298 \pm 52$ & 0,11 \\
\hline RPP & $274 \pm 84$ & $263 \pm 83$ & $323 \pm 74$ & 0,08 \\
\hline \%IAP & $0(0-0)$ & $0(0-7)$ & $0(0-0)$ & 0,39 \\
Día +2 & & & & \\
BASE & $275 \pm 60$ & $263 \pm 52$ & $327 \pm 70$ & 0,009 \\
\hline RPP & $271 \pm 74$ & $261 \pm 69$ & $319 \pm 81$ & 0,055 \\
\hline \%IAP & $2(0-11,5)$ & $2(0-11)$ & $2(0-13)$ & 0,6 \\
Coronariografía & & & & \\
BASE & $271 \pm 57$ & $262 \pm 56$ & $304 \pm 52$ & 0,08 \\
\hline RPP & $249 \pm 82$ & $246 \pm 88$ & $260 \pm 55$ & 0,7 \\
\hline \%IAP & $3(0-19)$ & $2,5(0-12,7)$ & $15(2-27)$ & 0,6 \\
\hline
\end{tabular}

\subsection{CORONARIOGRAFÍA}

Todos los pacientes incluidos en el análisis final fueron enviados para la realización de coronariografía electiva tras fibrinolisis con criterios de reperfusión y siempre y cuando las dosis establecidas de clopidogrel hubieran sido administradas adecuadamente.

La mediana de tiempo entre el ingreso y la realización de la coronariografía fue de 3 días, con un rango intercuartil de 2 a 5 días.

Se presentan a continuación los datos diagnósticos anatómicos generales y la indicación de tipo de revascularización en función de los hallazgos anatómicos.

La mayoría de los pacientes presentaron enfermedad de uno o dos vasos (Figura 57), y se eligió tratamiento de revascularización mediante ICP electiva. Dos pacientes fueron derivados a cirugía de revascularización coronaria por enfermedad de tres vasos y mala función ventricular y en 3 casos no se realizó revascularización por ausencia de estenosis angiográficamente significativas. 


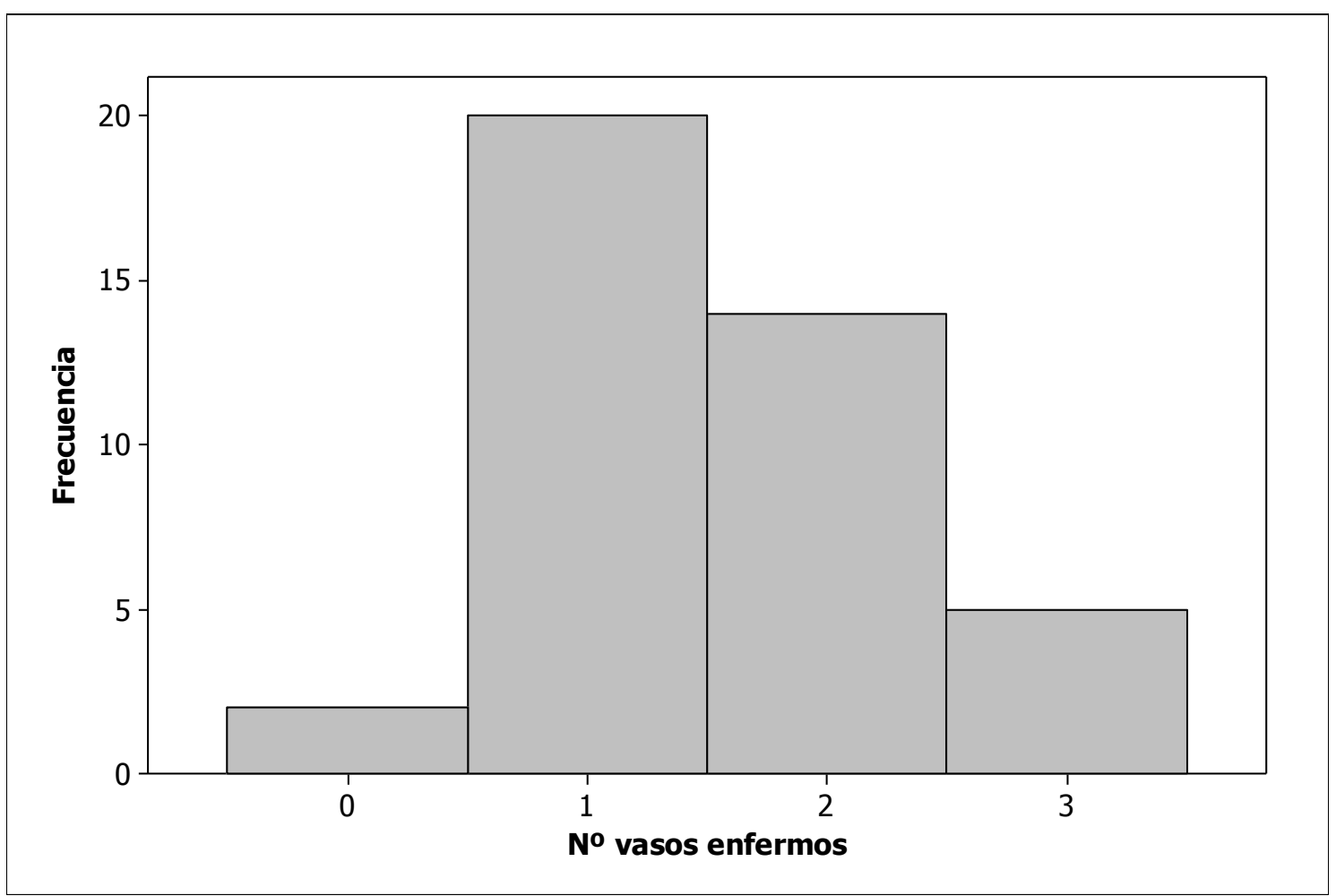

Figura 57: Distribución del número de vasos enfermos encontrados durante la coronariografía entre los pacientes de la muestra.

Tabla 10: tipo de intervención efectuada en función de los hallazgos anatómicos.

\begin{tabular}{rc}
\hline Intervención efectuada & \\
\hline Cirugía cardiaca & $2(4,88 \%)$ \\
Angioplastia electiva & $36(87,80 \%)$ \\
Tto médico & $3(7,32 \%)$ \\
Total & $\mathbf{4 1 ( 1 0 0 \% )}$ \\
\hline
\end{tabular}

Tabla 11: Localización de la lesión responsable.

\section{Localización de la lesión}

responsable

$\begin{array}{rc}\text { CD } & 25(60,97 \%) \\ \text { CX } & 4(9,76 \%) \\ \text { DA } & 11(26,83 \%) \\ \text { no disponible* } & 1(2,44 \%) \\ \text { Total } & \mathbf{4 1 ( 1 0 0 \% )}\end{array}$

*Paciente con IAMCEST sin estenosis angiográficamente significativas en ninguna de las tres arterias coronarias. 
Tabla 12: características del flujo según la clasificación TIMI en la arteria responsable del infarto.

\begin{tabular}{rcc}
\hline Flujo TIMI & & \\
\hline & TIMI 0 & $1(2,44 \%)$ \\
TIMI 1 & $1(2,44 \%)$ \\
TIMI 2 & $12(29,27 \%)$ \\
TIMI 3 & $26(63,41 \%)$ \\
ND & $1(2,44 \%)$ \\
Total & $\mathbf{4 1 ( 1 0 0 \% )}$ \\
\hline
\end{tabular}

\subsection{INTERVENCIONISMO CORONARIO PERCUTÁNEO}

\subsubsection{LESIÓN, PROCEDIMIENTO Y STENT}

En la tabla 13 se exponen los datos más importantes correspondientes a los casos en los que se realizó ICP de forma electiva. La información hace referencia a datos sobre la lesión responsable, sobre el stent utilizado, sobre la técnica de implante y sobre otras datos asociados al intervencionismo como son la cantidad de contraste utilizado o la utilización o no de abciximab como antiplaquetario adyuvante durante el procedimiento.

El tamaño de referencia del vaso responsable fue de $3 \mathrm{~mm}$, y el diámetro luminal mínimo fue de $0,8 \mathrm{~mm}$. De los 36 procedimientos se logró un éxito del mismo en el $100 \%$ de los casos a pesar de que en uno de los casos no se pudo implantar stent por la presencia de una arteria aneurismática de $>10 \mathrm{~mm}$ de diámetro (se realizó sólo angioplastia con balón). En los restantes 35 casos se consiguió cubrir la lesión responsable con un solo stent en 32 y 3 casos requirieron dos stents, con una media de 1,1 stent por paciente. Al analizar los datos en función del sexo sólo se encontraron diferencias significativas en cuanto al volumen de contraste utilizado, que fue significativamente menor entre las mujeres.

Tabla 13: Resumen de datos correspondientes al ICP.

\begin{tabular}{lllll} 
& TOTAL & Varones & Mujeres & $\mathrm{p}$ \\
\hline Diámetro referencia (mm) & $3,04(2,6-3,6)$ & $3,1(2,6-3,6)$ & $2,8(2,4-3,5)$ & 0,48 \\
DLM (mm) & $0,84 \pm 0,44$ & $0,86 \pm 0,08$ & $0,77 \pm 0,17$ & 0,65 \\
Diámetro stent (mm) & $3(3,0-3,5)$ & $3(3,0-3,8)$ & $3,6(2,9-3,6)$ & 0,75 \\
Longitud stent (mm) & $18(16-28)$ & $18(16-28)$ & $18(16,5-33)$ & 0,62 \\
Stent directo & $21(60 \%)$ & $18(62 \%)$ & $3(50 \%)$ & 0,66 \\
Sobredilatación & $13(37 \%)$ & $11(38 \%)$ & $2(33 \%)$ & 0,74 \\
Presión máxima (atms) & $16(14-18,5)$ & $16(14-20)$ & $14(12,5-16)$ & 0,08 \\
Stent farmacoactivo & $8(23 \%)$ & $7(24 \%)$ & $1(17 \%)$ & 0,81 \\
Contraste (c.c.) & $253 \pm 88$ & $271 \pm 14$ & $175 \pm 30$ & 0,007 \\
Éxito ICP & $36(100 \%)$ & $30(100 \%)$ & $6(100 \%)$ & - \\
Diámetro ref. POST (mm) & $3,1(2,7-3,8)$ & $3,2(2,7-4)$ & $3,04(2,7-3,8)$ & 0,65 \\
DLM POST (mm) & $3,07 \pm 0,8$ & $3,06 \pm 0,9$ & $3,1 \pm 0,6$ & 0,91 \\
Uso abciximab & $25(69 \%)$ & $20(67 \%)$ & $5(83 \%)$ & 0,39 \\
\hline
\end{tabular}




\subsubsection{USO DE ABCIXIMAB Y ACTIVIDAD DEL RECEPTOR IIB/IIIA DURANTE EL ICP}

Además de la utilización o no de este fármaco, detallada en la tabla anterior, en este apartado se detallan los valores de actividad plaquetaria dependiente del receptor IIb/IIIa determinada mediante kits específicos del sistema VerifyNowIIb/IIIa, en el caso de que este fármaco se utilizara. Los valores de esta variable se expresan en unidades de reactividad plaquetaria (por sus siglas en inglés Platelet Reaction Units, PAU), pre y pos- administración del tratamiento, así como la respuesta a este fármaco expresada como la relación entre ambos valores previos obtenida mediante la fórmula:

$\%$ abciximab $=\left(1-\frac{P A U \text { abciximab }}{P A U \text { basal }}\right) \cdot 100$

La interpretación de esta fórmula es directa, dado que lo que representa es el porcentaje de plaquetas que el abciximab es capaz de inhibir de una manera efectiva tras su administración intravenosa.

Es importante no confundir la actividad plaquetaria basal del receptor IIb/IIIa con la RPP basal, ya que, a pesar de ser determinadas ambas con el VerifyNow, tanto los receptores como los agonistas utilizados son diferentes y los valores brutos difieren sensiblemente.

Como puede verse en las Figuras 58, 59 y 60, la potencia inhibidora del abciximab a los diez minutos de su infusión es muy superior a la lograda con las dosis administradas de clopidogrel, consiguiendo valores de porcentaje de inhibición del receptor diana muy próximos al 100\%. 


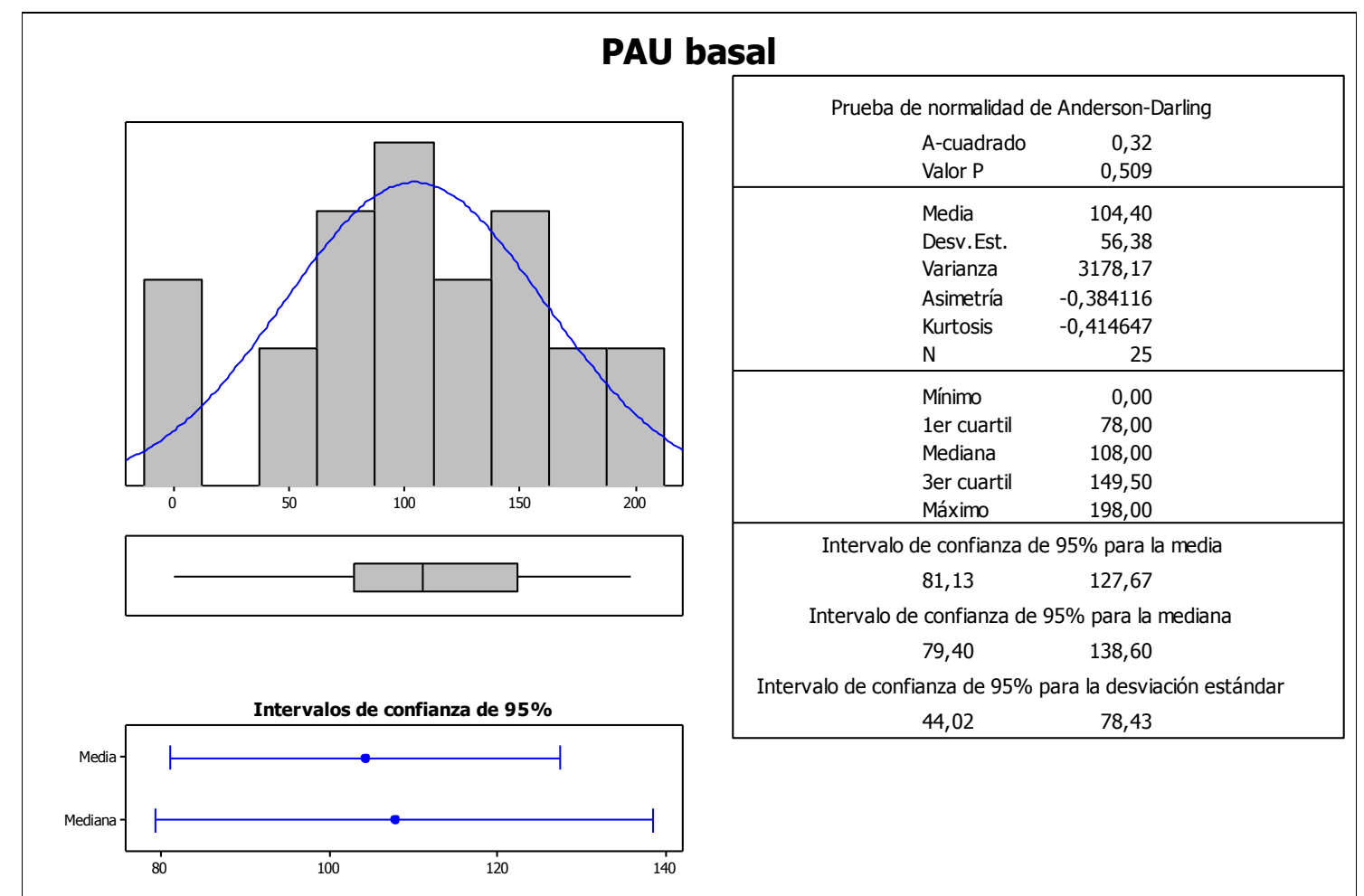

Figura 58: Resumen de la información estadística correspondiente a la variable PAU basal (agregación plaquetaria dependiente del receptor IIb/IIIa previa a la administración de abciximab).

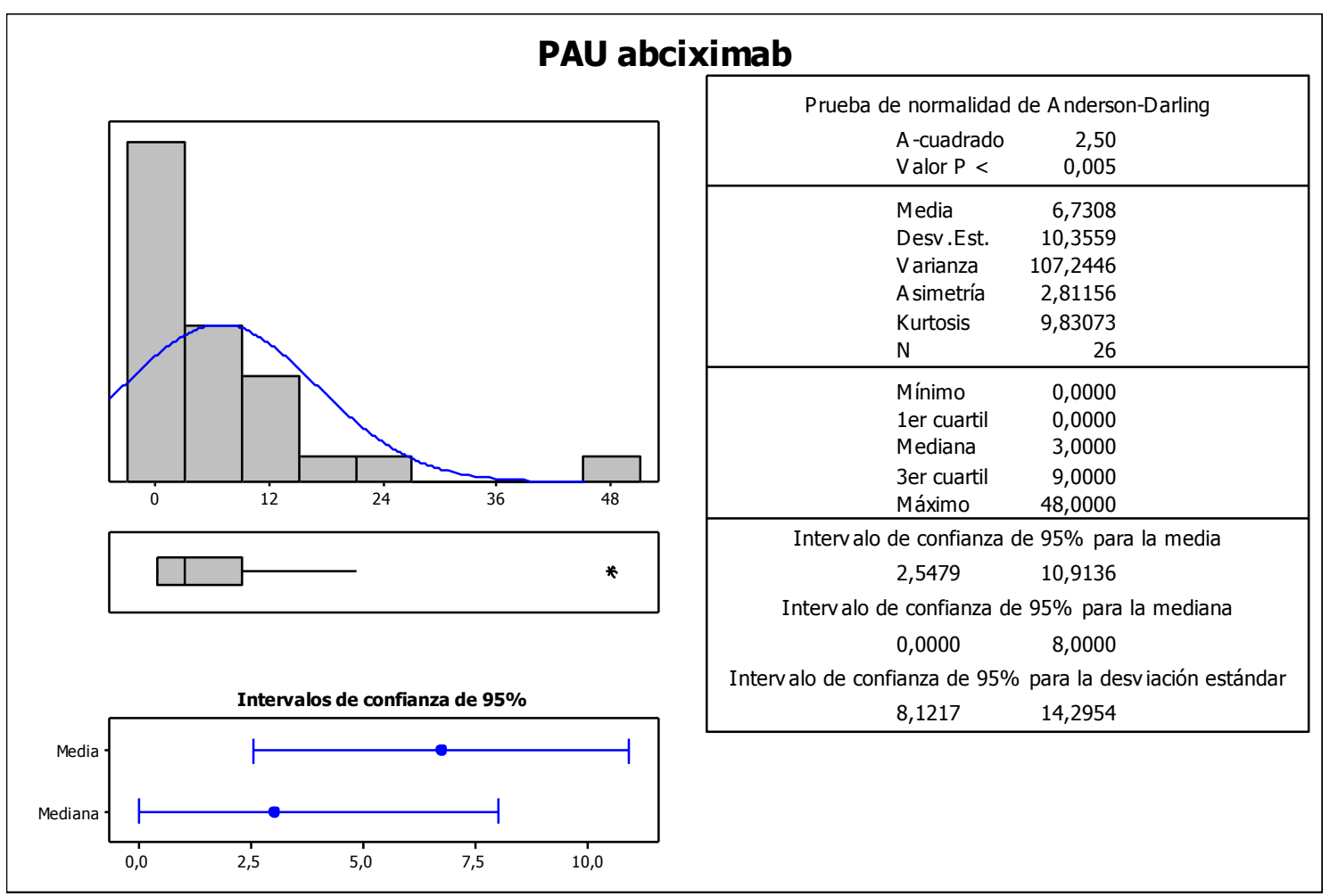

Figura 59: Resumen de la información estadística correspondiente a la variable PAU Reopro (reactividad plaquetaria dependiente del receptor IIb/IIIa tras la administración de abciximab). 


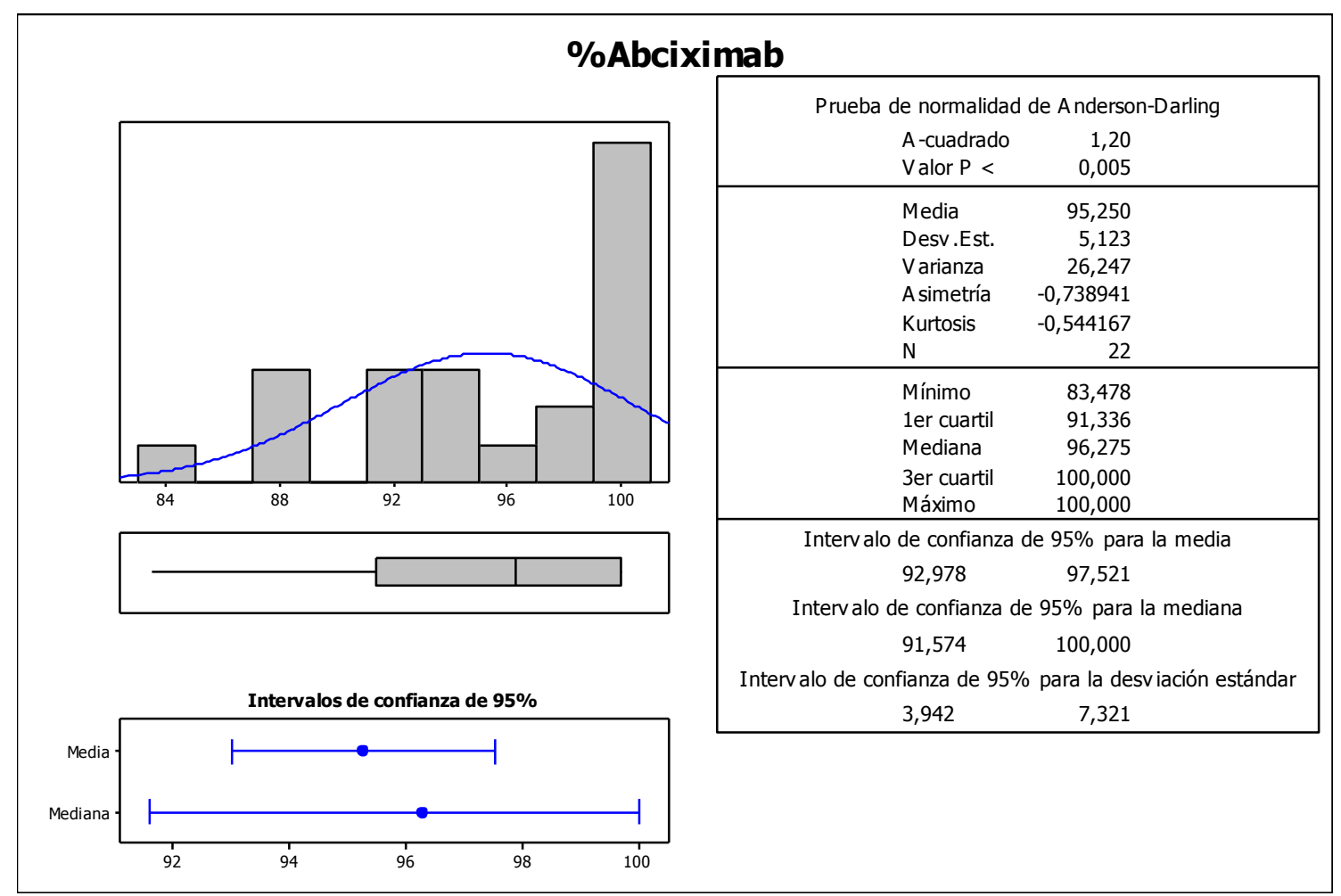

Figura 60: Resumen de la información estadística correspondiente a la variable \%REOPRO (respuesta al abciximab) entre los pacientes sometidos a ICP en los que se utilizó este fármaco como terapia antiplaquetaria adyuvante.

\subsection{EVOLUCIÓN CLÍNICA INTRAHOSPITALARIA}

Dentro de la categoría de variables relacionadas con la evolución intrahospitalaria posterior al ingreso, se ha optado por dividir la información disponible en las siguientes categorías: recurrencia isquémica, nefropatía inducida por contraste, daño cardíaco pos intervención y complicaciones hemorrágicas, por ser las complicaciones más frecuentes tras el tratamiento fibrinolítico y el ICP.

\subsubsection{RECURRENCIA ISQUÉMICA}

La recurrencia isquémica se definió como la reaparición de los síntomas, acompañada o no de manifestaciones electrocardiográficas, después de haberse logrado los criterios de reperfusión. Esta complicación sucedió en dos de los casos y se controló mediante la administración de nitratos y betabloqueantes intravenosos, pero motivó la realización del ICP de forma precoz, aunque no urgente (no angioplastia de rescate). 


\subsubsection{NEFROPATÍA INDUCIDA POR CONTRASTE}

El daño renal producido por la utilización de contraste es una de las complicaciones más frecuentes de los estudios hemodinámicos, y mucho más frecuente dentro de los procedimientos invasivos, ya que su freciuencia es directamente proporcional a la cantidad de contraste necesaria para completar la intervención. Se presentó sólo un caso de nefropatía inducida por contraste (definida en Anexo II) y en el que se alcanzó un valor máximo de Cr de 3,6 mg/dl y fue manejado médicamente sin necesidad de diálisis y con recuperación completa al alta hospitalaria. Entre la población total del estudio no se encontraron diferencias significativas entre los valores de creatinina antes y después de la coronariografía/ICP $(\mathrm{p}=0,46)$. La distribución de los valores pre y post- ICP se presentan en la Figura 61.

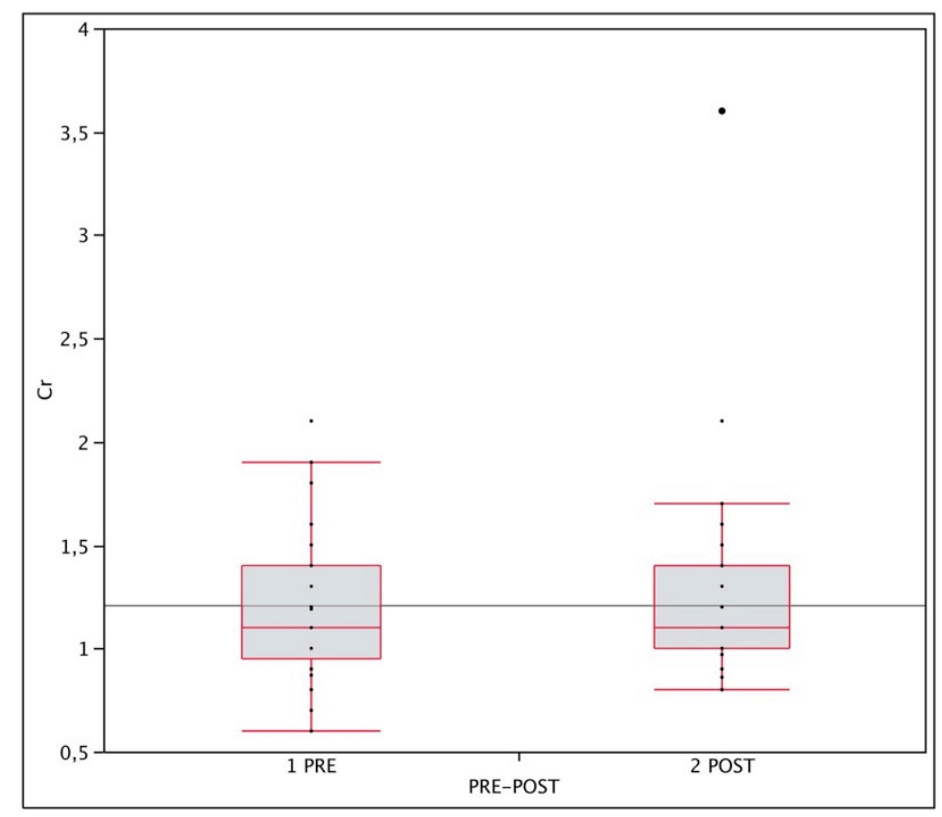

Figura 61: Distribución de los valores de creatinina plasmática antes y después de la realización de la coronariografía \pm ICP.

\subsubsection{DAÑO MIOCÁRDICO POSTERIOR A LA INTERVENCIÓN}

Para determinar el daño inducido por el ICP electivo en los pacientes que acaban de sufrir un IAMCEST no pueden utilizarse los valores normales de referencia que proporciona cada laboratorio, ya que el daño ocasiona por el propio infarto eleva los valores muy por encima de sus cifras habituales y de forma persistente durante varios días. Para evaluar entonces el daño miocárdico dependiente exclusivamente de la intervención es necesario aportar los valores de enzimas cardiacas inmediatamente antes del ICP y cuantificar posteriormente el incremento sobre éstos. Así, se utilizaron como medidas para orientar sobre el sufrimiento miocárdico secundario al ICP los valores de Troponina T y de CK-MB determinados la mañana del procedimiento. 
Los valores de referencia que se obtuvieron para estudiar el daño miocárdico tras ICP mostraron distribuciones no normales con valores de mediana de 35 (14$70) \mathrm{mg} / \mathrm{dl}$ para la CK-MB y de $3,5(1,4-17,6)$ para la troponina $\mathrm{T}$.

El pico máximo de daño tras la intervención se recogió a las 12 horas tras ICP. Las Figiuras 62-65 muestran los valores de ambas enzimas a las 6 y a las $12 \mathrm{~h}$

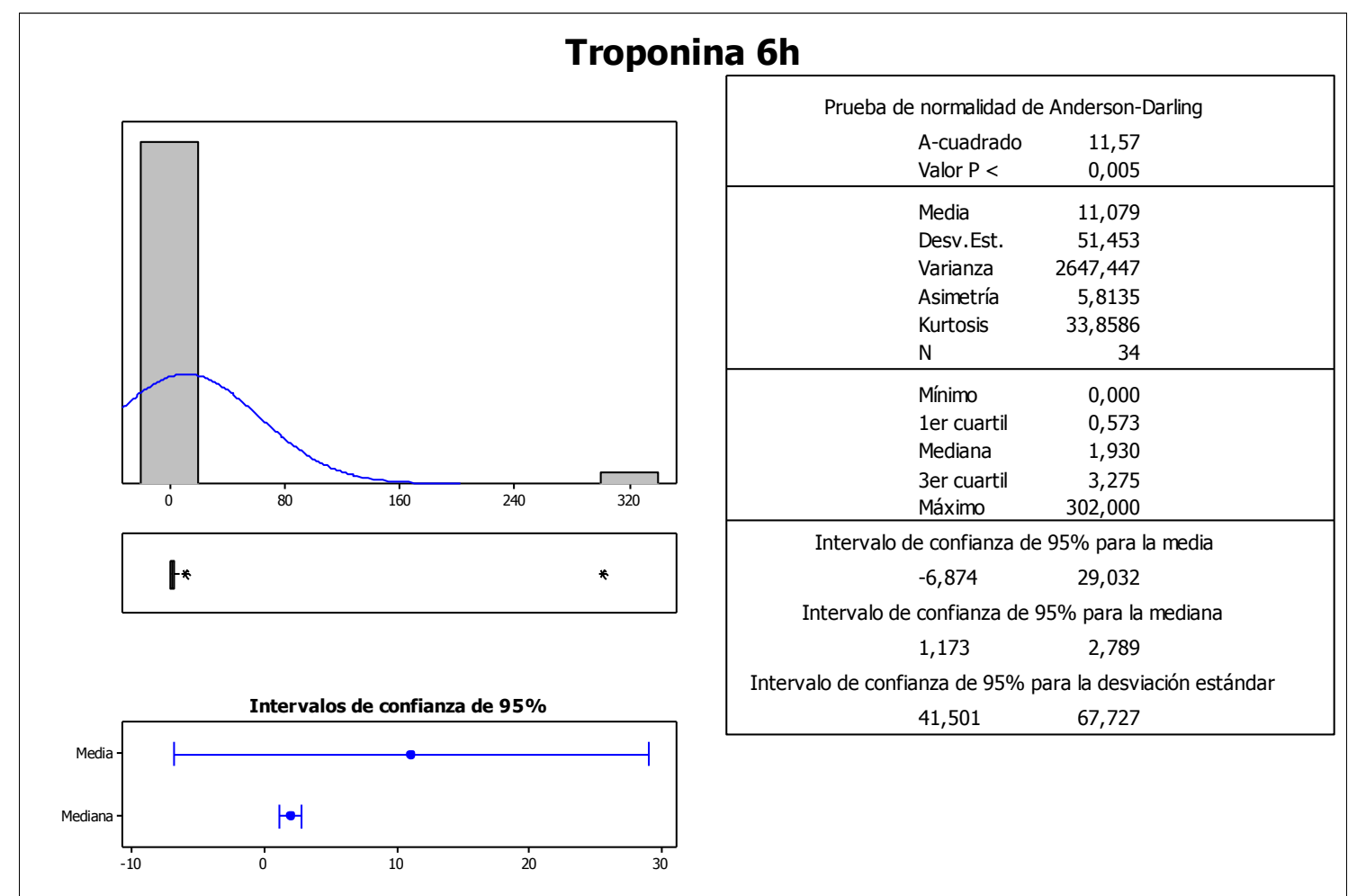

Figura 62: Valor de la enzima troponina T a las seis horas del ICP. 


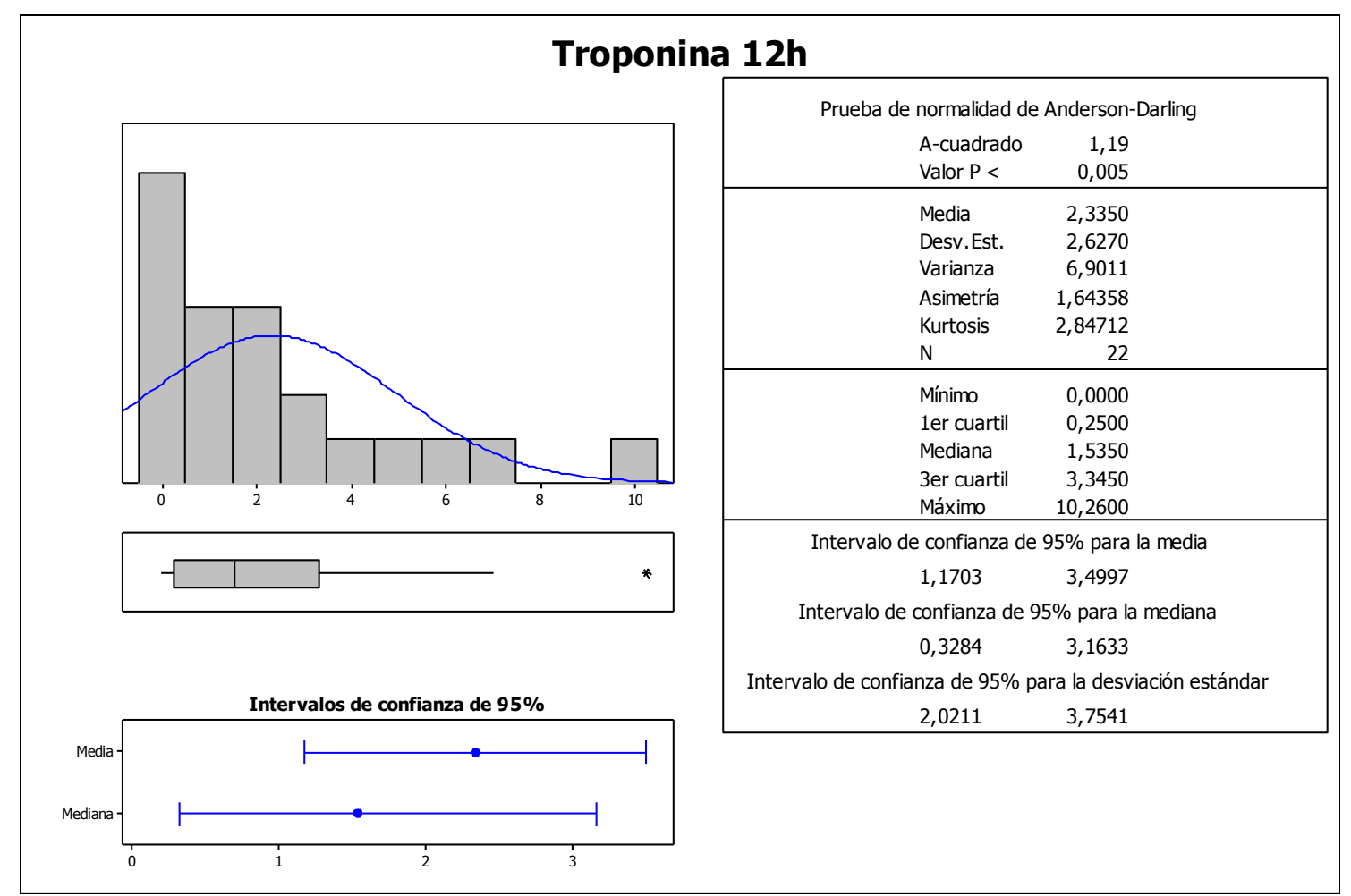

Figura 63: Valor de los niveles de la enzima troponina T a las 12 horas tras el ICP.

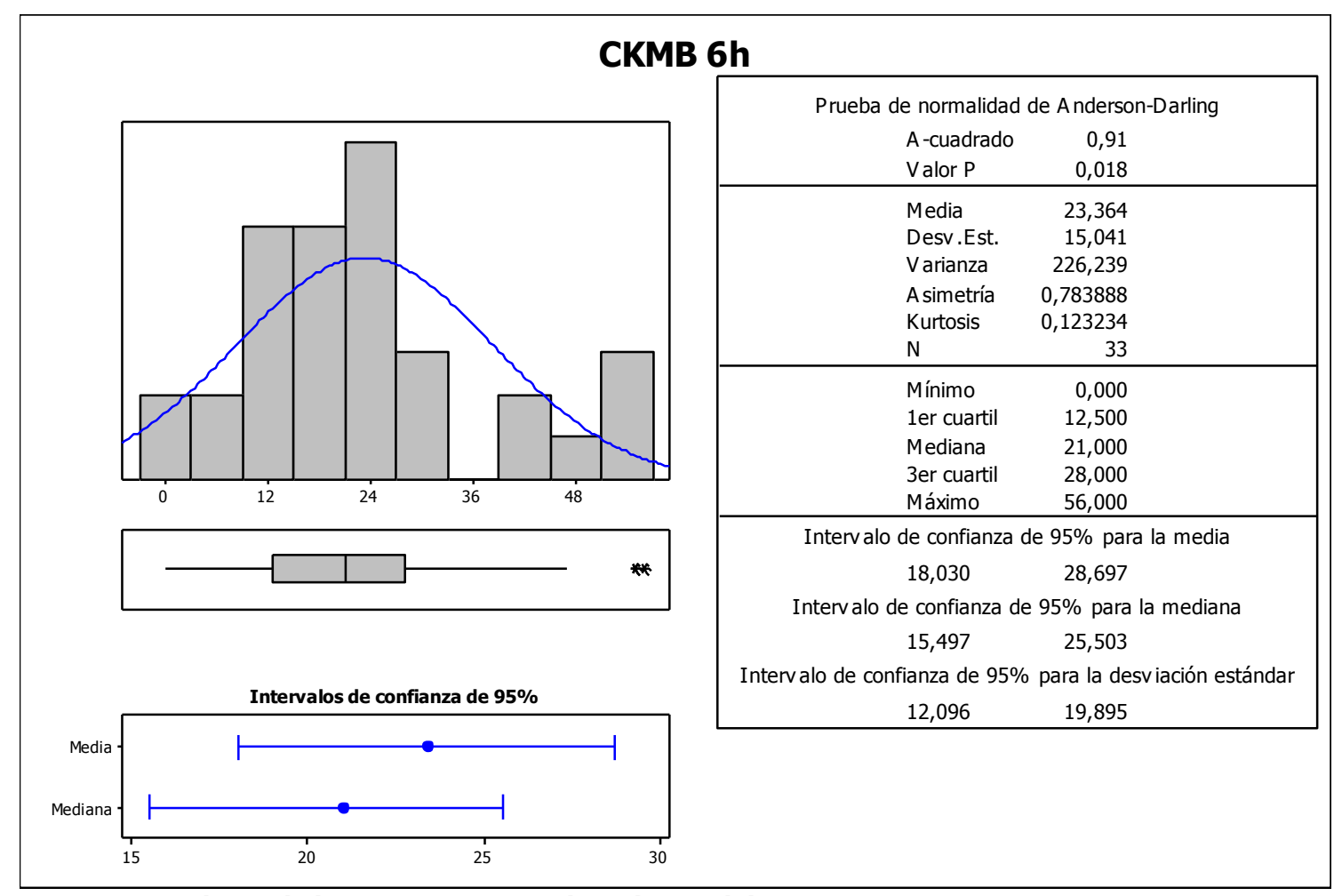

Figura 64: Valores de la enzima CK-MB a las 6 horas del ICP. 


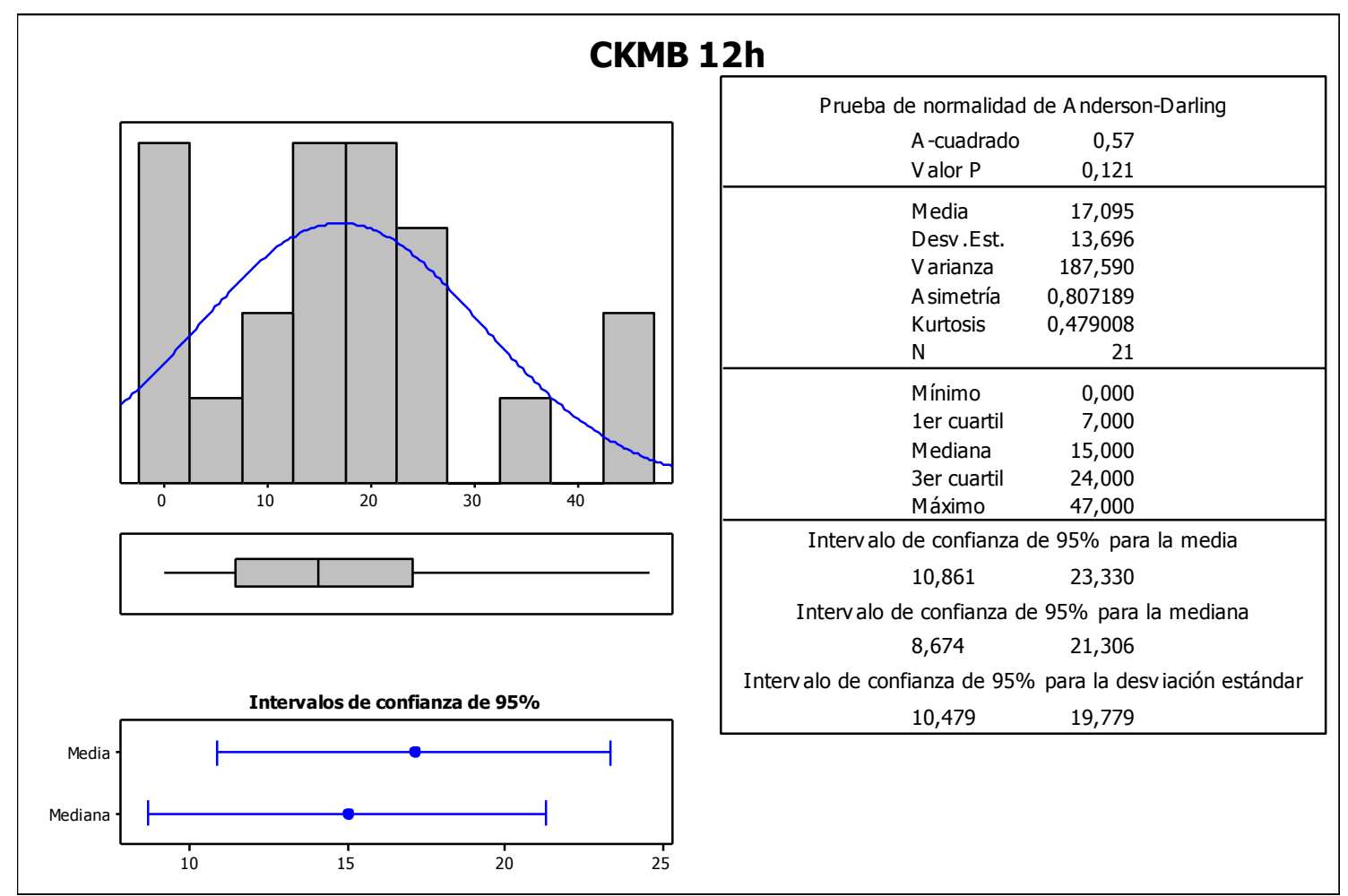

Figura 65: Valores de la enzima CK-MB a las 12 horas del ICP.

\subsubsection{COMPLICACIONES HEMORRÁGICAS}

Durante la fase intrahospitalaria y después de completar los criterios de inclusión ene le estudio se presentaron dos hemorragias mayores según los criterios TIMI, un hematoma en la zona de punción de la arteria femoral tras el ICP y un síndrome de Mallory-Weiss (hemorragia digestiva alta secundaria a laceración de la mucosa esofágica). Ambos eventos requirieron trasfusión de hemoderivados y ninguno de ellos resultó letal.

\subsection{SEGUIMIENTO CLÍNICO AL ALTA}

En el siguiente apartado se presenta la información estadística sobre el seguimiento clínico de los pacientes. Se definieron como eventos cardiovasculares adversos durante el seguimiento la muerte de cualquier causa, infarto de miocardio, accidente cerebrovascular o necesidad de nueva revascularización. La mediana de tiempo de seguimiento tras el alta hospitalaria fue de 347 días (Figura 66), durante este tiempo se registraron 3 eventos (MACE por sus siglas en inglés, major adverse cardiovascular event), los tres entre la población de varones de la muestra. En la Figura 67 se representa la curva de supervivencia de la muestra. 


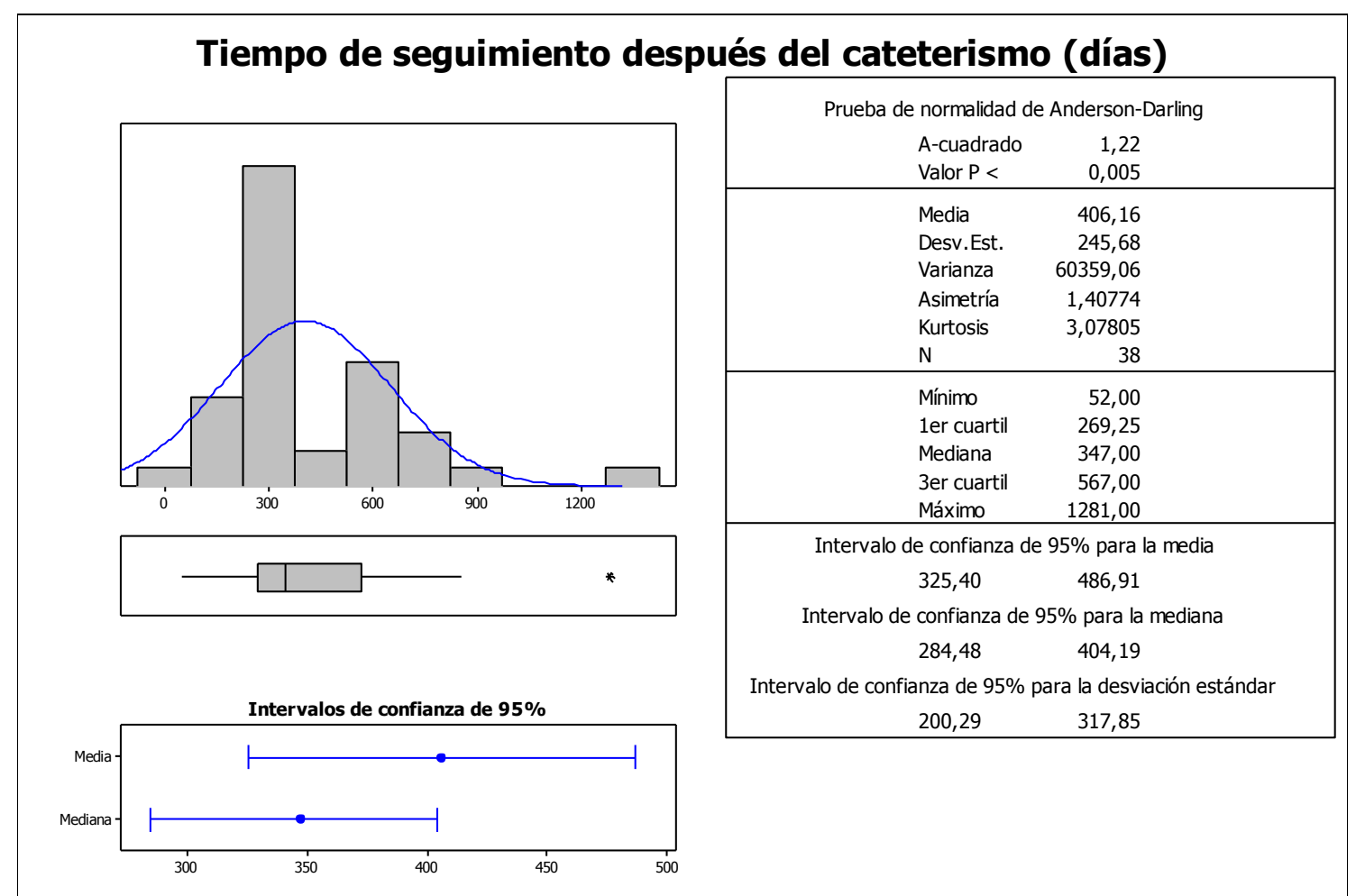

Figura 66: Tiempo de seguimiento tras la realización de la coronariografía.

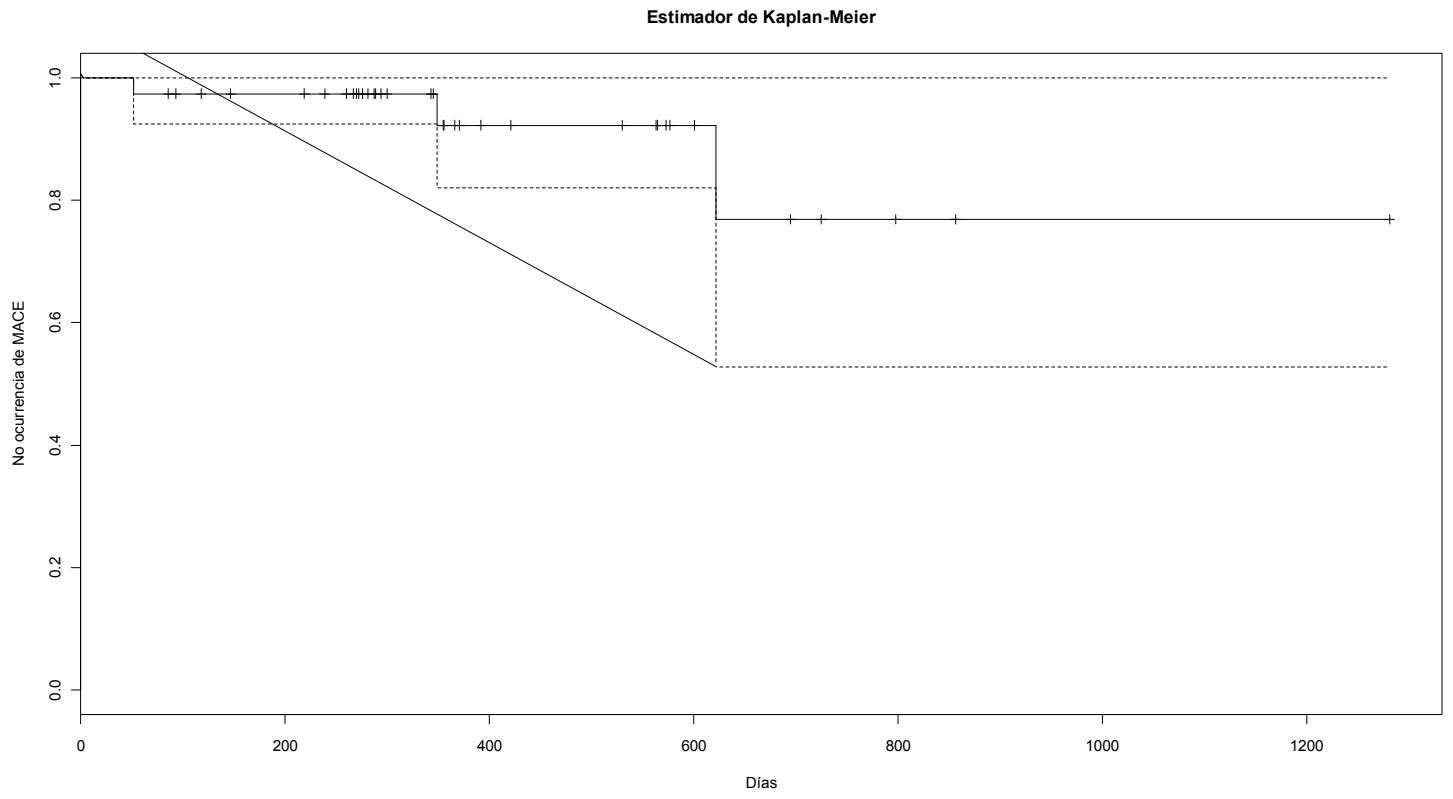

Figura 67: Curvas Kaplan-Meier de no ocurrencia de MACE con representación de su intervalo de confianza al 95\%. 


\section{ESTADÍSTICA INFERENCIAL UNIVARIANTE}

\subsection{INFORMACIÓN DE LOS PACIENTES PREVIA AL INGRESO}

La comparación entre grupos de las características basales, variables y comunes y factores de riesgo cardiovascular de lo pacientes de la muestra, se presentaron el capítulo sobre estadística descriptiva, en la Tabla 6, para implementar la comprensión de ese apartado.

Los resultados obtenidos en la comparación univariante permiten afirmar que no existen diferencias estadísticamente significativas entre la edad o los factores de riesgo cardiovascular entre las poblaciones de hombres y mujeres de la muestra. Sí se encontraron diferencias, como era esperable, en el peso y la talla, mayores ambas en la población de hombres.

Las tablas de los diferentes test estadísticos realizados se presentan en el anexo informático de datos suplementarios.

\subsection{INFORMACIÓN CORRESPONDIENTE AL MOMENTO DEL INGRESO}

En la Figura 68 se representa un gráfico que muestra la relación existente entre el tiempo que transcurre entre el comienzo del dolor y la llegada del paciente a urgencias en función de su edad. En dicho gráfico se han separado los pacientes hombre de las mujeres. La recta de regresión que se ha obtenido para los dos conjuntos de datos muestra que para los pacientes varones a mayor edad, menor es el tiempo transcurrido entre el comienzo del dolor y la llegada del paciente a urgencias, mientras que para el caso de las mujeres parece ocurrir lo contrario. Así, a la vista de estos resultados, parece que la frase "a mayor edad mayor demora" se verifica solo para las mujeres. Sin embargo, dado que el coeficiente de correlación entre las variables tiempo de dolor y edad es para el conjunto de todos los pacientes es muy bajo (inferior a 0,2 ), los datos del presente trabajo no permiten refrendar la afirmación anterior para el conjunto de pacientes formado por hombres y mujeres. En el caso del subconjunto de pacientes mujeres el coeficiente de correlación entre ambas variables se eleva hasta 0,458 valor que sigue siendo considerado como insuficiente para afirmar la existencia de una relación lineal importante entre ambas variables. 


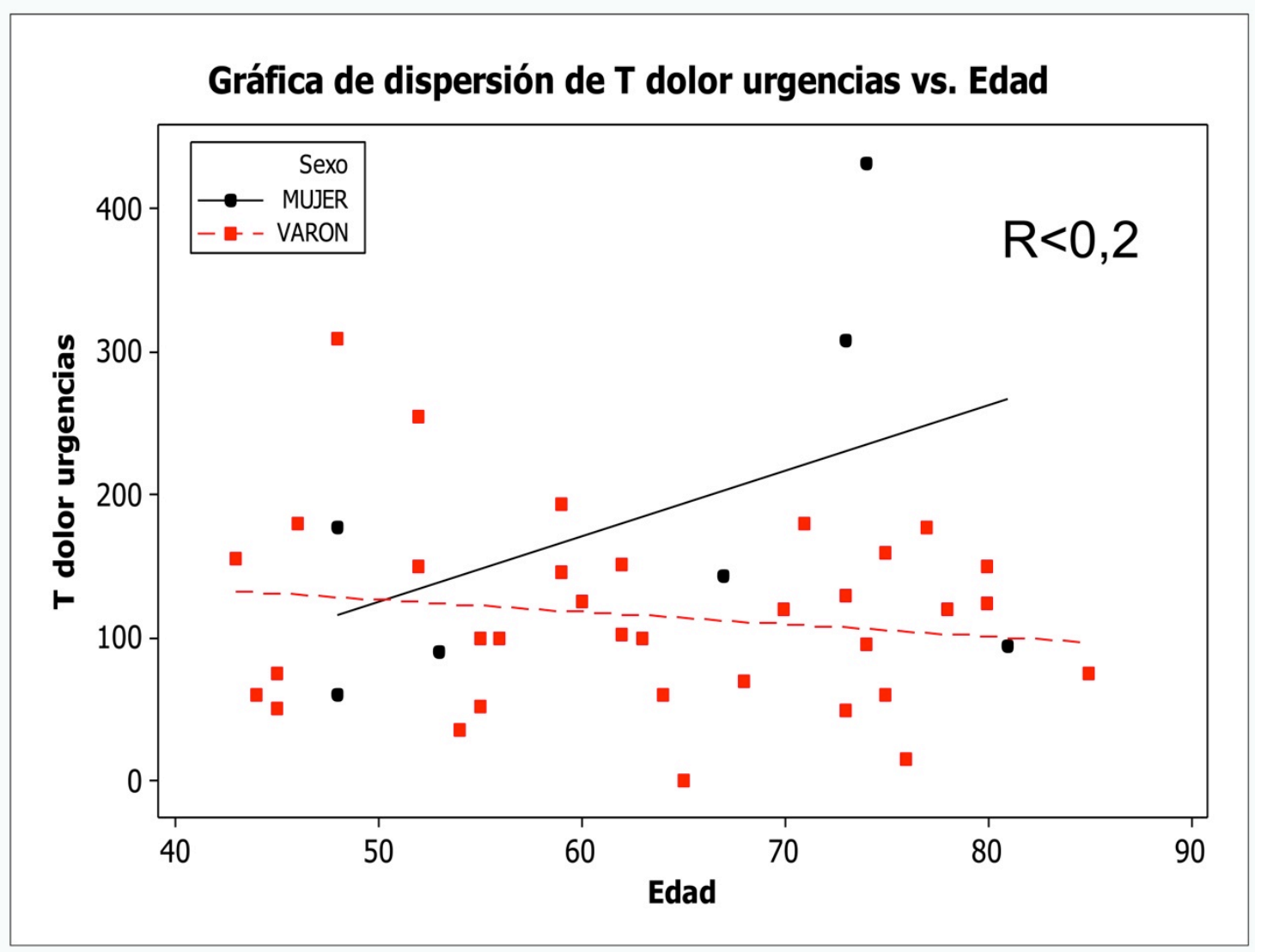

Figura 68: Gráfico de dispersión del tiempo transcurrido entre el comienzo del dolor y la llegada del paciente al Servicio de Urgencias en función de la edad y diferenciando entre varones y mujeres.

En la Tabla 14 se muestran los resultados correspondientes a la aplicación del test ANOVA unidireccional a la variable suma ST Ingreso de los pacientes de la muestra clasificados en función de la localización del infarto. Debe resaltarse que para el infarto de localización lateral solo se dispone de información relativa a dos casos. Los resultados del test ANOVA no evidencian la existencia de una diferencia estadísticamente significativa en la variable Suma ST en función de la localización del infarto. Nótese cómo en la tabla ANOVA, el valor p (0.145) para la variable Localización Infarto indica que existen evidencias suficientes de que no todas las medias son iguales cuando alfa se establece en 0.05. Para explorar las diferencias entre las medias, se pueden examinar los resultados de las comparaciones múltiples.

Tabla 14: Aplicación del test ANOVA unidireccional a la variable sumatorio ST en el momento del ingreso a los pacientes de la muestra en función de la localización del infarto.

\begin{tabular}{|lrrrrr}
\hline \multicolumn{6}{|l}{ ANOVA unidireccional: Suma ST Ingreso vs. Localización Infarto } \\
Fuente & GL & SC & CM & F & P \\
Localización Infarto & 2 & 71,7 & 35,8 & 2,03 & 0,145 \\
Error & 38 & 669,9 & 17,6 & & \\
Total & 40 & 741,6 & & &
\end{tabular}




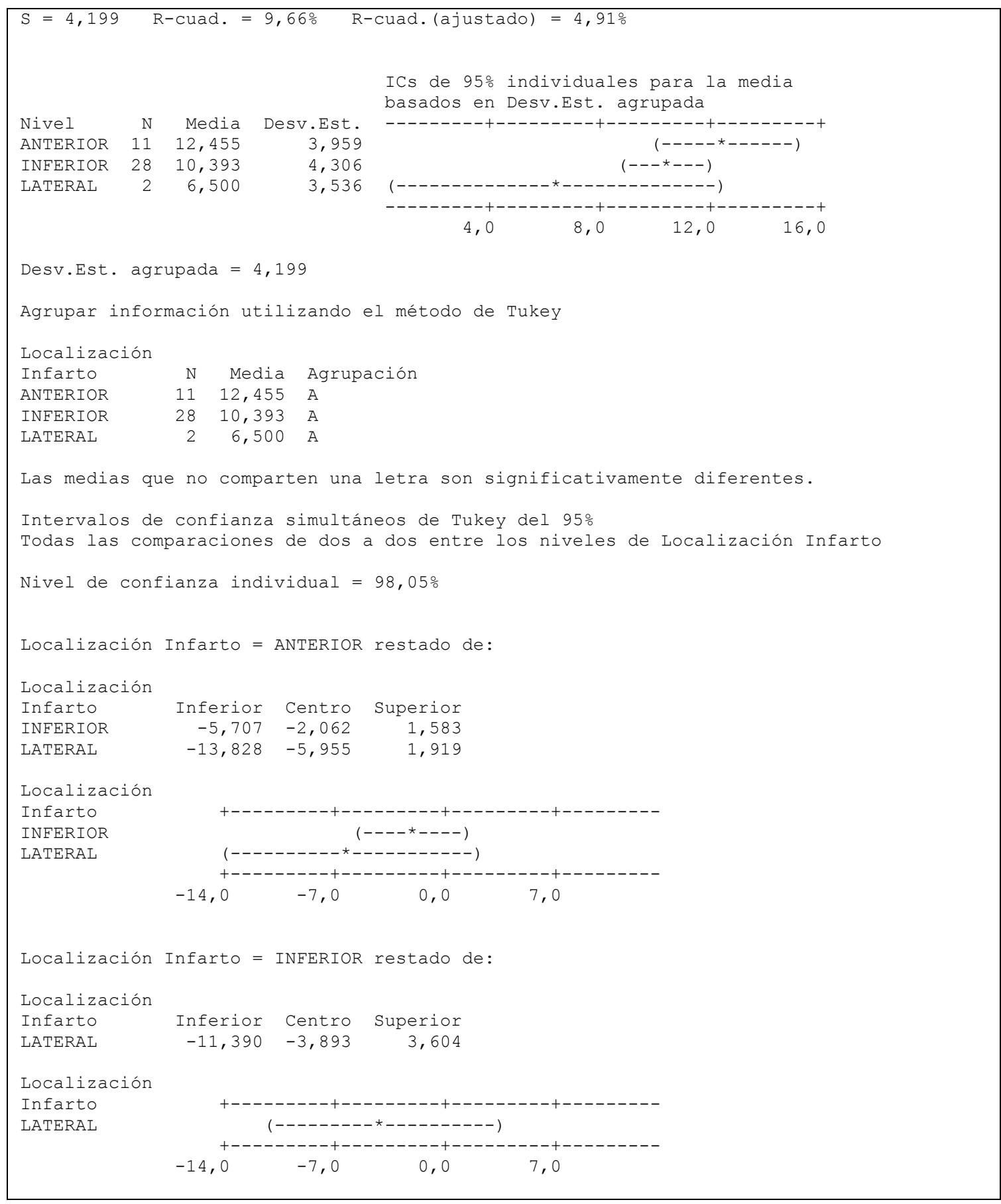

Así, examinando los resultados de las comparaciones múltiples efectuadas en la Tabla 14, se observa cómo la tabla de información de agrupación muestra en formato resumido los grupos de las medidas de los niveles de factores que no son diferentes de forma significativa. Dichos niveles son los que comparten la misma letra. En nuestro caso, tanto anterior, como inferior y lateral comparten todos la misma letra (letra A) y por tanto no son significativamente diferentes. Habiendo llegado a este resultado, ya no es necesaria la comprobación de los intervalos de confianza simultáneos de Tukey al 95\%.

En cambio, el análisis de la variable máxima elevación del ST mediante el test de ANOVA mostró diferencias entre los tres grupos en función de su localización. El 
posterior test de Tukey-Kramer, demuestra que esta significación está causada por la diferencia existente entre la desviación máxima del ST entre los infartos de localización anterior y los de localización inferior.

Oneway Analysis of Máx ST ingreso By Localización

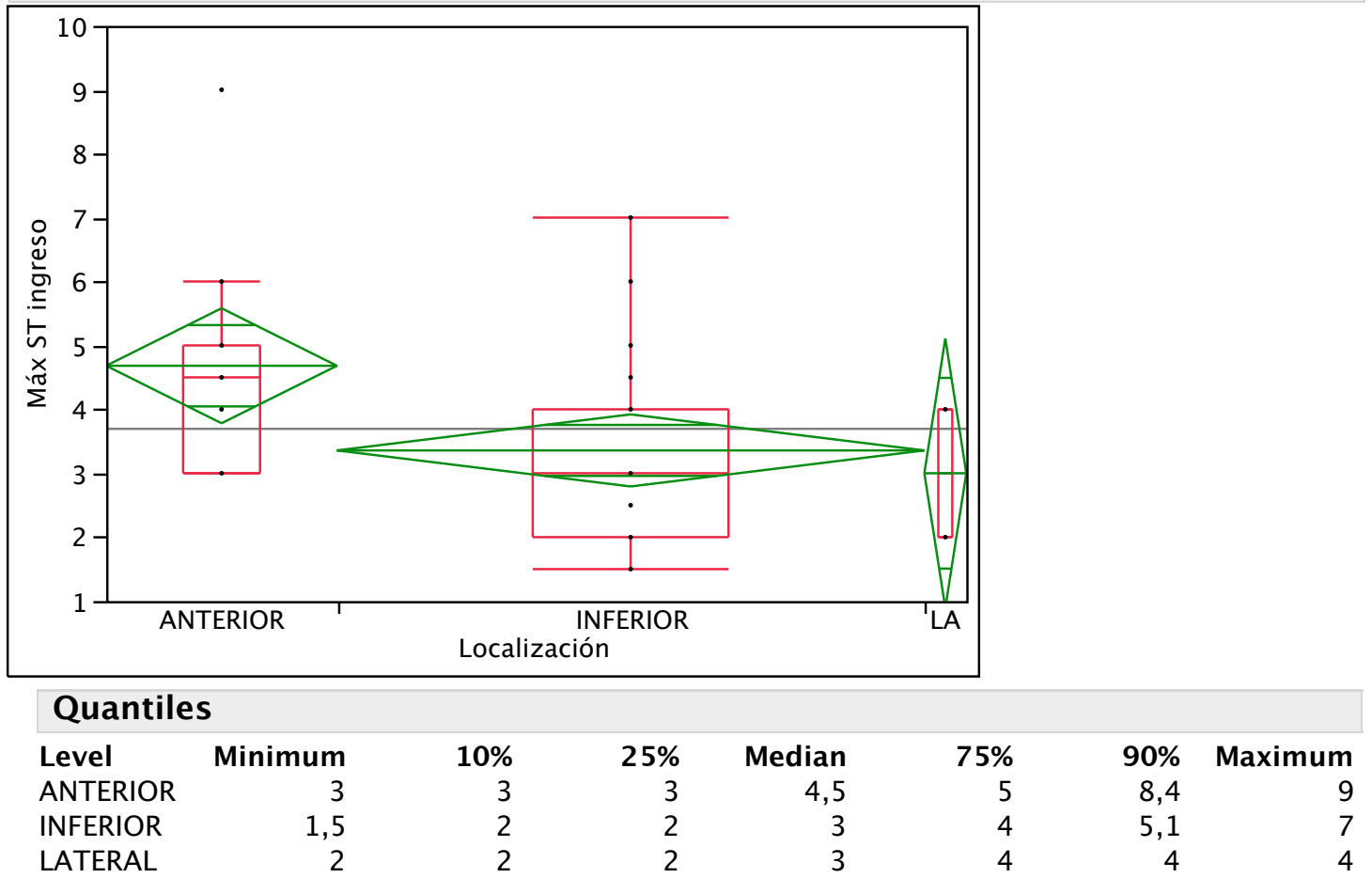

Oneway Anova

Summary of Fit

Rsquare

Adj Rsquare

Root Mean Square Error

Mean of Response

Observations (or Sum Wgts)
0,15265

0,108053

1,474029

3,695122

\begin{tabular}{lrrrrr}
\multicolumn{2}{l}{ Analysis of Variance } & & & \\
Source & Sum of & & \\
Localización & 2 & 14,874089 & 7,43704 & 3,4229 & $0,0430^{*}$ \\
Error & 38 & 82,564935 & 2,17276 & & \\
C. Total & 40 & 97,439024 & & &
\end{tabular}

\section{Means for Oneway Anova}

$\begin{array}{lrrrrr}\text { Level } & \text { Number } & \text { Mean } & \text { Std Error } & \text { Lower 95\% } & \text { Upper 95\% } \\ \text { ANTERIOR } & 11 & 4,68182 & 0,4444 & 3,7821 & 5,5815 \\ \text { INFERIOR } & 28 & 3,35714 & 0,2786 & 2,7932 & 3,9211 \\ \text { LATERAL } & 2 & 3,00000 & 1,0423 & 0,8900 & 5,1100\end{array}$

Std Error uses a pooled estimate of error variance

Figura 69: Gráfica de boxplot y ANOVA de la variable Máxima desviación ST al ingreso. 


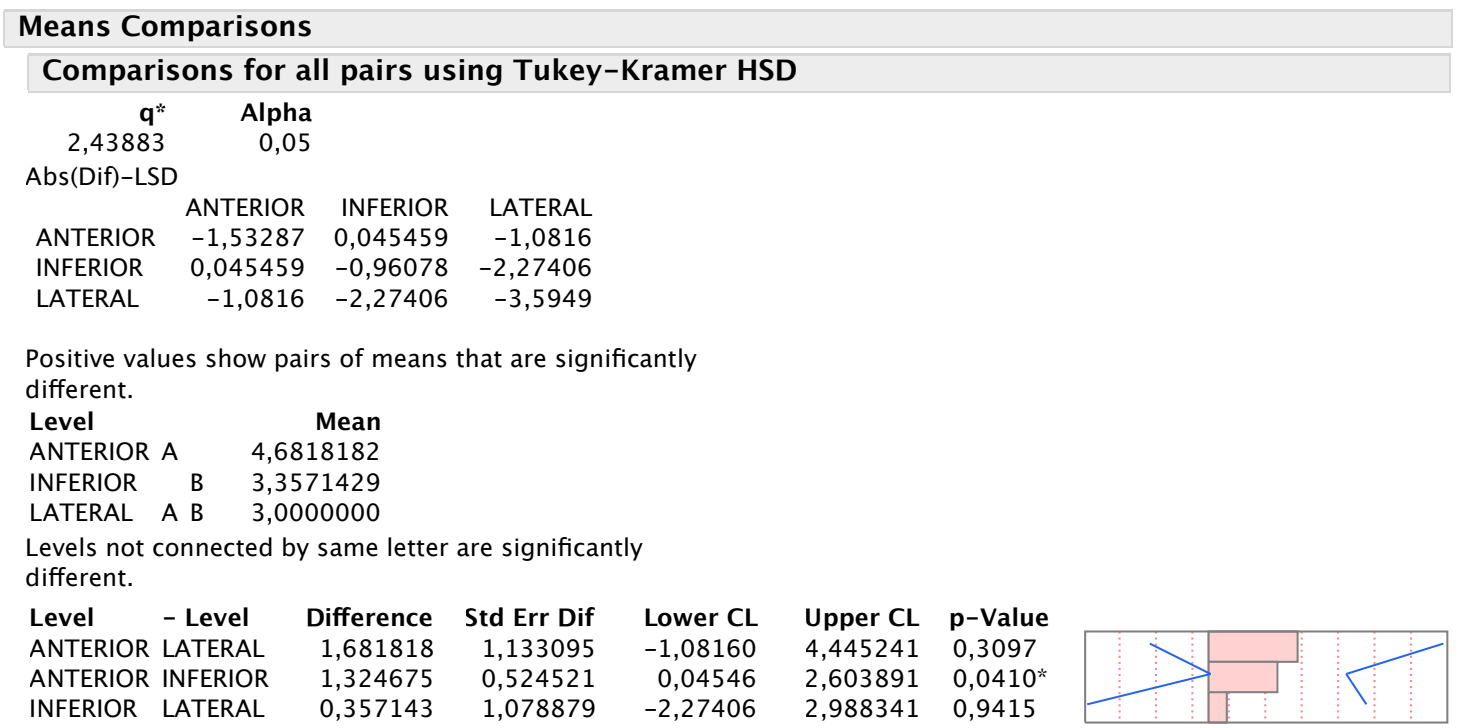

Figura 70: Test de Tukey-Kramer para la variable máxima desviación ST en función de la localización del infarto.

El análisis de los datos electrocardiográficos a los 90 minutos tras la fibrinolisis mostró una correlación significativa con los datos al ingreso sin que se encontraran diferencias significativas en cuanto a la localización del infarto. Los datos se muestran en las Figuras 71 y 71.

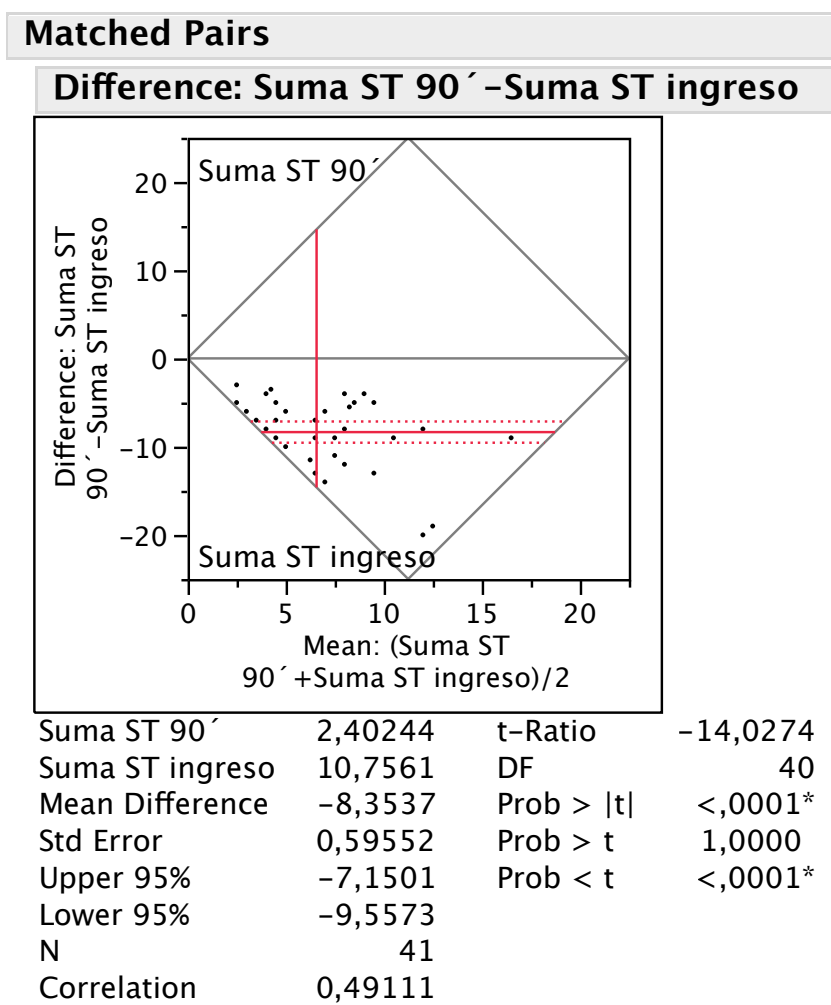

Figura 71: Resumen de la comparación mediante t para datos apareados entre las variables sumatorio del ST al ingreso y sumatorio del ST a los 90 minutos tras la fibrinolisis. 


\section{Matched Pairs}

Difference: Máx ST 90'-Máx ST ingreso

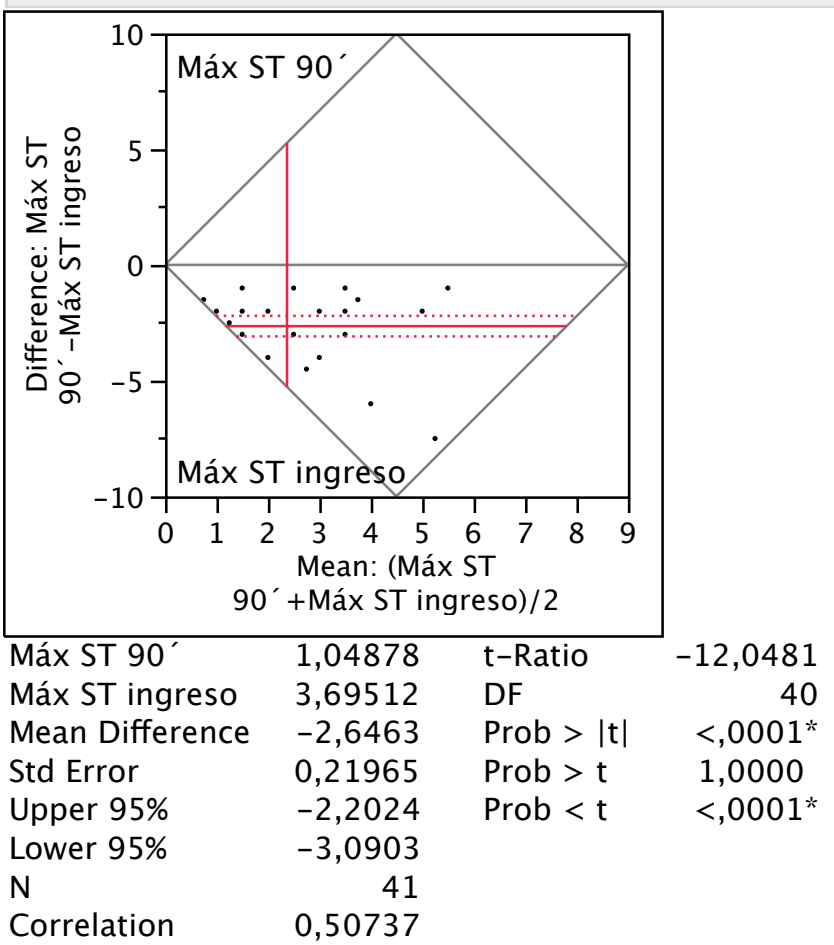

Figura 72: Resumen de la comparación mediante $t$ para datos apareados entre las variables máxima desviación del ST al ingreso y máxima desviación del ST a los 90 minutos tras la fibrinolisis.

La Figura 73 muestra la distribución de la edad de los pacientes de la muestra en función de la localización del infarto. Los resultados del test ANOVA unidireccional de esta variable nos permite afirmar que no existen diferencias estadísticamente significativas en la edad de los pacientes en función de la localización del infarto. Los resultados obtenidos se muestran en el anexo informático de datos suplementarios. 


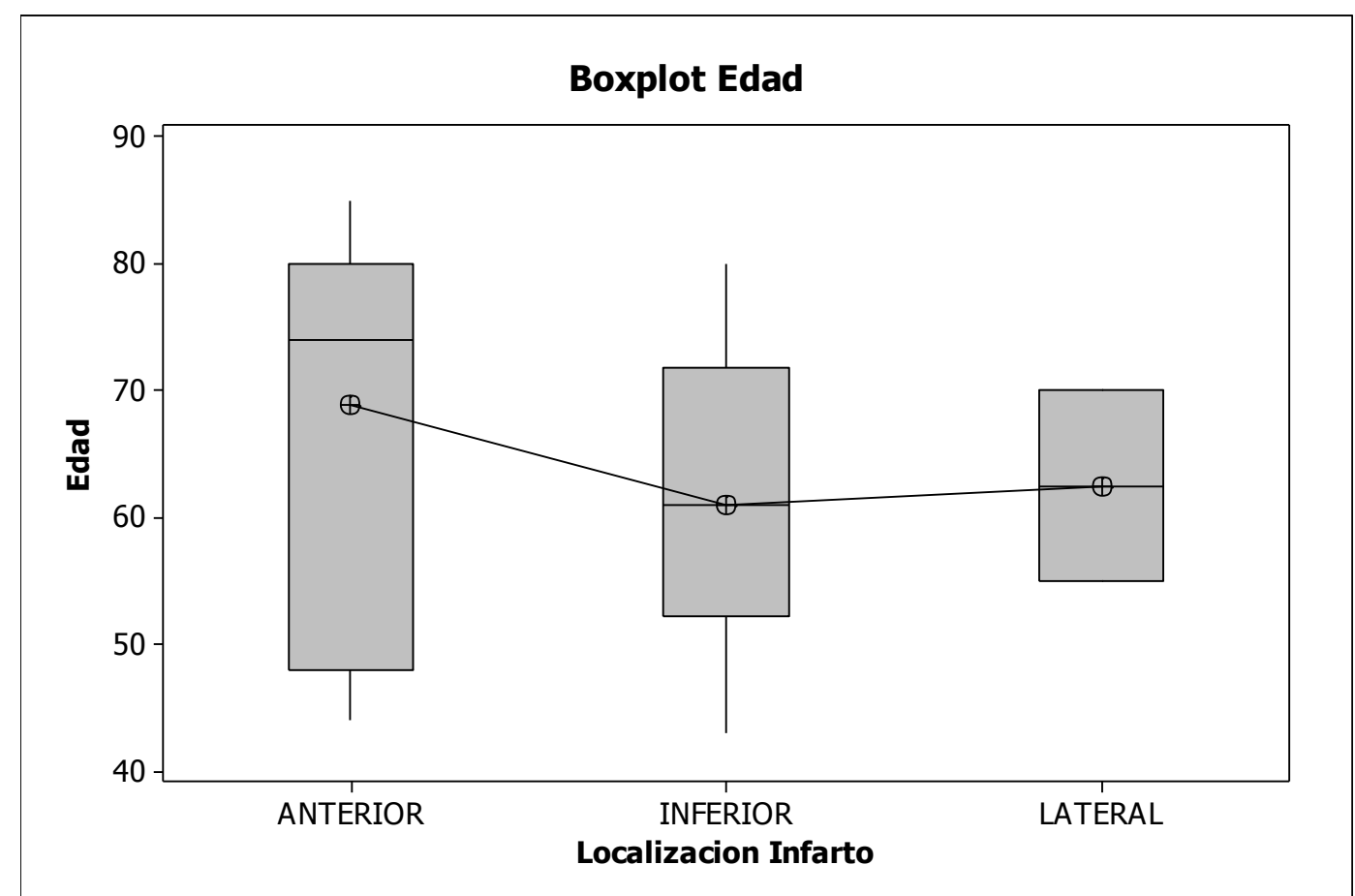

Figura 73: Gráfico de boxplot de la variable edad de los pacientes de la muestra divididos en función de la localización del infarto.

\subsection{INFORMACIÓN CORRESPONDIENTE A LA EVOLUCIÓN DE LAS PRUEBAS COMPLEMENTARIAS POSFIBRINOLISIS}

Tal y como es conocido, el valor de la variable CK-MB depende del tiempo de evolución desde el inicio de los síntomas hasta la administración del tratamiento. Así, dicha variable debe tener relación con la localización del infarto con, RIVA, Suma ST90 y max. ST90. A menor Suma ST90, más precoz el CK MB. En la Tabla 15 se muestran los valores de la matriz de correlación de las variables CK-MB1, CKMB2, CK-MB3, CK-MB4, CK-MB5, T Fibri, T Clopi, Suma ST 90 y Max. ST 90. A la vista de los resultados obtenidos, se observa cómo las mayores correlaciones entre estas variables son las siguientes: CK-MB4 y CK-MB5 (coeficiente de correlación de 0,977), CK-MB3 y CK-MB4 $(0,946)$ y CK-MB3 y CK-MB5 $(0,939)$. Otros valores dignos de consideración son: T Fibri y T clopi $(0,906)$, max ST 90 y suma ST 90 $(0,897)$ у CK-MB2 у CK-MB3 $(0,855)$.

Tabla 15: Matriz de correlaciones correspondiente a las variables CK-MB1, CK-MB2, CKMB3, CK-MB 4, CK-MB5, T Fibri, T Clopi, Suma ST 90 y Máx ST 90.

\begin{tabular}{|c|c|c|c|c|c|c|}
\hline \multicolumn{7}{|c|}{ Correlaciones: CKMB 1; CKMB 2; CKMB 3; CKMB 4; CKMB 5; T Fibri; T clopi } \\
\hline & CKMB 1 & CKMB 2 & CKMB 3 & CKMB 4 & CKMB 5 & T Fibri \\
\hline CKMB 2 & 0,793 & & & & & \\
\hline CKMB 3 & 0,594 & 0,855 & & & & \\
\hline CKMB 4 & 0,424 & 0,724 & 0,946 & & & \\
\hline CKMB 5 & 0,361 & 0,726 & 0,939 & 0,977 & & \\
\hline T Fibri & 0,297 & 0,360 & 0,383 & 0,360 & 0,336 & \\
\hline T clopi & $-0,043$ & 0,214 & 0,253 & 0,257 & 0,252 & 0,906 \\
\hline
\end{tabular}




\begin{tabular}{|lrrr}
\multicolumn{6}{c}{ Correlaciones: Suma ST Ingreso; Suma ST 90; T Fibri; T clopi } & \\
\multicolumn{7}{r}{ Suma ST } & Ingreso & Suma ST 90 & T Fibri \\
Suma ST 90 & 0,491 & 0,000 & \\
T Fibri & $-0,032$ & $-0,106$ & 0,906 \\
T clopi & $-0,080$ &
\end{tabular}

Contenido de la celda: Correlación de Pearson

Correlaciones: Suma ST 90; Max ST 90; T Fibri; T clopi

$\begin{array}{lrrr} & \text { Suma ST } 90 & \text { Max ST } 90 & \text { T Fibri } \\ \text { Max ST 90 } & 0,897 & & \\ \text { T Fibri } & 0,000 & -0,063 & \\ \text { T clopi } & -0,106 & -0,181 & 0,906\end{array}$

Tabla 16: Aplicación del test ANOVA unidireccional a la variable CK-MB1 de los pacientes de la muestra clasificados en función de la localización del infarto.

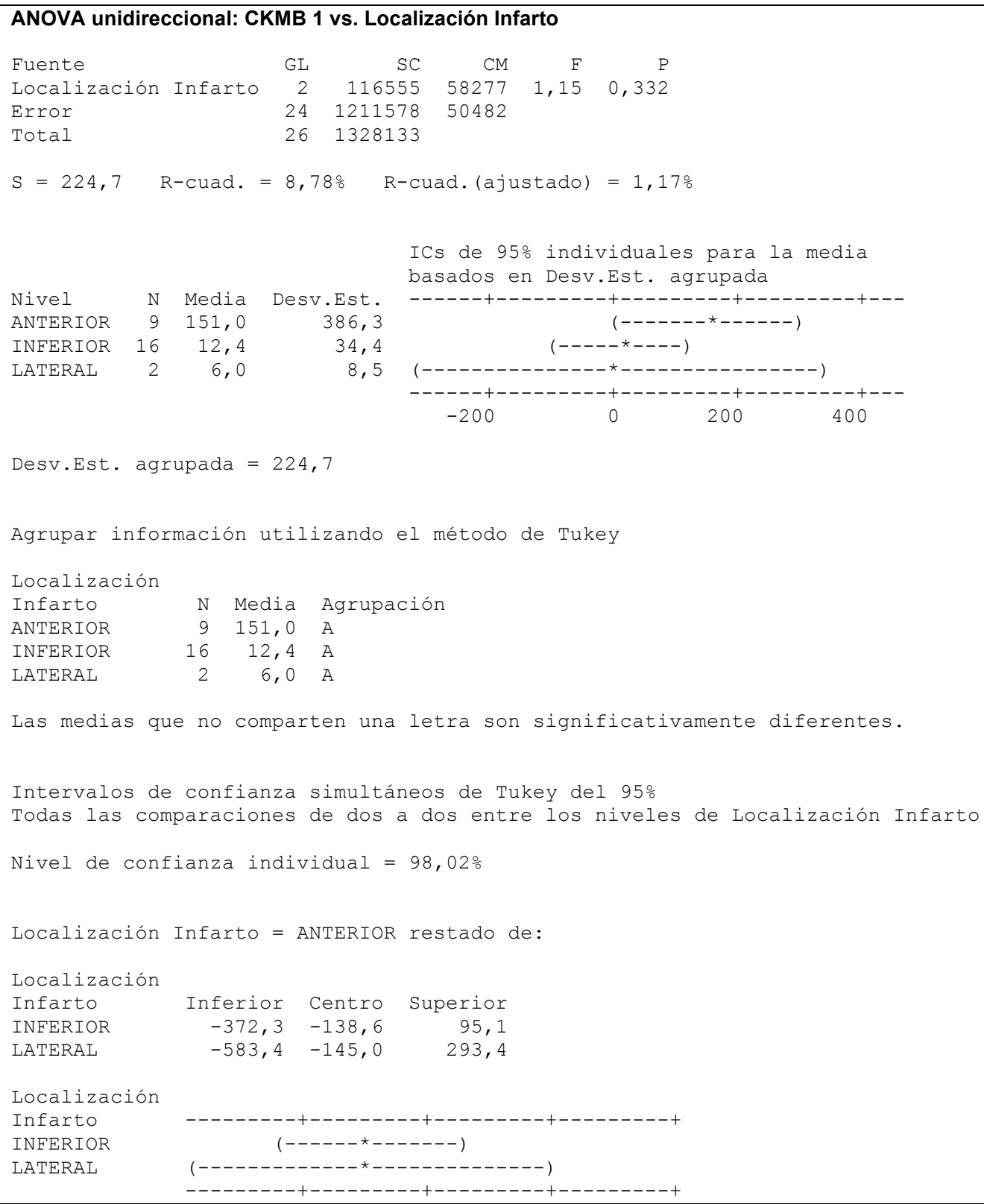




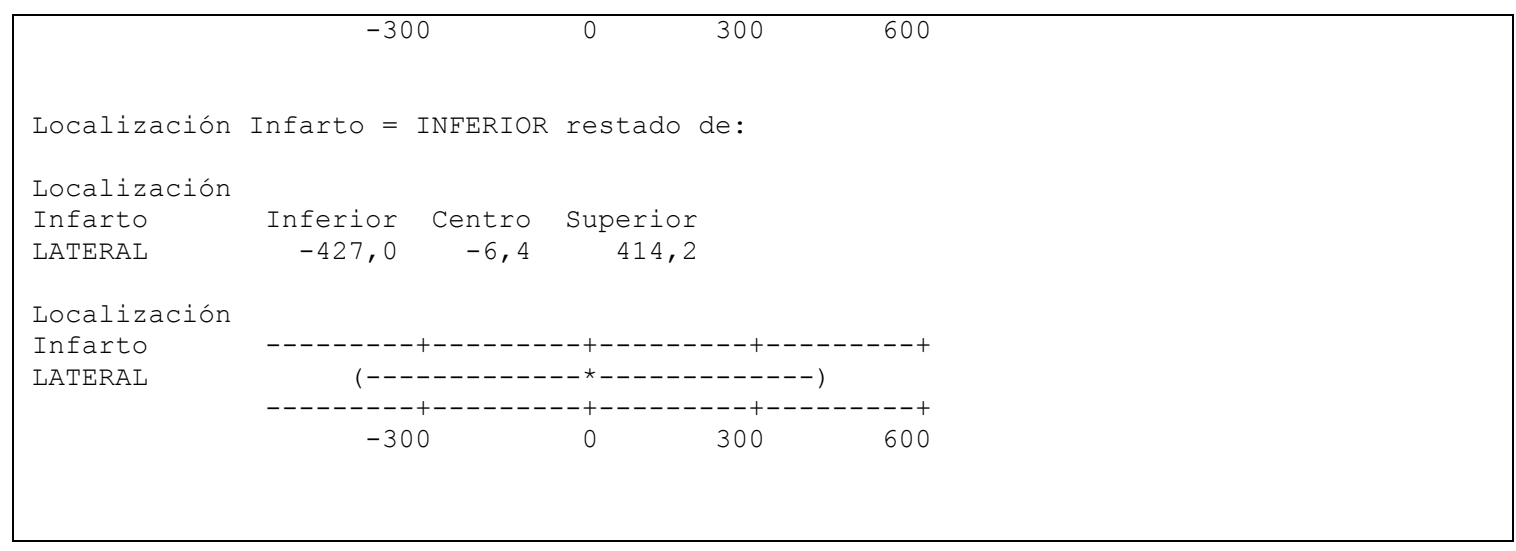

La información recogida en la Tabla 15 corresponde a la aplicación de un test de análisis de la varianza a la variable CK-MB1 de los pacientes de la muestra en función de la localización del infarto. A la vista de los resultados, el valor de la variable CK-MB1 no parece estar estadísticamente influido por la localización del infarto. Dicho test de ANOVA se repitió igualmente para la variable CK-MB5 así como para los valores promedios de CK-MB en cada uno de los pacientes sin que estos tests arrojasen significación estadística alguna. Ante estos datos, podemos afirmar que a pesar de las diferencias encontradas en las variables electrocardiográficas, no existen diferencias significativas en el tamaño del infarto en función de su localización en los pacientes de la muestra.

\subsection{ESTADÍSTICA INFERENCIAL CORRESPONDIENTES A LOS DATOS SOBRE ACTIVIDAD PLAQUETARIA}

El siguiente apartado presenta los resultados correspondientes a las comparaciones univariantes de las variables de actividad plaquetaria.

Esta sección se clasificará en los apartados correspondientes a las tres variables sobre actividad plaquetaria obtenidas mediante el test VerifyNow® -P2Y12: BASE, RPP y \%IAP.

\subsubsection{BASE}

Dado que los valores de las variables BASE (las variables correspondientes a las diferentes determinaciones de este parámetro) se puede considerar que siguen una distribución normal se aplicará un test de análisis de la varianza ANOVA de un factor con el fin de comprobar si existe igualdad en los valores de las medias de la variable BASE para los cuatro momentos considerados. En la Tabla 17 se representan los resultados fundamentales de los análisis de la varianza aplicados a las diferentes mediciones realizadas de dicha variable. Dado el valor de $\mathrm{p}$ obtenido, se puede afirmar que hay suficiente evidencia de que no todas las medias son iguales para un nivel de significación alfa establecido en el 5\%. Para explorar las diferencias entre las medias, es necesario el estudio de los resultados de las 
comparaciones múltiples así como los intervalos de confianza al 95\% para la media. Así, vemos cómo los valores de las medias de la variable BASE en los instantes 1 y 3 tienen una diferencia estadísticamente significativa. Esta misma información se observa con mayor claridad en la Tabla 18, en la que se presentan los intervalos de confianza simultáneos de Tukey al 95\%, pudiéndose afirmar que los datos de BASE 1 y BASE 3 son estadísticamente diferentes dado que la interacción de los intervalos de confianza de ambas variables no incluye el cero.

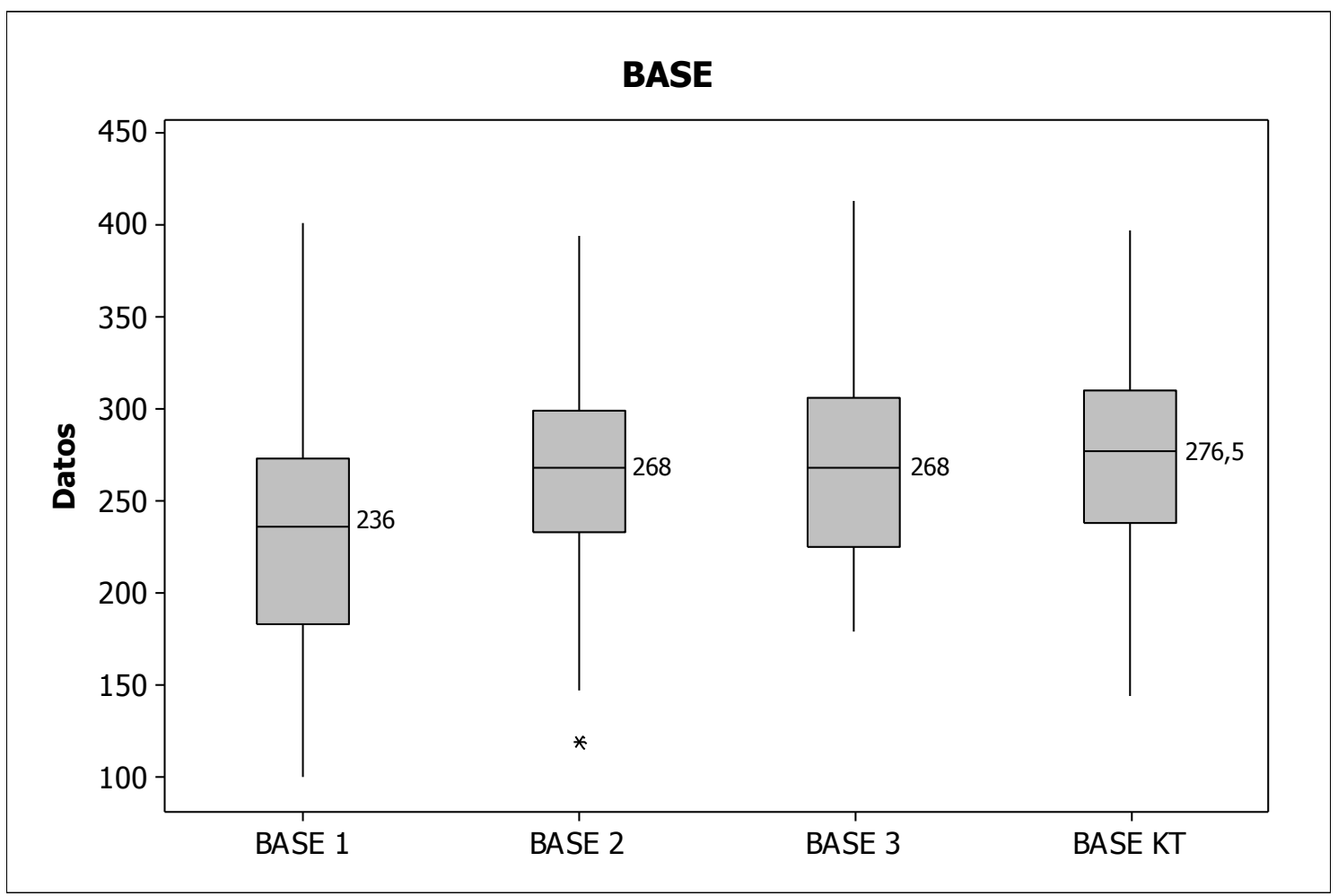

Figura 74: Representación por medio de un gráfico de boxplot de la evolución temporal de la variable BASE.

Tabla 17: Resultados del test ANOVA aplicado a las diferentes mediciones realizadas para la variable BASE.

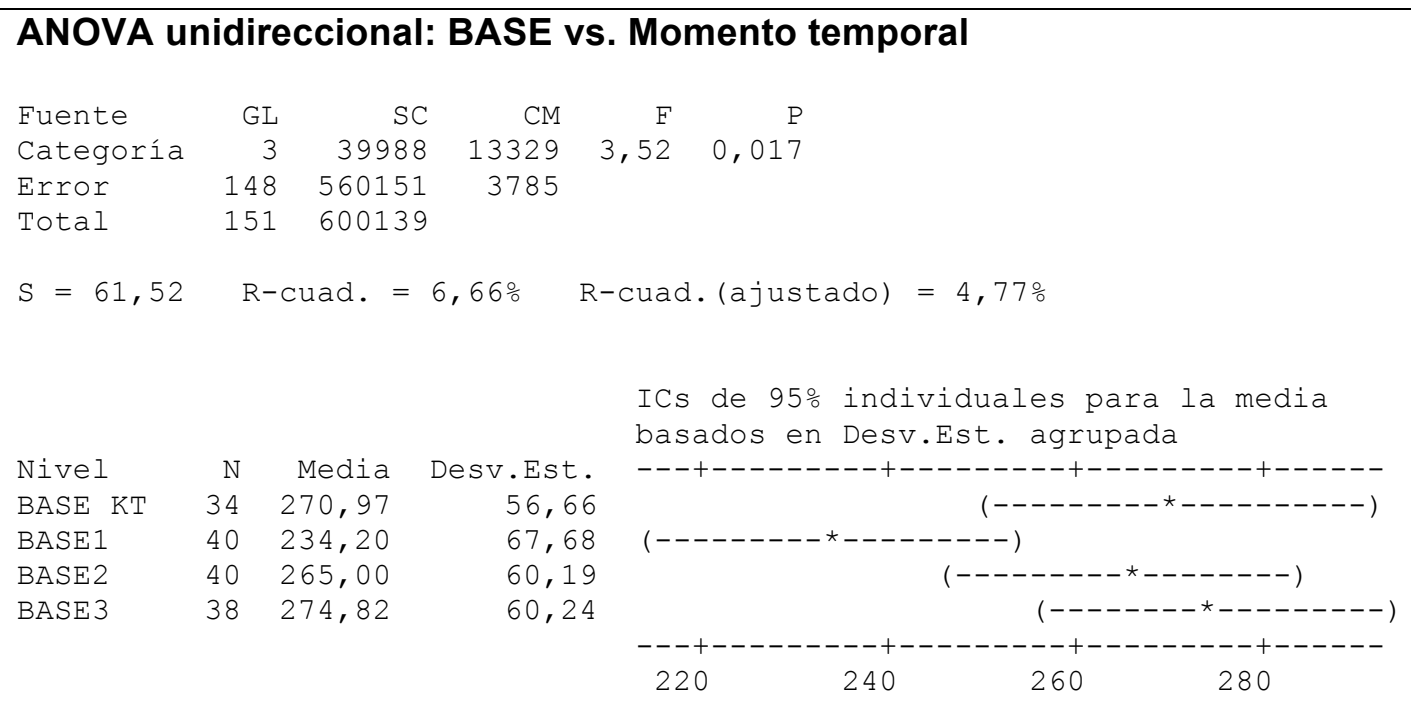




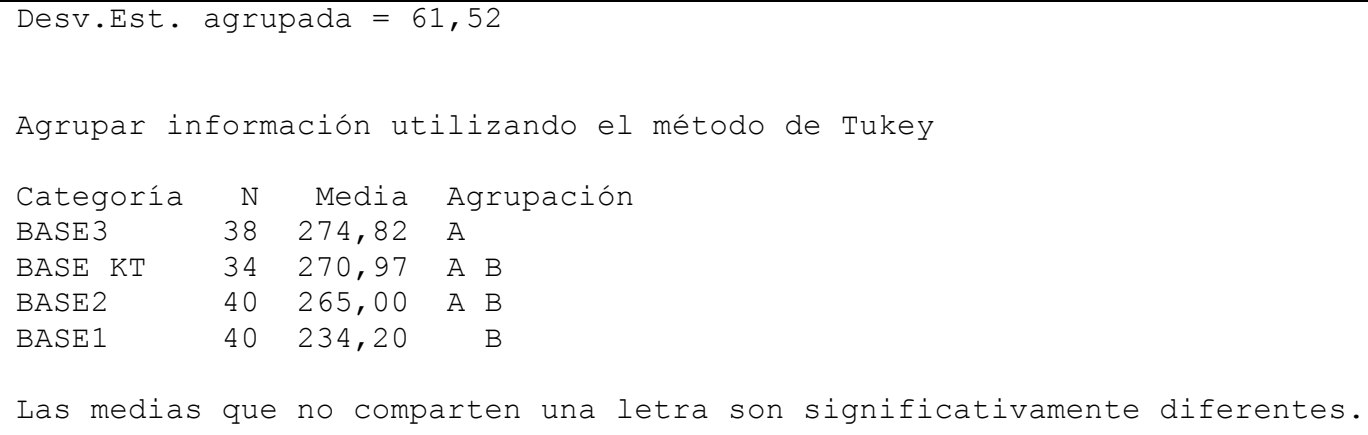

Tabla 18: Intervalos de confianza simultáneos de Tukey al 95\% para la variable BASE.

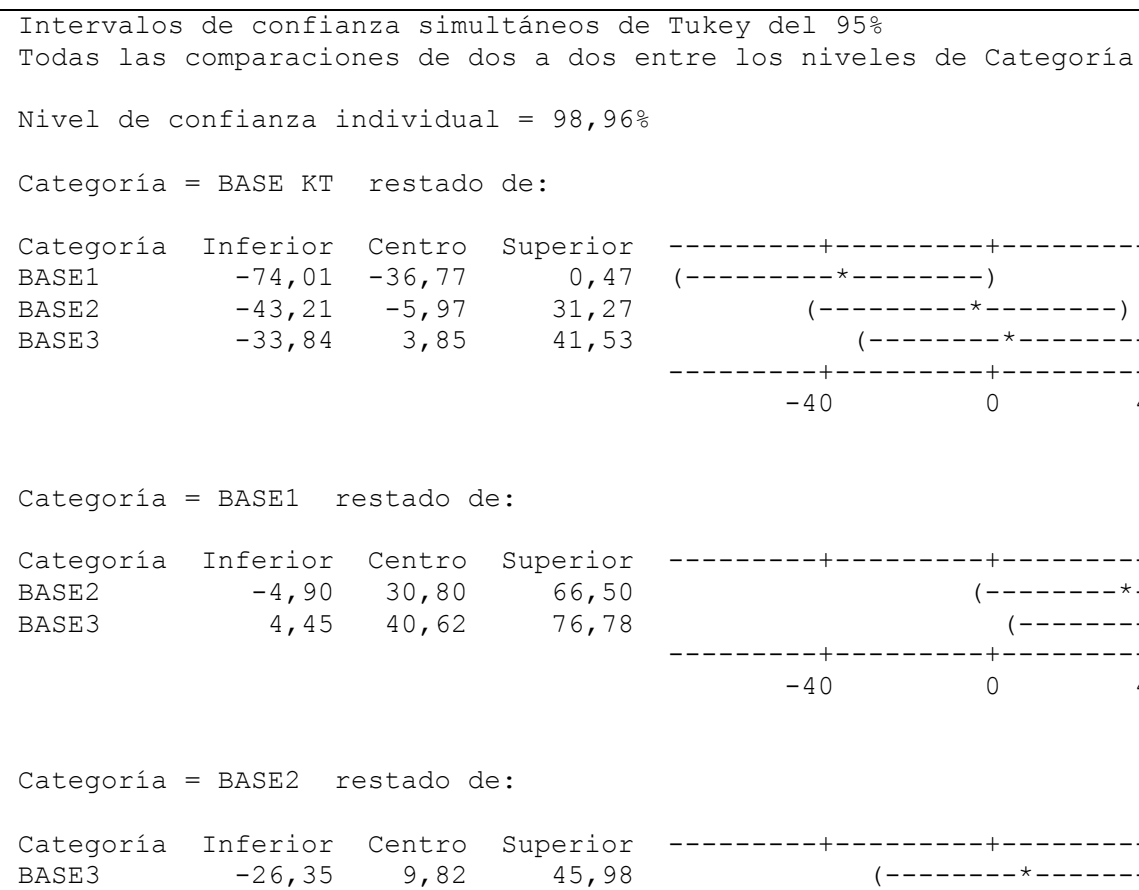

Según estos resultados, podemos afirmar que la variable BASE, es decir, la reactividad plaquetaria estimulada por iso-TRAP e independiente del receptor P2Y12 se incrementa progresivamente tras la administración del fibrinolítico, alcanzando el máximo de actividad entre las 24 y las 48 horas (determinación en momento 3 o Día +2 ). 


\subsubsection{REACTIVIDAD PLAQUETARIA POSTRATAMIENTO (RPP)}

De manera análoga a como se procedió con la variable BASE se procede ahora con la variable RPP, resultando el gráfico de boxplot que se observa en la Figura 75 así como el análisis de la varianza cuyos resultados se muestran en la Tabla 19 junto con el test de Tukey asociado de la Tabla 20. Los resultados del ANOVA efectuado muestran que no existen diferencias estadísticamente significativas en los valores de las medias en función del tiempo. Esta afirmación se ve corroborada por los resultados del test de Tukey.

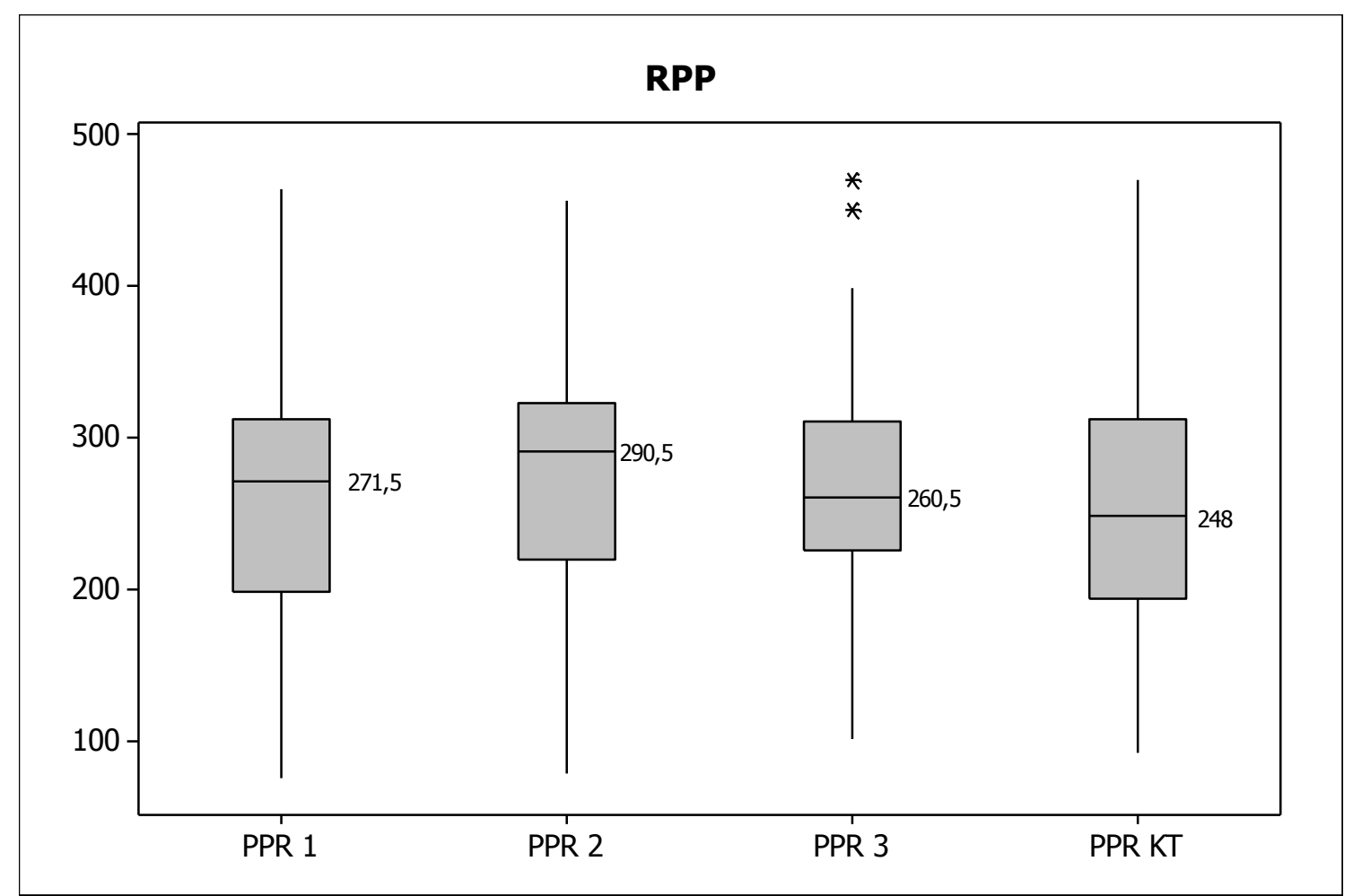

Figura 75: Representación por medio de un gráfico de boxplot de la evolución temporal de la variable RPP.

Tabla 19: Resultados del test ANOVA aplicado a las diferentes mediciones realizadas de la variable RPP.

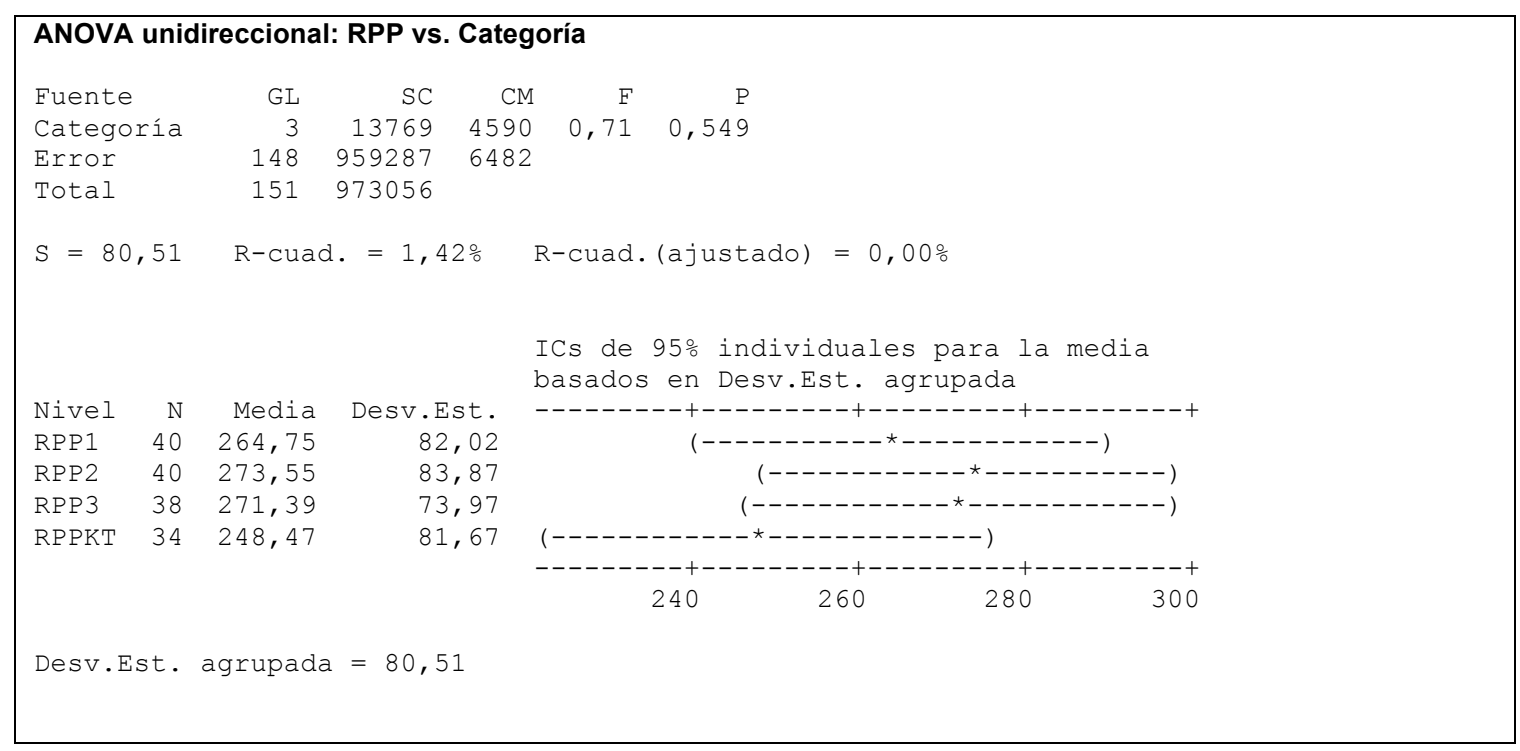




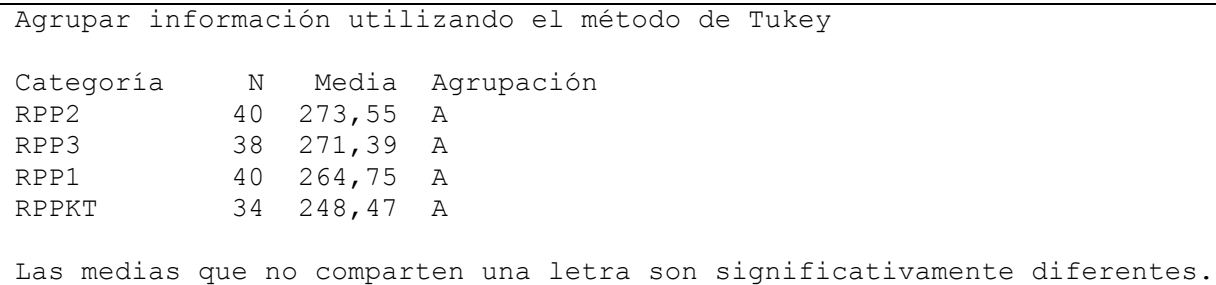

Tabla 20: Intervalos de confianza simultáneos de Tukey al 95\% para la variable RPP.

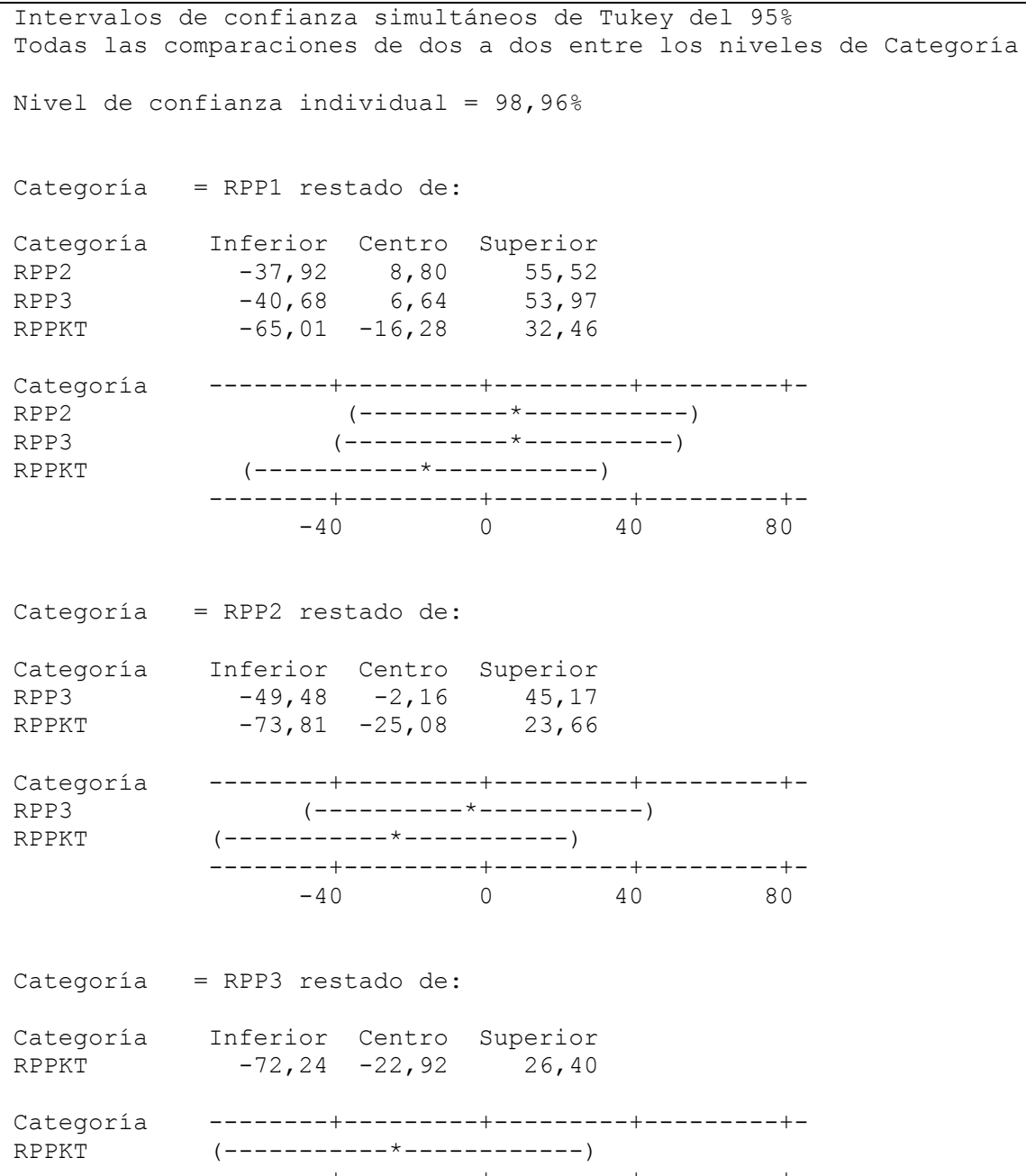

Dados los resultados obtenidos, podemos afirmar que la reactividad plaquetaria dependiente del receptor P2Y12 entre los pacientes de la muestra no se modifica tras la administración de las dosis aprobadas de clopidogrel para esta situación. Si bien la RPP en el momento de la coronariografía tiene unos valores más bajos que en las determinaciones previas, las diferencias no son estadísticamente significativas. 


\subsubsection{PORCENTAJE DE INHIBICIÓN DE LA ACTIVIDAD PLAQUETARIA (\%IAP)}

De manera análoga a lo hecho para las variables BASE y RPP, se procedió a la representación de un boxplot de la evolución temporal de la variable \%IAP. Dicho boxplot se presenta en la Figura 76, mientras que los resultados del ANOVA y los intervalos de confianza del test de Tukey se presentan respectivamente en la Tabla 21 y la Tabla 22 respectivamente. A la vista de estos resultados se puede afirmar que existe una diferencia estadísticamente significativa en los valores medios medidos en la variable \%IAP en el instante 1 y en el momento de la realización del cateterismo.

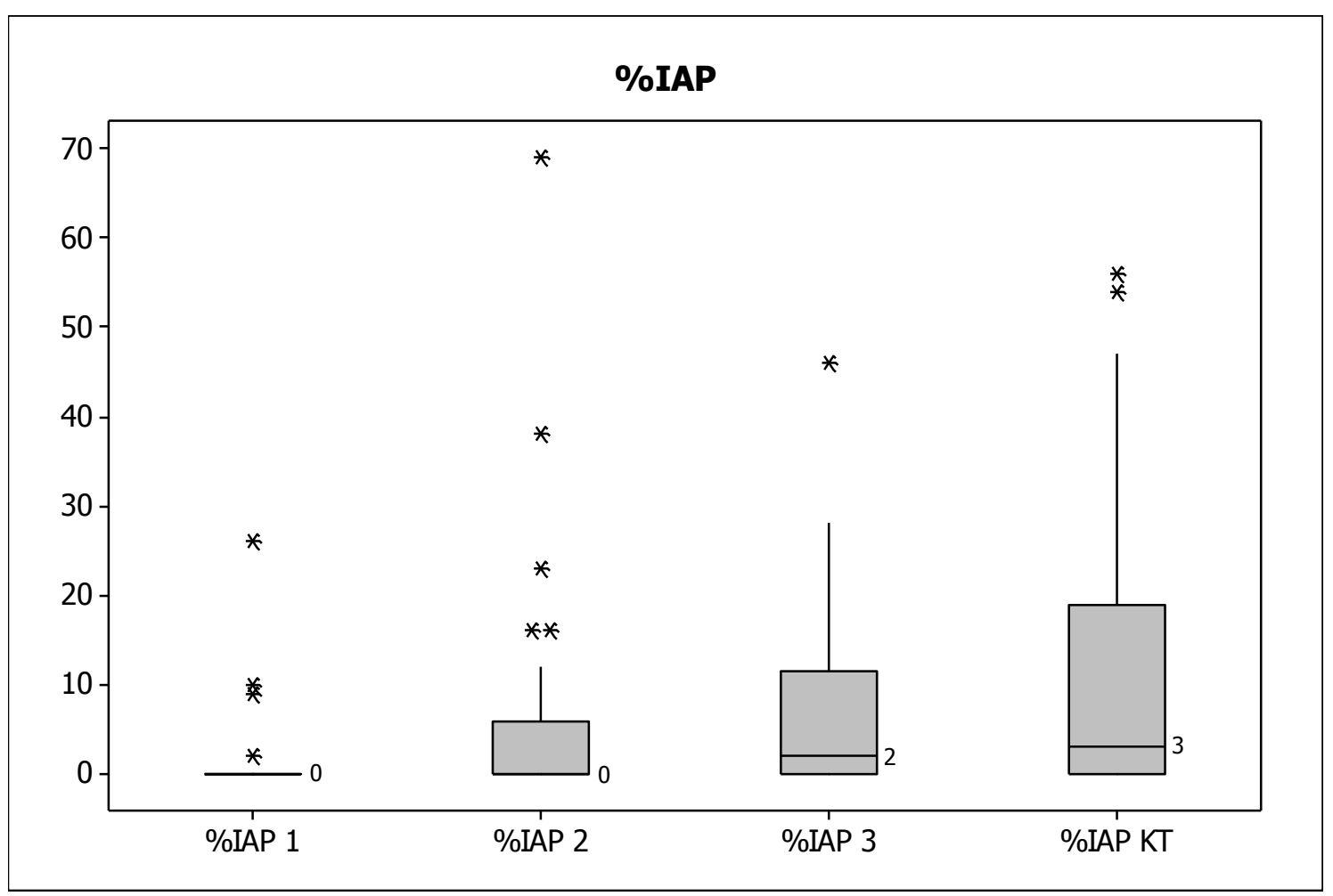

Figura 76: representación por medio de gráfico de boxplot de la evolución temporal de la variable \%IAP.

Tabla 21: Resultados del test ANOVA aplicado a las diferentes medidas realizadas de la variable \%IAP.

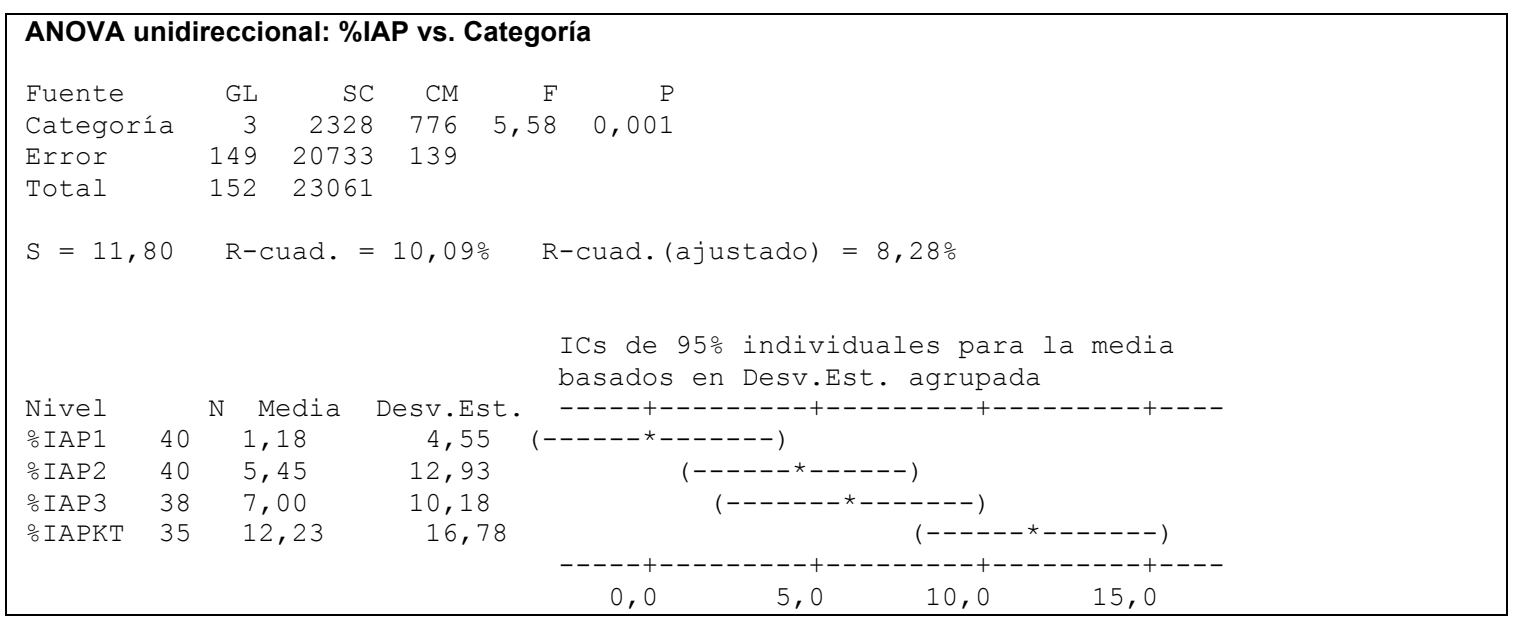




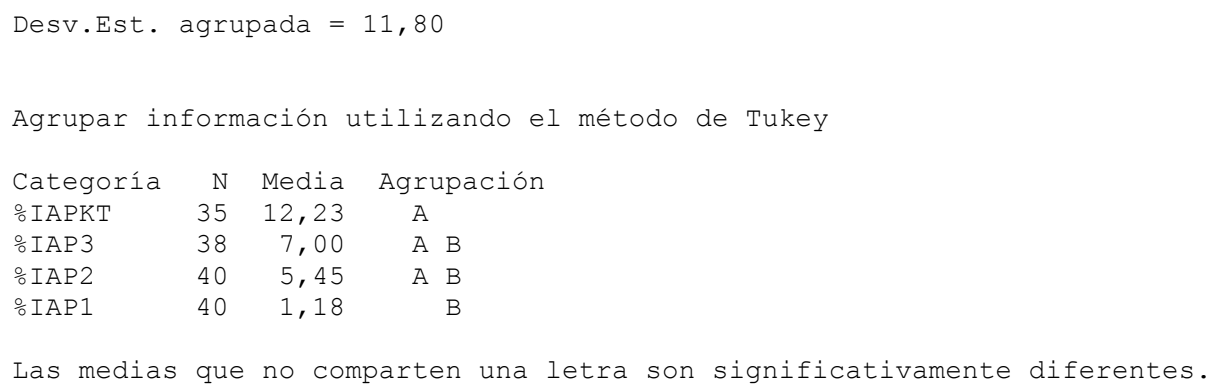

Tabla 22: Intervalos de confianza simultáneos de Tukey al 95\% para la variable \%IAP.

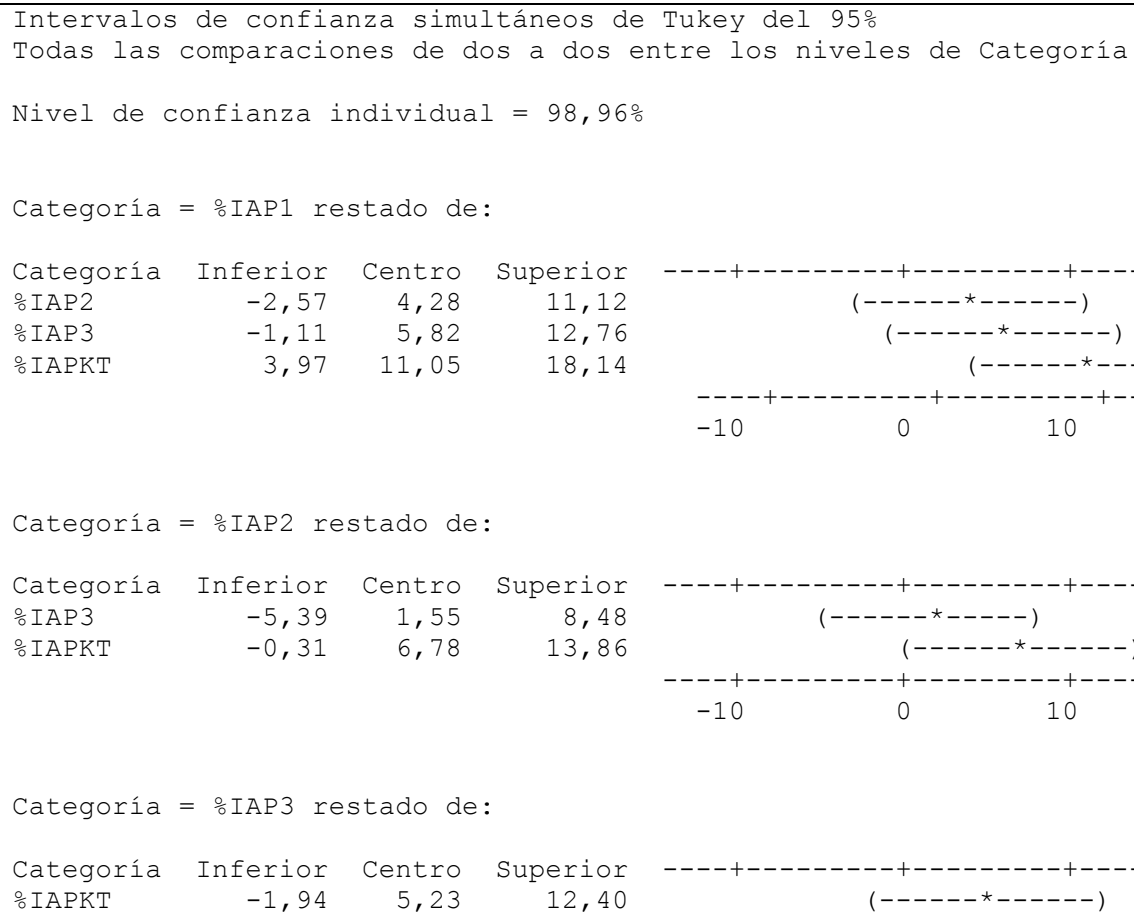

Según los resultado expuestos podemos afirmar que la inhibición de la actividad plaquetaria lograda tras la administración de las dosis aprobadas de clopidogrel para el IAMCEST fibrinolisado crece de forma paulatina desde el estado basal preadministración hasta el momento de la coronariografía en los pacientes de la muestra.

\subsubsection{CORRELACIÓN ENTRE BASE Y RPP}

Una de las críticas más frecuentemente realizadas al sistema de medición de función plaquetaria VerifyNow®-P2Y12 es la utilización de la estimulación con iso-TRAP como un estimador de la reactividad plaquetaria basal o pretratamiento 
y así calcular el \%IAP. Teniendo en cuenta el diseño de este estudio permite obtener los valores reales de actividad pretratamiento del receptor P2Y12, como criterio de consistencia interna y para resolver el problema que supone la extrapolación del valor BASE como reactividad pretratamiento, se procedió a determinar la correlación entre los valores BASE y RPP antes de recibir la primera dosis de clopidogrel.

La correlación entre ambas variables es excelente con un R2 de 0,74 (p<0,0001) como muestran la Figura 77 y la Tabla 23.

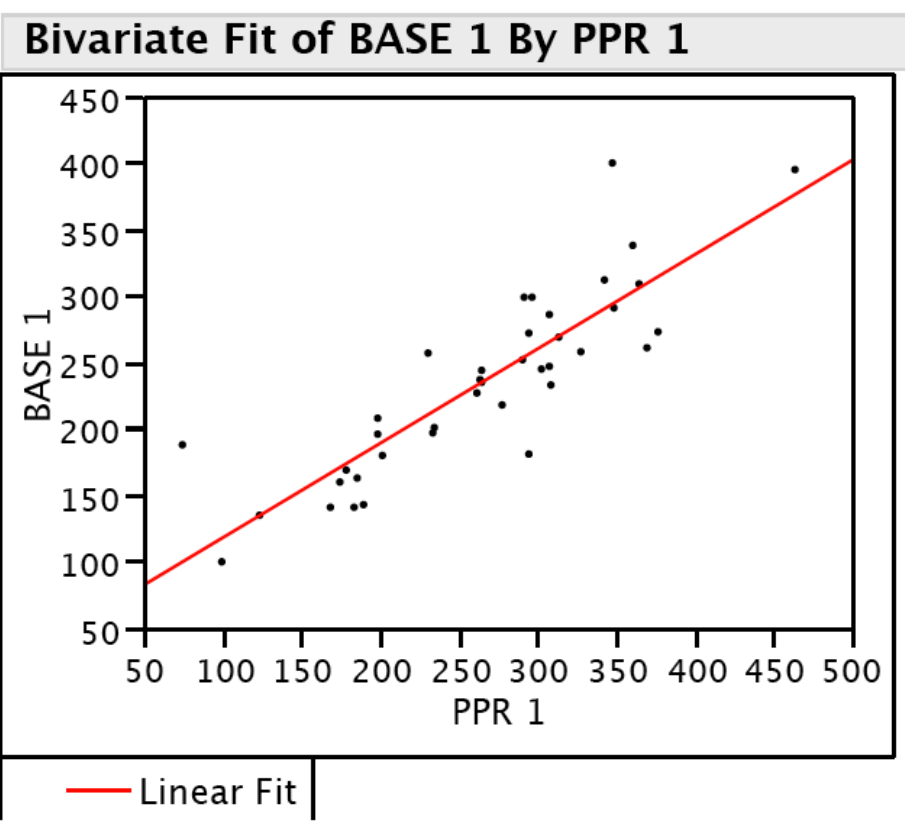

Figura 77: Gráfica de dispersión correspondiente a los valores de las variables BASE y RPP medidos en el momento del ingreso y antes de la primera administración de clopidogrel.

Tabla 23: Test de Pearson para la comprobación del grado de correlación entre los valores pretratamiento de las variables BASE y RPP.

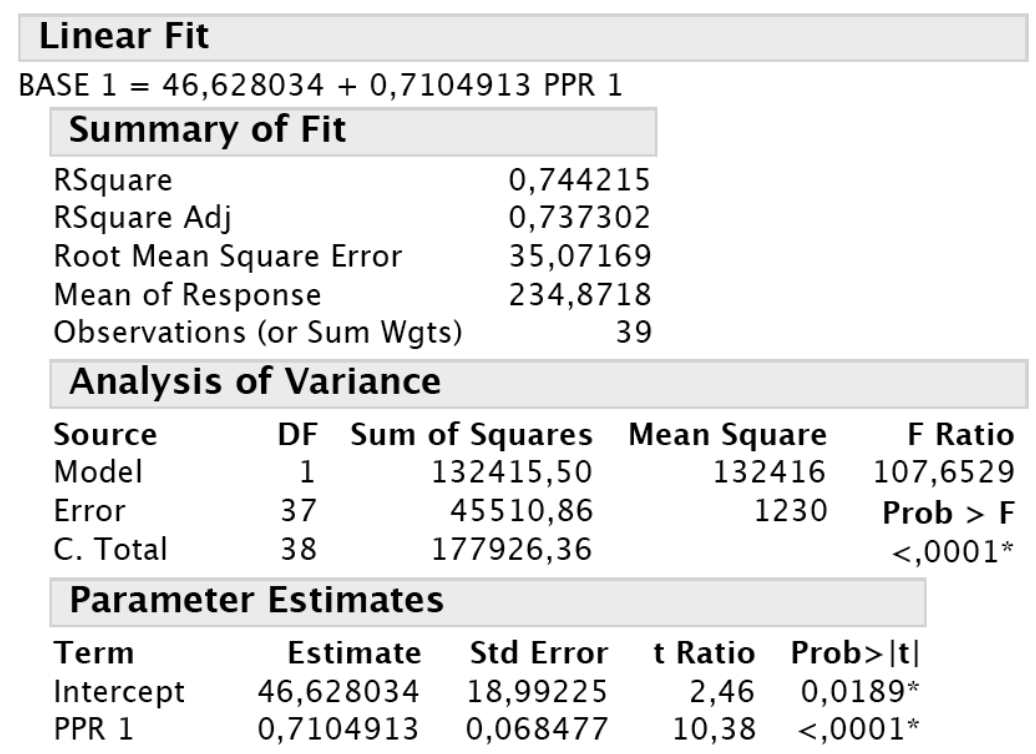




\subsection{ESTADÍSTICA INFERENCIAL DE LAS VARIABLES ANALÍTICAS POSTERIORES A LA COROANRIOGRAFÍA E ICP}

En el presente apartado, se ha realizado la estadística inferencial de las variables de cada paciente relativas al estado posterior al intervencionismo coronario percutáneo. En primer lugar se ha llevado a cabo una comparación por medio del análisis de la varianza del valor de la enzima CK-MB en el momento previo al cateterismo con los valores obtenidos a las 6 horas y a las 12 horas. Los resultados obtenidos se presentan en la Tabla 24 y muestran diferencias estadísticamente significativas en los niveles de esta enzima antes y después del cateterismo, pero no muestran un daño miocárdico sino la disminución progresiva de los valores enzimáticos propios de las fases evolutivas del IAMCEST.

Para las determinaciones de troponina $\mathrm{T}$ al ser ésta una enzima que presenta mucha mayor sensibilidad para detectar el daño miocárdico post procedimiento, se procede a la realización de un modelo predictivo que se muestra en la sección siguiente de estadística multivariante.

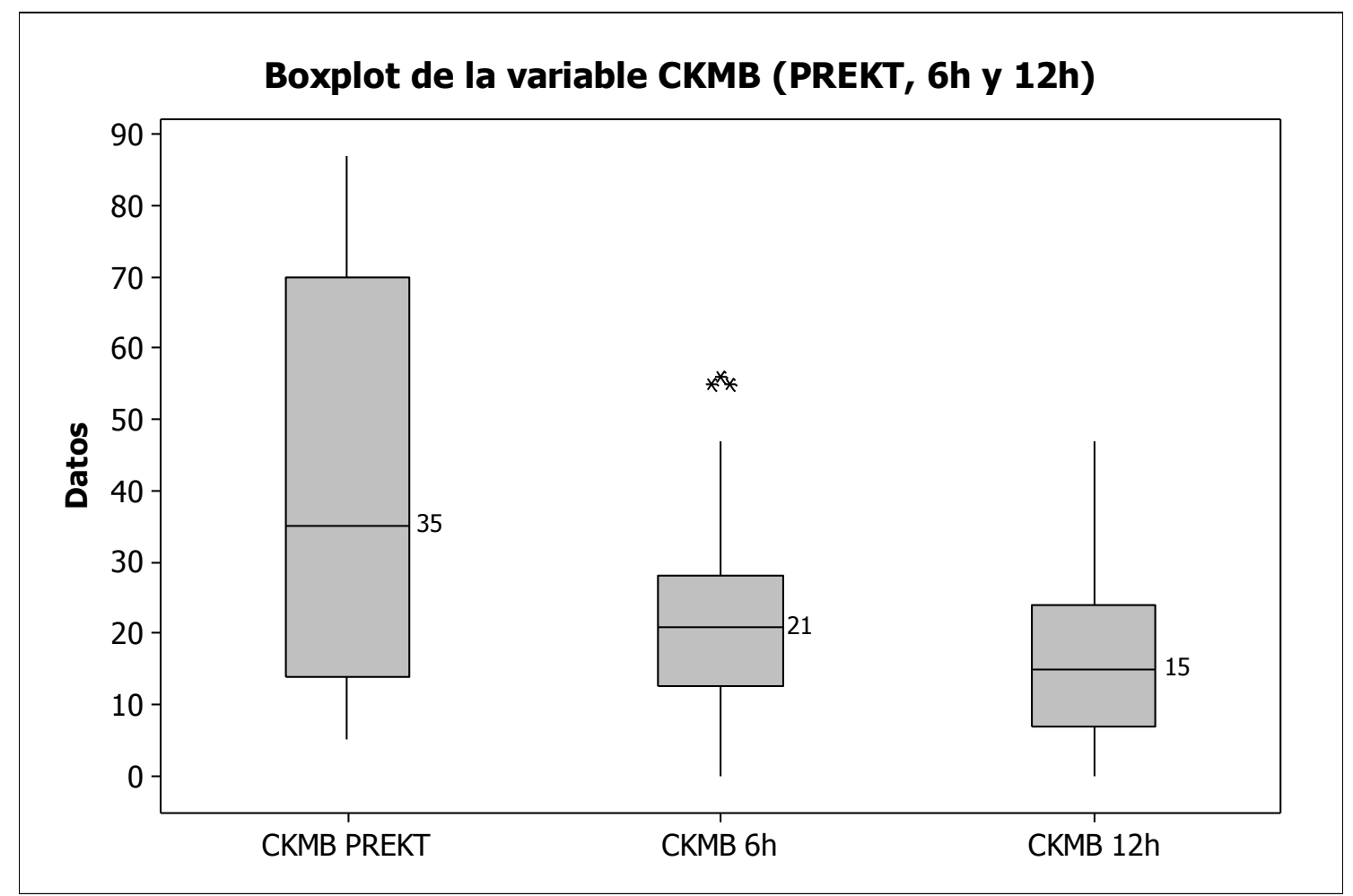

Figura 78: Gráfica de boxplot que muestra la variación entre las determinaciones seriadas de la enzima CK-MB antes y después del ICP.

Tabla 24: Comparación mediante test ANOVA de los valores de la enzima CK-MB previa al cateterismo, a las seis horas y a las 12 horas tras la intervención.

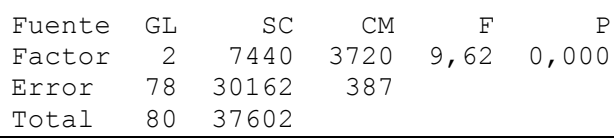




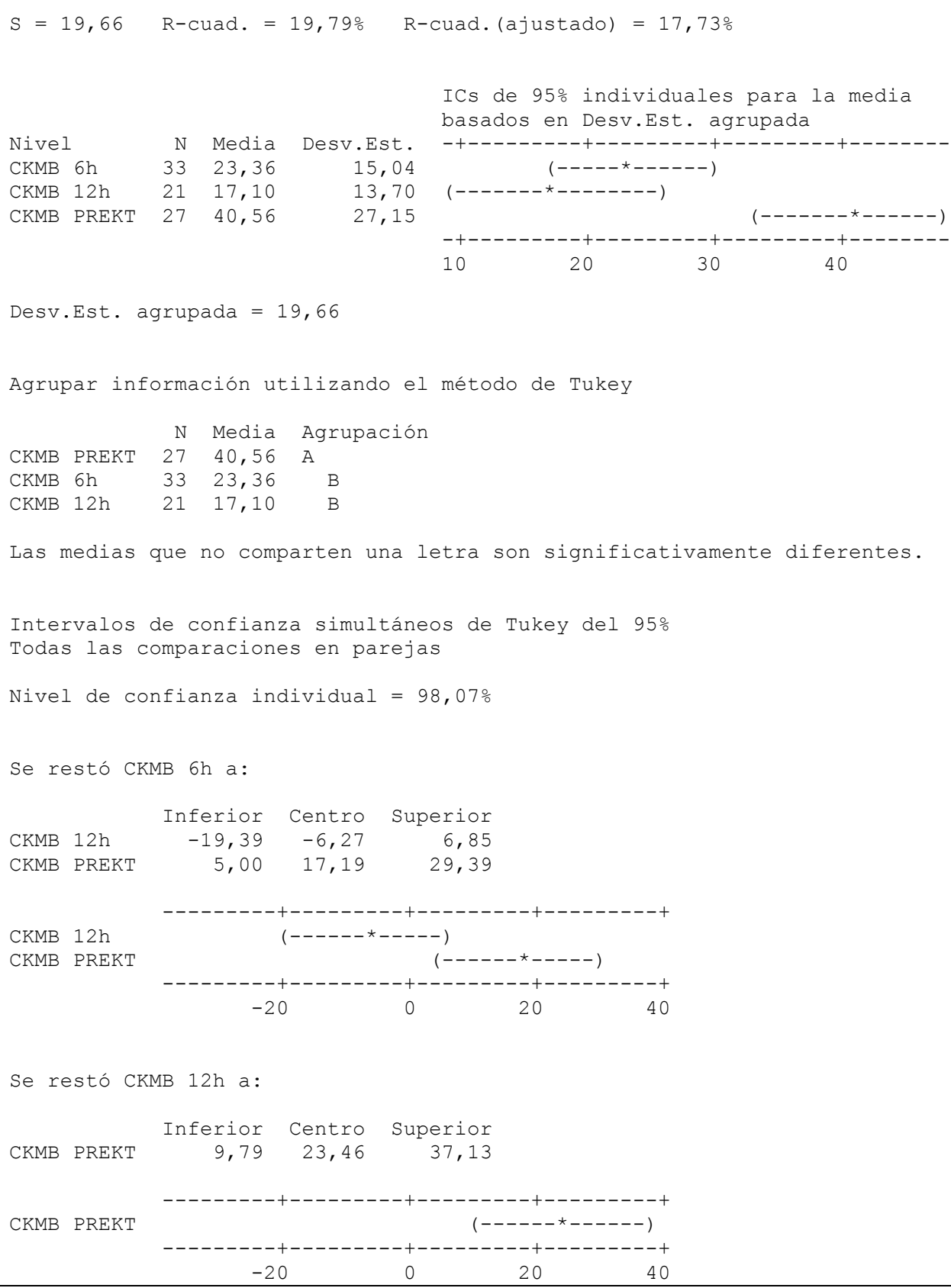

De forma análoga al análisis realizado para la variable CK-MB, se procedió al análisis por medio de ANOVA de los valores de hemoglobina antes y después del cateterismo así como del contaje total de plaquetas pre y post- ICP. Tanto para la variable hemoglobina total como para la variable plaquetas totales se apreció una disminución significativa de sus valores posteriores al procedimiento. 


\section{Oneway Analysis of Hb By ICP}

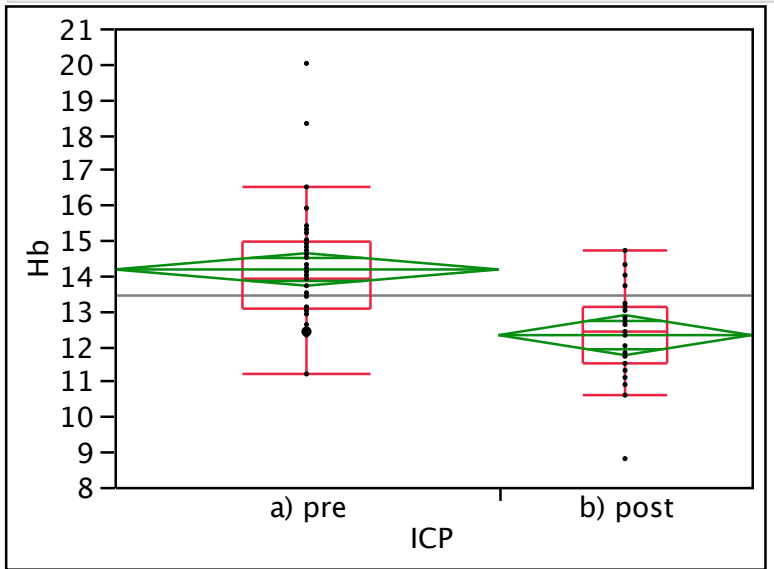

Missing Rows 14

Quantiles

$\begin{array}{lrrrrrrr}\text { Level } & \text { Minimum } & \mathbf{1 0 \%} & \mathbf{2 5 \%} & \text { Median } & \mathbf{7 5 \%} & \mathbf{9 0 \%} & \text { Maximum } \\ \text { a) pre } & 11,2 & 12,44 & 13,05 & 13,9 & 14,95 & 15,8 & 20 \\ \text { b) post } & 8,8 & 10,84 & 11,5 & 12,4 & 13,1 & 14,06 & 14,7\end{array}$

Oneway Anova

\section{Summary of Fit}

$\begin{array}{lr}\text { Rsquare } & 0,281395 \\ \text { Adj Rsquare } & 0,270507 \\ \text { Root Mean Square Error } & 1,476983 \\ \text { Mean of Response } & 13,42206 \\ \text { Observations (or Sum Wgts) } & 68 \\ \text { t Test } & \end{array}$

\section{t Test}

b) post-a) pre

Assuming equal variances

$\begin{array}{lrl}\text { Difference } & -1,8610 \text { t Ratio } \\ \text { Std Err Dif } & 0,3661 \text { DF } \\ \text { Upper CL Dif } & -1,1301 \text { Prob }>|t| \\ \text { Lower CL Dif } & -2,5918 \text { Prob }>t \\ \text { Confidence } & 0,95 \text { Prob }<\mathrm{t}\end{array}$

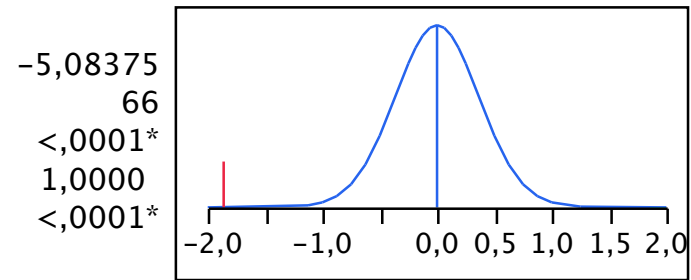

\section{Analysis of Variance}

$\begin{array}{lrrrrr}\text { Source } & \text { DF } & \begin{array}{r}\text { Sum of } \\ \text { Squares }\end{array} & \text { Mean Square } & \text { F Ratio } & \text { Prob > F } \\ \text { ICP } & 1 & 56,37935 & 56,3794 & 25,8446 & <, 0001^{*} \\ \text { Error } & 66 & 143,97756 & 2,1815 & & \\ \text { C. Total } & 67 & 200,35691 & & & \end{array}$

\section{Means for Oneway Anova}

Level Number Mean Std Error Lower 95\% Upper 95\%
a) pre
41
14,1610
0,23067
13,700
14,622
b) post
$27 \quad 12,3000$
0,28425
11,732
12,868

Std Error uses a pooled estimate of error variance

Figura 79: Representación en gráfico de boxplot y ANOVA de los valores de la variable hemoglobina total antes y después del ICP. 
Oneway Analysis of Plq By ICP

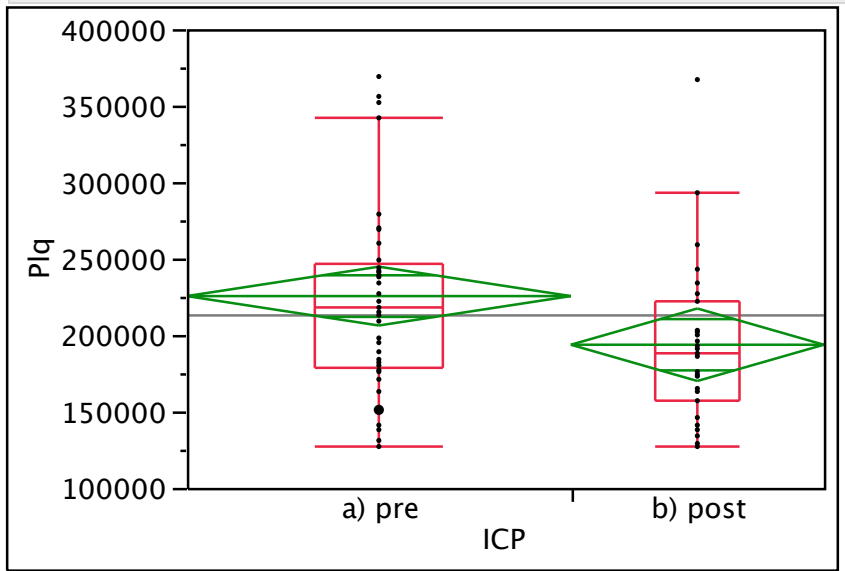

Missing Rows 14

Quantiles

$\begin{array}{lrrrrrrr}\text { Level } & \text { Minimum } & \mathbf{1 0 \%} & \mathbf{2 5 \%} & \text { Median } & \mathbf{7 5 \%} & \mathbf{9 0 \%} & \text { Maximum } \\ \text { a) pre } & 127000 & 143000 & 178500 & 218000 & 246500 & 350000 & 410000 \\ \text { b) post } & 127000 & 133000 & 157000 & 188000 & 222000 & 265800 & 367000\end{array}$

Oneway Anova

\section{Summary of Fit}

Rsquare

Adj Rsquare

Root Mean Square Error

Mean of Response

Observations (or Sum Wgts)
0,061557

0,047338

61707,82

212779,4

68

\section{t Test}

b) post-a) pre

Assuming equal variances

$\begin{array}{lr}\text { Difference } & -31822 \text { t Ratio } \\ \text { Std Err Dif } & 15294 \text { DF } \\ \text { Upper CL Dif } & -1287 \text { Prob }>|t| \\ \text { Lower CL Dif } & -62357 \text { Prob }>t \\ \text { Confidence } & 0,95 \text { Prob }<\mathrm{t}\end{array}$

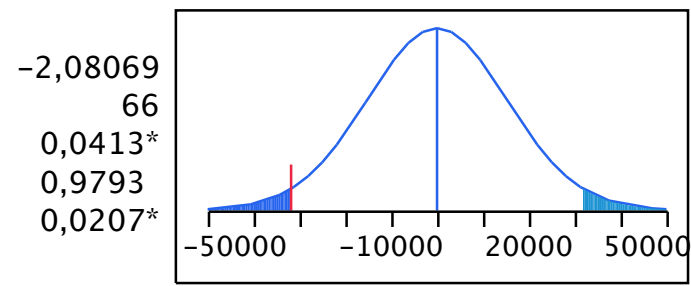

Analysis of Variance

$\begin{array}{lrrrrr}\text { Source } & \text { DF } & \begin{array}{r}\text { Sum of } \\ \text { Squares }\end{array} & \text { Mean Square } & \text { F Ratio } & \text { Prob > F } \\ \text { ICP } & 1 & 1,6485 \mathrm{e}+10 & 1,649 \mathrm{e}+10 & 4,3293 & 0,0413^{*} \\ \text { Error } & 66 & 2,5132 \mathrm{e}+11 & 3,8079 \mathrm{e}+9 & & \\ \text { C. Total } & 67 & 2,678 \mathrm{e}+11 & & & \end{array}$

\section{Means for Oneway Anova}

$\begin{array}{lrrrrr}\text { Level } & \text { Number } & \text { Mean } & \text { Std Error } & \text { Lower 95\% } & \text { Upper 95\% } \\ \text { a) pre } & 41 & 225415 & 9637 & 206173 & 244656 \\ \text { b) post } & 27 & 193593 & 11876 & 169882 & 217303\end{array}$

Std Error uses a pooled estimate of error variance

Figura 80: Representación en gráfica de boxplot y ANOVA de la variable plaquetas totales antes y después del ICP. 


\section{MODELOS PREDICTIVOS MULTIVARIANTES}

\subsection{APLICACIÓN DE UN MODELO MULTIVARIANTE ADAPTATIVO DE REGRESIÓN POR MEDIO DE SPLINES (MARS) A LA MODELIZACIÓN DE LA VARIABLE TROPONINA $6 \mathrm{H}$.}

\subsubsection{MODELIZACIÓN INICIAL}

En el presente apartado se ha realizado un modelo MARS que emplea como variables de entrada todas aquellas que han sido consideradas por criterio clínico y/o bibliográfico como influyentes sobre la variable Troponina T determinada a las 6 horas tras el ICP. Tal y como ya se ha explicado, los modelos MARS (multivariate adaptive regression splines) son una forma de análisis de regresión introducido por Jerome Friedman en 1991. Se trata de una técnica de regresión no paramétrica y puede ser considerada como una extensión de los modelos lineales capaz de modelizar tanto no linealidades como interacciones entre variables.

Para la realización del presente modelo se han utilizado todos aquellos pacientes para los que se dispone de información relativa a la variable Troponina a las 6 horas de la intervención. Se trata de un total de 34 pacientes. Se han empleado como variables de entrada para la realización del modelo todas las variables que se listan en la Tabla 25. En dicha tabla se puede apreciar que la nomenclatura abreviada de las variables hace uso del guión bajo. Esto es debido a que para poder ser procesadas con el software estadístico $\mathrm{R}$, el cual es una evolución del bien conocido lenguaje estadístico denominado S(Chambers, 1992), en el que cada una de ellas ha de corresponderse con un identificador formado por una única palabra sin espacios. La correspondencia de estas variables con los nombres empleados en esta investigación se recoge en la misma tabla.

Tabla 25: Abreviaturas empleadas para la realización del modelo con el programa estadístico $\mathrm{R}$ junto con el significado de cada una de las variables.

\begin{tabular}{|c|c|}
\hline Abreviatura & Significado de la variable \\
Sexo & Sexo del paciente \\
Num_vasos_enf & Número de vasos enfermos \\
Dia_Ref & Diámetro de referencia \\
Flujo_TIMI_pre & Flujo TIMI previo al cateterismo \\
Flujo_TIMI_post & Flujo TIMI posterior al cateterismo \\
PAU_basal & PAU basal \\
PAU_Reopro & PAU post abciximab \\
Dia_Stent & Diámetro del stent \\
Long_Stent & Longitud total del stent/stents \\
Presion_Stent & Presión de inflado \\
DiaRefPOST & Diámetro referencia posterior al \\
Tabaquismo & cateterismo \\
Reopro_si_no & Consumo de tabaco \\
RPP_KT & Utilización o no de abciximab \\
& Reactividad plaquetaria postratamiento en \\
& el momento de la coronariografía \\
\hline
\end{tabular}


Con el fin de poder realizar el modelo, la información disponible fue procesada previamente. Así, en aquellas variables de las que no se disponía de datos para alguno de los pacientes se ha optado por reemplazar el valor faltante por la mediana de dicha variable en la muestra de pacientes. Tal y como ha sido puesto de manifiesto con anterioridad por otros autores(Farhangfar, 2007; Myrtveit, 2001), la imputación de la mediana es probablemente la técnica más ampliamente usada para la realización de sustituciones y ha demostrado también ser una de las más efectivas. Otra de las motivaciones fundamentales para su uso es la rapidez computacional que proporciona. Además, y dado que los modelos MARS permiten el empleo de variables categóricas, ), éstas han sido incluidas en el modelo. Para dichas variables se han empleado las codificaciones que se exponen a continuación: para la variable sexo 0 significa mujer y 1 varón. En la variable tabaquismo se ha codificado como 0 a los no fumadores, 1 a los fumadores y 0,5 a los ex fumadores.

El modelo conseguido a partir de todas estas variables ha sido el que se representa en la Tabla 26. En dicha tabla se recoge la información fundamental de dicho MARS. En concreto, los términos componentes de cada uno de los sumandos de la ecuación. Intercept representa el término independiente y tal y como se explicó en Material y Metodología, el significado de la función h es el siguiente:

$$
h(x)=x \text { si } x \geq 0 y h(x)=0 \text { si } x<0
$$

Tabla 26: Ecuación del modelo MARS generado para la variable de salida Troponina a las 6 horas.

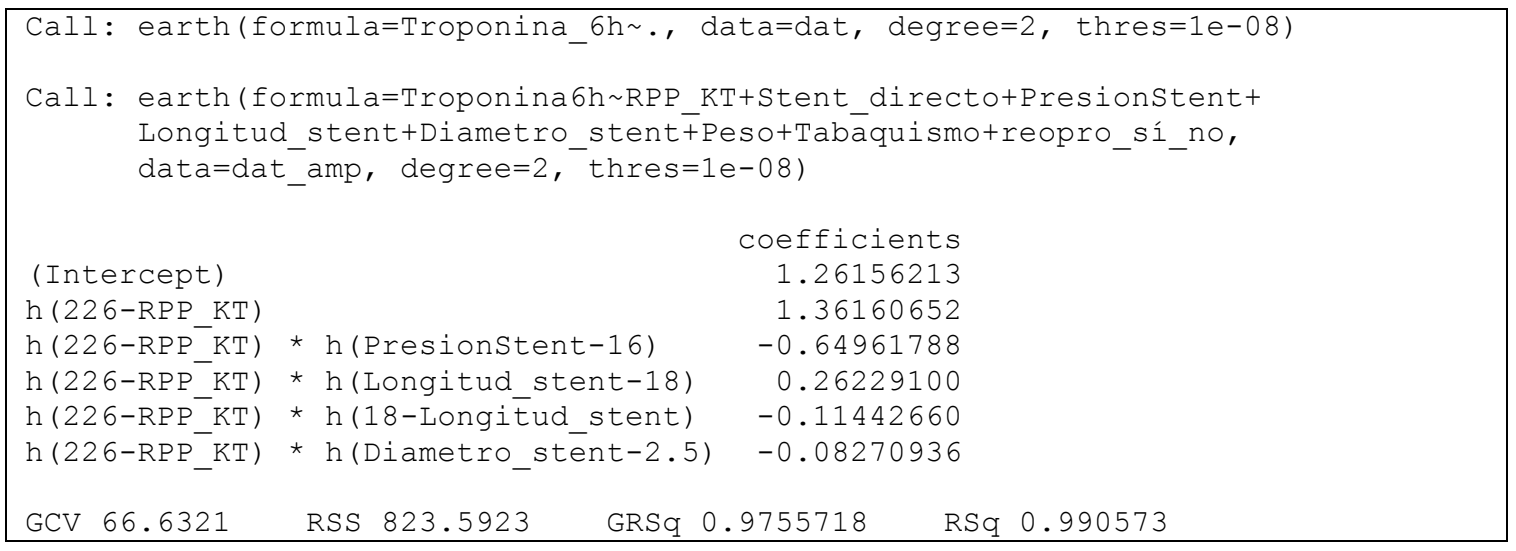

Así, en la Tabla 26 se puede observar cómo del total de 14 variables (predictores) que habían sido elegidas a priori como influyentes según el criterio del experto, el modelo MARS ha empleado un total de 4, de las cuales todas ellas participan en términos en los que se ponen de manifiesto relaciones de dos a dos variables y además una de ellas forma un término lineal (RPP_KT). Finalmente resulta de interés destacar que el Rsq obtenido por este modelo es del 99,06\% mientras que el valor del Rsq (adj) es del 98,92\%, valor que puede ser considerado como muy elevado (buen ajuste de la variable de salida frente a las variables de entrada seleccionadas). Debe tenerse en cuenta que el Rsq (adj) ${ }^{1}$ representa el

\footnotetext{
${ }^{1} R s q a d j{ }^{2}=R^{2}-\left(1-R^{2}\right) \frac{p}{n-p-1}$ siendo $\mathrm{n}$ el número de pacientes y p el número de predoctores.
} 
ajuste del modelo teniendo en cuenta el número de pacientes y predictores que se han utilizado para su elaboración.

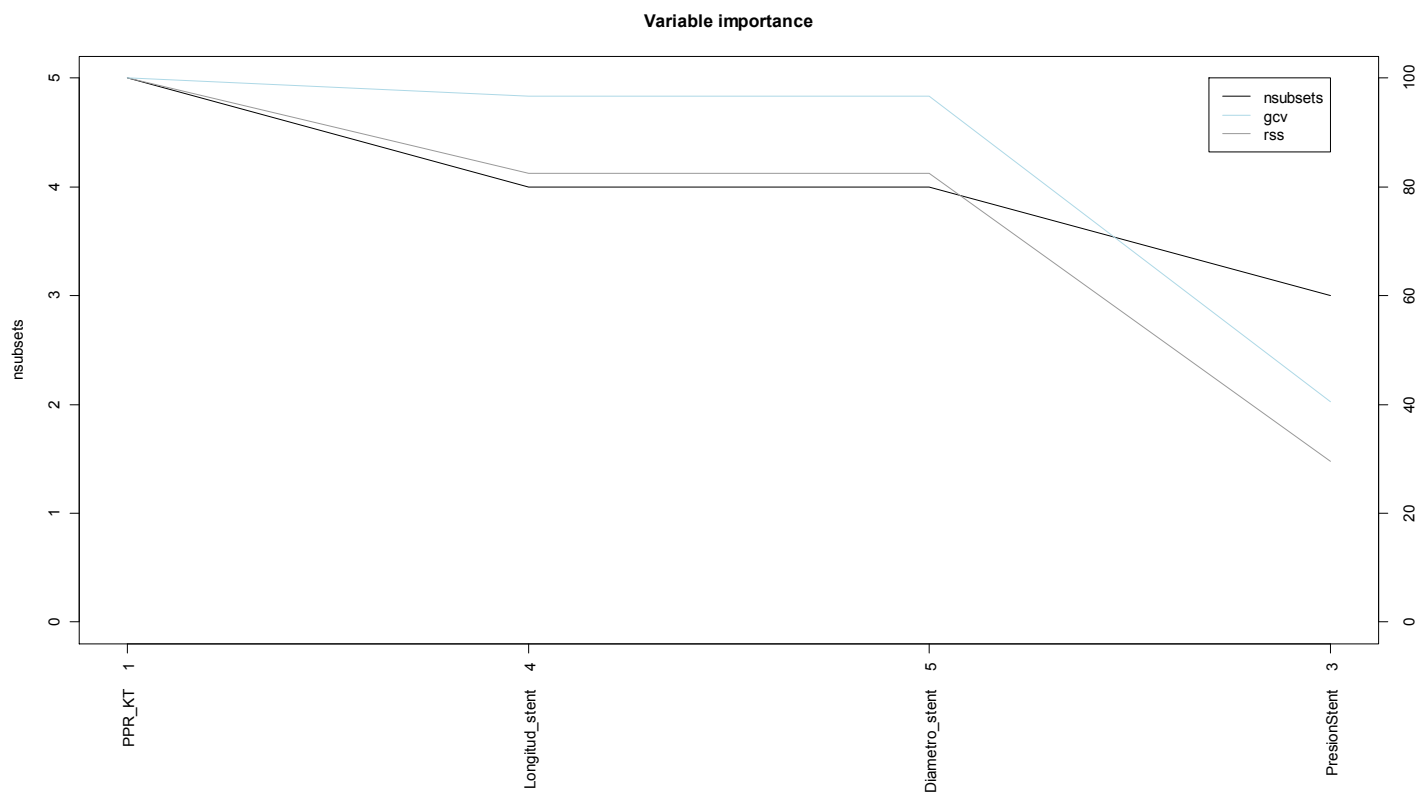

Figura 81: Variables empleadas por el modelo y orden de importancia de las mismas.

En la figura precedente vemos las variables que han sido utilizadas por el modelo y su orden de importancia. Igualmente, dicha información se encuentra recogida de una manera cuantitativa en la Tabla 27. En dicha tabla se ordenan por importancia atendiendo a los tres criterios descritos en Material y Metodología: nsubsets, GCV y RSS que en el presente caso y como es habitual coinciden en su ordenación en todas las variables. A la vista de los resultados, se puede afirmar que la variable más importante para determinar el valor de la variable Troponina en los pacientes de la muestra seis horas después de la intervención es el RPP_KT, siendo la siguiente en importancia la longitud del stent, su diámetro y finalmente la presión de inflado empleada durante la intervención.

Tabla 27: Orden de importancia de las variables utilizadas por el modelo.

\begin{tabular}{|lcrr|}
\hline COl used & nsubsets & gCV & \multicolumn{1}{c|}{ rSs } \\
RPP_KT & 5 & 100.00000 & 100.00000 \\
Longitud_stent & 4 & 96.75299 & 82.55201 \\
Diametro_stent & 4 & 96.75299 & 82.55201 \\
Presionstent & 3 & 40.45977 & 29.51067 \\
\hline
\end{tabular}

La participación de las variables en la construcción del modelo puede verse reflejada en el gráfico de la siguiente figura. Dicho gráfico representa los términos de la ecuación en los que existe interacción entre una y dos variables frente a la variable de salida. Esta figura es una representación gráfica de la ecuación descrita anteriormente en la Tabla 27. 


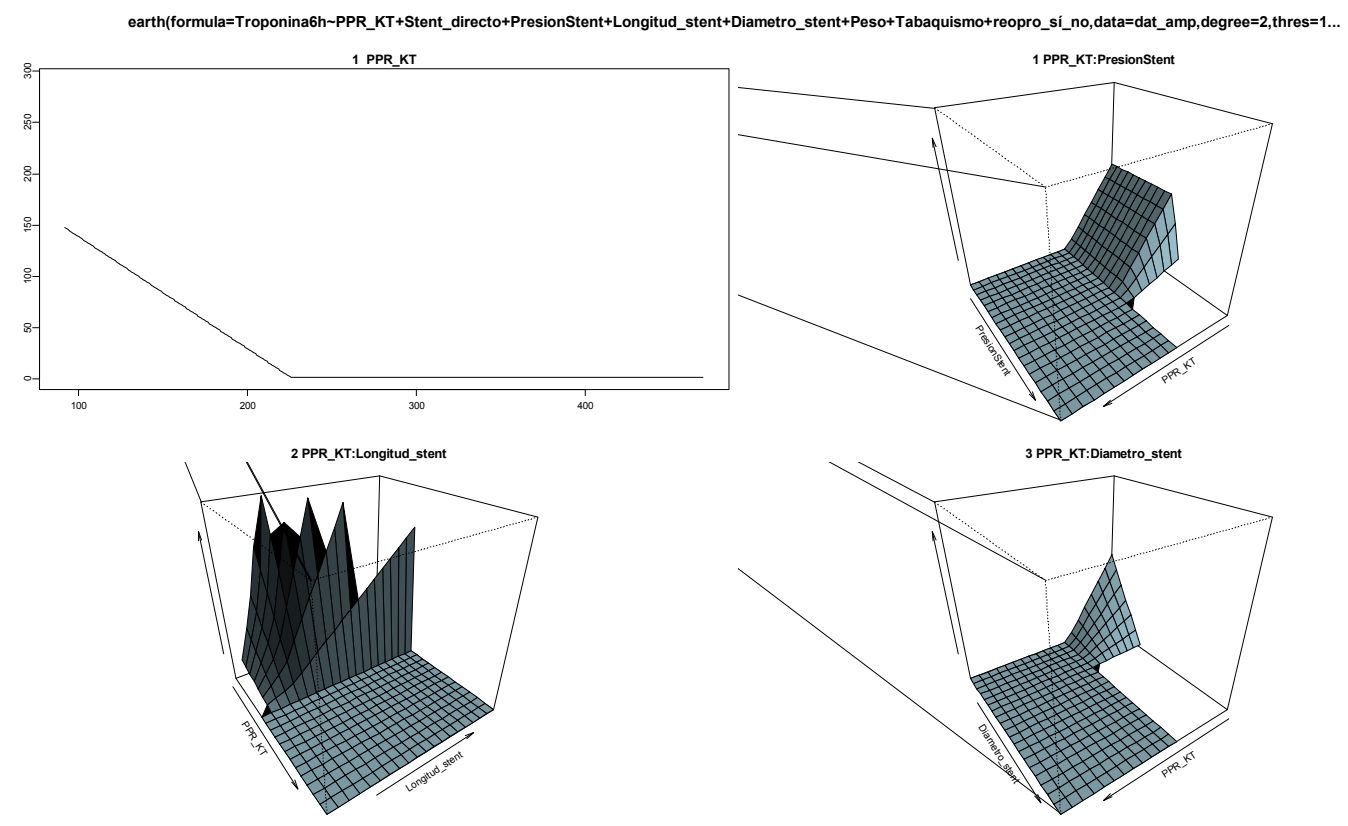

Figura 82: Representación gráfica de los términos componentes del modelo MARS de la variable de salida Troponina T a las 6 horas.

\subsubsection{VALIDACIÓN CRUZADA EXHAUSTIVA DEL MODELO}

Dado que para la realización del modelo del valor de Troponina en los pacientes a las 6 horas se disponía solo de la información relativa a un grupo de 34, resulta necesario realizar algún tipo de validación que permita afirmar que el modelo obtenido es coherente y no simplemente el resultado de un sobre-entrenamiento matemático que si bien es capaz de ajustar los datos usados para su construcción es inútil a la hora de inferir conocimiento sobre pacientes ajenos a la muestra empleada para dicho entrenamiento. Este es el motivo fundamental por el que se ha optado en el presente apartado por realizar una validación cruzada. La metodología que se aplica para dicha validación se encuentra resumida en la parte correspondiente de Material y Métodos y su esquema se presenta en la Figura 24.

A continuación, en la Figura 83, se presentan dos curvas que representan respectivamente los valores reales de la variable Troponina a las 6 horas (curva de color rojo) frente a los valores predichos por los modelos aplicados a cada uno de los pacientes (curva de color azul) Se puede observar cómo el modelo es capaz de detectar los pacientes con elevaciones del valor de la variable Troponina. Uno de los inconvenientes que tiene la aplicación de esta técnica es que tal y como se puede observar en esta figura, se obtienen valores de la variable Troponina a las 6 horas sin valor biológico (valores negativos). 


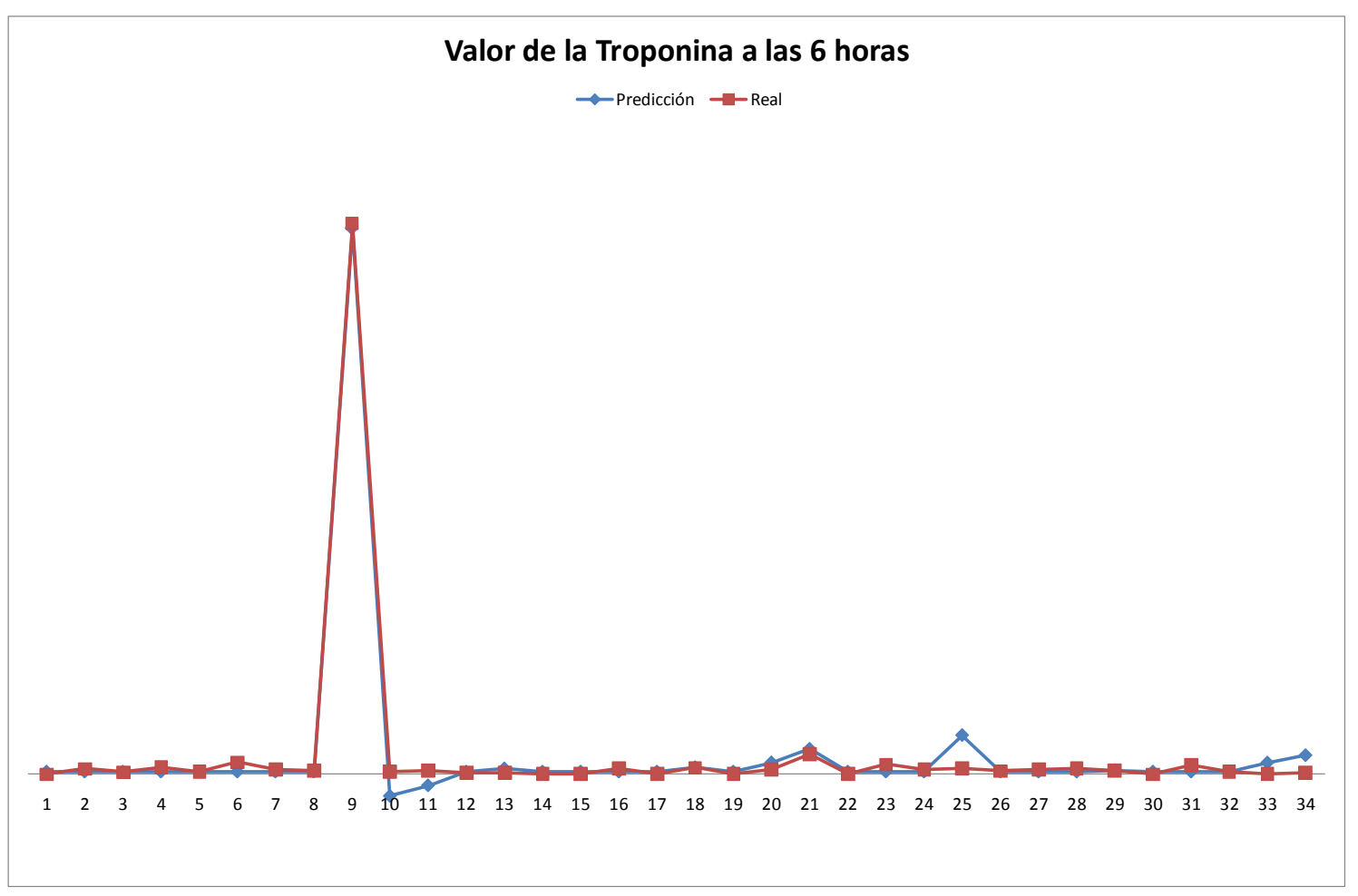

Figura 83: Representación del valor real y el predicho por los modelos para el valor de la Troponina a las 6 horas.

Si se generaliza y al modelo entrenado para la predicción del paciente i-ésimo se le denomina Modelo $_{i}=\operatorname{abs}\left(f\left(\right.\right.$ Dia $_{\text {Stent }}$, Presion $_{\text {Stent }}, P P R_{K T}$, Longitud $\left.\left._{\text {Stent }}\right)\right)$ dicho modelo puede mejorarse y hacer que no tome valores negativos aplicando la función valor absoluto, es decir:

Modelo $_{i}=\operatorname{abs}\left(f\left(\right.\right.$ Dia $_{\text {Stent }}$, Presion $_{\text {Stent }}, P P R_{K T}$, Longitud $\left.\left._{\text {Stent }}\right)\right)$

Así, si aplicamos esta modificación a los modelos realizados, se obtiene la representación de la Figura 84, en la que se observa con claridad cómo el modelo es capaz de reproducir el comportamiento de la variable Troponina a las 6 horas en los distintos pacientes de la muestra. 


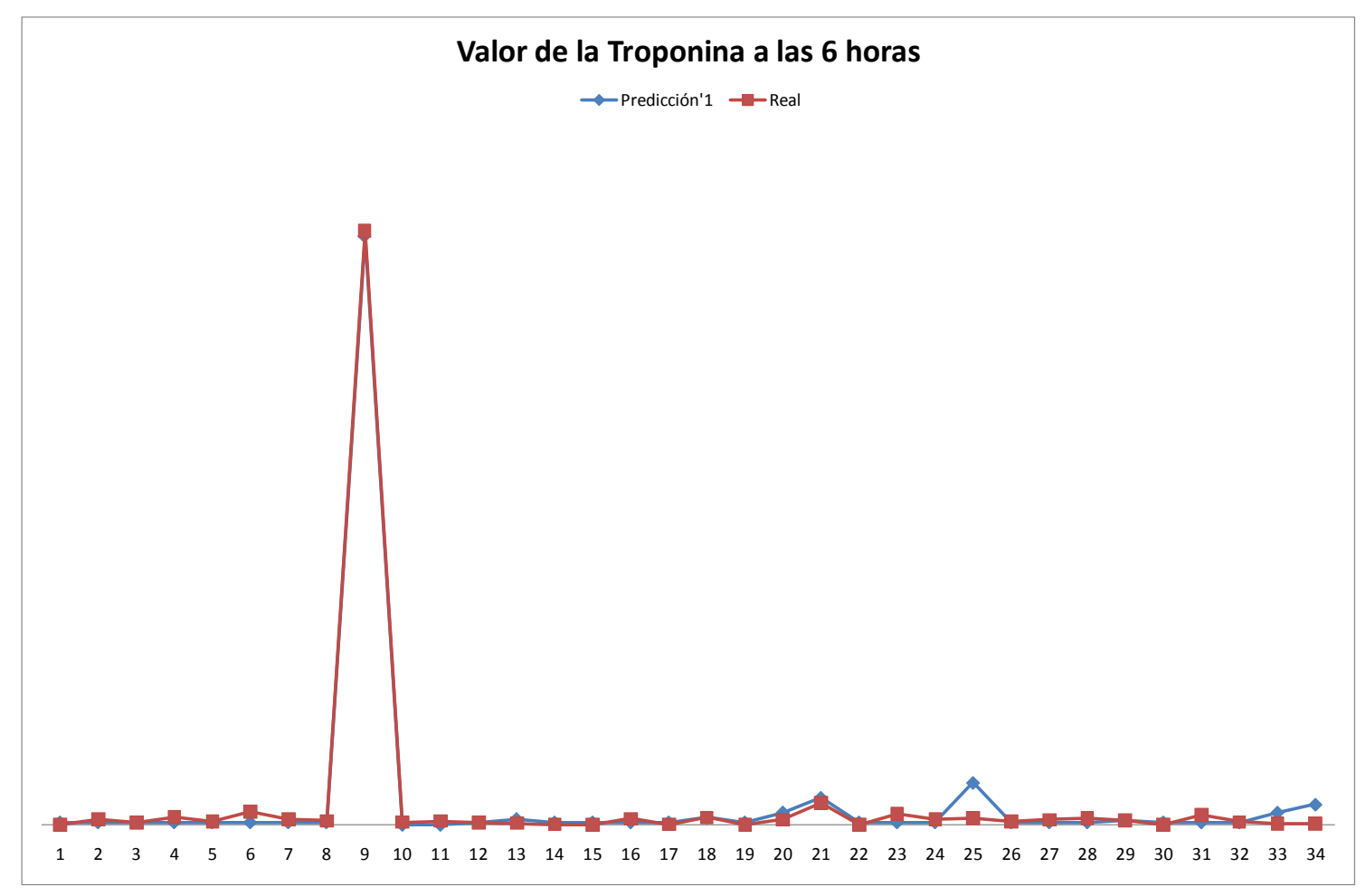

Figura 84: Representación del valor real y el predicho por los modelos mejorados para el valor de la Troponina a las 6 horas.

\subsection{MODELIZACIÓN DEL VALOR DE LA VARIABLE RPP EN EL MOMENTO DEL CATETERISMO TOMANDO COMO VARIABLES DE ENTRADA TODAS LAS DISPONIBLES EN LOS PACIENTES DE LA MUESTRA.}

En el presente apartado, se realiza una modelización de la variable RPP empleando como posibles variables de entrada todas las disponibles en los pacientes de la muestra.

Dado que algunas variables disponibles en la base de datos no eran numéricas, se ha realizado su conversión de manera que se expresasen en forma de valores numéricos. Con el fin de mantener la trazabilidad en el proceso de conversión, los valores empleados se muestran en la Tabla 28.

Tal y como se hizo para la modelización efectuada con la variable Troponina a las 6 horas, también en este caso en aquellas variables de las que no se disponía de información para alguno de los pacientes se ha optado por reemplazar el valor faltante por la mediana de dicha variable en la muestra de pacientes. 
Tabla 28: Codificación empleada para la conversión de variables cualitativas en numéricas.

\begin{tabular}{|l|l|}
\hline Sexo: & AnginaPreinfarto: \\
0 mujer & 0 no ha tenido \\
1 varón & 11 a 7 días \\
Antiagregantes previos: & $2<24$ horas \\
0 no & Tabaquismo: \\
1 sí & 0 no \\
Transfusion: & 0,5 exfumador \\
0 no & 1 fumador \\
1 sí & Localiz. Infarto: \\
DM: & 0 Inferior \\
0 no & 1 lateral \\
1 Dieta & 2 anterior \\
2 ADO & Heparinas: \\
Interv_Coronario: & 0 HBPM \\
0 no & 1 HNF \\
1 electiva & \\
2 cirugía & \\
\hline
\end{tabular}

\subsubsection{REDUCCIÓN DIMENSIONAL}

Dado el elevado número de variables de entrada disponibles en los pacientes de la muestra, antes de proceder a la modelización es necesario efectuar una reducción dimensional que permita desechar cierto número de variables. Antes de llevar a cabo este proceso de reducción dimensional, se procedió a la normalización de los datos.

\subsubsection{Aplicación del método de las componentes principales}

La primera técnica empleada con el fin de lograr la reducción dimensional fue el análisis de componentes principales. A la vista de los resultados obtenidos se descartó la posibilidad de aplicación de dicha técnica, dado que era necesario el empleo de 27 componentes para representar un 99\% de la variabilidad de los datos (en el caso de querer representar el $90 \%$ de la variabilidad, el número de 
componentes necesarias era de 18). Sin embargo y dado que se trata de una técnica conocida y de empleo generalizado se quiere destacar los resultados de su aplicación a nuestro caso.

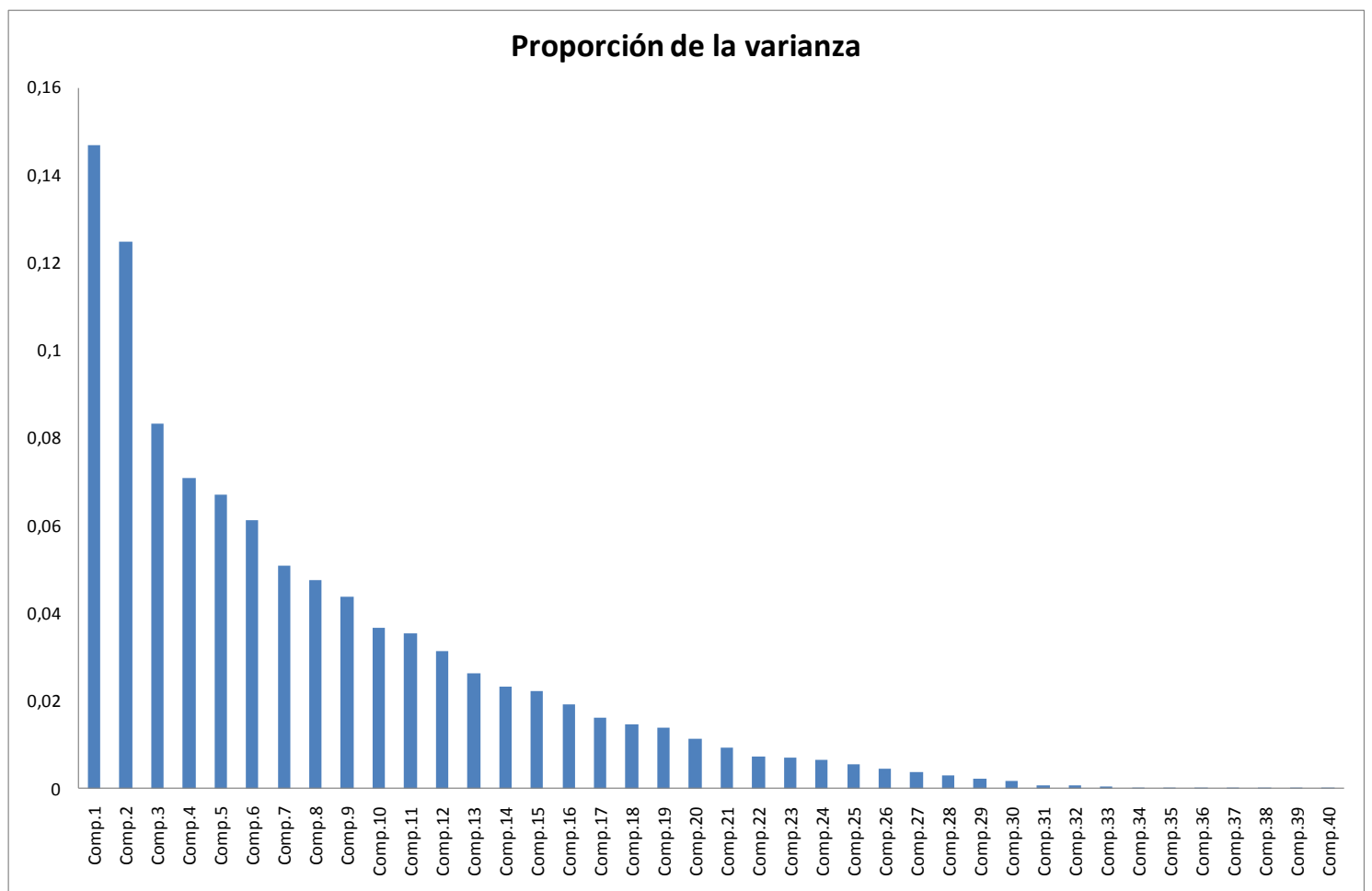

Figura 85: Proporción de la varianza contenida en cada una de las componentes principales.

\subsubsection{Selección de variables por medio de la determinación del mejor subconjunto posible para la realización de un modelo lineal multivariante}

Aplicando la técnica de selección de variables por medio del mejor subconjunto posible para la realización de un modelo lineal multivariante se ha obtenido el modelo lineal cuya ecuación de regresión se presenta en la Tabla 29. Así el subconjunto de variables seleccionado y que se empleará como entrada para el siguiente paso del proceso es el que se lista en Tabla 30.

Tabla 29: Ecuación de regresión del modelo obtenido aplicando la selección de variables por medio de la determinación del mejor subconjunto posible para la realización de un modelo lineal multivariante.

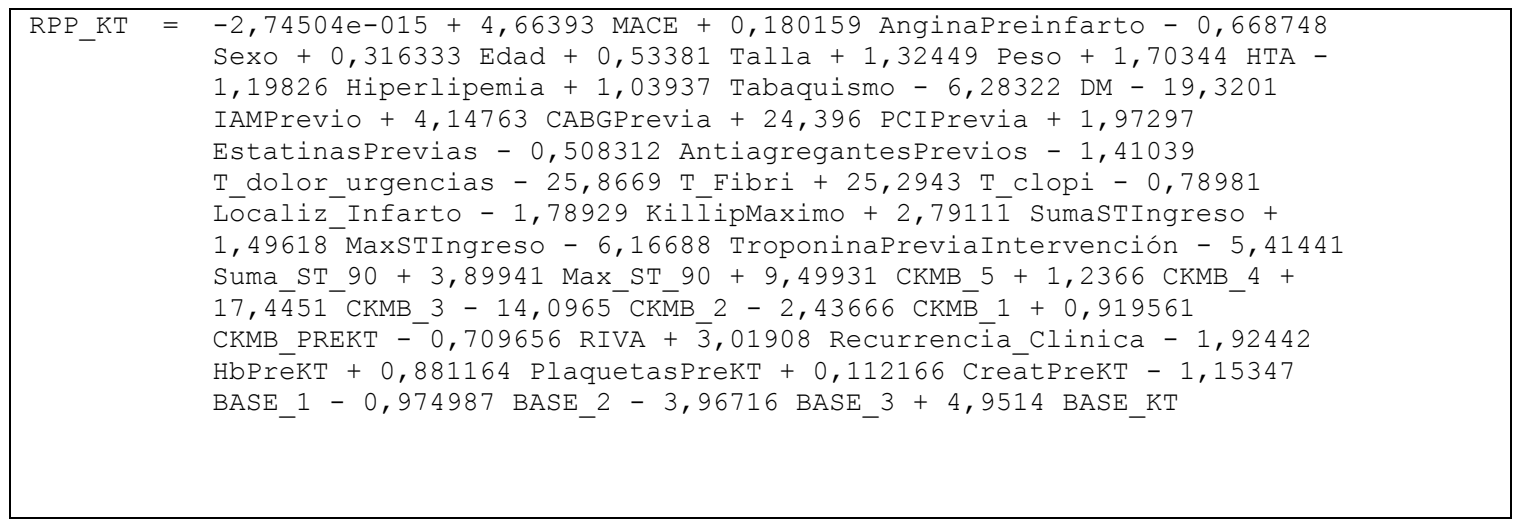


Tabla 30: Variables consideradas de importancia por el modelo de regresión lineal multivariante para la variable de salida RPP KT.

\begin{tabular}{cc}
\hline Codificación de la variable & Codificación de la variable \\
\hline AnginaPreinfarto & IAMPrevio \\
AntiagregantesPrevios & KillipMaximo \\
BASE_1 & Localiz_Infarto \\
BASE_2 & MACE \\
BASE_3 & Max_ST_90 \\
BASE_KT & MaxSTIngreso \\
CABGPrevia & PCIPrevia \\
CKMB_1 & Peso \\
CKMB_2 & PlaquetasPreKT \\
CKMB_3 & Recurrencia_Clinica \\
CKMB_4 & RIVA \\
CKMB_5 & Sexo \\
CKMB_PREKT & Suma_ST_90 \\
CreatPreKT & SumaSTIngreso \\
DM & T_clopi \\
Edad & T_dolor_urgencias \\
EstatinasPrevias & T_Fibri \\
HbPreKT & Tabaquismo \\
Hiperlipemia & Talla \\
HTA & TroponinaPrevialntervención \\
\hline
\end{tabular}

\subsubsection{MODELIZACIÓN MARS DE LA VARIABLE RPP EN EL MOMENTO DE LA CORONARIOGRAFÍA ELECTIVA}

En el presente apartado se proponen una serie de modelos MARS de la variable RPP en el momento de la coronariografía electiva. En primer lugar, se realizó un modelo en el que se han empleado como variables de entrada todas las recogidas en la Tabla 30. La ecuación del modelo obtenido y sus principales características se exponen en la Tabla 31. El valor del Rsq del modelo es de 0,9450, es decir, del $94,50 \%$, valor que nos hace poder afirmar que con este modelo se obtiene un muy buen ajuste de la variable RPP en el momento de la coronariografía. Una lista de las variables que intervienen en dicho modelo ordenadas por importancia se recoge en la Tabla 32. Se observa cómo del total de 40 variables de entrada el modelo sólo emplea 7.

Finalmente, en la Figura 86 se muestra una representación gráfica de la ecuación. 
Tabla 31: Coeficientes e indicadores principales del modelo MARS obtenido.

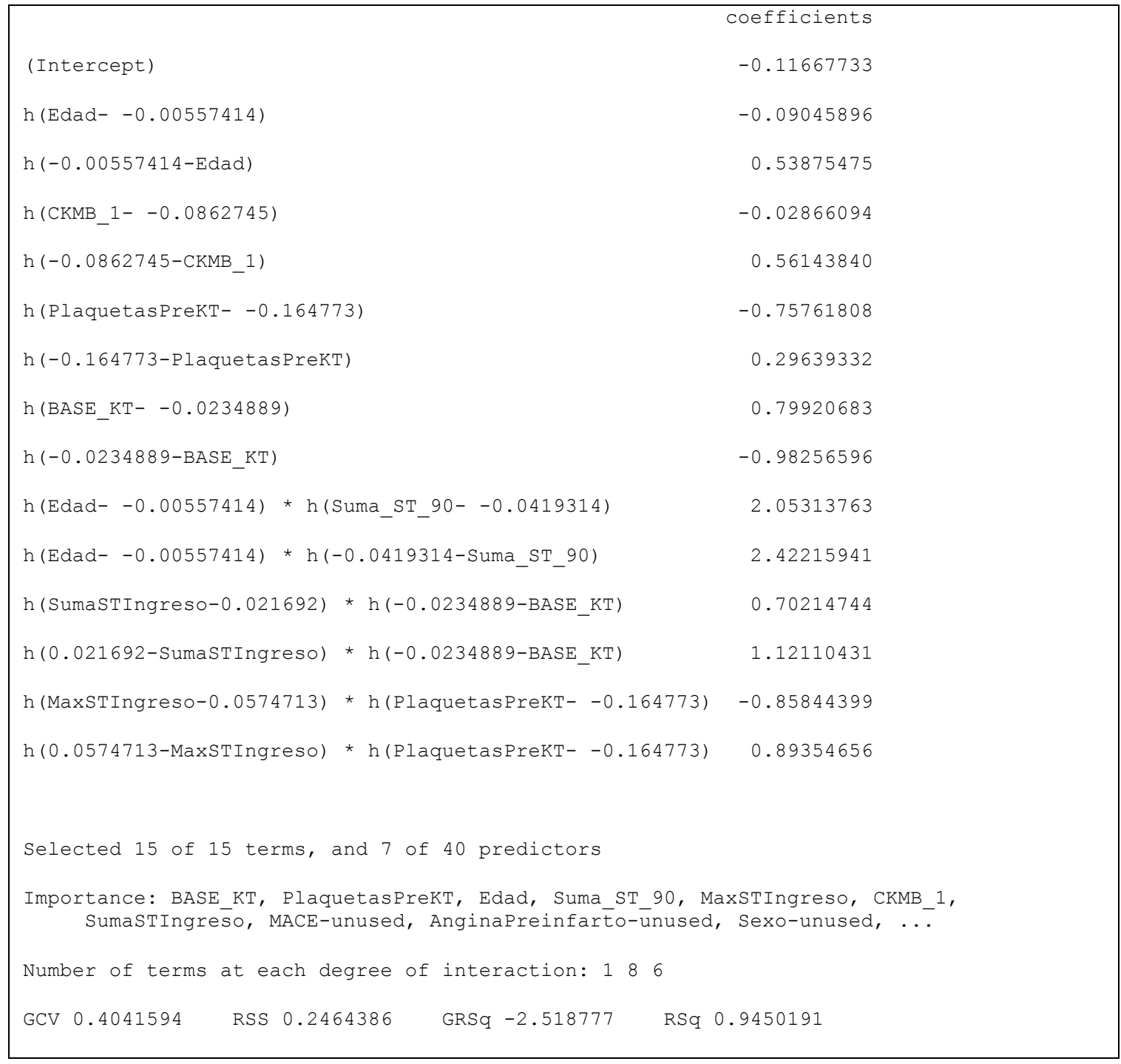

Tabla 32: Variables que intervienen en el modelo MARS clasificadas por importancia.

\begin{tabular}{|lccc|}
\hline & nsubsets & gCV & rSS \\
BASE_KT & 14 & -81.35477 & 100.000000 \\
PlaquetasPreKT & 12 & -97.00164 & 35.951627 \\
Edad & 11 & -97.86031 & 28.340540 \\
Suma_ST_90 & 9 & -99.71961 & 15.759586 \\
MaxSTIngreso & 9 & -100.00000 & 15.287153 \\
CKMB_1 & 8 & -99.16487 & 12.724649 \\
SumaSTIngreso & 6 & -99.81871 & 5.513784 \\
\hline
\end{tabular}




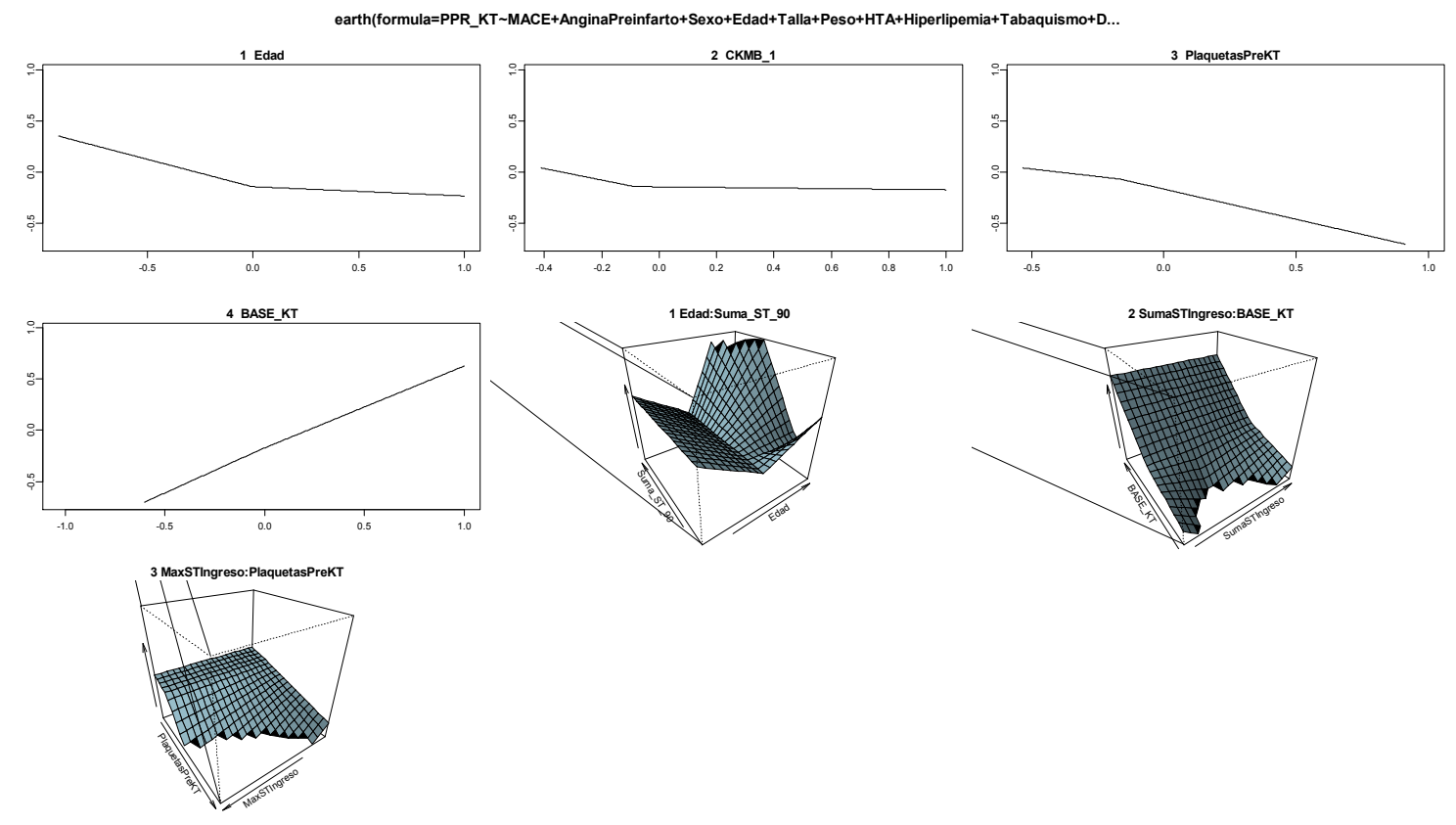

Figura 86: Representación gráfica del modelo MARS obtenido.

Si se comparan los resultados obtenidos por el modelo anterior con las variables recogidas en la Tabla 33 (variables consideradas de importancia según criterio clínico y bibliográfico) se observa que si bien el modelo obtenido está formado por variables contenidas en dicha tabla salvo la variable CKMB1, no se incluyen exactamente las consideradas de mayor importancia según estos criterios clínicos y bibliográficos.

Tabla33: Variables consideradas de importancia según criterio experto (clasificación de su importancia según experiencia clínica y revisión bibliográfica e inclusión en el modelo).

\begin{tabular}{ccc}
\hline Nombre de la variable & Importancia & Incluida en el modelo \\
\hline AnginaPreinfarto & 3 & No \\
AntiagregantesPrevios & 3 & No \\
BASE_KT & 3 & Sí \\
CABGPrevia & 1 & No \\
CKMB_2 & 3 & No \\
CKMB_3 & 3 & No \\
DM & 2 & No \\
Edad & 3 & Sí \\
EstatinasPrevias & 2 & No \\
Hiperlipemia & 1 & No \\
HTA & 1 & No \\
IAMPrevio & 1 & No \\
Max_ST_90 & 2 & Sí \\
MaxSTIngreso & 2 & No \\
Peso & 2 & No \\
PlaquetasPreKT & 3 & Sí
\end{tabular}




$\begin{array}{ccc}\text { Sexo } & 1 & \text { No } \\ \text { Suma_ST_90 } & 2 & \text { Sí } \\ \text { SumaSTIngreso } & 2 & \text { Sí } \\ \text { T_clopi } & 1 & \text { No } \\ \text { T_Fibri } & 2 & \text { No } \\ \text { Tabaquismo } & 2 & \text { No } \\ \text { Talla } & 1 & \text { No }\end{array}$

Así, se procede a continuación a realizar un modelo empleando solamente aquellas variables consideradas como de nivel de importancia 3 (AnginaPreinfarto, AntiagregantesPrevios, BASE_KT, CKMB_2,CKMB_3, Edad y PlaquetasPreKT) El resultado de este modelo es el que se presenta en la Tabla 34. La relación de variables que forman parte de ese modelo y el orden de importancia de las mismas se recoge en la Tabla 35. Finalmente, en la Figura 87 se realiza la representación gráfica del modelo MARS obtenido con las variables de nivel de importancia 3.

Tabla 34: Coeficientes e indicadores principales del modelo MARS obtenido usando como variables de entrada aquellas consideradas como de nivel de importancia 3.

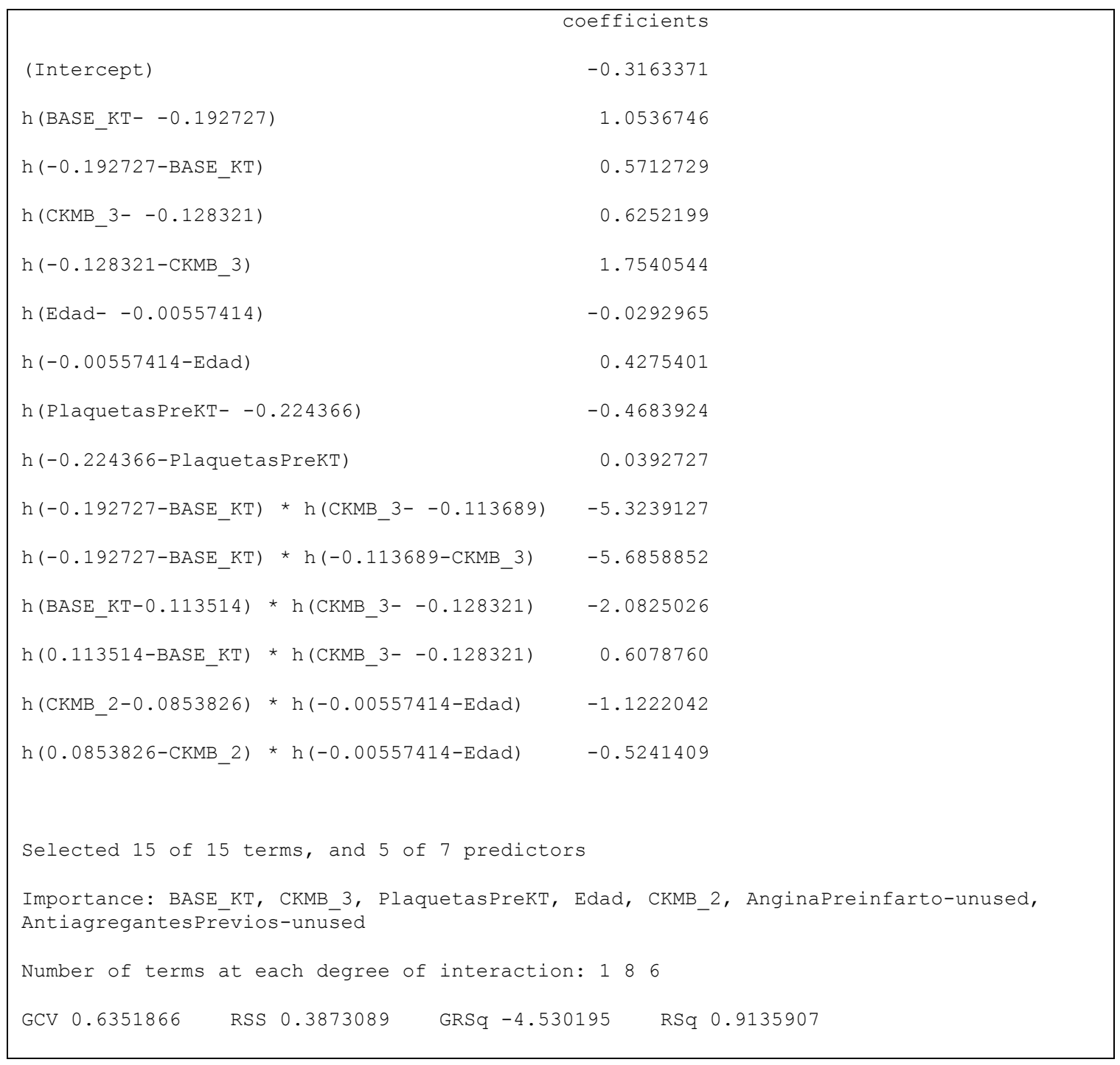


Tabla 35: Clasificación por orden de importancia de las variables que emplea el modelo MARS de las variables de nivel de importancia 3.

\begin{tabular}{|lcccccccc|}
\hline & Col used & nsubsets & gCV & rSs \\
BASE_KT & 3 & 1 & 14 & -88.22827 & 1 & 100.000000 & 1 \\
CKMB_3 & 5 & 1 & 13 & -98.35078 & 1 & 36.743179 & 1 \\
PlaquetasPreKT & 7 & 1 & 12 & -98.97554 & 1 & 28.100005 & 1 \\
Edad & 6 & 1 & 11 & -100.00000 & 1 & 19.125142 & 1 \\
CKMB_2 & 4 & 1 & 7 & -99.56596 & 0 & 5.013353 & 1 \\
\hline
\end{tabular}
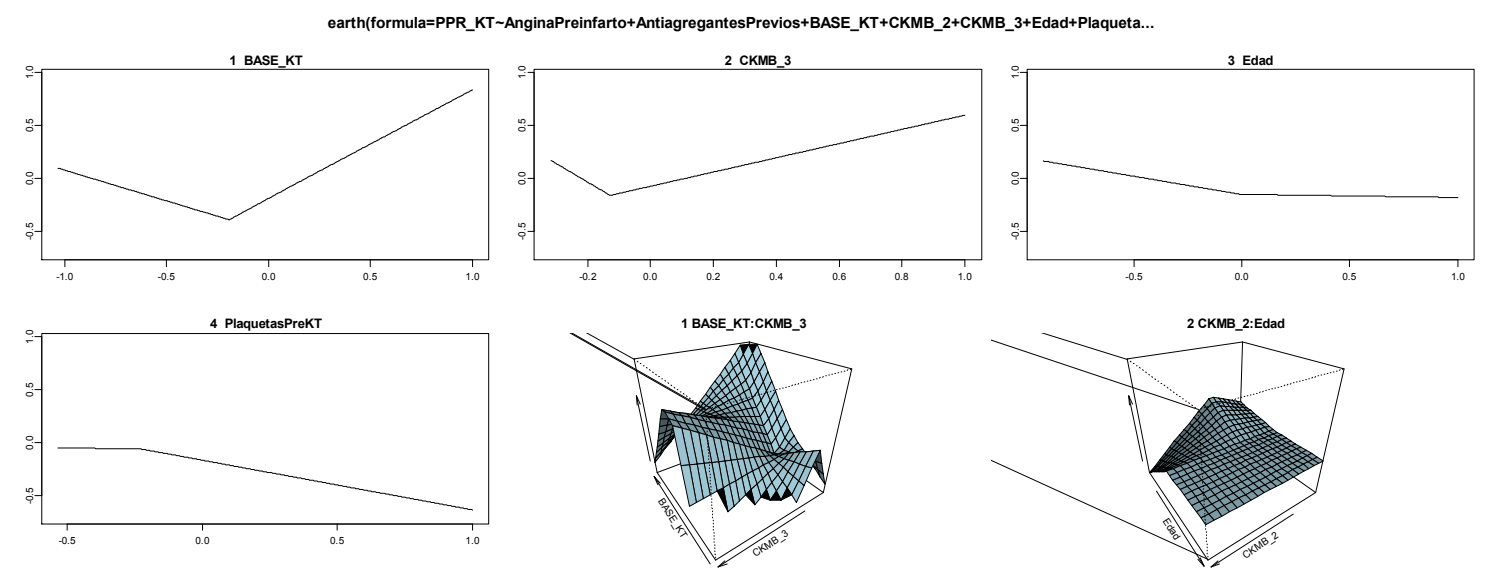

Figura 87: Representación gráfica del modelo MARS obtenido con las variables de nivel de importancia 3.

Finalmente y como último modelo a incluir en este apartado se repite el modelo anterior incluyendo además de las variables de nivel de importancia 3 aquellas consideradas de nivel 2, dado que todas las obtenidas en el primer modelo elaborado son bien de nivel 2 o de nivel 3. El valor del RSq obtenido en este último modelo es del 93,77\%, muy similar al de los dos anteriores. Las variables que constituyen este último modelo (Tabla 36) son BASE_KT, PlaquetasPreKT, Edad, MaxSTIngreso, Suma_ST_90, SumaSTIngreso y CKMB_3.

Tabla 36: Coeficientes e indicadores principales del modelo MARS obtenido usando como variables de entrada aquellas consideradas como de nivel de importancia 2 y 3.

\begin{tabular}{|lc|}
\hline & coefficients \\
(Intercept) & -0.12274564 \\
h(BASE_KT- -0.0234889$)$ & 0.80151264 \\
\hline
\end{tabular}




\begin{tabular}{|c|c|}
\hline $\mathrm{h}(-0.0234889-$ BASE_KT $)$ & -1.03841900 \\
\hline h (CKMB_3- - 0.128321$)$ & 0.01805315 \\
\hline h $\left(-0.128321-C K M B \_3\right)$ & 0.84526535 \\
\hline h(Edad- -0.00557414) & -0.08383675 \\
\hline h $(-0.00557414-E d a d)$ & 0.52740953 \\
\hline h(PlaquetasPreKT- -0.164773$)$ & -0.81305874 \\
\hline h (-0.164773-PlaquetasPreKT) & 0.26367896 \\
\hline $\mathrm{h}(-0.0234889-$ BASE_KT $) * \mathrm{~h}($ SumaSTIngreso- -0.0672451$)$ & 0.71633077 \\
\hline$h\left(-0.0234889-B A S E \_K T\right) * h(-0.0672451$-SumaSTIngreso $)$ & 1.91254664 \\
\hline $\mathrm{h}($ Edad --0.00557414$) * \mathrm{~h}($ Suma_ST_90- -0.0419314$)$ & 1.99281268 \\
\hline h(Edad- -0.00557414) *h(-0.0419314-Suma_ST_90) & 2.64426955 \\
\hline h(PlaquetasPreKT- -0.164773$) * h($ MaxSTIngreso-0.0574713) & -0.63446255 \\
\hline$h($ PlaquetasPreKT- -0.164773$) * h(0.0574713$-MaxSTIngreso) & 1.17897476 \\
\hline \multirow{2}{*}{\multicolumn{2}{|c|}{$\begin{array}{l}\text { Selected } 15 \text { of } 15 \text { terms, and } 7 \text { of } 16 \text { predictors } \\
\text { Importance: BASE_KT, PlaquetasPreKT, Edad, MaxSTIngreso, Suma_ST_90, SumaSTIngreso, } \\
\text { CKMB_3, AnginaPreinfarto-unused, AntiagregantesPrevios-unused, CKMB_2-unused, ... }\end{array}$}} \\
\hline & \\
\hline Number of terms at each degree of interaction: 186 & \\
\hline GCV $0.4577461 \quad$ RSS 0.2791135 & 0.9377293 \\
\hline
\end{tabular}

Tabla 37: Clasificación por orden de importancia de las variables que emplea el modelo MARS de las variables de nivel de importancia 2 y 3.

\begin{tabular}{|lccccccc|}
\hline & Col used nsubsets & \multicolumn{1}{c|}{ gCV } & rSS \\
BASE_KT & 3 & 1 & 14 & -83.30659 & 1 & 100.000000 & 1 \\
PlaquetasPreKT & 7 & 1 & 12 & -96.82488 & 1 & 35.453722 & 1 \\
Edad & 6 & 1 & 11 & -97.56674 & 1 & 27.783467 & 1 \\
MaxSTIngreso & 11 & 1 & 10 & -99.89463 & 1 & 17.687134 & 1 \\
Suma_ST_90 & 13 & 1 & 9 & -99.53338 & 0 & 14.453967 & 1 \\
SumaSTIngreso & 14 & 1 & 7 & -100.00000 & 1 & 6.9163451 \\
CKMB_3 & 5 & 1 & 6 & -99.44786 & 0 & 4.5985621 & 1 \\
\hline
\end{tabular}




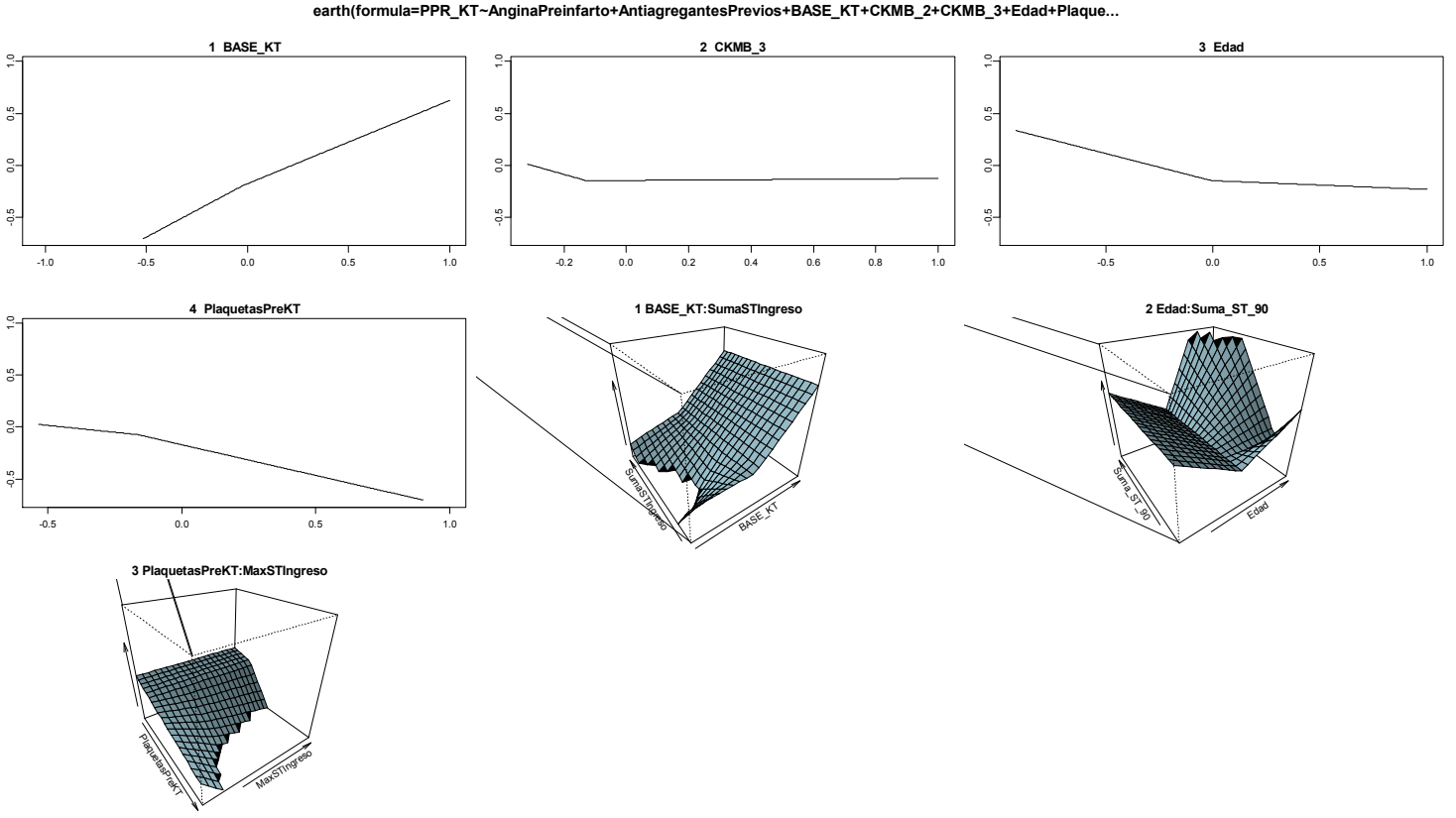

Figura 88: Representación gráfica del modelo MARS obtenido con las variables de nivel de importancia 2 y 3. 
DISCUSIÓN 



\section{DISCUSIÓN}

\section{RESUMEN DE HALLAZGOS}

Con el fin de facilitar el análisis y discusión de los resultados del presente trabajo de tesis doctoral, se resumen a continuación los hallazgos más relevantes del mismo. Así, se procede posteriormente a organizar la discusión por apartados de forma que la información presentada en el apartado de resultados sea manejable y sistematizada.

-Este estudio prospectivo observacional descriptivo muestra como hallazgo principal una ausencia de reducción de los valores de reactividad plaquetaria postratamiento (RPP) tras la administración de dosis aprobadas de clopidogrel en los pacientes ingresados por un infarto agudo de miocardio y que reciben terapia fibrinolítica como estrategia de reperfusión coronaria.

-La respuesta al clopidogrel, evaluada en función del porcentaje de inhibición de la actividad plaquetaria (\%IPA), presenta unos valores muy retrasados en el tiempo y atenuados de forma importante con respecto a los valores observados en otros contextos clínicos.

-Esta ausencia de reducción de los valores de RPP y de respuesta al clopidogrel es objetivada durante la realización de la coronariografía electiva, el momento en el que más necesaria es la inhibición de la función plaquetaria con vistas a reducir las complicaciones de un eventual intervencionismo coronario percutáneo.

-La resistencia observada al tratamiento con clopidogrel es consistente a pesar de la realización de la coronariografía electiva en un plazo de tiempo medio superior al recomendado en las guías de actuación clínica.

-La respuesta al clopidogrel presenta una relación muy débil con el tiempo en este contexto, y la atenuación observada se mantiene hasta varios días después de la administración del fármaco fibrinolítico.

-El abciximab, fármaco más potente conocido para inhibir la reactividad plaquetaria, no presenta dificultad para conseguir valores máximos de antiagregación dentro del mismo contexto.

-Los hallazgos observados no han demostrado relacionarse con el pronóstico clínico a largo plazo ni con las variables angiográficas de los pacientes de nuestra muestra.

-Los hallazgos en el análisis multivariante y tras la realización de modelos de predicción muestran como variables relacionadas con la reactividad plaquetaria postratamiento: los valores basales de reactividad plaquetaria y contaje total de plaquetas, la edad de los pacientes y ciertas variables electrocardiográficas y analíticas relacionadas con el tamaño del infarto. 
-A su vez, en los modelos predictivos la reactividad plaquetaria postratamiento se mostró como el valor relacionado con mayor intensidad con el grado de daño miocárdico posterior a la realización de ICP.

Seguidamente se detalla la discusión por apartados.

\section{SOBRE LOS HALLAZGOS}

\subsection{SOBRE LA MUESTRA}

El primer punto a comentar sobre la muestra de este estudio se centra en su escaso tamaño. A pesar de que el periodo de reclutamiento se extendió durante más de 12 meses, periodo primeramente programado, el tamaño muestral se limitó finalmente a 41 pacientes que completaron todos los criterios de inclusión y no presentaron criterios de exclusión.

Se trata pues de un tamaño suficiente para aportar datos significativos sobre la actividad plaquetaria pero que queda muy limitada para encontrar diferencias en cuanto a pronóstico clínico, teniendo en cuenta además la escasa prevalencia de recurrencia de eventos isquémicos o hemorrágicos tras un IAMCEST de estas características en el momento actual.

Los factores que determinan el tamaño muestral de este estudio son fundamentalmente tres: el coste, el establecimiento de los protocolos de fibrinolisis extrahospitalaria y la preferencia por el ICP primario como estrategia de reperfusión urgente de elección.

En cuanto al coste, el análisis VerifyNow® a pesar de que las guías reconocen su utilidad, no está aprobado para su utilización en la práctica clínica habitual, de manera que sólo puede ser utilizado con fines de investigación y por lo tanto no está presupuestado por el Complejo Asistencial Universitario de León. Teniendo en cuenta que cada kit específico, tanto para el receptor P2Y12 como para el receptor IIb/IIIa, tiene un coste aproximado de 60 euros, a pesar de obtener el analizador de forma gratuita en función de cesión por utilización de consumibles, el gasto de este estudio superó ampliamente los 12.000 euros concedidos por la Beca de la Sociedad Española de Cardiología con la que fue financiado. Por ese motivo el periodo de inclusión de pacientes no pudo ser ampliado.

El protocolo establecido de fibrinolisis extrahospitalaria funciona en León desde el año 2006. Este protocolo pone en contacto a los médicos de los Servicios de Emergencias del 112 con el cardiólogo de guardia en el Hospital para evaluar la posible indicación de tratamiento de reperfusión. En caso de que se decida que el paciente es candidato a tratamiento fibrinolítico (pacientes jóvenes, infartos de preferencia no anteriores, grado Killip I-II y especialmente tiempo de aparición de los síntomas menor de 90 minutos), la tenecteplasa es iniciada en el punto de contacto médico. Por las particularidades del diseño de este estudio, que debía comparar la actividad plaquetaria a lo largo del tiempo con una muestra tomada en 
condiciones basales, los pacientes que recibieron fibrinolisis extrahospitalaria no podían ser incluidos en el mismo ya que la primera muestra tomada en tubo citratado para hacer el análisis pretratamiento no podía ser obtenida.

Otro factor limitante fue el incremento de la angioplastia primaria sobre el fibrinolítico como tratamiento de reperfusión preferido. En el momento en el que se diseñó el estudio, 2007, ambas estrategias se trataban como opciones equivalentes en las guías de actuación clínica, en especial tras la publicación del estudio CAPTIM que ofrecía una puerta al tratamiento personalizado en función del tiempo de presentación y la localización del infarto(Steg et al., 2003). Pero posteriormente, y coincidiendo con la fase de reclutamiento de pacientes de este estudio, los resultados de los últimos registros de actividad fueron poniendo de acuerdo a la comunidad científica en elegir la angioplastia primaria como tratamiento de reperfusión siempre y cuando ésta fuera accesible, como es el caso de nuestro centro. De esta forma, durante el año en que se realizó el reclutamiento, en la gran mayoría de los pacientes a los que se les indicaba un tratamiento de reperfusión urgente por un IAMCEST fueron derivados a ICP primario.

El mayor valor que presenta la muestra de pacientes seleccionados es que, por su carácter de inclusión consecutiva y no aleatorizada, las características basales de la población incluida en el estudio es lo más próxima a la realidad de la práctica clínica habitual, a la que se realiza de forma rutinaria tratamiento fibrinolítico, por lo que predominan los pacientes con infartos no anteriores y sin signos de insuficiencia cardiaca de pacientes relativamente jóvenes y con tiempos de evolución de síntomas relativamente recortados, a pesar de que ningún criterio especificaba la exclusión de lo contrario.

De esta forma, dejando la elección de la estrategia de reperfusión a criterio de los médicos de guardia, este estudio garantizaba una muestra de alta similitud con la población diana real, con el inconveniente de que se procedía de esta forma a la selección de una población de un perfil de riesgo algo inferior a la población general que se presenta con IAMCEST, lo que disminuye el riesgo de eventos en el seguimiento.

Puede resumirse entonces que se trata de una muestra que permite proporcionar información válida y veraz sobre la actividad plaquetaria de los pacientes ingresados por un IAMCEST en un hospital de tercer nivel con posibilidad de ICP primario y a los que se les realiza tratamiento fibrinolítico como alternativa a éste, una práctica muy común todavía hoy, de efectividad validada y recomendada en las guías de actuación clínica.

Teniendo en cuenta que el tratamiento fibrinolítico sigue siendo todavía hoy la estrategia de reperfusión más utilizada en nuestro medio, la muestra de pacientes incluida en este estudio ofrece información que puede trasladarse a una gran parte de la población afectada por un IAMCEST. 


\subsection{SOBRE EL SISTEMA DE ANÁLISIS DE LA FUNCIÓN PLAQUETARIA}

A la hora de elegir el sistema más apropiado para realizar las determinaciones analíticas de la actividad del los receptor plaquetario P2Y12, objetivo principal del estudio, la primera cuestión que se tuvo en cuenta era la necesidad de disponer de un sistema capaz de permitir que todas las muestras obtenidas pudieran ser analizadas en el momento de ser extraídas o que, al menos, pudieran almacenarse de forma sencilla a temperatura ambiente para su posterior análisis. De esta manera, quedaban descartados los sistemas que requieren de un procesado inmediato de la muestra. Dentro de los sistemas que utilizaban sangre fresca total no procesada, los más atractivos eran la citometría de flujo de sangre entera y el sistema VerifyNow®. Lógicamente, teniendo en cuenta la dificultad técnica que entraña el primero de ellos, con una variabilidad interoperador muy elevada, no parecía la prueba más recomendable con el diseño de estudio presentado. En cambio, el dispositivo VerifyNow ${ }^{\circledR}$ presentaba la posibilidad de trabajar con sangre entera a temperatura ambiente $\mathrm{y}$ el análisis es completamente automatizado, sin necesidad de procesado ni pipeteo, por lo que la variabilidad interoperador es virtualmente nula. La única desventaja es que la muestra debe ser obtenida en tubos citratados y analizada en un plazo inferior a tres horas, por lo que debía ser extraída en el hospital (descartándose así la lisis extrahospitalaria como se ha comentado previamente) y analizada en la mayoría de los casos por el equipo de cardiología de guardia. Estos motivos, la escasa variabilidad interoperador, la facilidad de uso y la consistencia de sus resultados, hacían a este dispositivo el ideal según el diseño de este estudio.

La crítica más frecuentemente realizada sobre el sistema VerifyNow®-P2Y12 es el hecho de que utiliza la agregabilidad mediada por estimulación iso-TRAP como valor de referencia, haciéndolo equivalente a la reactividad plaquetaria basal o pretratamiento, cuando, si bien son conceptos extrapolables, no son exactamente lo mismo. El propio diseño de este estudio, al obtener una muestra basal antes de la administración por vez primera de clopidogrel, permite librar este problema al disponer de una muestra con los verdaderos valores pretratamiento. Además, esto permitió comprobar la excelente correlación que en verdad existe entre la agregabilidad BASE y la reactividad plaquetaria pretratamiento mediada por el receptor P2Y12, como aparece reflejado en el capítulo de resultados.

\subsection{SOBRE LA ACTIVIDAD PLAQUETARIA}

\subsubsection{ACTIVIDAD DEL RECEPTOR P2Y12}

Que el tratamiento con fármacos fibrinolíticos conduce a un estado de hiperreactividad plaquetaria es un hecho conocido desde hace tiempo. Los estudios que realizaron estos hallazgos en los años 90 se centraron en la determinación de la biosíntesis de tromboxano A2(Fitzgerald et al., 1988; Rasmanis et al., 1992), formación de complejos IIb/IIIa(Bihour et al., 1995), liberación de $\alpha$-gránulos(Frandsen et al., 1996) y expresión de P-selectina y unión de fibrinógeno a complejo IIb/IIIa(Moser et al., 1999) como indicadores inespecíficos de hiperagregabilidad plaquetaria tras la administración de 
diferentes trombolíticos y en una época en la que la aspirina era el único tratamiento antiagregante administrado a estos pacientes.

Tras la publicación de los estudios CLARITY(Sabatine et al., 2005) y COMMIT(Chen et al., 2005) y la generalización del uso del clopidogrel como tratamiento adyuvante antiplaquetario para reducir las complicaciones isquémicas de la fase precoz del infarto de miocardio fibrinolisado, toma una importancia especial incrementar el conocimiento sobre el comportamiento de este receptor en este escenario tan particular y difícil de explorar.

Hasta la fecha, la agregabilidad plaquetaria dependiente del receptor P2Y12 no ha sido estudiada aún tras la administración de un fármaco fibrinolítico, de manera que la potencial influencia que este estado protrombótico pueda tener sobre la respuesta al clopidogrel era desconocida.

Por lo tanto, a pesar de que el estado de hiperagregabilidad plaquetaria inducido tras la administración de fibrinolíticos ha sido demostrado previamente, el presente es el primer estudio que confirma este fenómeno in vivo y de forma específica para el receptor P2Y12.

Pasamos a comentar de forma individualizada los resultados obtenidos en los diferentes parámetros de actividad del receptor P2Y12:

\section{Sobre el valor del canal BASE}

Un tema de debate no infrecuente tras la publicación de estudios que utilizan el sistema VerifyNow ${ }^{\circledR}$ para determinar la actividad plaquetaria en los diferentes contextos clínicos consiste en el hecho de que este sistema utiliza como valor de referencia el resultado del canal que el fabricante denomina BASE. Ciertamente este hecho puede dar lugar a error ya que este canal no determina la actividad plaquetaria basal, siempre y cuando entendamos ésta como valor pre-tratamiento. El valor BASE, como ya se ha expuesto previamente, es un valor de agregabilidad medida mediante la estimulación con iso-TRAP, que produce la agregación plaquetaria a través de su vía final común, la unión entre los receptores IIb/IIIa. Al ser ésta la vía final de agregación plaquetaria y a su vez ser independiente para la actividad de otros receptores como el P2Y12, se puede considerar que este valor es equivalente al de la actividad plaquetaria total en ausencia de inhibidores plaquetarios.

La diferencia que este valor presenta con respecto a la agregabilidad pretratamiento, a pesar de ser sutil, no deja de ser evidente. No es lo mismo la reactividad plaquetaria independiente del tratamiento, que la presente antes de iniciar tratamiento. De todos modos, el diseño de este estudio nos permite obtener la información correspondiente a ambos conceptos: los verdaderos valores de la actividad plaquetaria pre-tratamiento, estimulando las plaquetas mediante la adición tanto de iso-TRAP para evidenciar la ruta final IIb/IIIa como ADP para cuantificar la actividad dependiente del receptor P2Y12 y comprobar cómo el tratamiento ejerce su efecto a mayor o menor velocidad durante un contexto clínico muy específico: el infarto de miocardio fibrinolisado. 
A su vez, el valor de este canal no se limita a servir como referencia para el cálculo del \%IAP, ya que, en ausencia de inhibidores de la GP IIb/IIIa, nos proporciona un valor que se corresponde con el estado de agregabilidad total de las plaquetas, independiente de otras rutas de activación exploradas por otros canales. Las variaciones en este valor a lo largo del tiempo nos sugieren de esta forma la presencia de factores proagregantes o antiagregantes más allá de las propias medidas farmacológicas realizadas.

Los valores del canal BASE del sistema VerifyNow® mostraron durante este estudio diferencias significativas a lo largo de las cuatro determinaciones temporales: tras la administración del tratamiento fibrinolítico se comprueba un aumento de la reactividad dependiente del receptor IIb/IIIa como se aprecia en la Figura 74. Estos datos se pueden corresponder con el conocido efecto proagregante inespecífico ya conocido que la administración de este tipo de fármacos produce y logra una diferencia estadísticamente significativa $(p=0,017) a$ partir de las primeras 24 horas.

\section{Sobre el valor de la Reactividad Plaquetaria Postratamiento (RPP)}

Los hallazgos en relación con la reactividad plaquetaria postratamiento reproducen en cierta manera lo observado para el valor BASE. En contraste con esta variable, que no debería modificarse por el tratamiento, sí se hubiera esperado que la RPP mostrase un progresivo descenso en las sucesivas determinaciones a medida que el tratamiento con clopidogrel fuese alcanzando niveles terapéuticos. Teniendo en cuenta el estado protrombótico y proagregante que supone un infarto agudo sería esperable que esta respuesta estuviera atenuada, pero esto no sólo es así, sino que de hecho no se encontraron diferencias significativas entre ninguna de las determinaciones; incluso se puede apreciar un aumento no significativo en la determinación Día +1 con respecto a la reactividad plaquetaria basal. Este hallazgo demuestra la presencia de una hiperreactividad plaquetaria intensa y sostenida tras el inicio de la terapia fibrinolítica que se mantiene hasta el momento de la coronariografía electiva.

Se trata así pues del hallazgo más relevante de este estudio y el que nos permite confirmar la hipótesis de partida. Ante los resultados de las distintas mediciones de la reactividad plaquetaria postratamiento se puede afirmar que, en el grupo de pacientes con IAMCEST sometidos a tratamiento fibrinolítico, el incremento de la reactividad plaquetaria que estos fármacos producen afecta también al receptor P2Y12, condicionando una reactividad residual dependiente del ADP que las dosis aprobadas de clopidogrel son incapaces de suprimir durante los primeros días tras el ingreso.

Este hallazgo cobra su mayor trascendencia en el momento de la coronariografía, ya que la RPP en este momento es la variable de función plaquetaria que mejor se ha relacionado con el resultado clínico en pacientes inestables(de Miguel Castro et al., 2009) y en aquellos que reciben revascularización percutánea electiva(Price et al., 2008). 
Sobre el valor de la inhibición de la agregación plaquetaria (\%IPA)

Con respecto a la respuesta al clopidogrel o el porcentaje de la actividad plaquetaria inhibido por este fármaco, los valores de este parámetro, al estar directamente relacionados con los previos, siguen la misma línea. Tras el lógico valor 0 de partida en la determinación basal, la inhibición de la actividad del receptor se va produciendo de forma muy lenta y atenuada hasta alcanzar valores máximos en el momento de la coronariografía, cuando más dosis acumulada de clopidogrel han recibido los pacientes.

Las diferencias entre los valores basales y en el momento de la coronariografía son estadísticamente significativos y muestran de hecho el efecto inhibitorio producido por el clopidogrel, pero esta respuesta presenta, como veremos en el punto siguiente, valores muy por debajo de los esperados al comparar esta población con estudios previos realizados en otras formas de presentación clínica.

\section{Distribución por sexos}

Al realizar la comparación en función del sexo para las variables de función plaquetaria, tanto los valores de BASE como de la RPP resultaron superiores en el grupo de mujeres con respecto a los hombres de la muestra. Estas diferencias resultaron consistentes en las cuatro determinaciones seriadas y para las dos variables, y a pesar de que las diferencias estadísticamente significativas sólo se encontraron para la determinación de BASE en el momento 3, se puede apreciar una clara tendencia general, con valores de p muy próximos al nivel de error $\alpha$ establecido también en las determinaciones de RPP de los momentos 2 y 3 (a las 24 y 48 horas) y en la primera determinación de BASE.

Estos hallazgos resultan concordantes con la reciente publicación de Breet y colaboradores que demuestran la presencia de valores más elevados de RPP en mujeres que en hombres de una población sometida a ICP electivo. A pesar de ello, los autores concluyen que no se encontraron diferencias en los eventos aparecidos durante el seguimiento clínico y que el punto de corte para discriminar la aparición o no de MACE fueron similares en ambos grupos, por lo que no se puede concluir que estas diferencias puedan ser la causa del peor pronóstico general que las mujeres presentan en la enfermedad coronaria y su relevancia clínica sigue siendo desconocida(Breet et al., 2011).

Comparación de los hallazgos en actividad plaquetaria del receptor P2Y12 con estudios similares realizados en otros contextos clínicos:

Al comparar los resultados obtenidos con los hallazgos realizados en otros estudios, encontramos que los niveles de RPP son, en este contexto, considerablemente superiores a los descritos durante otros procesos. Aún más llamativos son los valores de \%IPA que permanece muy por debajo a lo esperado y de forma persistente. 
En pacientes estables, Cuisset encontró valores de \%IPA de entre el $25 \%$ y el $38 \%$ en función de que se produjera daño miocárdico periprocedimiento o no, y de media de RPP entre 190 y 221 URP(Cuisset et al., 2008), ambos valores muy inferiores a los presentados por esta población.

En pacientes inestables, estas diferencias son consistentes. En un estudio descriptivo de similares características al que nos ocupa realizado en nuestro centro sobre un grupo de pacientes con síndrome coronario agudo sin elevación del ST, incluyendo una alta proporción de IAM sin onda Q, los valores medios de \%IPA fueron del $43 \pm 21 \%$ y de RPP de $157 \pm 68$ URP (alcanzando IPA de $31 \pm$ $21 \%$ y RPP de $204 \pm 60$ URP entre los pacientes que presentaron eventos adversos a largo plazo)(de Miguel Castro et al., 2009). En este estudio, se identificó un punto de corte en 175 URP como valor de referencia para discriminar la recurrencia de eventos isquémicos en el seguimiento con una sensibilidad del $75 \%$ y una especificidad del 64\%, con un valor predictivo positivo del $20 \%$ y un valor predictivo negativo del $96 \%$.

De forma similar, Price y colaboradores(Price et al., 2008), en un estudio sobre ICP con implante de stents farmacoactivos sobre pacientes estables o ingresados por síndrome coronario agudo sin elevación del ST, definieron un valor de 235 URP para predecir la aparición de eventos en el seguimiento con una sensibilidad del $78 \%$, una especificidad de $68 \%$ y un valor predictivo negativo del $99 \%$. Posteriormente y tras realizar un subanálisis sobre un estudio con pacientes con respuesta atenuada al clopidogrel ya indican un valor más bajo, 208 URP, como el más eficiente para discriminar la aparición o no de MACE en el seguimiento(Price, Angiolillo, et al., 2011).

Se utilice el punto de corte que se utilice, parece claro que los pacientes de este estudio presentan valores medios de RPP muy por encima de los previos a lo largo de todas las determinaciones realizadas. La RPP media más baja se obtuvo en el

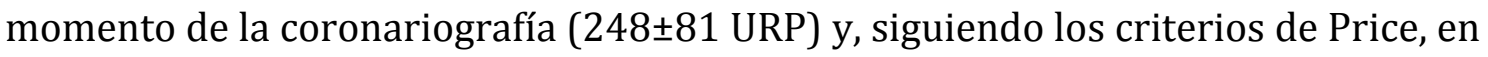
este momento $>70 \%$ de los pacientes estarían en el grupo de "no respondedores" utilizando el punto de corte de 208PRU y $>50 \%$ lo estarían utilizando el de 235PRU.

En resumen los datos obtenidos en los tres parámetros previos nos muestran tres aspecto diferentes aunque relacionados de la actividad plaquetaria posinfarto fibrinolisado que muestran un incremento en la actividad basal y una falta de efecto farmacológico del clopidogrel. A saber:

- Incremento de la agregabilidad plaquetaria: determinado por el aumento de los valores de la variable BASE.

- Reactividad plaquetaria residual dependiente del receptor del ADP incrementada a pesar de tratamiento activo con clopidogrel: evaluado con los resultados del parámetro RPP.

- Ausencia de respuesta antiplaquetaria, o resistencia al clopidogrel, determinada por el valor del \%IPA. 


\subsubsection{ACTIVIDAD DEL RECEPTOR IIB/IIIA}

El estudio de la respuesta de este receptor a su inhibidor específico, el abciximab, es uno de los objetivos secundarios de este estudio. Su análisis se realizó en todos los pacientes en los que la utilización de este fármaco fue indicada por el operador durante el ICP electivo. Así, el abciximab se utilizó en 25 de las 36 angioplastias electivas que se realizaron.

En contraste con los valores mostrados con el uso del clopidogrel, la potencia de este inhibidor de la GP IIb/IIIa no parece ser afectada por el contexto proagregante del posinfarto fibrinolisado y el porcentaje de inhibición sobre este receptor, ruta común final de la agregación plaquetaria, muestra una mediana del 95\% (RIQ:91100) a los pocos minutos de la administración de un bolo ajustado al peso.

Estos hallazgos concuerdan con un estudio previo realizado por nuestro equipo en circunstancias similares de hipertrombogenicidad: la angioplastia primaria durante el IAMCEST. En este estudio se evidenció una inhibición plaquetaria del receptor IIb/IIIa del 98\% (RIQ: 91-100) con la misma pauta de tratamiento(Perez de Prado et al., 2006).

Podemos afirmar entonces, que la potencia del abciximab logra que su efectividad antiplaquetaria no se vea afectada por la situación de trombofilia del posinfarto fibrinolisado, o al menos lo haga en mucha menor medida que el clopidogrel a dosis estándares.

Una posible explicación del hecho de que el estado de hiperagregabilidad plaquetaria no se correlacione con una mayor tasa de aparición de eventos en el seguimiento, aparte del escaso tamaño muestral, pueda ser la alta tasa de utilización de abciximab durante el procedimiento, que contrarreste la falta de inhibición conseguida por el clopidogrel en el momento del ICP que es cuando más necesaria es la inhibición plaquetaria máxima.

A pesar de no haber sido demostrada, esta hipótesis ya se apunta en el reciente análisis de subgrupos del estudio GRAVITAS(Yan et al., 2011) como causa posible de la variabilidad de resultados publicada y que veremos más detenidamente en el siguiente apartado.

\subsection{CONTRIBUCIÓN DEL TRATAMIENTO FIBRINOLÍTICO AL ESTADO DE HIPERAGREGABILIDAD DEL CONTEXTO CLÍNICO}

Es incuestionable que un estado protrombótico es precisamente el causante de los fenómenos agudos intravasculares que condicionan la oclusión de la arteria coronaria responsable del cuadro, estado protrombótico condicionado por una etiología multifactorial compleja.

A su vez, la propia oclusión arterial y el daño celular masivo que se produce en esta situación también favorece la hiperagregabilidad y la coagulación intravascular a través de diversos factores como el incremento de mediadores de la inflamación o de catecolaminas circulantes. 
A los dos puntos anteriores es necesario sumar la propia actividad proagregante que, como se ha expuesto, presentan de forma intrínseca todos los fármacos fibrinolíticos y atribuida de forma más específica al aumento de la actividad de trombina plasmática secundaria a la lisis del trombo intraarterial y la activación subsiguiente de los receptores PAR-1 plaquetarios.

En esta situación, más allá del hecho de que nos encontramos ante una situación de hiperreactividad plaquetaria, determinar la contribución parcial sobre el estado global de hiperagregabilidad que depende de forma específica de la administración del lítico, resulta muy difícil.

Diseñar un estudio de forma sencilla para aclarar esta cuestión chocaría de forma frontal con la praxis médica habitual durante el infarto de miocardio, ya que no puede asignarse de forma aleatoria a estos pacientes a recibir tratamiento fibrinolítico o placebo, lo que sería la opción más fácil para lograr una comparación de grupos en los que el tratamiento fibrinolítico fuera la única variable diferencial. Evidentemente, hoy en día un diseño como éste es completamente contrario a las normas éticas de práctica médica y resulta implanteable.

Otra posibilidad sería realizar un estudio que comparase a los pacientes con IAMCEST y tratamiento antiplaquetario a recibir fibrinolisis o ICP primario y valorar las diferencias existentes en los valores de reactividad plaquetaria. Independientemente de que esta estrategia fuera éticamente aceptable, ahora que las guías recomiendan claramente la realización de ICP siempre que esta esté disponible, este diseño presenta múltiples desventajas, como serían el hecho de que la mayoría de los pacientes que reciben ICP primario son tratados de forma concomitante con inhibidores de la GP IIb/IIIa, las diferencias en el tiempo bajo tratamiento antiplaquetario previo a la realización del intervencionismo o la posible modificación de la función plaquetaria que pudiera condicionar el intervencionismo en sí. Todos estos factores introducirían un sesgo de un peso posiblemente mayor de lo admisible.

Así, la única forma de establecer que la administración del fibrinolítico supone un factor añadido que incrementa la ya de por sí hiperestimulada actividad plaquetaria es la comparación con los valores obtenidos en estudios clínicos realizados en otros contextos hipertrombogénicos pero que no reciban este tipo de tratamiento, como podría ser el del infarto sin elevación del segmento ST.

De todos modos, a pesar de esta lógica limitación, la curva de actividad plaquetaria que se aprecia en este estudio en todos los parámetros de reactividad plaquetaria, sufre un incremento entre la determinación basal y las determinaciones de Día +1 y Día +2 , lo que en ausencia de otra explicación podremos asumir que se corresponde con el efecto protrombótico y proagregante de la administración del lítico y que se explica por la masiva liberación de trombina intravascular que se produce tras la fibrinolisis efectiva(Zeymer et al., 1998). El valor añadido de este estudio es la demostración de la extensión de este efecto al receptor P2Y12. 


\subsection{SOBRE EL SEGUIMIENTO CLÍNICO}

El primer punto a destacar en el análisis de los resultados del seguimiento clínico es la escasez de eventos registrados. A pesar de que los resultados del estudio carecen de la potencia necesaria para demostrar una relación robusta entre la actividad plaquetaria y los eventos clínicos y/o MACEs (por sus siglas en ingles: Major Adverse Cardiovascular Events), la escasez de recurrencias isquémicas, con apenas tres eventos en un seguimiento superior al año, hace suponer que estamos ante una población de muy bajo riesgo, lo que impide sacar conclusiones definitivas al respecto.

Efectivamente, la aparición de MACE sólo se registra en un 7,3\% de los pacientes, cifra inferior a lo esperable para pacientes con IAMCEST que, en poblaciones no seleccionadas, se encuentra entre el 15 y el 30\%(Buch et al., 2007; Lekston et al., 2011). Estos resultados indican que la selección de un método determinado de revascularización urgente supone un sesgo no despreciable, al menos en la población de pacientes de nuestro Centro, ya que la revascularización mediante angioplastia primaria se reserva para los pacientes más graves: mayor edad, mayor proporción de infartos anteriores, mayor tiempo de evolución y clase Killip más avanzada.

La selección realizada por la estrategia de reperfusión no sólo condiciona una población de bajo riesgo, sino que además este perfil está relacionado directamente con el resultado de las estrategias combinadas de reperfusión como la que nos ocupa. En el caso de fibrinolisis y angioplastia electiva realizada en las primeras 24 horas, los hallazgos de un reciente análisis del estudio TRANSFER(Cantor et al., 2009), mostraron una gran heterogeneidad entre los distintos grupos de riesgo. El estudio TRANSFER fue uno de los primeros en evidenciar el beneficio de la estrategia fármaco-invasiva precoz, con traslado inmediato para ICP tras administración de lítico, con respecto a la estrategia convencional. Los resultados de este subanálisis demuestran que, a pesar de que en la población global esta combinación disminuyó la aparición de eventos, los pacientes dentro del grupo de alto riesgo no sólo no se benefician de esta precocidad en el intervencionismo coronario, sino que incluso este adelanto en su manejo puede ser perjudicial, con un OR de 2,4 con respecto a la estrategia convencional, más lenta a la hora de establecer intervenciones coronarias (superior a 24 horas).

Los mismos autores de este estudio reconocen que estos datos provienen de hallazgos post-hoc y que deben ser tomados con precaución pero apuntan a la posibilidad de que la menor frecuencia de utilización de inhibidores de la GPIIb/IIIa pueda ser uno de los factores determinantes de este peor pronóstico en el grupo de alto riesgo. Especialmente teniendo en cuenta la alta frecuencia de fenómeno de no-reflujo en el grupo de alto riesgo que recibía tratamiento con estrategia precoz.

Así, en la muestra de bajo riesgo de nuestro estudio, una utilización de abciximab en el 69\% de los casos de ICP (similar a la utilizada en el grupo de bajo riesgo del TRANSFER) podría ser el factor que contrarrestase la hiperagregabilidad dependiente del receptor P2Y12 y de esta forma no se encuentra relación entre el RPP durante el intervencionismo y el resultado clínico. 
La importante relación encontrada en estudios previos entre la respuesta al abciximab y el resultado tras ICP primario es concordante con nuestra teoría (Perez de Prado et al., 2006), y refuerza la evidencia sobre la extraordinaria potencia inhibidora de este fármaco.

\subsection{SOBRE LOS MODELOS MATEMÁTICOS DE ANÁLISIS MULTIVARIANTE}

Para la realización de un modelo matemático que ayude al entendimiento del comportamiento de la actividad plaquetaria en este contexto, se optó por la realización de modelos predictivos multivariantes de regresión mediante splines adaptativos. Se hizo de esta forma, ya que algunas de las variables del estudio no son continuas sino discretas, y por este motivo el estudio de la influencia de dichas variables sobre las variables de salida no debe ser abordado mediante la utilización de modelos lineales multivariantes.

Estos análisis, si bien no permiten demostrar una relación causal entre dos variables, sí permiten obtener información muy valiosa sobre los factores que las determinan. Además, los modelos MARS no sólo resultan de utilidad para predecir el valor de las variables incluidas al inicio, sino también para poder discernir la importancia relativa de cada variable en el modelo a partir de los coeficientes de cada una de ellas.

Para los modelos, se eligieron las variables de salida consideradas como más interesantes. En el primer modelo se eligió el valor de troponina T a las seis horas del ICP como indicador de daño miocárdico periprocedimiento, posiblemente el parámetro analítico más relacionado con el pronóstico a largo plazo. El segundo modelo realizado se centró en la predicción del valor de reactividad plaquetaria postratamiento (RPP), objetivo principal de este estudio y de valor pronóstico ya comentado previamente.

Ambos modelos obtienen valores de R2 ajustado que superan los obtenidos por medio de modelos de regresión lineal multivariante.

Así, en el primero de los modelos encontramos el importante hallazgo de que la RPP es la variable que con más consistencia se relaciona con el valor de troponina $\mathrm{T}$ posprocedimiento, lo que pone de manifiesto la importancia que puede tener la adecuada inhibición de la actividad plaquetaria residual a la hora de proceder con seguridad al ICP.

El segundo de los modelos fue realizado con la intención de estudiar las variables que pudieran tener más relación con la RPP en el momento del cateterismo electivo, resultando ser las variables directamente dependientes de la activación plaquetaria (contaje plaquetario y BASE), y las variables relacionadas con el tamaño y extensión del infarto: CK-MB máxima y máxima elevación del ST. Esto parece indicar que la extensión del infarto (en relación con una mayor carga trombótica y una mayor respuesta inflamatoria) puede ser uno de los condicionantes de la mayor protrombogenicidad de estos procesos clínicos. 


\section{SIGNIFICADO CLÍNICO DE LOS HALLAZGOS ENCONTRADOS}

De acuerdo con nuestra hipótesis de partida y en concordancia con los datos encontrados, podríamos concluir que "la terapia fibrinolítica sobre el IAMCEST induce un estado de hiperagregabilidad plaquetaria que condiciona una resistencia al clopidogrel durante la coronariografía electiva".

De esta forma, es necesario reflexionar sobre las consecuencias de la resistencia al clopidogrel para extraer la potencial relevancia clínica de este hallazgo.

Las implicaciones clínicas de una inhibición deficiente de la actividad plaquetaria de los pacientes con enfermedad coronaria han sido descritas en múltiples ensayos clínicos en otros contextos. Geisler fue uno de los primeros en describir un aumento de los eventos cardiovasculares adversos en pacientes con "baja respuesta" comparados con pacientes con una respuesta normal al fármaco en pacientes sometidos a intervencionismo coronario electivo(Geisler et al., 2006).

De manera similar, nuestro grupo demostró la relación entre el la reactividad plaquetaria postratamiento y el resultado clínico sobre una población de pacientes inestables que incluía una alta proporción de infarto agudo de miocardio sin elevación del segmento ST(de Miguel Castro et al., 2009)

En un contexto más parecido al que nos interesa, Matetzky demostró en pacientes con infarto agudo de miocardio sometido a angioplastia primaria una recurrencia de eventos cardiovasculares a 6 meses entre los pacientes con menor inhibición dependiente del receptor de ADP(Matetzky et al., 2004).

Además del resultado clínico directo, Cuisset describió que una mayor RPP se asocia con mayor daño miocárdico tras implante de stent coronario en el contexto de síndrome coronario sin elevación del segmento ST(Cuisset et al., 2007) y nuestro grupo demostró que, en este mismo contexto, la RPP predice el daño miocárdico postintervención mejor que el \%IPA(Perez de Prado et al., 2009). Marcucci demostró que la RPP elevada afecta la severidad del infarto de miocardio de forma independiente a otros datos clínicos, técnicos o analíticos en el paciente con un infarto sometido a intervencionismo coronario(Marcucci et al., 2007).

Gurbel demostró a su vez que la presencia de valores elevados de RPP es más frecuente entre los pacientes que presentan trombosis del stent durante el seguimiento tras ICP(Gurbel, Bliden, Samara, et al., 2005) .

En resumen podemos concluir que la respuesta al clopidogrel y la actividad plaquetaria residual subsiguiente son datos estrechamente ligados a los eventos clínicos y la supervivencia, tanto en los pacientes que presentan un síndrome coronario agudo, como en aquellos que requieren ser sometidos a intervencionismo coronario percutáneo, y, cuando coinciden estas dos situaciones, la respuesta al clopidogrel cobra una importancia incluso más determinante.

Esta relación entre actividad plaquetaria y eventos trombóticos será tanto mayor en función de la carga trombótica del síndrome coronario que presente el paciente. 
El caso del síndrome coronario agudo con elevación del segmento ST es sin lugar a dudas la situación más trombogénica dentro del espectro de enfermedad coronaria. La intervención coronaria con implante de stent coronario en esta situación requerirá entonces una inhibición de la actividad plaquetaria incluso más potente que en el resto de presentaciones clínicas.

La pregunta que surge en este punto será sobre las posibilidades que tiene el cardiólogo clínico para enfrentar esta situación.

\section{¿QUÉ DEBEMOS HACER ANTE UN PACIENTE CON RESPUESTA REDUCIDA AL CLOPIDOGREL?}

Todavía no se ha establecido de una manera clara la estrategia antitrombótica en los pacientes que tienen una respuesta subóptima al tratamiento con clopidogrel.

Como punto de partida, podríamos asumir que factores como la adherencia al tratamiento y la dosificación adecuada pueden contribuir de manera notable a reducir el número de pacientes que presenten este tipo de respuesta reducida. Por otra parte, el control estricto de los factores de riesgo cardiovasculares también puede contribuir a una mejor respuesta a la droga, si bien todas estas medidas quedan fuera del alcance del manejo agudo de un infarto de miocardio.

Los efectos inhibidores del clopidogrel sobre el receptor P2Y12 son tiempo y dosis dependientes. Una dosis de 600mg de carga produce una inhibición más precoz y más estable que una dosis de 300mg(Kandzari et al., 2004; Muller et al., 2001). Además, esta dosificación ha demostrado una reducción de las complicaciones isquémicas sin un incremento en las complicaciones hemorrágicas(Patti et al., 2005); de todos modos, a pesar de lo que pudiera suponerse según estos resultados, parece que una dosis de $900 \mathrm{mg}$ de clopidogrel de carga ya no aporta una reducción de la RPP más intensa y dosis de carga superiores a $600 \mathrm{mg}$ no han demostrado tampoco beneficios clínicos(Montalescot et al., 2006; von Beckerath et al., 2005), por lo que suponemos que no es sólo una cuestión de dosificación, sino que otros factores determinan esta capacidad del clopidogrel para inhibir la agregación plaquetaria y que esta droga presenta, para cada paciente y situación clínica, un "techo" de actividad.

Lo que sabemos ya de manera bastante firme, es que en pacientes sometidos a intervencionismo coronario de forma electiva, se necesita un mínimo de 6 horas para alcanzar un nivel adecuado de eficacia antiagregante dependiente del clopidogrel tras una dosis de carga de 300mg(Montalescot et al., 2006) y un mínimo de dos horas tras una dosis de 600mg(Hochholzer et al., 2006). Atendiendo a la naturaleza mucho más trombogénica de la presentación clínica de un síndrome coronario agudo, es de esperar que estos tiempos se encuentren alargados, y tanto más cuando se utilizan terapias con efectos protrombóticos y proagregantes como son los fármacos fibrinolíticos.

A pesar de estos hallazgos, las guías previas de actuación clínica en el síndrome coronario agudo sin elevación del segmento ST no recomendaban la utilización de dosis de carga de clopidogrel superiores a 300mg (J. L. Anderson et al., 2007; Bassand et al., 2007; King et al., 2008). No ha sido hasta la última actualización de 
estas guías en septiembre de 2011 que se ha incluido de forma sistemática la recomendación de dosis de carga superiores a $300 \mathrm{mg}$ y éstas lo han hecho sólo de forma dependiente de la indicación de ICP, manteniendo la recomendación de 300mg de forma genérica (Hamm et al., 2011).

En el caso del IAMCEST, si la estrategia de reperfusión elegida es el ICP primario, al requerirse una inhibición plaquetaria especialmente rápida, sí que se contemplan dosis de 600mg (Van de Werf et al., 2009). En cambio, en el caso del ICP electivo tras tratamiento fibrinolítico, dado que la evidencia principal sobre su manejo antiplaquetario procede de los comentados estudios CLARITY y COMMIT, las guías europeas siguen recomendando dosis de carga de 300mg de clopidogrel seguidos de $75 \mathrm{mg}$ al día en aquellos pacientes de menos de 75 años de edad y sin dosis de carga para aquellos $>75$ años. Estas dosis de carga, además, no se recomiendan en pacientes que estén ya de hecho activamente bajo tratamiento con clopidogrel (Van de Werf et al., 2009).

Sólo las guías de práctica clínica americanas (American College of Cardiology Foundation y American Heart Association) dejan una puerta abierta para la dosis de carga de $600 \mathrm{mg}$ en pacientes con IAMCEST que vayan a recibir ICP electivo y éste se vaya a retrasar $>48$ horas(Kushner et al., 2009).

El estudio CURRENT-OASIS 7 pretendía evaluar de forma randomizada la utilidad de un régimen de clopidogrel a altas dosis (carga de 600mg seguido de $150 \mathrm{mg}$ al día durante la primera semana) en comparación con el régimen estándar (300mg de carga seguidos de $75 \mathrm{mg} /$ día) y régimen de altas dosis de aspirina (300$325 \mathrm{mg} /$ día) en comparación con dosis estándar de 75-100mg/día en pacientes con SCA con o sin elevación del segmento ST que fueran a ser manejados según una estrategia de intervencionismo precoz (coronariografía más eventual intervencionismo en un plazo que no superase las 72h)(Mehta et al., 2010). La estrategia más agresiva logró tasas más reducidas de trombosis del stent y otros eventos cardiovasculares en la población de pacientes que fueron finalmente sometidos a ICP. La reducción de eventos fue lograda fundamentalmente gracias a una reducción dramática de los infartos no letales, pero presentó una tasa mayor de eventos hemorrágicos según la definición del estudio. De todos modos, el estudio no demostró beneficio en la cohorte entera de pacientes (más de 25000) y el efecto absoluto en la cohorte de ICP (17000) fue sólo modesto. Las diferencias encontradas, eso sí, se debieron a los grupos de dosificación de clopidogrel, sin que las variaciones de dosis de AAS tuvieran ningún efecto sobre el resultado clínico, lo que permite suponer que las dosis convencionales de AAS son suficientes para lograr la máxima inhibición plaquetaria dependiente de este fármaco, y que, en cambio, existe un margen terapéutico aún no perfectamente aclarado en cuanto a la inhibición del receptor P2Y12 para el ADP.

Los parámetros de eficacia y seguridad de dosificaciones de clopidogrel superiores a $75 \mathrm{mg}$ al día todavía no están aclarados. El estudio OPTIMUS demostró que, en pacientes diabéticos, $150 \mathrm{mg}$ al día de mantenimiento producía una inhibición plaquetaria superior a las dosis convencionales, aunque la respuesta antiplaquetaria era muy variable entre cada individuo y una respuesta subóptima se podía encontrar incluso en el $60 \%$ de los casos que recibían la dosis superior(Angiolillo et al., 2007). 
A pesar de todos los datos aportados, hasta el momento las sociedades científicas no recomiendan dosis de mantenimiento superiores a $75 \mathrm{mg}$ al día de clopidogrel, y éstas sólo pueden ser consideradas durante los primeros días tras un SCASEST, y siempre en contexto de ICP(Hamm et al., 2011).

Se plantea entonces la cuestión de si al menos el subgrupo de pacientes con mala respuesta al clopidogrel podría beneficiarse de una estrategia más agresiva.

\section{¿PODEMOS OPTIMIZAR LA DOSIFICAICIÓN DEL CLOPIDOGREL EN FUNCIÓN DE LAS PRUEBAS FUNCIONALES?}

Se han realizado muchos intentos de individualizar el tratamiento antiplaquetario en función de los resultados de las pruebas de laboratorio, con la idea de optimizar la eficacia antiagregante y sin aumentar el riesgo de hemorragias graves.

Así, Neubauer y colaboradores realizaron un estudio observacional sobre pacientes estables sometidos a ICP en el que proponían, tras una precarga de $600 \mathrm{mg}$ y $75 \mathrm{mg}$ diarios, un algoritmo para reducir la tasa de pacientes no respondedores, analizando la respuesta al clopidogrel mediante agregometría óptica. En los pacientes que no alcanzaban valores adecuados de inhibición plaquetaria se repetía una dosis de carga de 600mg y recibían posteriormente $75 \mathrm{mg}$ cada doce horas. En el caso de que persistieran cifras de agregación plaquetaria superiores a lo aceptable, los pacientes eran cambiados a un régimen de ticlopidina, $250 \mathrm{mg}$ dos veces al día. Con este protocolo se logró disminuir la prevalencia de no respondedores del 23,6\% al 5\%(Neubauer, Lask, Engelhardt, \& Mugge, 2008).

De forma similar, Bonello et al, también en pacientes estables que iban ser sometidos a intervencionismo coronario percutáneo, tras carga de $600 \mathrm{mg}$ realizaron una pauta de tratamiento ajustada mediante los resultados de la determinación de VASP, demostrando una eficacia en la reducción de eventos cardiovasculares mayores. En este estudio, la resistencia al clopidogrel fue definida como un índice-VASP $>50 \%$ tras dosis de $600 \mathrm{mg}$. Si estos valores se mantenían, se permitía hasta tres dosis de carga adicionales dadas cada 24 horas según necesidad hasta que el índice-VASP alcanzaba valores por debajo de 50\% antes de realizar el ICP. La población de dosificación guiada mediante VASP presentó una tasa de MACE a los 30 días del 5 frente al 10\% en la cohorte de tratamiento según pauta convencional, sin un incremento en los sangrados (4 vs 5\%)(Bonello et al., 2008).

De todos modos, la ausencia de una respuesta adecuada al fármaco parece que obedece a múltiples factores individuales. El estudio GRAVITAS, que pretendía comparar dos pautas de dosificación entre pacientes que presentaran una resistencia al clopidogrel definida como RPP superior a 230 URP, no encontró beneficio clínico en el seguimiento entre dosis altas o estándar de clopidogrel (Price, Berger, et al., 2011).

A pesar de la evidencia comentada, el problema sigue sin resolverse, tanto por la falta de unificación en los criterios para definir la resistencia al clopidogrel como 
por la inexistencia de estudios que evalúen este tipo de estrategias guiadas sobre pacientes inestables que sufren IAMCEST.

Las pruebas de agregabilidad plaquetaria han estado clásicamente delimitadas al campo de la investigación clínica y el Grupo de Trabajo en Trombosis de la Sociedad Europea de Cardiología publicó en 2009 un manifiesto en el que reflejaba la no aprobación de estos métodos para la determinación rutinaria de la respuesta antiplaquetaria de los pacientes en la práctica clínica rutinaria(Kuliczkowski et al., 2009).

Recientemente y teniendo en cuenta el peso de los resultados de los ensayos clínicos, las sociedades científicas comienzan a asumir las posibilidades que ofrecen las pruebas de función plaquetaria. Así, en el año 2011 se han publicado tres actualizaciones abriendo la indicación de este tipo de tests para pacientes seleccionados. La ACCF/AHA incluye una recomendación IIb/B para estas pruebas con el objetivo de conocer el estado la de la función plaquetaria en pacientes que van a ser sometidos a ICP de alto riesgo(Wright et al., 2011), la Sociedad Europea de Cardiología admite también su uso con indicación IIb/B en pacientes seleccionados, sin especificar cuáles (Hamm et al., 2011). Lógicamente, en estas recomendaciones sobre pacientes seleccionados podría incluirse aquellos con recurrencias isquémicas a pesar de cumplir el tratamiento a las dosis estándares, o lo que es denominado también "resistencia clínica".

Como hemos comentado previamente, la variabilidad en los puntos de corte encontrados entre distintos ensayos clínicos parecen señalar que, a mayor carga trombótica en la situación clínica que porta el paciente, la actividad plaquetaria se encuentra más exaltada, siendo esta situación otro de los factores a tener en cuenta a la hora de valorar el grado de "agresividad" en el tratamiento que debe ser ofrecido a estos pacientes.

Otra forma de abordar el problema, diferente a la evaluación de dosis altas de copidogrel, es la posibilidad de añadir fármacos adyuvantes, como es el caso del abciximab, o la utilización de nuevos fármacos más potentes inhibidores del receptor P2Y12. Con esta perspectiva, y con la premisa de que la angioplastia electiva tras el infarto de miocardio fibrinolisado es una situación de hiperagregabilidad que produce una resistencia casi completa al clopidogrel, para garantizar el óptimo resultado del intervencionismo coronario se requiere la utilización de abciximab para contrarrestar esta resistencia, y/o otras dianas terapéuticas más potentes o novedosas., como los modernos inhibidores del receptor de ADP plaquetario.

\section{¿ASOCIAR ABCIXIMAB DURANTE EL ICP ELECTIVO?}

Como ya hemos visto, el abciximab presenta una potencia no afectada por el estado hipertrombogénico del posinfarto fibrinolisado. Esta efectividad en estados hipertrombóticos ha sido ya descrita previamente (Perez de Prado et al., 2006) y su utilidad radica principalmente en la reducción de las complicaciones reológicas del intervencionismo coronario. La posibilidad de que su aplicación sea infrautilizada en pacientes de alto riesgo por el miedo a los eventos hemorrágicos 
podría explicar además las diferencias apreciadas entre las distintas estrategias de reperfusión combinada como ya se ha expuesto previamente. Es necesario destacar que, aunque los pacientes de alto riesgo son aquellos que más hemorragias sufren, también es cierto que son en los que más eventos isquémicos recurren, una complicación más frecuente que la hemorragia y cuya carga neta sobre la supervivencia debe ser evaluada con sumo cuidado.

Es posible que la alta frecuencia de utilización de abciximab en este estudio sea en parte responsable de la escasa tasa de eventos observada durante el seguimiento clínico.

\section{¿RETRASAR LA ICP EN LOS PACIENTES DE ALTO RIESGO?}

En este estudio, el valor de la RPP alcanza su valor máximo a las 24 horas de la fibrinolisis, para descender posteriormente de forma paulatina, lo que coincide con los hallazgos clásicos realizados en los años 90 con biosíntesis de tromboxano A2, pero aun así permanece considerablemente elevado. Este hallazgo choca notablemente con la práctica habitual en la mayoría de laboratorios de hemodinámica donde se realiza el estudio angiográfico y la revascularización percutánea tras un infarto con elevación de ST fibrinolisado en las siguientes 3-24 horas tras la administración de la droga, práctica establecida a raíz de la publicación de los resultados de los estudio GRACIA (Fernandez-Aviles et al., 2004), con participación muy activa de nuestro grupo y WEST(Armstrong, 2006) y recomendado de esta forma en las guías de actuación clínica más recientes (Van de Werf et al., 2009). Valorando los hallazgos de estos estudios y lo publicado en el subanálisis del estudio TRANSFER (Yan et al., 2011), comentado en el apartado anterior, es necesario contemplar que una estrategia en la que la revascularización percutánea fuese retrasada hasta que la actividad plaquetaria estuviese más atenuada, pudiera ejercer un efecto protector ante la recurrencia isquémica, al menos, dentro del grupo de pacientes de más alto riesgo.

\section{¿PUEDE ESTAR LA RESPUESTA EN NUEVOS FÁRMACOS ANTI-P2Y12?}

La reciente introducción en el arsenal terapéutico de fármacos como el prasugrel y el ticagrelor podrían añadir valor terapéutico en las situaciones de hiperagregabilidad plaquetaria y resistencia al clopidogrel, ya que ambos fármacos han demostrado tener una potencia inhibitoria superior a la del clopidogrel y una menor variabilidad interindividual(Husted et al., 2006; Payne et al., 2007).

\section{Prasugrel}

El estudio TRITON (Wiviott, Braunwald, et al., 2007) comparó el prasugrel con dosis de clopidogrel de $300 \mathrm{mg}$, la dosis aprobada por la Food \& Drugs Administration (FDA) para el tratamiento de este tipo de pacientes, siendo el resultado positivo para el primero. En el estudio PRINCIPLE-TIMI 44 (Wiviott, Trenk, et al., 2007) el prasugrel se comparó con dosis de 600mg de dosis de carga, 
un régimen cada vez más seguido en pacientes sometidos a ICP. En este estudio el beneficio clínico neto del prasugrel era superior en pacientes con diabetes mellitus, incluyendo un gradiente de beneficio en pacientes sin o con tratamiento activo con insulina(Wiviott et al., 2008). Estas observaciones pueden explicarse por la mayor incidencia de sangrados que puede presentar una pauta de $600 \mathrm{mg}$ y por el la especialmente frecuente incidencia de no respondedores al clopidogrel entre la población diabética.

En resumen, estos estudios demuestran que:

1. El prasugrel reduce de forma eficaz el riesgo de muerte, infarto o ictus isquémico en el seguimiento de los pacientes con enfermedad coronaria.

2. Esta diferencia es tanto más acusada entre la población de pacientes con diabetes mellitus o que se presentan con infarto con elevación del ST.

3. La reducción de hasta un $50 \%$ en las tasas de trombosis del stent (tanto para stents metálicos como farmacoactivos) defiende la utilización de prasugrel sobre el clopidogrel en pacientes sometidos a ICP con implante de stent coronario.

4. Existe un incremento de eventos hemorrágicos en los pacientes tratados con prasugrel que con clopidogrel, lo que conlleva un beneficio clínico neto similar (en la población de TRITón con una incidencia de sangrados especialmente alta en relación con la cirugía).

Ante la preocupación que ha causado el incremento de hemorragias con el tratamiento con prasugrel, se ha identificado a los subgrupos en mayor riesgo: pacientes ancianos (edad superior a 75 años), pacientes con bajo peso (menos de $60 \mathrm{Kg}$ ) y pacientes con antecedentes de ACV previo.

Para evitar este incremento de hemorragias se están evaluando dosis de mantenimiento de $5 \mathrm{mg}$ al día para el tratamiento de estos pacientes de alto riesgo, pero los resultado aún no son concluyentes.

Otra cuestión importante durante el estudio se desprende del subgrupo que requirió cirugía cardiaca durante el ingreso. En este grupo de pacientes, se encontró un incremento de las hemorragias de hasta cuatro veces más en el brazo del prasugrel que en el de clopidogrel. Por este motivo se ha recomendado que este tratamiento no sea proporcionado antes de conocer la anatomía coronaria de los pacientes.

\section{Ticagrelor}

Los prometedores estudios realizados con este nuevo inhibidor oral reversible no tienopiridínico del receptor P2Y12 presentan al ticagrelor como la respuesta a muchos de los problemas planteados por el clopidogrel e incluso por el prausgrel, ya que aúna la potencia del segundo con la seguridad del primero.

Especialmente destacable con respecto al prasugrel es la baja incidencia de hemorragias perioperatorias sobre los pacientes que requieren cirugía cardiaca observadas en el estudio PLATO (Wallentin et al., 2009). Este fenómeno puede explicarse fácilmente por el carácter reversible de la unión al receptor del 
ticagrelor y la corta vida media del fármaco. De todos modos, hay que tener en cuenta que este nuevo fármaco de rápida acción y corta vida media presentó sangrados perioperatorios similares a los que se observan en pacientes en tratamiento activo con clopidogrel, tienopiridina de unión irreversible al receptor.

Además, el carácter reversible de la unión con el receptor que caracteriza a este nuevo fármaco es un arma de doble filo ya que exige una administración cada doce horas para mantener niveles terapéuticos, lo que conlleva unas exigencias en cuanto a la adherencia al tratamiento muy superiores a las que requieren las tienopiridinas, ya que el incumplimiento de los horarios de administración conduciría irremediablemente a una situación de desprotección en cuanto a inhibición de la actividad plaquetaria se refiere, situación que en circunstancias en las que se requiera periodos muy prolongados de doble antiagregación, como sería el implante de stents farmacoactivos, pueden llegar a ser un problema a largo plazo.

En resumen, a pesar de que los nuevos inhibidores del ADP se presentan como un avance importante en la farmacoterapia de la enfermedad coronaria también presentan inconvenientes. Por este motivo, la posibilidad de encontrar un tratamiento más específicamente dirigido hacia el mecanismo subyacente de la hiperagregabilidad inducida por fibrinolíticos resulta especialmente atractiva.

\section{¿TENDRÍAN UTILIDAD LOS NUEVOS FÁRMACOS QUE PUEDEN INHIBIR LA RUTA ESPECÍFICA QUE CONDICIONA LA HIPERAGREGABILIDAD PLAQUETARIA POSFIBRINOLISIS?}

Como se ha presentado previamente en el capítulo de antecedentes sobre el tema, la teoría más aceptada que explica la causa subyacente al repunte de actividad plaquetaria inducida por el tratamiento fibrinolítico es la activación de los receptores plaquetarios PAR-1 y PAR-4, especialmente el primero de ellos, por el exceso de trombina generada durante la lisis del trombo intravascular(Zeymer et al., 1998).

\section{Inhibidores del PAR-1: vorapaxar y atopaxar}

Los inhibidores específicos del receptor PAR-1 son los antiplaquetarios más modernos, diseñados para inhibir la ruta de la trombina, una de las más potentes vías de activación plaquetaria(Coughlin, 2005). Hasta la fecha se han presentado dos moléculas: el vorapaxar, antes SCH 530348, y el atopaxar, antes E5555. La primera de ellas es la que más se ha probado en ensayos clínicos de gran tamaño para profilaxis secundaria de enfermedad coronaria, pero tras los malos resultados del estudio TRACER, que tuvo que ser suspendido prematuramente por un incremento inasumible de eventos hemorrágicos, especialmente sangrado intracraneal (Tricoci et al., 2012), su inclusión en el arsenal terapéutico cardiovascular ha quedado frenada, al menos hasta la reciente publicación del estudio TRA-2P, cuyos resultados parecen ser más prometedores (Morrow et al., 2012). Aun así, teniendo en cuenta los antecedentes, es probable que se requieran resultados mucho más consistentes antes de poder hacer una recomendación 
sobre su utilización, especialmente en un proceso como el IAMCEST fibrinolisado, donde las hemorragias son un condicionante de mortalidad crucial.

El atopaxar dispone tan sólo de estudios de pequeño tamaño y por el momento se reconoce su seguridad y tolerabilidad pero requiere de ensayos clínicos de mayor tamaño(O'Donoghue et al., 2011).

\section{Inhibición directa de la trombina: bivalirudina}

Existe otra posibilidad de inhibición de la trombina durante el IAMCEST, y especialmente durante el ICP relacionado con él: la bivalirudina. Este inhibidor directo de la trombina se lleva utilizando como alternativa a la heparina no fraccionada en el síndrome coronario agudo desde hace años.

Tras ser probada en distintos contextos de la patología cardiovascular, con resultados generalmente de no inferioridad con respecto a la heparina no fraccionada, su uso en el contexto del IAMCEST ha quedado ligado al intervencionismo coronario primario, especialmente tras la publicación del estudio HORIZONS-AMI que demostró un resultado similar a la combinación de heparina y abciximab en cuanto a la reducción de eventos isquémicos con una menor tasa de hemorragias (Mehran et al., 2009).

El potencial poder inhibidor plaquetario que se atribuyó a esta molécula ha quedado recientemente demostrado en una reciente publicación (Kimmelstiel et al., 2011) donde se ha objetivado que posee de forma intrínseca capacidad para inhibir de forma específica la actividad plaquetaria dependiente de trombina (actividad antiPAR-1). Este efecto puede explicar un hecho muy interesante para la presente tesis que se desprende de los resultados del estudio HERO-2. Este ensayo clínico randomizó a mas de 17000 pacientes a recibir bivalirudina o heparina no fraccionada precisamente durante el IAMCEST tratado con fibrinolíticos. En él no se encontraron diferencias en mortalidad y sí un mayor número de eventos hemorrágicos, pero resulta muy llamativo que se observó una reducción del 30\% en las tasas de reinfarto durante las primeras 96h (H. White, 2001). Si el efecto antiplaquetario directo de la bivalirudina es el responsable de este beneficio por la inhibición de la hiperreactividad inducida por fibrinolíticos es una interesante posibilidad a explorar en futuras líneas de investigación. 


\section{LIMITACIONES DEL ESTUDIO}

La limitación fundamental de este estudio se debe a lo limitado de su tamaño muestral, que impide realizar un análisis adecuado sobre la consecuencia en cuanto a eventos cardiovasculares que pudiera tener el efecto observado.

Otra limitación se centra en el sesgo que el diseño del propio estudio introduce en cuanto a la selección de pacientes de bajo perfil de riesgo. La necesidad de compatibilizar el estudio con la práctica clínica habitual en el Hospital Universitario de León hizo necesario incluir a una mayoría de pacientes con infartos de localización no anterior y sin signos de insuficiencia cardiaca grave. Este hecho, aparte del sesgo evidente que produce, disminuye la posibilidad de aparición de eventos adversos en el seguimiento. A pesar de ello, este mismo diseño nos ofrece la valiosa posibilidad de estudiar una población que se corresponde exactamente con la práctica real en un centro de atención hospitalario de tercer nivel con acceso no limitado a todas las estrategias de reperfusión durante el IAMCEST.

\section{IMPLICACIONES PARA LA PRÁCTICA CLÍNICA}

Dados los hallazgos de este estudio y siempre y cuando las condiciones del infarto de miocardio no cambien, el periodo posterior a la administración de un fármaco fibrinolítico como tratamiento de reperfusión en un IAMCEST debe seguirse considerando como una situación de alto riesgo isquémico por hiperagregabilidad plaquetaria sostenida que dificulta la correcta inhibición del receptor P2Y12 por parte del clopidogrel. Así, el intervencionismo coronario subsiguiente, cuando sea realizado en este contexto, debería asociar terapia antiplaquetaria de mayor potencia para evitar complicaciones isquémicas y optimizar el resultado, siempre y cuando pueda minimizarse el riesgo hemorrágico.

Teniendo en cuenta la importancia que esta diana terapéutica está adquiriendo en el desarrollo de nuevas estrategias farmacológicas para el manejo de este síndrome, así como su relación inmediata con los resultados del intervencionismo coronario y el incremento de la presencia de éste en las estrategias terapéuticas cardiológicas actuales, creemos que los resultados de este estudio ofrecen información de alto valor y principalmente sugiere las líneas futuras de investigación, mencionadas en el siguiente apartado. 


\section{LÍNEAS FUTURAS DE INVESTIGACIÓN}

Teniendo en cuenta los resultados del presente estudio y las implicaciones clínicas que suscita, parece conveniente proseguir con la investigación sobre la actividad del receptor P2Y12 en los diferentes contextos clínicos propios de la enfermedad coronaria: la enfermedad coronaria estable, el síndrome coronario agudo sin elevación del segmento ST y el infarto agudo de miocardio con elevación del segmento ST, muy especialmente ante la inminente aplicación en la práctica clínica habitual de novedades farmacológicas como el prasugrel y el ticagrelor.

De la misma forma y precisamente por la importante relación que la actividad de este receptor tiene con el resultado de las intervenciones coronarias percutáneas, es preciso determinar la efectividad de estas nuevas moléculas y su comparación dentro de las diferentes estrategias de reperfusión.

En cuanto a otras novedades terapéuticas, será necesario estudiar adecuadamente si la bivalirudina o los más modernos inhibidores del recpetor PAR-1 son capaces de inhibir el efecto observado en este estudio.

En el caso concreto de la angioplastia electiva tras el tratamiento fibrinolítico, será necesario no sólo continuar con la investigación sobre la actividad plaquetaria, sino centrar además futuros esfuerzos en descifrar los diferentes condicionantes de la misma: los diferentes marcos temporales para las intervenciones, los distintos perfiles de riesgo que puedan presentar los pacientes y la influencia de los diversos fármacos adyuvantes durante el procedimiento.

La idea general sería proseguir con la investigación clínica hacia la consecución de una terapia de reperfusión para el infarto de miocardio que logre los mejores resultados aplicando un criterio de individualización para cada paciente en función de:

1. Las características clínicas determinadas del síndrome coronario (tiempo de evolución, clase Killip, localización, complicaciones mecánicas o eléctricas, etc...).

2. Las características clínicas propias del paciente (edad, pesao, factores de riesgo, comorbilidad, etc...)

3. Infraestructura sanitaria local y facilidades hospitalarias en los centros cercanos, así como tiempos de traslado y de retraso promedio hasta la realización de procedimiento de revascularización. 

CONCLUSIONES 



\section{CONCLUSIONES}

1. El infarto agudo de miocardio que recibe tratamiento fibrinolítico induce un estado de hiperagregabilidad plaquetaria que se extiende a la reactividad mediada por ADP.

2. La hiperactividad de este receptor conduce a una resistencia a la terapia con dosis aprobadas para este contexto de clopidogrel que se prolonga en el tiempo durante los primeros días tras la administración del fármaco.

3. La inhibición de la actividad plaquetaria conseguida con este fármaco en la muestra de este estudio es muy inferior a la conseguida en otros contextos clínicos de menor carga trombótica.

4. El abciximab no presenta disminuida su capacidad de inhibición del receptor IIb/IIIa durante el intervencionismo coronario electivo tras el infarto fibrinolisado.

5. El tratamiento fibrinolítico en nuestro centro, con acceso a angioplastia primaria 24 horas, se reserva para un perfil de pacientes de menor riesgo.

6. La hiperactividad plaquetaria demostrada en este estudio no se relacionó con un peor pronóstico en el seguimiento clínico.

7. En los modelos predictivos multivariantes, las variables que se relacionaron en mayor medida con del daño miocárdico posintervención incluyeron como valor más destacado la reactividad plaquetaria postratamiento.

8. Los predictores de la respuesta plaquetaria postratamiento incluyeron por orden de importancia el valor de reactividad plaquetaria basal determinado por estimulación con iso-TRAP, el contaje total plaquetario, la edad de los pacientes y las variables electrocardiográficas y analíticas indicadoras del mayor tamaño del infarto. 





\section{BIBLIOGRAFÍA}

Ahsan, C. H., Shah, A., \& Ezekowitz, M. (2001). Acute statin treatment in reducing risk after acute coronary syndrome: the MIRACL (Myocardial Ischemia Reduction with Aggressive Cholesterol Lowering) Trial. Curr Opin Cardiol, 16(6), 390-393.

Aleil, B., Ravanat, C., Cazenave, J. P., Rochoux, G., Heitz, A., \& Gachet, C. (2005). Flow cytometric analysis of intraplatelet VASP phosphorylation for the detection of clopidogrel resistance in patients with ischemic cardiovascular diseases. $J$ Thromb Haemost, 3(1), 85-92.

Anderson, H. V., \& Willerson, J. T. (1993). Thrombolysis in acute myocardial infarction. N Engl J Med, 329(10), 703-709.

Anderson, J. L., Adams, C. D., Antman, E. M., Bridges, C. R., Califf, R. M., Casey, D. E., Jr., ... Riegel, B. (2007). ACC/AHA 2007 guidelines for the management of patients with unstable angina/non-ST-Elevation myocardial infarction: a report of the American College of Cardiology/American Heart Association Task Force on Practice Guidelines (Writing Committee to Revise the 2002 Guidelines for the Management of Patients With Unstable Angina/Non-STElevation Myocardial Infarction) developed in collaboration with the American College of Emergency Physicians, the Society for Cardiovascular Angiography and Interventions, and the Society of Thoracic Surgeons endorsed by the American Association of Cardiovascular and Pulmonary Rehabilitation and the Society for Academic Emergency Medicine. J Am Coll Cardiol, 50(7), e1-e157.

Anderson, T. D., DA. (1952). Asymptotic theory of certain "goodness-of-fit" criteria based on stochastic processes. Annals of Mathematical Statistics(23), 193212.

Angiolillo, D. J., Fernandez-Ortiz, A., Bernardo, E., Ramirez, C., Barrera-Ramirez, C., Sabate, M., ... Macaya, C. (2005). Identification of low responders to a 300mg clopidogrel loading dose in patients undergoing coronary stenting. Thromb Res, 115(1-2), 101-108.

Angiolillo, D. J., Shoemaker, S. B., Desai, B., Yuan, H., Charlton, R. K., Bernardo, E., ... Costa, M. A. (2007). Randomized comparison of a high clopidogrel maintenance dose in patients with diabetes mellitus and coronary artery disease: results of the Optimizing Antiplatelet Therapy in Diabetes Mellitus (OPTIMUS) study. Circulation, 115(6), 708-716.

Armstrong, P. W. (2006). A comparison of pharmacologic therapy with/without timely coronary intervention vs. primary percutaneous intervention early after ST-elevation myocardial infarction: the WEST (Which Early ST- 
elevation myocardial infarction Therapy) study. Eur Heart J, 27(13), 15301538.

Aros, F., Cunat, J., Loma-Osorio, A., Torrado, E., Bosch, X., Rodriguez, J. J., . . . Marrugat, J. (2003). [Management of myocardial infarction in Spain in the year 2000. The PRIAMHO II study]. Rev Esp Cardiol, 56(12), 1165-1173.

Aros, F., Heras, M., Vila, J., Sanz, H., Ferreira-Gonzalez, I., Permanyer-Miralda, G., ... Marrugat, J. (2011). [Reduction in 28 days and 6 months of acute myocardial infarction mortality from 1995 to 2005. Data from PRIAMHO I, II and MASCARA registries]. Rev Esp Cardiol, 64(11), 972-980.

Asadoorian, M. K., D. (2008). Essentials of Inferencial Statistics. Lenham MD: University Press of America.

The aspirin myocardial infarction study: final results. The Aspirin Myocardial Infarction Study research group. (1980). Circulation, 62 (6 Pt 2), V79-84.

Awtry, E. H., \& Loscalzo, J. (2000). Aspirin. Circulation, 101(10), 1206-1218.

Bassand, J. P., Hamm, C. W., Ardissino, D., Boersma, E., Budaj, A., Fernandez-Aviles, F., ... Wijns, W. (2007). Guidelines for the diagnosis and treatment of nonST-segment elevation acute coronary syndromes. Eur Heart J, 28(13), 15981660.

Bauters, C., Delomez, M., Van Belle, E., McFadden, E., Lablanche, J. M., \& Bertrand, M. E. (1999). Angiographically documented late reocclusion after successful coronary angioplasty of an infarct-related lesion is a powerful predictor of long-term mortality. Circulation, 99(17), 2243-2250.

Bechhofer, R. D., CW. (1988). Percentage points of multivariate Student $t$ distributions (Vol. 11): American Mathematical Society.

Bhatt, D. L., Cryer, B. L., Contant, C. F., Cohen, M., Lanas, A., Schnitzer, T. J., . . . Cannon, C. P. (2010). Clopidogrel with or without omeprazole in coronary artery disease. $N$ Engl J Med, 363(20), 1909-1917.

Bhatt, D. L., Lincoff, A. M., Gibson, C. M., Stone, G. W., McNulty, S., Montalescot, G., . . Harrington, R. A. (2009). Intravenous platelet blockade with cangrelor during PCI. N Engl J Med, 361(24), 2330-2341.

Bhatt, D. L., Scheiman, J., Abraham, N. S., Antman, E. M., Chan, F. K., Furberg, C. D., . . . Quigley, E. M. (2008). ACCF/ACG/AHA 2008 expert consensus document on reducing the gastrointestinal risks of antiplatelet therapy and NSAID use: a report of the American College of Cardiology Foundation Task Force on Clinical Expert Consensus Documents. Circulation, 118(18), 1894-1909.

Bihour, C., Durrieu-Jais, C., Besse, P., Nurden, P., \& Nurden, A. T. (1995). Flow cytometry reveals activated GP IIb-IIIa complexes on platelets from patients undergoing thrombolytic therapy after acute myocardial infarction. Blood Coagul Fibrinolysis, 6(5), 395-410. 
Blankenship, J. C. (2009). Farmacology of glycoprotein IIb/IIIa intravenous inhibitors. In S. D. Wiviott (Ed.), Antiplatelet Therapy in Ischemic Heart DIsease. Hoboken: Wiley-Blackwell.

Bliden, K. P., DiChiara, J., Tantry, U. S., Bassi, A. K., Chaganti, S. K., \& Gurbel, P. A. (2007). Increased risk in patients with high platelet aggregation receiving chronic clopidogrel therapy undergoing percutaneous coronary intervention: is the current antiplatelet therapy adequate? J Am Coll Cardiol, $49(6), 657-666$.

Boersma, E., Maas, A. C., Deckers, J. W., \& Simoons, M. L. (1996). Early thrombolytic treatment in acute myocardial infarction: reappraisal of the golden hour. Lancet, 348(9030), 771-775.

Boie, Y., Rushmore, T. H., Darmon-Goodwin, A., Grygorczyk, R., Slipetz, D. M., Metters, K. M., \& Abramovitz, M. (1994). Cloning and expression of a cDNA for the human prostanoid IP receptor. J Biol Chem, 269(16), 12173-12178.

Bonello, L., Camoin-Jau, L., Arques, S., Boyer, C., Panagides, D., Wittenberg, O., . . Paganelli, F. (2008). Adjusted clopidogrel loading doses according to vasodilator-stimulated phosphoprotein phosphorylation index decrease rate of major adverse cardiovascular events in patients with clopidogrel resistance: a multicenter randomized prospective study. J Am Coll Cardiol, 51(14), 1404-1411.

Bonnefoy, E., Steg, P. G., Boutitie, F., Dubien, P. Y., Lapostolle, F., Roncalli, J., ... Touboul, P. (2009). Comparison of primary angioplasty and pre-hospital fibrinolysis in acute myocardial infarction (CAPTIM) trial: a 5-year followup. Eur Heart J, 30(13), 1598-1606.

Born, G. V. (1962). Aggregation of blood platelets by adenosine diphosphate and its reversal. Nature, 194, 927-929.

Brandt, J. T., Close, S. L., Iturria, S. J., Payne, C. D., Farid, N. A., Ernest, C. S., 2nd, . . Winters, K. J. (2007). Common polymorphisms of CYP2C19 and CYP2C9 affect the pharmacokinetic and pharmacodynamic response to clopidogrel but not prasugrel. J Thromb Haemost, 5(12), 2429-2436.

Brar, S. S., ten Berg, J., Marcucci, R., Price, M. J., Valgimigli, M., Kim, H. S., . . . Dangas, G. (2011). Impact of platelet reactivity on clinical outcomes after percutaneous coronary intervention. A collaborative meta-analysis of individual participant data. J Am Coll Cardiol, 58(19), 1945-1954.

Brass, L. F., Hoxie, J. A., \& Manning, D. R. (1993). Signaling through G proteins and G protein-coupled receptors during platelet activation. Thromb Haemost, 70(1), 217-223.

Breet, N. J., Sluman, M. A., van Berkel, M. A., van Werkum, J. W., Bouman, H. J., Harmsze, A. M., . . . Ten Berg, J. M. (2011). Effect of gender difference on platelet reactivity. Neth Heart J, 19(11), 451-457. 
Breet, N. J., van Werkum, J. W., Bouman, H. J., Kelder, J. C., Ruven, H. J., Bal, E. T., ... ten Berg, J. M. (2010). Comparison of platelet function tests in predicting clinical outcome in patients undergoing coronary stent implantation. JAMA, 303(8), 754-762.

Bruschke, A. V., Kramer, J. R., Jr., Bal, E. T., Haque, I. U., Detrano, R. C., \& Goormastic, M. (1989). The dynamics of progression of coronary atherosclerosis studied in 168 medically treated patients who underwent coronary arteriography three times. Am Heart J, 117(2), 296-305.

Buch, P., Rasmussen, S., Gislason, G. H., Rasmussen, J. N., Kober, L., Gadsboll, N., ... Abildstrom, S. Z. (2007). Temporal decline in the prognostic impact of a recurrent acute myocardial infarction 1985 to 2002. Heart, 93(2), 210-215.

Burke, A. P., Farb, A., Malcom, G. T., Liang, Y., Smialek, J., \& Virmani, R. (1998). Effect of risk factors on the mechanism of acute thrombosis and sudden coronary death in women. Circulation, 97(21), 2110-2116.

Burke, A. P., Farb, A., Malcom, G. T., Liang, Y. H., Smialek, J., \& Virmani, R. (1997). Coronary risk factors and plaque morphology in men with coronary disease who died suddenly. $N$ Engl J Med, 336(18), 1276-1282.

Camejo, G., Hurt-Camejo, E., Wiklund, O., \& Bondjers, G. (1998). Association of apo B lipoproteins with arterial proteoglycans: pathological significance and molecular basis. Atherosclerosis, 139(2), 205-222.

Campo, G., Valgimigli, M., Gemmati, D., Percoco, G., Tognazzo, S., Cicchitelli, G., .. . Ferrari, R. (2006). Value of platelet reactivity in predicting response to treatment and clinical outcome in patients undergoing primary coronary intervention: insights into the STRATEGY Study. J Am Coll Cardiol, 48(11), 2178-2185.

Cannon, C. P., Husted, S., Harrington, R. A., Scirica, B. M., Emanuelsson, H., Peters, G., \& Storey, R. F. (2007). Safety, tolerability, and initial efficacy of AZD6140, the first reversible oral adenosine diphosphate receptor antagonist, compared with clopidogrel, in patients with non-ST-segment elevation acute coronary syndrome: primary results of the DISPERSE- 2 trial. J Am Coll Cardiol, 50(19), 1844-1851.

Canto, J. G., Every, N. R., Magid, D. J., Rogers, W. J., Malmgren, J. A., Frederick, P. D., . . Barron, H. V. (2000). The volume of primary angioplasty procedures and survival after acute myocardial infarction. National Registry of Myocardial Infarction 2 Investigators. N Engl J Med, 342(21), 1573-1580.

Cantor, W. J., Fitchett, D., Borgundvaag, B., Ducas, J., Heffernan, M., Cohen, E. A., ... Goodman, S. G. (2009). Routine early angioplasty after fibrinolysis for acute myocardial infarction. $N$ Engl J Med, 360(26), 2705-2718.

Casserly, I. P., \& Topol, E. J. (2002). Glycoprotein IIb/IIIa antagonists--from bench to practice. Cell Mol Life Sci, 59(3), 478-500. 
Chambers, J. H., TJ. (1992). Statistical Models in S. New York: Chapman \& Hall.

Chang, Y., Bluteau, D., Debili, N., \& Vainchenker, W. (2007). From hematopoietic stem cells to platelets. J Thromb Haemost, 5 Suppl 1, 318-327.

Chatzizisis, Y. S., Baker, A. B., Sukhova, G. K., Koskinas, K. C., Papafaklis, M. I., Beigel, R., ... Stone, P. H. (2011). Augmented expression and activity of extracellular matrix-degrading enzymes in regions of low endothelial shear stress colocalize with coronary atheromata with thin fibrous caps in pigs. Circulation, 123(6), 621-630.

Chen, Z. M., Jiang, L. X., Chen, Y. P., Xie, J. X., Pan, H. C., Peto, R., .. Liu, L. S. (2005). Addition of clopidogrel to aspirin in 45,852 patients with acute myocardial infarction: randomised placebo-controlled trial. Lancet, 366(9497), 16071621.

Cheng, G. C., Loree, H. M., Kamm, R. D., Fishbein, M. C., \& Lee, R. T. (1993).

Distribution of circumferential stress in ruptured and stable atherosclerotic lesions. A structural analysis with histopathological correlation. Circulation, 87(4), 1179-1187.

Cines, D. B., Pollak, E. S., Buck, C. A., Loscalzo, J., Zimmerman, G. A., McEver, R. P., .. . Stern, D. M. (1998). Endothelial cells in physiology and in the pathophysiology of vascular disorders. Blood, 91(10), 3527-3561.

Classics in arteriosclerosis research: On experimental cholesterin steatosis and its significance in the origin of some pathological processes by N. Anitschkow and S. Chalatow, translated by Mary Z. Pelias, 1913. (1983). Arteriosclerosis, $3(2), 178-182$.

Collaborative meta-analysis of randomised trials of antiplatelet therapy for prevention of death, myocardial infarction, and stroke in high risk patients. (2002). BMJ, 324(7329), 71-86.

Coughlin, S. R. (2005). Protease-activated receptors in hemostasis, thrombosis and vascular biology. J Thromb Haemost, 3(8), 1800-1814.

Cournand, A., Baldwin, E. D., Darling, R. C., \& Richards, D. W. (1941). Studies on intrapulmonary mixture of gases. iv. The significance of the pulmonary emptying rate and a simplified open circuit measurement of residual air. $J$ Clin Invest, 20(6), 681-689.

Cuisset, T., Frere, C., Quilici, J., Morange, P. E., Nait-Saidi, L., Carvajal, J., . . A Alessi, M. C. (2006). Benefit of a 600-mg loading dose of clopidogrel on platelet reactivity and clinical outcomes in patients with non-ST-segment elevation acute coronary syndrome undergoing coronary stenting. J Am Coll Cardiol, 48(7), 1339-1345.

Cuisset, T., Frere, C., Quilici, J., Morange, P. E., Nait-Saidi, L., Mielot, C., .. Bonnet, J. L. (2007). High post-treatment platelet reactivity is associated with a high 
incidence of myonecrosis after stenting for non-ST elevation acute coronary syndromes. Thromb Haemost, 97(2), 282-287.

Cuisset, T., Frere, C., Quilici, J., Poyet, R., Gaborit, B., Bali, L., ... Bonnet, J. L. (2009). Comparison of omeprazole and pantoprazole influence on a high 150-mg clopidogrel maintenance dose the PACA (Proton Pump Inhibitors And Clopidogrel Association) prospective randomized study. J Am Coll Cardiol, 54(13), 1149-1153.

Cuisset, T., Hamilos, M., Sarma, J., Sarno, G., Wyffels, E., Vanderheyden, M., ... Wijns, W. (2008). Relation of low response to clopidogrel assessed with point-ofcare assay to periprocedural myonecrosis in patients undergoing elective coronary stenting for stable angina pectoris. Am J Cardiol, 101(12), 17001703.

Cybulsky, M. I., \& Gimbrone, M. A., Jr. (1991). Endothelial expression of a mononuclear leukocyte adhesion molecule during atherogenesis. Science, 251(4995), 788-791.

Davies, M. J., Gordon, J. L., Gearing, A. J., Pigott, R., Woolf, N., Katz, D., \& Kyriakopoulos, A. (1993). The expression of the adhesion molecules ICAM-1, VCAM-1, PECAM, and E-selectin in human doi: 10.1002/path.1711710311

Davies, M. J., Richardson, P. D., Woolf, N., Katz, D. R., \& Mann, J. (1993). Risk of thrombosis in human atherosclerotic plaques: role of extracellular lipid, macrophage, and smooth muscle cell content. Br Heart J, 69(5), 377-381.

De Luca, G., Suryapranata, H., Ottervanger, J. P., \& Antman, E. M. (2004). Time delay to treatment and mortality in primary angioplasty for acute myocardial infarction: every minute of delay counts. Circulation, 109(10), 1223-1225.

De Luca, G., Suryapranata, H., Stone, G. W., Antoniucci, D., Tcheng, J. E., Neumann, F. J., ... Topol, E. J. (2005). Abciximab as adjunctive therapy to reperfusion in acute ST-segment elevation myocardial infarction: a meta-analysis of randomized trials. JAMA, 293(14), 1759-1765.

De Luca, G., Suryapranata, H., Zijlstra, F., van 't Hof, A. W., Hoorntje, J. C., Gosselink, A. T., ... de Boer, M. J. (2003). Symptom-onset-to-balloon time and mortality in patients with acute myocardial infarction treated by primary angioplasty. J Am Coll Cardiol, 42(6), 991-997.

de Miguel Castro, A. (2010). Clopidogrel Response in Acute Coronary Siyndromes. Clinical Implications and Emerging Therapies. New York: Nova.

de Miguel Castro, A., Cuellas Ramon, C., Diego Nieto, A., Samaniego Lampon, B., Alonso Rodriguez, D., Fernandez Vazquez, F., ... Perez de Prado, A. (2009). Post-treatment platelet reactivity predicts long-term adverse events better than the response to clopidogrel in patients with non-ST-segment elevation acute coronary syndrome. Rev Esp Cardiol, 62(2), 126-135. 
Deutsch, V. R., \& Tomer, A. (2006). Megakaryocyte development and platelet production. Br J Haematol, 134(5), 453-466.

Di Mario, C., Dudek, D., Piscione, F., Mielecki, W., Savonitto, S., Murena, E., ... Flather, M. (2008). Immediate angioplasty versus standard therapy with rescue angioplasty after thrombolysis in the Combined Abciximab REteplase Stent Study in Acute Myocardial Infarction (CARESS-in-AMI): an open, prospective, randomised, multicentre trial. Lancet, 371(9612), 559568.

Dollery, C. M., McEwan, J. R., \& Henney, A. M. (1995). Matrix metalloproteinases and cardiovascular disease. Circ Res, 77(5), 863-868.

Dong, Z. M., Chapman, S. M., Brown, A. A., Frenette, P. S., Hynes, R. O., \& Wagner, D. D. (1998). The combined role of P- and E-selectins in atherosclerosis. J Clin Invest, 102(1), 145-152.

Dotter, C. T., \& Judkins, M. P. (1964). Transluminal treatment of arteriosclerotic obstruction. Description of a new technic and a preliminary report of its application. Circulation, 30, 654-670.

Eisenberg, P. R., \& Miletich, J. P. (1989). Induction of marked thrombin activity by pharmacologic concentrations of plasminogen activators in nonanticoagulated whole blood. Thromb Res, 55(5), 635-643.

Ellis, S. G., Tendera, M., de Belder, M. A., van Boven, A. J., Widimsky, P., Janssens, L., ... Topol, E. J. (2008). Facilitated PCI in patients with ST-elevation myocardial infarction. $N$ Engl J Med, 358(21), 2205-2217.

Elwood, P. C., Cochrane, A. L., Burr, M. L., Sweetnam, P. M., Williams, G., Welsby, E., ... Renton, R. (1974). A randomized controlled trial of acetyl salicylic acid in the secondary prevention of mortality from myocardial infarction. $\mathrm{Br}$ Med J, 1(5905), 436-440.

Emeson, E. E., \& Robertson, A. L., Jr. (1988). T lymphocytes in aortic and coronary intimas. Their potential role in atherogenesis. Am J Pathol, 130(2), 369-376.

Fabre, J. E., Nguyen, M., Athirakul, K., Coggins, K., McNeish, J. D., Austin, S., . . Koller, B. H. (2001). Activation of the murine EP3 receptor for PGE2 inhibits cAMP production and promotes platelet aggregation. J Clin Invest, 107(5), 603-610.

Falk, E., Shah, P. K., \& Fuster, V. (1995). Coronary plaque disruption. Circulation, 92(3), 657-671.

Farb, A., Burke, A. P., Tang, A. L., Liang, T. Y., Mannan, P., Smialek, J., \& Virmani, R. (1996). Coronary plaque erosion without rupture into a lipid core. A frequent cause of coronary thrombosis in sudden coronary death. Circulation, 93(7), 1354-1363. 
Farhangfar, A. K., LA; Pedrycz, W. (2007). A novel framework for imputation of missing values in databases. Systems, Man and Cybernetics, Part A: Systems and Humans, IEEE Transactions on 37(5), 692-709.

Fernandez-Aviles, F., Alonso, J. J., Castro-Beiras, A., Vazquez, N., Blanco, J., AlonsoBriales, J., ... Ramos, B. (2004). Routine invasive strategy within 24 hours of thrombolysis versus ischaemia-guided conservative approach for acute myocardial infarction with ST-segment elevation (GRACIA-1): a randomised controlled trial. Lancet, 364(9439), 1045-1053.

Ferraris, V. A., Brown, J. R., Despotis, G. J., Hammon, J. W., Reece, T. B., Saha, S. P., ... Shann, K. G. (2011). 2011 update to the Society of Thoracic Surgeons and the Society of Cardiovascular Anesthesiologists blood conservation clinical practice guidelines. Ann Thorac Surg, 91(3), 944-982.

Ferreira-Gonzalez, I., Permanyer-Miralda, G., Marrugat, J., Heras, M., Cunat, J., Civeira, E., ... Bueno, H. (2008). MASCARA (Manejo del Sindrome Coronario Agudo. Registro Actualizado) study. General findings. Rev Esp Cardiol, 61(8), 803-816.

Fitzgerald, D. J., Catella, F., Roy, L., \& FitzGerald, G. A. (1988). Marked platelet activation in vivo after intravenous streptokinase in patients with acute myocardial infarction. Circulation, 77(1), 142-150.

Fletcher, A. P., Alkjaersig, N., Smyrniotis, F. E., \& Sherry, S. (1958). The treatment of patients suffering from early myocardial infarction with massive and prolonged streptokinase therapy. Trans Assoc Am Physicians, 71, 287-296.

Francis, J. (2007). The platelet function analyzer (PFA)-100. In A. Michelson (Ed.), Platelets (pp. 519-534). San Diego: Elsevier/Academic Press.

Frandsen, N. J., Winther, K., Pedersen, F., Christiansen, I., \& McNair, P. (1996). Time course of platelet alpha granule release in acute myocardial infarction treated with streptokinase. Heart, 75(2), 141-144.

Frenette, P. S., \& Wagner, D. D. (1996). Adhesion molecules--Part 1. N Engl J Med, 334(23), 1526-1529.

Friedman, J. H., \& Roosen, C. B. (1995). An introduction to multivariate adaptive regression splines. Stat Methods Med Res, 4(3), 197-217.

Frossard, M., Fuchs, I., Leitner, J. M., Hsieh, K., Vlcek, M., Losert, H., ... Jilma, B. (2004). Platelet function predicts myocardial damage in patients with acute myocardial infarction. Circulation, 110(11), 1392-1397.

Gaglia, M. A., Jr., Torguson, R., Hanna, N., Gonzalez, M. A., Collins, S. D., Syed, A. I., . . Waksman, R. (2010). Relation of proton pump inhibitor use after percutaneous coronary intervention with drug-eluting stents to outcomes. Am J Cardiol, 105(6), 833-838. 
Galis, Z. S., Sukhova, G. K., Lark, M. W., \& Libby, P. (1994). Increased expression of matrix metalloproteinases and matrix degrading activity in vulnerable regions of human atherosclerotic plaques. J Clin Invest, 94(6), 2493-2503.

Geisler, T., Langer, H., Wydymus, M., Gohring, K., Zurn, C., Bigalke, B., ... Gawaz, M. (2006). Low response to clopidogrel is associated with cardiovascular outcome after coronary stent implantation. Eur Heart J, 27(20), 2420-2425.

Gershlick, A. H., Stephens-Lloyd, A., Hughes, S., Abrams, K. R., Stevens, S. E., Uren, N. G., ... Wilcox, R. (2005). Rescue angioplasty after failed thrombolytic therapy for acute myocardial infarction. $N$ Engl J Med, 353(26), 2758-2768.

Gessi, S., Varani, K., Merighi, S., Ongini, E., \& Borea, P. A. (2000). A(2A) adenosine receptors in human peripheral blood cells. Br J Pharmacol, 129(1), 2-11.

Gibson, C. M., de Lemos, J. A., Murphy, S. A., Marble, S. J., McCabe, C. H., Cannon, C. P., ... Braunwald, E. (2001). Combination therapy with abciximab reduces angiographically evident thrombus in acute myocardial infarction: a TIMI 14 substudy. Circulation, 103(21), 2550-2554.

Gilard, M., Arnaud, B., Cornily, J. C., Le Gal, G., Lacut, K., Le Calvez, G., . . Boschat, J. (2008). Influence of omeprazole on the antiplatelet action of clopidogrel associated with aspirin: the randomized, double-blind OCLA (Omeprazole CLopidogrel Aspirin) study. J Am Coll Cardiol, 51(3), 256-260.

Gimbrone, M. A., Jr., Cybulsky, M. I., Kume, N., Collins, T., \& Resnick, N. (1995). Vascular endothelium. An integrator of pathophysiological stimuli in atherogenesis. Ann N Y Acad Sci, 748, 122-131; discussion 131-122.

Giugliano, R. P., White, J. A., Bode, C., Armstrong, P. W., Montalescot, G., Lewis, B. S., ... Newby, L. K. (2009). Early versus delayed, provisional eptifibatide in acute coronary syndromes. $N$ Engl J Med, 360(21), 2176-2190.

Gorchakova, O., von Beckerath, N., Gawaz, M., Mocz, A., Joost, A., Schomig, A., \& Kastrati, A. (2004). Antiplatelet effects of a $600 \mathrm{mg}$ loading dose of clopidogrel are not attenuated in patients receiving atorvastatin or simvastatin for at least 4 weeks prior to coronary artery stenting. Eur Heart J, 25(21), 1898-1902.

Gore, J. M., Granger, C. B., Simoons, M. L., Sloan, M. A., Weaver, W. D., White, H. D., ... et al. (1995). Stroke after thrombolysis. Mortality and functional outcomes in the GUSTO-I trial. Global Use of Strategies to Open Occluded Coronary Arteries. Circulation, 92(10), 2811-2818.

Granger, C. B., Hirsch, J., Califf, R. M., Col, J., White, H. D., Betriu, A., ... Topol, E. J. (1996). Activated partial thromboplastin time and outcome after thrombolytic therapy for acute myocardial infarction: results from the GUSTO-I trial. Circulation, 93(5), 870-878. 
Gremmel, T., Steiner, S., Seidinger, D., Koppensteiner, R., Panzer, S., \& Kopp, C. W. (2010). Calcium-channel blockers decrease clopidogrel-mediated platelet inhibition. Heart, 96(3), 186-189.

Grines, C. L., Cox, D. A., Stone, G. W., Garcia, E., Mattos, L. A., Giambartolomei, A., .. . Morice, M. C. (1999). Coronary angioplasty with or without stent implantation for acute myocardial infarction. Stent Primary Angioplasty in Myocardial Infarction Study Group. N Engl J Med, 341(26), 1949-1956.

Gross, S., Tilly, P., Hentsch, D., Vonesch, J. L., \& Fabre, J. E. (2007). Vascular wallproduced prostaglandin E2 exacerbates arterial thrombosis and atherothrombosis through platelet EP3 receptors. J Exp Med, 204(2), 311320.

Grosser, T., Fries, S., \& FitzGerald, G. A. (2006). Biological basis for the cardiovascular consequences of COX-2 inhibition: therapeutic challenges and opportunities. J Clin Invest, 116(1), 4-15.

Grotemeyer, K. H., Scharafinski, H. W., \& Husstedt, I. W. (1993). Two-year follow-up of aspirin responder and aspirin non responder. A pilot-study including 180 post-stroke patients. Thromb Res, 71(5), 397-403.

Gruber, A., Pal, A., Kiss, R. G., Sas, G., \& Griffin, J. H. (1993). Generation of activated protein C during thrombolysis. Lancet, 342(8882), 1275-1276.

Gruntzig, A., \& Schneider, H. J. (1977). [The percutaneous dilatation of chronic coronary stenoses--experiments and morphology]. Schweiz Med Wochenschr, 107(44), 1588.

Gum, P. A., Kottke-Marchant, K., Welsh, P. A., White, J., \& Topol, E. J. (2003). A prospective, blinded determination of the natural history of aspirin resistance among stable patients with cardiovascular disease. J Am Coll Cardiol, 41(6), 961-965.

Gurbel, P. A., Bliden, K. P., Guyer, K., Cho, P. W., Zaman, K. A., Kreutz, R. P., . . Tantry, U. S. (2005). Platelet reactivity in patients and recurrent events poststenting: results of the PREPARE POST-STENTING Study. J Am Coll Cardiol, 46(10), 1820-1826.

Gurbel, P. A., Bliden, K. P., Hayes, K. M., Yoho, J. A., Herzog, W. R., \& Tantry, U. S. (2005). The relation of dosing to clopidogrel responsiveness and the incidence of high post-treatment platelet aggregation in patients undergoing coronary stenting. J Am Coll Cardiol, 45(9), 1392-1396.

Gurbel, P. A., Bliden, K. P., Samara, W., Yoho, J. A., Hayes, K., Fissha, M. Z., \& Tantry, U. S. (2005). Clopidogrel effect on platelet reactivity in patients with stent thrombosis: results of the CREST Study. J Am Coll Cardiol, 46(10), 18271832.

Gurbel, P. A., Serebruany, V. L., Shustov, A. R., Bahr, R. D., Carpo, C., Ohman, E. M., \& Topol, E. J. (1998). Effects of reteplase and alteplase on platelet aggregation 
and major receptor expression during the first 24 hours of acute myocardial infarction treatment. GUSTO-III Investigators. Global Use of Strategies to Open Occluded Coronary Arteries. J Am Coll Cardiol, 31(7), 1466-1473.

Hamm, C. W., Bassand, J. P., Agewall, S., Bax, J., Boersma, E., Bueno, H., . . Widimsky, P. (2011). ESC Guidelines for the management of acute coronary syndromes in patients presenting without persistent ST-segment elevation: The Task Force for the management of acute coronary syndromes (ACS) in patients presenting without persistent ST-segment elevation of the European Society of Cardiology (ESC). Eur Heart J, 32(23), 2999-3054.

Harrington, R. A., Stone, G. W., McNulty, S., White, H. D., Lincoff, A. M., Gibson, C. M., ... Bhatt, D. L. (2009). Platelet inhibition with cangrelor in patients undergoing PCI. N Engl J Med, 361(24), 2318-2329.

Harrison, P. (2007). Clinical tests of paltelet function. In A. Michelson (Ed.), Platelets (pp. 445-474.). San Diego: Elsevier/Academic Press.

Harrison, P., \& Cramer, E. M. (1993). Platelet alpha-granules. Blood Rev, 7(1), 52-62.

Hayward, C. P., Harrison, P., Cattaneo, M., Ortel, T. L., \& Rao, A. K. (2006). Platelet function analyzer (PFA)-100 closure time in the evaluation of platelet disorders and platelet function. J Thromb Haemost, 4(2), 312-319.

Hechler, B., Cattaneo, M., \& Gachet, C. (2005). The P2 receptors in platelet function. Semin Thromb Hemost, 31(2), 150-161. doi: 10.1055/s-2005-869520

Henney, A. M., Wakeley, P. R., Davies, M. J., Foster, K., Hembry, R., Murphy, G., \& Humphries, S. (1991). Localization of stromelysin gene expression in atherosclerotic plaques by in situ hybridization. Proc Natl Acad Sci U S A, 88(18), 8154-8158.

Herrick, J. B. (1983). Landmark article (JAMA 1912). Clinical features of sudden obstruction of the coronary arteries. By James B. Herrick. JAMA, 250(13), 1757-1765.

Ho, P. M., Maddox, T. M., Wang, L., Fihn, S. D., Jesse, R. L., Peterson, E. D., \& Rumsfeld, J. S. (2009). Risk of adverse outcomes associated with concomitant use of clopidogrel and proton pump inhibitors following acute coronary syndrome. JAMA, 301(9), 937-944.

Hobikoglu, G. F., Norgaz, T., Aksu, H., Ozer, O., Erturk, M., Destegul, E., . . . Narin, A. (2007). The effect of acetylsalicylic acid resistance on prognosis of patients who have developed acute coronary syndrome during acetylsalicylic acid therapy. Can J Cardiol, 23(3), 201-206.

Hochholzer, W., Trenk, D., Bestehorn, H. P., Fischer, B., Valina, C. M., Ferenc, M., ... Neumann, F. J. (2006). Impact of the degree of peri-interventional platelet inhibition after loading with clopidogrel on early clinical outcome of elective coronary stent placement. J Am Coll Cardiol, 48(9), 1742-1750. 
Hovens, M. M., Snoep, J. D., Eikenboom, J. C., van der Bom, J. G., Mertens, B. J., \& Huisman, M. V. (2007). Prevalence of persistent platelet reactivity despite use of aspirin: a systematic review. Am Heart J, 153(2), 175-181.

Hudson, M. P., Granger, C. B., Topol, E. J., Pieper, K. S., Armstrong, P. W., Barbash, G. I., ... Ohman, E. M. (2001). Early reinfarction after fibrinolysis: experience from the global utilization of streptokinase and tissue plasminogen activator (alteplase) for occluded coronary arteries (GUSTO I) and global use of strategies to open occluded coronary arteries (GUSTO III) trials. Circulation, 104(11), 1229-1235.

Husted, S., Emanuelsson, H., Heptinstall, S., Sandset, P. M., Wickens, M., \& Peters, G. (2006). Pharmacodynamics, pharmacokinetics, and safety of the oral reversible P2Y12 antagonist AZD6140 with aspirin in patients with atherosclerosis: a double-blind comparison to clopidogrel with aspirin. Eur Heart J, 27(9), 1038-1047.

Indications for fibrinolytic therapy in suspected acute myocardial infarction: collaborative overview of early mortality and major morbidity results from all randomised trials of more than 1000 patients. Fibrinolytic Therapy Trialists' (FTT) Collaborative Group. (1994). Lancet, 343(8893), 311-322.

Inhibition of the platelet glycoprotein IIb/IIIa receptor with tirofiban in unstable angina and non-Q-wave myocardial infarction. Platelet Receptor Inhibition in Ischemic Syndrome Management in Patients Limited by Unstable Signs and Symptoms (PRISM-PLUS) Study Investigators. (1998). N Engl J Med, 338(21), 1488-1497.

ISIS-3: a randomised comparison of streptokinase vs tissue plasminogen activator vs anistreplase and of aspirin plus heparin vs aspirin alone among 41,299 cases of suspected acute myocardial infarction. ISIS-3 (Third International Study of Infarct Survival) Collaborative Group. (1992). Lancet, 339(8796), 753-770.

Ito, H., Maruyama, A., Iwakura, K., Takiuchi, S., Masuyama, T., Hori, M., . . Minamino, T. (1996). Clinical implications of the 'no reflow' phenomenon. A predictor of complications and left ventricular remodeling in reperfused anterior wall myocardial infarction. Circulation, 93(2), 223-228.

Ito, H., Okamura, A., Iwakura, K., Masuyama, T., Hori, M., Takiuchi, S., . . Minamino, T. (1996). Myocardial perfusion patterns related to thrombolysis in myocardial infarction perfusion grades after coronary angioplasty in patients with acute anterior wall myocardial infarction. Circulation, 93(11), 1993-1999.

Ito, H., Tomooka, T., Sakai, N., Yu, H., Higashino, Y., Fujii, K., ... Minamino, T. (1992). Lack of myocardial perfusion immediately after successful thrombolysis. A predictor of poor recovery of left ventricular function in anterior myocardial infarction. Circulation, 85(5), 1699-1705. 
Itoh, T., Fukami, K., Suzuki, T., Kimura, T., Kanaya, Y., Orii, M., ... Nakamura, M. (2010). Comparison of long-term prognostic evaluation between preintervention thrombolysis and primary coronary intervention: a prospective randomized trial: five-year results of the IMPORTANT study. Circ J, 74(8), 1625-1634.

Jaremo, P., Lindahl, T. L., Fransson, S. G., \& Richter, A. (2002). Individual variations of platelet inhibition after loading doses of clopidogrel. J Intern Med, 252(3), 233-238.

Jennings, L. (2007). Platelet aggregation. In A. Michelson (Ed.), Platelets (pp. 495508). San Diego: Elsevier/Academic Press.

Johnson, R. W., DW. (1992). Applied Multivariate Statistical Methods: Prentice Hall.

Jollife, I. (2002). Principal Component Analysis. New York: Springer.

Kabbani, S. S., Watkins, M. W., Ashikaga, T., Terrien, E. F., Sobel, B. E., \& Schneider, D. J. (2003). Usefulness of platelet reactivity before percutaneous coronary intervention in determining cardiac risk one year later. Am J Cardiol, 91(7), 876-878.

Kandzari, D. E., Berger, P. B., Kastrati, A., Steinhubl, S. R., Mehilli, J., Dotzer, F., . . Schomig, A. (2004). Influence of treatment duration with a 600-mg dose of clopidogrel before percutaneous coronary revascularization. J Am Coll Cardiol, 44(11), 2133-2136.

Kaplan, E. M., P. (1958). Nonparametric estimation from incomplete observations. J Amer Statist Assn(43), 457-481.

Kastrati, A., Dibra, A., Spaulding, C., Laarman, G. J., Menichelli, M., Valgimigli, M., ... Schomig, A. (2007). Meta-analysis of randomized trials on drug-eluting stents vs. bare-metal stents in patients with acute myocardial infarction. Eur Heart J, 28(22), 2706-2713.

Kaul, S., \& Ito, H. (2004). Microvasculature in acute myocardial ischemia: part II: evolving concepts in pathophysiology, diagnosis, and treatment. Circulation, 109(3), 310-315.

Keeley, E. C., Boura, J. A., \& Grines, C. L. (2003). Primary angioplasty versus intravenous thrombolytic therapy for acute myocardial infarction: a quantitative review of 23 randomised trials. Lancet, 361(9351), 13-20.

Kelly, R. V., Cohen, M. G., Runge, M. S., \& Stouffer, G. A. (2004). The no-reflow phenomenon in coronary arteries. J Thromb Haemost, 2(11), 1903-1907.

Killip, T., 3rd, \& Kimball, J. T. (1967). Treatment of myocardial infarction in a coronary care unit. A two year experience with 250 patients. Am J Cardiol, 20(4), 457-464. 
Kimmelstiel, C., Zhang, P., Kapur, N. K., Weintraub, A., Krishnamurthy, B., Castaneda, V., ... Kuliopulos, A. (2011). Bivalirudin is a dual inhibitor of thrombin and collagen-dependent platelet activation in patients undergoing percutaneous coronary intervention. Circ Cardiovasc Interv, 4(2), 171-179.

King, S. B., 3rd, Smith, S. C., Jr., Hirshfeld, J. W., Jr., Jacobs, A. K., Morrison, D. A., Williams, D. O., ... Yancy, C. W. (2008). 2007 focused update of the ACC/AHA/SCAI 2005 guideline update for percutaneous coronary intervention: a report of the American College of Cardiology/American Heart Association Task Force on Practice guidelines. J Am Coll Cardiol, 51(2), 172-209.

Kolh, P., \& Wijns, W. (2011). Joint ESC/EACTS guidelines on myocardial revascularization. J Cardiovasc Med (Hagerstown), 12(4), 264-267.

Kruth, H. S. (1997). The fate of lipoprotein cholesterol entering the arterial wall. Curr Opin Lipidol, 8(5), 246-252.

Kuliczkowski, W., Witkowski, A., Polonski, L., Watala, C., Filipiak, K., Budaj, A., ... De Caterina, R. (2009). Interindividual variability in the response to oral antiplatelet drugs: a position paper of the Working Group on antiplatelet drugs resistance appointed by the Section of Cardiovascular Interventions of the Polish Cardiac Society, endorsed by the Working Group on Thrombosis of the European Society of Cardiology. Eur Heart J, 30(4), 426435.

Kushner, F. G., Hand, M., Smith, S. C., Jr., King, S. B., 3rd, Anderson, J. L., Antman, E. M., ... Williams, D. O. (2009). 2009 focused updates: ACC/AHA guidelines for the management of patients with ST-elevation myocardial infarction (updating the 2004 guideline and 2007 focused update) and ACC/AHA/SCAI guidelines on percutaneous coronary intervention (updating the 2005 guideline and 2007 focused update) a report of the American College of Cardiology Foundation/American Heart Association Task Force on Practice Guidelines. J Am Coll Cardiol, 54(23), 2205-2241.

Laarman, G. J., Suttorp, M. J., Dirksen, M. T., van Heerebeek, L., Kiemeneij, F., Slagboom, T., ... Patterson, M. (2006). Paclitaxel-eluting versus uncoated stents in primary percutaneous coronary intervention. $N$ Engl J Med, 355(11), 1105-1113.

Lau, W. C., Waskell, L. A., Watkins, P. B., Neer, C. J., Horowitz, K., Hopp, A. S., . . . Bates, E. R. (2003). Atorvastatin reduces the ability of clopidogrel to inhibit platelet aggregation: a new drug-drug interaction. Circulation, 107(1), 32-37.

Le May, M. R., Wells, G. A., Labinaz, M., Davies, R. F., Turek, M., Leddy, D., . . . Higginson, L. A. (2005). Combined angioplasty and pharmacological intervention versus thrombolysis alone in acute myocardial infarction (CAPITAL AMI study). J Am Coll Cardiol, 46(3), 417-424.

Lee, C. D., \& Mann, K. G. (1989). Activation/inactivation of human factor V by plasmin. Blood, 73(1), 185-190. 
Lekston, A., Tajstra, M., Gasior, M., Gierlotka, M., Pres, D., Hudzik, B., . . Zembala, M. (2011). Impact of multivessel coronary disease on one-year clinical outcomes and five-year mortality in patients with ST-elevation myocardial infarction undergoing percutaneous coronary intervention. Kardiol Pol, 69(4), 336-343.

Lepantalo, A., Virtanen, K. S., Heikkila, J., Wartiovaara, U., \& Lassila, R. (2004). Limited early antiplatelet effect of $300 \mathrm{mg}$ clopidogrel in patients with aspirin therapy undergoing percutaneous coronary interventions. Eur Heart J, 25(6), 476-483.

Lev, E. I., Patel, R. T., Maresh, K. J., Guthikonda, S., Granada, J., DeLao, T., ... Kleiman, N. S. (2006). Aspirin and clopidogrel drug response in patients undergoing percutaneous coronary intervention: the role of dual drug resistance. J Am Coll Cardiol, 47(1), 27-33.

Levin, J. (2007). The evolution of mamalian platelets. In M. Michelson (Ed.), Platelets (Vol. I). San Diego: Elsevier Science.

Li, H., Cybulsky, M. I., Gimbrone, M. A., Jr., \& Libby, P. (1993). An atherogenic diet rapidly induces VCAM-1, a cytokine-regulatable mononuclear leukocyte adhesion molecule, in rabbit aortic endothelium. Arterioscler Thromb, 13(2), 197-204.

Libby, P. (1995). Molecular bases of the acute coronary syndromes. Circulation, 91(11), 2844-2850.

Loree, H. M., Tobias, B. J., Gibson, L. J., Kamm, R. D., Small, D. M., \& Lee, R. T. (1994). Mechanical properties of model atherosclerotic lesion lipid pools. Arterioscler Thromb, 14(2), 230-234.

Loscalzo, J. (2001). Nitric oxide insufficiency, platelet activation, and arterial thrombosis. Circ Res, 88(8), 756-762.

Lozano, I., Avanzas, P., \& Rondan, J. (2010). Direct stenting should be attempted by default whenever possible. Heart, 96(20), 1684-1685; author reply 1685.

Luster, A. D. (1998). Chemokines--chemotactic cytokines that mediate inflammation. $N$ Engl J Med, 338(7), 436-445.

Maes, A., Van de Werf, F., Nuyts, J., Bormans, G., Desmet, W., \& Mortelmans, L. (1995). Impaired myocardial tissue perfusion early after successful thrombolysis. Impact on myocardial flow, metabolism, and function at late follow-up. Circulation, 92(8), 2072-2078.

Marcucci, R., Paniccia, R., Antonucci, E., Gori, A. M., Fedi, S., Giglioli, C., ... Gensini, G. F. (2006). Usefulness of aspirin resistance after percutaneous coronary intervention for acute myocardial infarction in predicting one-year major adverse coronary events. Am J Cardiol, 98(9), 1156-1159. 
Marcucci, R., Paniccia, R., Antonucci, E., Poli, S., Gori, A. M., Valente, S., .. . Gensini, G. F. (2007). Residual platelet reactivity is an independent predictor of myocardial injury in acute myocardial infarction patients on antiaggregant therapy. Thromb Haemost, 98(4), 844-851.

Maseri, A., \& Fuster, V. (2003). Is there a vulnerable plaque? Circulation, 107(16), 2068-2071.

Matetzky, S., Shenkman, B., Guetta, V., Shechter, M., Bienart, R., Goldenberg, I., . . . Hod, H. (2004). Clopidogrel resistance is associated with increased risk of recurrent atherothrombotic events in patients with acute myocardial infarction. Circulation, 109(25), 3171-3175.

McCullagh, P. N., JA. (1992). Generalized Linear Model: Chapman \& Hall.

McGill, H. C., Jr., McMahan, C. A., Zieske, A. W., Tracy, R. E., Malcom, G. T., Herderick, E. E., \& Strong, J. P. (2000). Association of coronary heart disease risk factors with microscopic qualities of coronary atherosclerosis in youth. Circulation, 102(4), 374-379.

McNicol, A., \& Israels, S. J. (1999). Platelet dense granules: structure, function and implications for haemostasis. Thromb Res, 95(1), 1-18.

Mega, J. L., Close, S. L., Wiviott, S. D., Shen, L., Hockett, R. D., Brandt, J. T., . . Sabatine, M. S. (2009). Cytochrome p-450 polymorphisms and response to clopidogrel. $N$ Engl J Med, 360(4), 354-362.

Mehran, R., Lansky, A. J., Witzenbichler, B., Guagliumi, G., Peruga, J. Z., Brodie, B. R., ... Stone, G. W. (2009). Bivalirudin in patients undergoing primary angioplasty for acute myocardial infarction (HORIZONS-AMI): 1-year results of a randomised controlled trial. Lancet, 374(9696), 1149-1159.

Mehta, S. R., Tanguay, J. F., Eikelboom, J. W., Jolly, S. S., Joyner, C. D., Granger, C. B., . . Yusuf, S. (2010). Double-dose versus standard-dose clopidogrel and highdose versus low-dose aspirin in individuals undergoing percutaneous coronary intervention for acute coronary syndromes (CURRENT-OASIS 7): a randomised factorial trial. Lancet, 376(9748), 1233-1243.

Mehta, S. R., \& Yusuf, S. (2000). The Clopidogrel in Unstable angina to prevent Recurrent Events (CURE) trial programme; rationale, design and baseline characteristics including a meta-analysis of the effects of thienopyridines in vascular disease. Eur Heart J, 21(24), 2033-2041.

Mehta, S. R., Yusuf, S., Peters, R. J., Bertrand, M. E., Lewis, B. S., Natarajan, M. K., . . Fox, K. A. (2001). Effects of pretreatment with clopidogrel and aspirin followed by long-term therapy in patients undergoing percutaneous coronary intervention: the PCI-CURE study. Lancet, 358(9281), 527-533.

Mendelsohn, M. E., O'Neill, S., George, D., \& Loscalzo, J. (1990). Inhibition of fibrinogen binding to human platelets by S-nitroso-N-acetylcysteine. J Biol Chem, 265(31), 19028-19034. 
Michelson, A. (2009). Laboratory assessment of platelet function and effects of antiplatelets drugs. In S. Wiviott (Ed.), Antiplatelet Therapy in Ischemic Heart Disease. (pp. 15-29). Hoboken: Wiley-Blackwell.

Milian, M. G. (1901). Technique pour l'etude clinique de la coagulation du sang. Soc Med Hosp Paris(18), 777-779.

Mitsios, J. V., Papathanasiou, A. I., Rodis, F. I., Elisaf, M., Goudevenos, J. A., \& Tselepis, A. D. (2004). Atorvastatin does not affect the antiplatelet potency of clopidogrel when it is administered concomitantly for 5 weeks in patients with acute coronary syndromes.

Mobley, J. E., Bresee, S. J., Wortham, D. C., Craft, R. M., Snider, C. C., \& Carroll, R. C. (2004). Frequency of nonresponse antiplatelet activity of clopidogrel during pretreatment for cardiac catheterization. Am J Cardiol, 93(4), 456458.

Mockel, M., Vollert, J., Lansky, A. J., Witzenbichler, B., Guagliumi, G., Peruga, J. Z., ... Stone, G. W. (2011). Comparison of direct stenting with conventional stent implantation in acute myocardial infarction. Am J Cardiol. doi: S00029149(11)02422-2 [pii]10.1016/j.amjcard.2011.07.040

Moncada, S., \& Vane, J. R. (1979). Arachidonic acid metabolites and the interactions between platelets and blood-vessel walls. $N$ Engl J Med, 300(20), 1142-1147.

Montalescot, G., Barragan, P., Wittenberg, O., Ecollan, P., Elhadad, S., Villain, P., ... Pinton, P. (2001). Platelet glycoprotein IIb/IIIa inhibition with coronary stenting for acute myocardial infarction. N Engl J Med, 344(25), 1895-1903.

Montalescot, G., Sideris, G., Meuleman, C., Bal-dit-Sollier, C., Lellouche, N., Steg, P. G., ... Drouet, L. (2006). A randomized comparison of high clopidogrel loading doses in patients with non-ST-segment elevation acute coronary syndromes: the ALBION (Assessment of the Best Loading Dose of Clopidogrel to Blunt Platelet Activation, Inflammation and Ongoing Necrosis) trial. J Am Coll Cardiol, 48(5), 931-938.

Morrow, D. A., Braunwald, E., Bonaca, M. P., Ameriso, S. F., Dalby, A. J., Fish, M. P., ... Murphy, S. A. (2012). Vorapaxar in the secondary prevention of atherothrombotic events. $N$ Engl J Med.

Moser, M., Nordt, T., Peter, K., Ruef, J., Kohler, B., Schmittner, M., ... Bode, C. (1999). Platelet function during and after thrombolytic therapy for acute myocardial infarction with reteplase, alteplase, or streptokinase. Circulation, 100(18), 1858-1864.

Mueller, M. R., Salat, A., Stangl, P., Murabito, M., Pulaki, S., Boehm, D., ... Wolner, E. (1997). Variable platelet response to low-dose ASA and the risk of limb deterioration in patients submitted to peripheral arterial angioplasty. Thromb Haemost, 78(3), 1003-1007. 
Muller, I., Besta, F., Schulz, C., Massberg, S., Schonig, A., \& Gawaz, M. (2003). Prevalence of clopidogrel non-responders among patients with stable angina pectoris scheduled for elective coronary stent placement. Thromb Haemost, 89(5), 783-787.

Muller, I., Seyfarth, M., Rudiger, S., Wolf, B., Pogatsa-Murray, G., Schomig, A., \& Gawaz, M. (2001). Effect of a high loading dose of clopidogrel on platelet function in patients undergoing coronary stent placement. Heart, 85(1), 9293.

Murrel, P. (2005). R Graphics. Boca Raton FL: Chapman \& Hall/CRC Press.

Myrtveit, I. S., E; Olsson, U. (2001). Analyzing data sets with missing data: an empirical evaluation of imputation methods and likelihood-based methods. Discussion of MDTs, 10-11.

Nallamothu, B., Fox, K. A., Kennelly, B. M., Van de Werf, F., Gore, J. M., Steg, P. G., .. . Eagle, K. A. (2007). Relationship of treatment delays and mortality in patients undergoing fibrinolysis and primary percutaneous coronary intervention. The Global Registry of Acute Coronary Events. Heart, 93(12), 1552-1555.

Nelken, N. A., Coughlin, S. R., Gordon, D., \& Wilcox, J. N. (1991). Monocyte chemoattractant protein-1 in human atheromatous plaques. J Clin Invest, 88(4), 1121-1127.

Neubauer, H., Gunesdogan, B., Hanefeld, C., Spiecker, M., \& Mugge, A. (2003). Lipophilic statins interfere with the inhibitory effects of clopidogrel on platelet function--a flow cytometry study. Eur Heart J, 24(19), 1744-1749.

Neubauer, H., Lask, S., Engelhardt, A., \& Mugge, A. (2008). How to optimise clopidogrel therapy? Reducing the low-response incidence by aggregometry-guided therapy modification. Thromb Haemost, 99(2), 357362.

Novel dosing regimen of eptifibatide in planned coronary stent implantation (ESPRIT): a randomised, placebo-controlled trial. (2000). Lancet, 356(9247), 2037-2044.

O'Donoghue, M. L., Bhatt, D. L., Wiviott, S. D., Goodman, S. G., Fitzgerald, D. J., Angiolillo, D. J., ... Flather, M. D. (2011). Safety and tolerability of atopaxar in the treatment of patients with acute coronary syndromes: the lessons from antagonizing the cellular effects of Thrombin-Acute Coronary Syndromes Trial. Circulation, 123(17), 1843-1853.

Oja, E. (1982). A simplified neuron model as a principal component analyzer. J Math Biol, 15(3), 267-273. 
Page, Y., Tardy, B., Zeni, F., Comtet, C., Terrana, R., \& Bertrand, J. C. (1991). Thrombotic thrombocytopenic purpura related to ticlopidine. Lancet, 337(8744), 774-776.

Papafaklis, M. I., Koskinas, K. C., Chatzizisis, Y. S., Stone, P. H., \& Feldman, C. L. (2010). In-vivo assessment of the natural history of coronary atherosclerosis: vascular remodeling and endothelial shear stress determine the complexity of atherosclerotic disease progression. Curr Opin Cardiol, 25(6), 627-638.

Pappas, J. M., Westengard, J. C., \& Bull, B. S. (1994). Population variability in the effect of aspirin on platelet function. Implications for clinical trials and therapy. Arch Pathol Lab Med, 118(8), 801-804.

Patrono, C., Coller, B., Dalen, J. E., FitzGerald, G. A., Fuster, V., Gent, M., .. Roth, G. (2001). Platelet-active drugs : the relationships among dose, effectiveness, and side effects. Chest, 119(1 Suppl), 39S-63S.

Patrono, C., Garcia Rodriguez, L. A., Landolfi, R., \& Baigent, C. (2005). Low-dose aspirin for the prevention of atherothrombosis. N Engl J Med, 353(22), 2373-2383.

Patti, G., Colonna, G., Pasceri, V., Pepe, L. L., Montinaro, A., \& Di Sciascio, G. (2005). Randomized trial of high loading dose of clopidogrel for reduction of periprocedural myocardial infarction in patients undergoing coronary intervention: results from the ARMYDA-2 (Antiplatelet therapy for Reduction of MYocardial Damage during Angioplasty) study. Circulation, 111(16), 2099-2106.

Payne, C. D., Li, Y. G., Small, D. S., Ernest, C. S., 2nd, Farid, N. A., Jakubowski, J. A., ... Winters, K. J. (2007). Increased active metabolite formation explains the greater platelet inhibition with prasugrel compared to high-dose clopidogrel. J Cardiovasc Pharmacol, 50(5), 555-562.

Pearson, K. (1900). On the criterion that a given system of deviations from the probable in the case of a correlated system of variables is such that it can be reasonably supposed to have arisen from random sampling. Philosophical Magazine, 50(302), 157-175.

Pearson, K. (1901). On Lines and Planes of Closest Fit to Systems of Points in Space. Philosophical Magazine, 2(6), 559-572.

Perez de Prado, A., Cuellas, C., Diego, A., de Miguel, A., Samaniego, B., Alonso-Orcajo, N., ... Calabozo, R. G. (2009). Influence of platelet reactivity and response to clopidogrel on myocardial damage following percutaneous coronary intervention in patients with non-ST-segment elevation acute coronary syndrome. Thromb Res, 124(6), 678-682.

Perez de Prado, A., Fernandez-Vazquez, F., Cuellas, J. C., Alonso-Orcajo, N., Carbonell, R., Pascual, C., . . . Calabozo, R. G. (2006). Association between 
level of platelet inhibition after early use of abciximab and myocardial reperfusion in ST-elevation acute myocardial Infarction treated by primary percutaneous coronary intervention. Am J Cardiol, 97(6), 798-803.

Pettersen, A. A., Seljeflot, I., Abdelnoor, M., \& Arnesen, H. (2004). Unstable angina, stroke, myocardial infarction and death in aspirin non-responders. A prospective, randomized trial. The ASCET (ASpirin non-responsiveness and Clopidogrel Endpoint Trial) design. Scand Cardiovasc J, 38(6), 353-356.

Picot, D., Loll, P. J., \& Garavito, R. M. (1994). The X-ray crystal structure of the membrane protein prostaglandin H2 synthase-1. Nature, 367(6460), 243249.

Pinto, D. S., Kirtane, A. J., Nallamothu, B. K., Murphy, S. A., Cohen, D. J., Laham, R. J., ... Gibson, C. M. (2006). Hospital delays in reperfusion for ST-elevation myocardial infarction: implications when selecting a reperfusion strategy. Circulation, 114(19), 2019-2025.

Poston, R. N., Haskard, D. O., Coucher, J. R., Gall, N. P., \& Johnson-Tidey, R. R. (1992). Expression of intercellular adhesion molecule-1 in atherosclerotic plaques. Am J Pathol, 140(3), 665-673.

Price, M. J., Angiolillo, D. J., Teirstein, P. S., Lillie, E., Manoukian, S. V., Berger, P. B., ... Topol, E. J. (2011). Platelet reactivity and cardiovascular outcomes after percutaneous coronary intervention: a time-dependent analysis of the Gauging Responsiveness With a VerifyNow P2Y12 Assay: Impact on Thrombosis and Safety (GRAVITAS) Trial. Circulation, 124(10), 1132-1137.

Price, M. J., Berger, P. B., Teirstein, P. S., Tanguay, J. F., Angiolillo, D. J., Spriggs, D., . . . Topol, E. J. (2011). Standard- vs high-dose clopidogrel based on platelet function testing after percutaneous coronary intervention: the GRAVITAS randomized trial. JAMA, 305(11), 1097-1105.

Price, M. J., Endemann, S., Gollapudi, R. R., Valencia, R., Stinis, C. T., Levisay, J. P., ... Teirstein, P. S. (2008). Prognostic significance of post-clopidogrel platelet reactivity assessed by a point-of-care assay on thrombotic events after drug-eluting stent implantation. Eur Heart J, 29(8), 992-1000.

Primary versus tenecteplase-facilitated percutaneous coronary intervention in patients with ST-segment elevation acute myocardial infarction (ASSENT-4 PCI): randomised trial. (2006). Lancet, 367(9510), 569-578.

Raju, N. (2009). Cyclooxigenase inhibitors. In S. Wiviott (Ed.), Antiplatelet Therapy in Ischemic Heart Disease (pp. 33-46). Hoboken: Wiley-Blackwell.

Randomised placebo-controlled trial of effect of eptifibatide on complications of percutaneous coronary intervention: IMPACT-II. Integrilin to Minimise Platelet Aggregation and Coronary Thrombosis-II. (1997). Lancet, 349(9063), 1422-1428. 
Randomised trial of intravenous streptokinase, oral aspirin, both, or neither among 17,187 cases of suspected acute myocardial infarction: ISIS-2. ISIS-2 (Second International Study of Infarct Survival) Collaborative Group. (1988). Lancet, 2(8607), 349-360.

A randomised, blinded, trial of clopidogrel versus aspirin in patients at risk of ischaemic events (CAPRIE). CAPRIE Steering Committee. (1996). Lancet, 348(9038), 1329-1339.

Rao, A. K., Pratt, C., Berke, A., Jaffe, A., Ockene, I., Schreiber, T. L., ... Terrin, M. L. (1988). Thrombolysis in Myocardial Infarction (TIMI) Trial--phase I: hemorrhagic manifestations and changes in plasma fibrinogen and the fibrinolytic system in patients treated with recombinant tissue plasminogen activator and streptokinase. J Am Coll Cardiol, 11(1), 1-11.

Rasmanis, G., Vesterqvist, O., Green, K., Edhag, O., \& Henriksson, P. (1992). Evidence of increased platelet activation after thrombolysis in patients with acute myocardial infarction. Br Heart J, 68(4), 374-376.

Rich, M. W. (1998). Heparin for acute myocardial infarction: the controversy continues. J Am Coll Cardiol, 31(5), 964-966.

Rittenhouse-Simmons, S. (1981). Differential activation of platelet phospholipases by thrombin and ionophore A23187. J Biol Chem, 256(9), 4153-4155.

Rokitansky, K. (1855). The Organs of Circulation: A Manual of Pathological Anatomy. Philadelphia: Blanchard \& Lea, IV.

Rong, J. X., Rangaswamy, S., Shen, L., Dave, R., Chang, Y. H., Peterson, H., ... Sevanian, A. (1998). Arterial injury by cholesterol oxidation products causes endothelial dysfunction and arterial wall cholesterol accumulation. Arterioscler Thromb Vasc Biol, 18(12), 1885-1894.

Rosado, J. A., Jenner, S., \& Sage, S. O. (2000). A role for the actin cytoskeleton in the initiation and maintenance of store-mediated calcium entry in human platelets. Evidence for conformational coupling. J Biol Chem, 275(11), 75277533.

Ruggeri, Z. M., \& Mendolicchio, G. L. (2007). Adhesion mechanisms in platelet function. Circ Res, 100(12), 1673-1685.

Sabatine, M. S., Cannon, C. P., Gibson, C. M., Lopez-Sendon, J. L., Montalescot, G., Theroux, P., ... Braunwald, E. (2005). Addition of clopidogrel to aspirin and fibrinolytic therapy for myocardial infarction with ST-segment elevation. $N$ Engl J Med, 352(12), 1179-1189.

Samara, W. M., Bliden, K. P., Tantry, U. S., \& Gurbel, P. A. (2005). The difference between clopidogrel responsiveness and posttreatment platelet reactivity. Thromb Res, 115(1-2), 89-94. 
Sandison, A. T. (1962). Degenerative vascular disease in the Egyptian mummy. Med Hist, 6, 77-81.

Savi, P., Combalbert, J., Gaich, C., Rouchon, M. C., Maffrand, J. P., Berger, Y., \& Herbert, J. M. (1994). The antiaggregating activity of clopidogrel is due to a metabolic activation by the hepatic cytochrome P450-1A. Thromb Haemost, 72(2), 313-317.

Savi, P., Pereillo, J. M., Uzabiaga, M. F., Combalbert, J., Picard, C., Maffrand, J. P., . . Herbert, J. M. (2000). Identification and biological activity of the active metabolite of clopidogrel. Thromb Haemost, 84(5), 891-896.

Schaper, W. (2005). Dipyridamole, an underestimated vascular protective drug. Cardiovasc Drugs Ther, 19(5), 357-363.

Scheller, B., Hennen, B., Hammer, B., Walle, J., Hofer, C., Hilpert, V., ... Bohm, M. (2003). Beneficial effects of immediate stenting after thrombolysis in acute myocardial infarction. J Am Coll Cardiol, 42(4), 634-641.

Schneider, D. J., \& Aggarwal, A. (2004). Development of glycoprotein IIb-IIIa antagonists: translation of pharmacodynamic effects into clinical benefit. Expert Rev Cardiovasc Ther, 2(6), 903-913.

Schwarz, U. R., Geiger, J., Walter, U., \& Eigenthaler, M. (1999). Flow cytometry analysis of intracellular VASP phosphorylation for the assessment of activating and inhibitory signal transduction pathways in human platelets-definition and detection of ticlopidine/clopidogrel effects. Thromb Haemost, 82(3), 1145-1152.

Serebruany, V. L., Steinhubl, S. R., Berger, P. B., Malinin, A. I., Bhatt, D. L., \& Topol, E. J. (2005). Variability in platelet responsiveness to clopidogrel among 544 individuals. J Am Coll Cardiol, 45(2), 246-251.

Shattil, S. J. (1995). Function and regulation of the beta 3 integrins in hemostasis and vascular biology. Thromb Haemost, 74(1), 149-155.

Sibbing, D., Morath, T., Stegherr, J., Braun, S., Vogt, W., Hadamitzky, M., ... von Beckerath, N. (2009). Impact of proton pump inhibitors on the antiplatelet effects of clopidogrel. Thromb Haemost, 101(4), 714-719.

Sigwart, U., Puel, J., Mirkovitch, V., Joffre, F., \& Kappenberger, L. (1987). Intravascular stents to prevent occlusion and restenosis after transluminal angioplasty. N Engl J Med, 316(12), 701-706.

Siller-Matula, J. M., Lang, I., Christ, G., \& Jilma, B. (2008). Calcium-channel blockers reduce the antiplatelet effect of clopidogrel. J Am Coll Cardiol, 52(19), 15571563.

Simoons, M. L. (2001). Effect of glycoprotein IIb/IIIa receptor blocker abciximab on outcome in patients with acute coronary syndromes without early 
coronary revascularisation: the GUSTO IV-ACS randomised trial. Lancet, 357(9272), 1915-1924.

Simsek, C., Magro, M., Boersma, E., Onuma, Y., Nauta, S., Daemen, J., . . . Serruys, P. (2011). Comparison of six-year clinical outcome of sirolimus- and paclitaxel-eluting stents to bare-metal stents in patients with ST-segment elevation myocardial infarction: an analysis of the RESEARCH (RapamycinEluting Stent Evaluated at Rotterdam Cardiology Hospital) and T-SEARCH (Taxus Stent Evaluated at Rotterdam Cardiology Hospital) registries.J Invasive Cardiol, 23(8), 336-341.

Smith, W. L., Garavito, R. M., \& DeWitt, D. L. (1996). Prostaglandin endoperoxide H synthases (cyclooxygenases)-1 and -2. J Biol Chem, 271(52), 33157-33160.

Sones, F. M., Jr. (1958). Cine-cardio-angiography. Pediatr Clin North Am, 5(4), 945979.

Sorajja, P., Gersh, B. J., Costantini, C., McLaughlin, M. G., Zimetbaum, P., Cox, D. A., . . Stone, G. W. (2005). Combined prognostic utility of ST-segment recovery and myocardial blush after primary percutaneous coronary intervention in acute myocardial infarction. Eur Heart J, 26(7), 667-674.

Spaulding, C., Henry, P., Teiger, E., Beatt, K., Bramucci, E., Carrie, D., ... Bode, C. (2006). Sirolimus-eluting versus uncoated stents in acute myocardial infarction. N Engl J Med, 355(11), 1093-1104.

Spaulding, C., Morice, M. C., Lancelin, B., El Haddad, S., Lepage, E., Bataille, S., ... de Vernejoul, N. (2006). Is the volume-outcome relation still an issue in the era of PCI with systematic stenting? Results of the greater Paris area PCI registry. Eur Heart J, 27(9), 1054-1060.

Stamler, J., Daviglus, M. L., Garside, D. B., Dyer, A. R., Greenland, P., \& Neaton, J. D. (2000). Relationship of baseline serum cholesterol levels in 3 large cohorts of younger men to long-term coronary, cardiovascular, and all-cause mortality and to longevity. JAMA, 284(3), 311-318.

Steg, P. G., Bonnefoy, E., Chabaud, S., Lapostolle, F., Dubien, P. Y., Cristofini, P., . . . Touboul, P. (2003). Impact of time to treatment on mortality after prehospital fibrinolysis or primary angioplasty: data from the CAPTIM randomized clinical trial. Circulation, 108(23), 2851-2856.

Steinhubl, S. (2007). The VerifyNow system. In A. Michelson (Ed.), Platelets (pp. 509-518). San Diego: Elsevier/Academic Press.

Steinhubl, S. R., Talley, J. D., Braden, G. A., Tcheng, J. E., Casterella, P. J., Moliterno, D. J., ... Kereiakes, D. J. (2001). Point-of-care measured platelet inhibition correlates with a reduced risk of an adverse cardiac event after percutaneous coronary intervention: results of the GOLD (AU-Assessing Ultegra) multicenter study. Circulation, 103(21), 2572-2578. 
Storey, R. F. (2006). Biology and pharmacology of the platelet P2Y12 receptor. Curr Pharm Des, 12(10), 1255-1259.

Storey, R. F., Melissa Thornton, S., Lawrance, R., Husted, S., Wickens, M., Emanuelsson, H., ... Armstrong, M. (2009). Ticagrelor yields consistent dose-dependent inhibition of ADP-induced platelet aggregation in patients with atherosclerotic disease regardless of genotypic variations in P2RY12, P2RY1, and ITGB3. Platelets, 20(5), 341-348.

Storey, R. F., Sanderson, H. M., White, A. E., May, J. A., Cameron, K. E., \& Heptinstall, S. (2000). The central role of the $\mathrm{P}(2 \mathrm{~T})$ receptor in amplification of human platelet activation, aggregation, secretion and procoagulant activity. $\mathrm{BrJ}$ Haematol, 110(4), 925-934.

Sukhova, G. K., Shi, G. P., Simon, D. I., Chapman, H. A., \& Libby, P. (1998). Expression of the elastolytic cathepsins $\mathrm{S}$ and $\mathrm{K}$ in human atheroma and regulation of their production in smooth muscle cells. J Clin Invest, 102(3), 576-583.

Szto, G. Y., Linnemeier, T. J., \& Ball, M. W. (1999). Fatal neutropenia and thrombocytopenia associated with ticlopidine after stenting. Am J Cardiol, 83(1), 138-139, A110.

Tabas, I. (1999). Nonoxidative modifications of lipoproteins in atherogenesis. Annu Rev Nutr, 19, 123-139.

Thygesen, K., Alpert, J. S., White, H. D., Jaffe, A. S., Apple, F. S., Galvani, M., . . AlAttar, N. (2007). Universal definition of myocardial infarction. Circulation, 116(22), 2634-2653.

Tillett, W. S., Edwards, L. B., \& Garner, R. L. (1934). Fibrinolytic activity of hemolytic streptococci. The development of resistance to fibrinolysis following acute hemolytic streptococcus infections. J Clin Invest, 13(1), 4778.

Topol, E. J. (2001). Reperfusion therapy for acute myocardial infarction with fibrinolytic therapy or combination reduced fibrinolytic therapy and platelet glycoprotein IIb/IIIa inhibition: the GUSTO V randomised trial. Lancet, 357(9272), 1905-1914.

Trenk, D., Hochholzer, W., Fromm, M. F., Chialda, L. E., Pahl, A., Valina, C. M., . . Neumann, F. J. (2008). Cytochrome P450 2C19 681G>A polymorphism and high on-clopidogrel platelet reactivity associated with adverse 1-year clinical outcome of elective percutaneous coronary intervention with drugeluting or bare-metal stents. J Am Coll Cardiol, 51(20), 1925-1934.

Tricoci, P., Huang, Z., Held, C., Moliterno, D. J., Armstrong, P. W., Van de Werf, F., ... Mahaffey, K. W. (2012). Thrombin-receptor antagonist vorapaxar in acute coronary syndromes. $N$ Engl J Med, 366(1), 20-33. 
Ushio-Fukai, M., Alexander, R. W., Akers, M., \& Griendling, K. K. (1998). p38 Mitogen-activated protein kinase is a critical component of the redoxsensitive signaling pathways activated by angiotensin II. Role in vascular smooth muscle cell hypertrophy. J Biol Chem, 273(24), 15022-15029.

Van De Werf, F., Adgey, J., Ardissino, D., Armstrong, P. W., Aylward, P., Barbash, G., ... White, H. (1999). Single-bolus tenecteplase compared with frontloaded alteplase in acute myocardial infarction: the ASSENT-2 double-blind randomised trial. Lancet, 354(9180), 716-722.

Van de Werf, F., Bax, J., Betriu, A., Blomstrom-Lundqvist, C., Crea, F., Falk, V., . . . Weis, M. (2009). ESC guidelines on management of acute myocardial infarction in patients presenting with persistent ST-segment elevation. Rev Esp Cardiol, 62(3), 293, e291-247.

van Werkum, J. W., van der Stelt, C. A., Seesing, T. H., Hackeng, C. M., \& ten Berg, J. M. (2006). A head-to-head comparison between the VerifyNow P2Y12 assay and light transmittance aggregometry for monitoring the individual platelet response to clopidogrel in patients undergoing elective percutaneous coronary intervention. J Thromb Haemost, 4(11), 2516-2518.

Vane, J. R. (1971). Inhibition of prostaglandin synthesis as a mechanism of action for aspirin-like drugs. Nat New Biol, 231(25), 232-235.

Varon, D. (2007). Impact Cone and Plate(let) Analyzer. In A. Michelson (Ed.), Platelets (pp. 535-544). San Diego: Elsevier/Academic Press.

Vilahur, G., Segales, E., Salas, E., \& Badimon, L. (2004). Effects of a novel platelet nitric oxide donor (LA816), aspirin, clopidogrel, and combined therapy in inhibiting flow- and lesion-dependent thrombosis in the porcine ex vivo model. Circulation, 110(12), 1686-1693.

Virchow, R. (1989). Cellular pathology. As based upon physiological and pathological histology. Lecture XVI--Atheromatous affection of arteries. 1858. Nutr Rev, 47(1), 23-25.

Vlaar, P. J., Svilaas, T., van der Horst, I. C., Diercks, G. F., Fokkema, M. L., de Smet, B. J.,... Zijlstra, F. (2008). Cardiac death and reinfarction after 1 year in the Thrombus Aspiration during Percutaneous coronary intervention in Acute myocardial infarction Study (TAPAS): a 1-year follow-up study. Lancet, 371(9628), 1915-1920.

von Beckerath, N., Pogatsa-Murray, G., Wieczorek, A., Sibbing, D., Schomig, A., \& Kastrati, A. (2006). Correlation of a new point-of-care test with conventional optical aggregometry for the assessment of clopidogrel responsiveness. Thromb Haemost, 95(5), 910-911.

von Beckerath, N., Taubert, D., Pogatsa-Murray, G., Schomig, E., Kastrati, A., \& Schomig, A. (2005). Absorption, metabolization, and antiplatelet effects of 300-, 600-, and 900-mg loading doses of clopidogrel: results of the ISAR- 
CHOICE (Intracoronary Stenting and Antithrombotic Regimen: Choose Between 3 High Oral Doses for Immediate Clopidogrel Effect) Trial. Circulation, 112(19), 2946-2950.

Vora, D. K., Fang, Z. T., Liva, S. M., Tyner, T. R., Parhami, F., Watson, A. D., . . Berliner, J. A. (1997). Induction of P-selectin by oxidized lipoproteins. Separate effects on synthesis and surface expression. Circ Res, 80(6), 810-818.

Wallentin, L., Becker, R. C., Budaj, A., Cannon, C. P., Emanuelsson, H., Held, C., . . . Thorsen, M. (2009). Ticagrelor versus clopidogrel in patients with acute coronary syndromes. $N$ Engl J Med, 361(11), 1045-1057.

Wallentin, L., Varenhorst, C., James, S., Erlinge, D., Braun, O. O., Jakubowski, J. A., . . . Siegbahn, A. (2008). Prasugrel achieves greater and faster P2Y12receptormediated platelet inhibition than clopidogrel due to more efficient generation of its active metabolite in aspirin-treated patients with coronary artery disease. Eur Heart J, 29(1), 21-30.

Weber, A. A., \& Schror, K. (1999). The significance of platelet-derived growth factors for proliferation of vascular smooth muscle cells. Platelets, 10(2-3), 77-96.

Weerakkody, G. J., Jakubowski, J. A., Brandt, J. T., Payne, C. D., Naganuma, H., \& Winters, K. J. (2007). Greater inhibition of platelet aggregation and reduced response variability with prasugrel versus clopidogrel: an integrated analysis. J Cardiovasc Pharmacol Ther, 12(3), 205-212.

White, H. (2001). Antithrombotics: platelet aggregation inhibitors, anticoagulants and thrombolytics. In L. Opie (Ed.), Drugs for the heart (pp. 340-400). Philadelphia: Saunders/McGraw-Hill.

White, H. (2001). Thrombin-specific anticoagulation with bivalirudin versus heparin in patients receiving fibrinolytic therapy for acute myocardial infarction: the HERO-2 randomised trial. Lancet, 358(9296), 1855-1863.

White, H. D., French, J. K., Hamer, A. W., Brown, M. A., Williams, B. F., Ormiston, J. A., \& Cross, D. B. (1995). Frequent reocclusion of patent infarct-related arteries between 4 weeks and 1 year: effects of antiplatelet therapy. J Am Coll Cardiol, 25(1), 218-223.

Wijeysundera, H. C., Vijayaraghavan, R., Nallamothu, B. K., Foody, J. M., Krumholz, H. M., Phillips, C. O., ... Ko, D. T. (2007). Rescue angioplasty or repeat fibrinolysis after failed fibrinolytic therapy for ST-segment myocardial infarction: a meta-analysis of randomized trials. J Am Coll Cardiol, 49(4), 422-430.

Winters, K. J., Santoro, S. A., Miletich, J. P., \& Eisenberg, P. R. (1991). Relative importance of thrombin compared with plasmin-mediated platelet activation in response to plasminogen activation with streptokinase. Circulation, 84(4), 1552-1560. 
Witztum, J. L., \& Berliner, J. A. (1998). Oxidized phospholipids and isoprostanes in atherosclerosis. Curr Opin Lipidol, 9(5), 441-448.

Wiviott, S. D., Braunwald, E., Angiolillo, D. J., Meisel, S., Dalby, A. J., Verheugt, F. W.,... Antman, E. M. (2008). Greater clinical benefit of more intensive oral antiplatelet therapy with prasugrel in patients with diabetes mellitus in the trial to assess improvement in therapeutic outcomes by optimizing platelet inhibition with prasugrel-Thrombolysis in Myocardial Infarction 38. Circulation, 118(16), 1626-1636.

Wiviott, S. D., Braunwald, E., McCabe, C. H., Montalescot, G., Ruzyllo, W., Gottlieb, S., ... Antman, E. M. (2007). Prasugrel versus clopidogrel in patients with acute coronary syndromes. N Engl J Med, 357(20), 2001-2015.

Wiviott, S. D., Trenk, D., Frelinger, A. L., O'Donoghue, M., Neumann, F. J., Michelson, A. D., ... Braunwald, E. (2007). Prasugrel compared with high loading- and maintenance-dose clopidogrel in patients with planned percutaneous coronary intervention: the Prasugrel in Comparison to Clopidogrel for Inhibition of Platelet Activation and Aggregation-Thrombolysis in Myocardial Infarction 44 trial. Circulation, 116(25), 2923-2932.

Wright, R. S., Anderson, J. L., Adams, C. D., Bridges, C. R., Casey, D. E., Jr., Ettinger, S. M., ... Jacobs, A. K. (2011). 2011 ACCF/AHA focused update of the guidelines for the management of patients with unstable angina/ non-STelevation myocardial infarction (updating the 2007 Guideline): a report of the American College of Cardiology Foundation/American Heart Association Task Force on Practice Guidelines. Circulation, 123(18), 20222060.

Yadolah. (2003). The Oxford Dictionary of Statistical Terms. New York: Oxford University Press.

Yan, A. T., Yan, R. T., Cantor, W. J., Borgundvaag, B., Cohen, E. A., Fitchett, D. H., .. . Goodman, S. G. (2011). Relationship between risk stratification at admission and treatment effects of early invasive management following fibrinolysis: insights from the Trial of Routine ANgioplasty and Stenting After Fibrinolysis to Enhance Reperfusion in Acute Myocardial Infarction (TRANSFER-AMI). Eur Heart J, 32(16), 1994-2002.

Yellon, D. M., \& Hausenloy, D. J. (2007). Myocardial reperfusion injury. N Engl J Med, 357(11), 1121-1135.

Yokoya, K., Takatsu, H., Suzuki, T., Hosokawa, H., Ojio, S., Matsubara, T., . . Fujiwara, H. (1999). Process of progression of coronary artery lesions from mild or moderate stenosis to moderate or severe stenosis: A study based on four serial coronary arteriograms per year. Circulation, 100(9), 903-909.

Zeymer, U., Mateblowski, M., \& Neuhaus, K. L. (1998). Thrombin Generation in Patients with Acute Myocardial Infarction Treated with Front-Loaded rt-PA and Recombinant Hirudin (HBW 023). J Thromb Thrombolysis, 5(3), 203207. 



\section{APÉNDICE I: Abreviaturas utilizadas}

\%IAP: porcentaje de inhibición de la actividad plaquetaria

5-HT: serotonina (derivado de su fórmula 5-hidroxitriptamina)

AA: ácido araquidónico

AAS: ácido acetilsalicílico

ACV: accidente cerebrovascular

ADP: adenosín difosfato

ATP: adenosín trifosfato.

CK-MB: isoforma MB (2) de la creatina-quinasa

CK: creatina-quinasa

COX: ciclooxigenasa

CY: citocromo

FvW: factor von Willebrand

GP IIb/IIIa: glicoproteína IIb/IIIa

HTA: hipertensión arterial

I-TAC: factor quimiotáctico alfa de las células T inducible por interferón (por inglés: interferon-inducible T-cell alpha chemoattractant)

IAMCEST: infarto agudo de miocardio con elevación del segmento ST.

ICAM-1: molécula 1 de adhesión intercelular (por inglés: intercellular adhesion molecule-1)

ICP: intervencionismo coronario percutáneo

IP-10: proteína 10 inducible por interferón (por inglés: interferon-inducible protein-10)

LDL: Lipoproteínas de baja densidad (por ingés: low-density lipoproteins)

MACE: eventos adversos cardiacos mayores (del ingles: major adverse cardiac events)

MARS: modelos adaptativos de regresión por medio de splines

MCP-1: porteína 1 quimioatractiva de monocitos (por inglés: monocyte chemotactic protein-1) 
MIG: monquina inducida por interferón-gamma (por inglés: monokine induced by gamma)

NO: oxido nítrico (del inglés: nitric oxide)

PAI-1: inhibidor del activador del plasminógeno 1 (por inglés: plasminogen activator inhibitor-1)

PAR: receptor activado por proteasa (del inglés: protease-activated receptor)

PAU: unidades de actividad plaquetaria (por inglés: platelet activity units)

PDGF: factor de crecimiento derivado de las plaquetas (por ingés: platelet-derived growth factor)

PG: prostaglandina

PLA2: fosfolipasa A2

RIVA: ritmo idioventricular acelerado

RPP: reactividad plaquetaria postratamiento

SCA: síndrome coronario agudo

SCASEST síndrome coronario agudo sin elevación del segmento ST

TGF- $\beta$ : factor de crecimiento transformante $\beta$ (por inglés: transforming grrowth factor- $\beta$ )

TIMI: Thrombolysis In Myocardial Infarction (grupo de investigación)

TRAP: péptido de trombina activador del receptor (del inglés: thrombin receptor activating peptide)

TTPA: tiempo de tromboplastina parcial activada

TXA2: tromboxano A2

URP: unidades de reactividad P2Y12

VASP: proteína estimulada por vasodilatación (del inglés: vasodilator-stimulated phosphoprotein)

VCAM-1: molécula-1 de adhesión a la célula vascular (por inglés: vascular cell adhesion molecule-1) 


\section{APÉNDICE II: Definiciones}

Angina preinfarto: presencia de dolor torácico de características similares a las del evento que motiva el ingreso, de duración menor a 30 minutos. Se clasifica en función de haber aparecido durante la semana previa pero no en las últimas 24 horas previas al infarto o en si ha aparecido en las 24 previas al infarto.

Clasificación Killip-Kimball(Killip \& Kimball, 1967): clasificación de los grados de insuficiencia cardiaca izquierda durante hospitalización por infarto de miocardio.

Clase funcional Killip I: paciente sin signos ni síntomas de insuficiencia cardíaca izquierda.

Clase funcional Killip II: paciente con estertores o crepitantes húmedos, tercer ruido cardíaco o aumento de la presión venosa yugular.

Clase funcional Killip III: paciente con edema agudo de pulmón.

Clase funcional Killip IV: pacientes en shock cardiogénico, hipotensión (presión arterial sistólica inferior a $90 \mathrm{~mm} \mathrm{Hg}$ ), y evidencia de vasoconstricción periférica (oliguria, cianosis o diaforesis).

Criterios TIMI para hemorragia mayor: hemorragia intracraneal o sangrado clínicamente manifiesto con caída de las cifras de hemoglobina $>5 \mathrm{~g} / \mathrm{dl}$ o del hematocrito $>15 \%$ (Rao et al., 1988).

Éxito ICP: consecución de reducción de la estenosis que condiciona la placa responsable hasta al menos $<50 \%$ del diámetro de referencia del vaso y flujo grado TIMI 2-3 tras la intervención coronaria.

Flujo TIMI en arteria responsable(Chesebro et al., 1987): escala semicuantitativa para la evaluación del flujo sanguíneo en la arteria responsable del infarto durante la coronariografía.

TIMI 0: ausencia de perfusión. No se aprecia contraste más allá del punto de oclusión.

TIMI 1: perfusión de contraste sin relleno completo del vaso distal a la lesión.

TIMI 2: el vaso distal se rellena por completo pero el flujo es más lento que en la arteria no responsable.

TIMI 3: relleno completo y velocidad de llenado normal.

Máxima desnivelación del ST: amplitud en milímetros de la desnivelación del ST en la derivación en la que ésta sea más acusada. Medido sobre ECG estándar de 12 derivaciones a $25 \mathrm{~mm} /$ segundo de velocidad de barrido y a una amplitud de $10 \mathrm{mV} / \mathrm{cm}$. 
Nefropatía inducida por contraste: incremento en los valores de creatinina plasmática de $0,5 \mathrm{mg} / \mathrm{dl}$ o de al menos un $25 \%$ tras la realización de pruebas diagnósticas con contrate iónico intravenoso con respecto a los valores basales(Pannu, Wiebe, \& Tonelli, 2006).

Recurrencia isquémica tras fibrinolisis efectiva: reaparición de síntomas característico similar al del evento que motiva ingreso, al menos 30 minutos tras haber alcanzado el paciente criterios clínicos y ECG de reperfusión, que persiste durante más de 5 minutos en reposo y/o condiciona nuevas alteraciones dinámicas electrocardiográficas.

Sumatorio de la deviación máxima del ST: sumatorio en milímeitros de la supradesnivelación del segmento ST medido a $80 \mathrm{~ms}$ del punto J en todas las derivaciones afectadas, incluyendo la infradesnivelación en V2 en el caso de infarto inferiores con extensión dorsal. Medido sobre ECG estándar de 12 derivaciones a $25 \mathrm{~mm} /$ segundo de velocidad de barrido y a una amplitud de $10 \mathrm{mV} / \mathrm{cm}$.

Chesebro, J. H., Knatterud, G., Roberts, R., Borer, J., Cohen, L. S., Dalen, J., . . e et al. (1987). Thrombolysis in Myocardial Infarction (TIMI) Trial, Phase I: A comparison between intravenous tissue plasminogen activator and intravenous streptokinase. Clinical findings through hospital discharge. Circulation, 76(1), 142-154.

Killip, T., 3rd, \& Kimball, J. T. (1967). Treatment of myocardial infarction in a coronary care unit. A two year experience with 250 patients. Am J Cardiol, 20(4), 457-464.

Pannu, N., Wiebe, N., \& Tonelli, M. (2006). Prophylaxis strategies for contrastinduced nephropathy. JAMA, 295(23), 2765-2779.

Rao, A. K., Pratt, C., Berke, A., Jaffe, A., Ockene, I., Schreiber, T. L., ... Terrin, M. L. (1988). Thrombolysis in Myocardial Infarction (TIMI) Trial--phase I: hemorrhagic manifestations and changes in plasma fibrinogen and the fibrinolytic system in patients treated with recombinant tissue plasminogen activator and streptokinase. J Am Coll Cardiol, 11(1), 1-11. 


\section{APÉNDICE III: Tablas y Figuras}

\section{TABLAS:}

Tabla 1: Indicaciones del tratamiento fibrinolítico.

Tabla 2: Contraindicaciones al tratamiento fibrinolítico.

Tabla 3: Mecanismos potenciales de respuesta variable al clopidogrel.

Tabla 4: organigrama de ventajas e inconvenientes de cada una de las pruebas de análisis de función plaquetaria.

Tabla 5: requerimientos ICP primario como 1o elección.

Tabla 6: características basales de la muestra.

Tabla 7: Características del infarto.

Tabla 8: presencia documentada de RIVAs durante los primeros 90 minutos tras la administración del fibrinolítico.

Tabla 9: resumen de la evolución temporal de las variables de función plaquetaria.

Tabla 10: tipo de intervención efectuada en función de los hallazgos anatómicos.

Tabla 11: localización de la lesión responsable.

Tabla 12: características del flujo según la clasificación TIMI en la arteria responsable del infarto.

Tabla 13: resumen de datos correspondientes al ICP.

Tabla 14: aplicación del test ANOVA unidireccional a la variable sumatorio ST en el momento del ingreso a los pacientes de la muestra en función de la localización del infarto.

Tabla 15: Matriz de correlaciones correspondiente a las variables CK-MB1, CK-MB2, CKMB3, CK-MB 4, CK-MB5, T Fibri, T Clopi, Suma ST 90 y Máx ST 90.

Tabla 16: Aplicación del test ANOVA unidireccional a la variable CK-MB1 de los pacientes de la muestra clasificados en función de la localización del infarto.

Tabla 17: resultados del test ANOVA aplicado a las diferentes mediciones realizadas para la variable BASE.

Tabla 18: intervalos de confianza simultáneos de Tukey al 95\% para la variable BASE.

Tabla 19: resultados del test ANOVA aplicado a las diferentes mediciones realizadas de la variable RPP .

Tabla 20: intervalos de confianza simultáneos de Tukey al 95\% para la variable RPP.

Tabla 21: resultados del test ANOVA aplicado a las diferentes medidas realizadas de la variable \%IAP.

Tabla 22: intervalos de confianza simultáneos de Tukey al 95\% para la variable \%IAP. 
Tabla 23: test de Pearson para la comprobación del grado de correlación entre los valores pretratamiento de las variables BASE y RPP.

Tabla 24: comparación mediante test ANOVA de los valores de la enzima CK-MB previa al cateterismo, a las seis horas y a las 12 horas tras la intervención.

Tabla 25: Abreviaturas empleadas para la realización del modelo con el programa estadístico R junto con el significado de cada una de las variables.

Tabla 26: Ecuación del modelo MARS generado para la variable de salida Troponina a las 6 horas.

Tabla 27: orden de importancia de las variables utilizadas por el modelo de predicción MARS para la variable Troponina $\mathrm{T}$ a las 6 horas.

Tabla 28: codificación empleada para la conversión de variables cualitativas en numéricas.

Tabla 29: Ecuación de regresión del modelo obtenido aplicando la selección de variables por medio de la determinación del mejor subconjunto posible para la realización de un modelo lineal multivariante.

Tabla 30: Variables consideradas de importancia por el modelo de regresión lineal multivariante para la variable de salida RPP KT.

Tabla 31: Coeficientes e indicadores principales del modelo MARS obtenido.

Tabla 32: Variables que intervienen en el modelo MARS clasificadas por importancia.

Tabla33: Variables consideradas de importancia según criterio experto (clasificación de su importancia según experiencia clínica y revisión bibliográfica e inclusión en el modelo).

Tabla 34: Coeficientes e indicadores principales del modelo MARS obtenido usando como variables de entrada aquellas consideradas como de nivel de importancia 3.

Tabla 35: Clasificación por orden de importancia de las variables que emplea el modelo MARS de las variables de nivel de importancia 3.

Tabla 36: Coeficientes e indicadores principales del modelo MARS obtenido usando como variables de entrada aquellas consideradas como de nivel de importancia 2 y 3.

Tabla 37: Clasificación por orden de importancia de las variables que emplea el modelo MARS de las variables de nivel de importancia 2 y 3.

\section{FIGURAS}

Figura 1: fotografía del Papiro de Ebers, en el la Biblioteca Universitaria de Leipzig.

Figura 2: Hipócrates de Cos.(grabado)

Figura 3: James B. Herrick.

Figura 4: Fotografías de Werner Forssman, André Cournand y Dickinson Richards.

Figura 5: fotografías de Mason Sones, Charles Dotter y Andreas Grntzig.

Figura 6: molécula del TNK-tPA. 
Figura 7: Envase comercial del TNK-tPA (Metalyse ${ }^{\circledR}$ )

Figura 8: imagen de microscopía electrónica de barrido en la que se muestran plaquetas activadas formando una red de pseudópodos.

Figura 9: estructura y función de la integrina $\alpha \operatorname{Ilb} \beta 3$ (cedido de Nature Reviews).

Figura 10: esquema de la función de los receptores plaquetarios P2 (cedido por Medscape).

Figura 11: Estructura molecular del receptor P2Y12 humano.

Figura 12: Fórmula del ácido acetil-salicílico (aspirina).

Figura 13: fórmula de la ticlopidina.

Figura 14: fórmula del clopidogrel.

Figura 15: fórmula del prasugrel

Figura 16: fórmula del ticagrelor.

Figura 17: fórmula del cangrelor.

Figura 18: agregación plaquetaria mediante puentes GP IIb/IIIa-fibrinógeno cedida de Medscape).

Figura 19: fotografía del sistema TEG ${ }^{\circledR}$ PlateletMapping ${ }^{\mathrm{TM}}$ System.

Figura 20: Fotografía del analizador Impact-R cone and plate.

Figura 21: sistema PFA-100®.

Figura 22: Fotografía del dispositivo VerifyNow®.

Figura 23: Interpretación de un diagrama de boxplot.

Figura 24: algoritmo empleado para la aplicación de la de la validación cruzada.

Figura 25: ejemplo de representación gráfica de variables en forma de histograma con test de Anderson-Darling y datos de distribución asociados.

Figura 26: esquema de selección de pacientes durante el periodo de reclutamiento. El grupo encuadrado en rojo lo forman los pacientes que finalmente cumplieron todos los criterios de inclusión y ninguno de los criterios de exclusión.

Figura 28: división de los pacientes de la muestra por sexo.

Figura 30: histograma de distribución de los datos de la variable tiempo desde el comienzo de los síntomas hasta la llegada al Servicio de Urgencias.

Figura 31: gráfico de boxplot que muestra la distribución de la variable tiempo desde inicio de los síntomas hasta llegada a urgencias en función del sexo del paciente.

Figura 32: curvas de densidad acumulada de la variable tiempo desde inicio de los síntomas hasta llegada al Servicio de Urgencias en función del sexo.

Figura 33: histograma de distribución de la variable tiempo desde la llegada al Servicio de Urgencias hasta la administración del fibrinolítico.

Figura 34: curvas de densidad acumulada de la variable tiempo desde llegada al Servicio de Urgencias hasta la administración del fibrinolítico en función del sexo.

Figura 35: histograma y distribución de los datos de la variable Máxima desviación del ST en el momento del ingreso. 
Figura 36: histograma y distribución de los datos de la variable Sumatorio desviación del ST en el momento del ingreso.

Figura 37: histograma y distribución de datos de la variable máxima desviación del ST a los 90 minutos de la administración del tratamiento fibrinolítico.

Figura 38: histograma y distribución de datos de la variable sumatorio de la desviación del ST a los 90 minutos de la administración del fibrinolítico.

Figura 39: gráfico de boxplot que muestra los valores de las cinco determinaciones seriadas cada seis horas de la fracción MB de la enzima creatinquinasa (CK-MB).

Figura 40: gráfico de evolución del valor de enzima CK-MB en todos los pacientes durante las cinco determinaciones seriadas cada seis horas tras el ingreso.

Figura 41: resumen de la información correspondiente a la variable BASE medida en el momento del ingreso y expresada en unidades de reactividad plaquetaria URP.

Figura 42: resumen de la información estadística correspondiente a la variable RPP medida en el momento del ingreso.

Figura 43: resumen de la información estadística correspondiente a la variable \%IAP medida en el momento del ingreso.

Figura 43: resumen de la información estadística correspondiente a la variable BASE medida a las 8:00 del primer día después del ingreso.

Figura 44: distribución de la variable tiempo entre el momento 1 y momento 2.

Figura 45: resumen de la información estadística correspondiente a la variable RPP medida a las 8:00 del primer día tras el ingreso.

Figura 47: resumen de la información estadística correspondiente a la variable \%IAP medida a las 8:00 hras del primer día tras el ingreso

Figura 48: resumen de la información estadística correspondiente a la variable BASE medida a las 8:00 del segundo día después del ingreso. a las 8:00 horas del primer día tras el ingreso.

Figura 49: resumen de la información estadística correspondiente a la variable RPP medida a las 8:00 del segundo día después del ingreso.

Figura 50: resumen de la información estadística correspondiente a la variable \%IAP medida a las 8:00 del segundo día después del ingreso.

Figura 51: resumen de la información estadística correspondiente a la variable BASE medida en el momento de la coronariografía.

Figura 52: resumen de la información estadística correspondiente a la variable RPP medida en el momento de la coronariografía.

Figura 53: Resumen de la información estadística correspondiente a la variable \%IAP medida en el momento de la coronariografía.

Figura 54: porcentaje de pacientes de la muestra con reactividad plaquetaria postratamiento igual o superior al punto de corte de 175URP en los diferentes momentos de medición.

Figura 55: porcentaje de pacientes de la muestra con reactividad plaquetaria postratamiento igual o superior al punto de corte de 208URP en los diferentes momentos de medición.

Figura 56: porcentaje de pacientes de la muestra con reactividad plaquetaria postratamiento igual o superior al punto de corte de 235URP en los diferentes momentos de medición. 
Figura 57: distribución del número de vasos enfermos encontrados durante la coronariografía entre los pacientes de la muestra.

Figura 58: Resumen de la información estadística correspondiente a la variable PAU basal (agregación plaquetaria dependiente del receptor IIb/IIIa previa a la administración de abciximab).

Figura 59: Resumen de la información estadística correspondiente a la variable PAU Reopro (reactividad plaquetaria dependiente del receptor IIb/IIIa tras la administración de abciximab).

Figura 60: Resumen de la información estadística correspondiente a la variable \%REOPRO (respuesta al abciximab) entre los pacientes sometidos a ICP en los que se utilizó este fármaco como terapia antiplaquetaria adyuvante.

Figura 61: distribución de los valores de creatinina plasmática antes y después de la realización de la coronariografía \pm ICP.

Figura 62: valor de la enzima troponina T a las seis horas del ICP.

Figura 63: valor de los niveles de la enzima troponina T a las 12 horas tras el ICP.

Figura 64: valores de la enzima CK-MB a las 6 horas del ICP.

Figura 65: valores de la enzima CK-MB a las 12 horas del ICP.

Figura 66: tiempo de seguimiento tras la realización de la coronariografía.

Figura 67: curvas Kaplan-Meier de no ocurrencia de MACE con representación de su intervalo de confianza al 95\%.

Figura 68: gráfico de dispersión del tiempo transcurrido entre el comienzo del dolor y la llegada del paciente al Servicio de Urgencias en función de la edad y diferenciando entre varones y mujeres.

Figura 69: gráfica de boxplot y ANOVA de la variable Máxima desviación ST al ingreso.

Figura 70: test de Tukey-Kramer para la variable máxima desviación ST en función de la localización del infarto.

Figura 71: resumen de la comparación mediante t para datos apareados entre las variables sumatorio del ST al ingreso y sumatorio del ST a los 90 minutos tras la fibrinolisis.

Figura 72: resumen de la comparación mediante t para datos apareados entre las variables máxima desviación del ST al ingreso y máxima desviación del ST a los 90 minutos tras la fibrinolisis.

Figura 73: gráfico de boxplot de la variable edad de los pacientes de la muestra divididos en función de la localización del infarto.

Figura 74: representación por medio de un gráfico de boxplot de la evolución temporal de la variable BASE.

Figura 75: representación por medio de un gráfico de boxplot de la evolución temporal de la variable RPP.

Figura 76: representación por medio de gráfico de boxplot de la evolución temporal de la variable \%IAP.

Figura 77: gráfica de dispersión correspondiente a los valores de las variables BASE y RPP medidos en el momento del ingreso y antes de la primera administración de clopidogrel.

Figura 78: gráfica de boxplot que muestra la variación entre las determinaciones seriadas de la enzima CK-MB antes y después del ICP. 
Figura 79: representación en gráfico de boxplot y ANOVA de los valores de la variable hemoglobina total antes y después del ICP.

Figura 80: representación en gráfica de boxplot y ANOVA de la variable plaquetas totales antes y después del ICP.

Figura 81: variables empleadas por el modelo y orden de importancia de las mismas.

Figura 82: representación gráfica de los términos componentes del modelo MARS de la variable de salida Troponina T a las 6 horas.

Figura 83: representación del valor real y el predicho por los modelos para el valor de la Troponina a las 6 horas.

Figura 84: representación del valor real y el predicho por los modelos mejorados para el valor de la Troponina a las 6 horas.

Figura 85: Proporción de la varianza contenida en cada una de las componentes principales.

Figura 86: representación gráfica del modelo MARS obtenido.

Figura 87: representación gráfica del modelo MARS obtenido con las variables de nivel de importancia 3.

Figura 88: Representación gráfica del modelo MARS obtenido con las variables de nivel de importancia 2 y 3. 